\title{
SYNTHETIC SORBENT MATERIALS BASED ON METAL SULPHIDES AND OXIDES
}

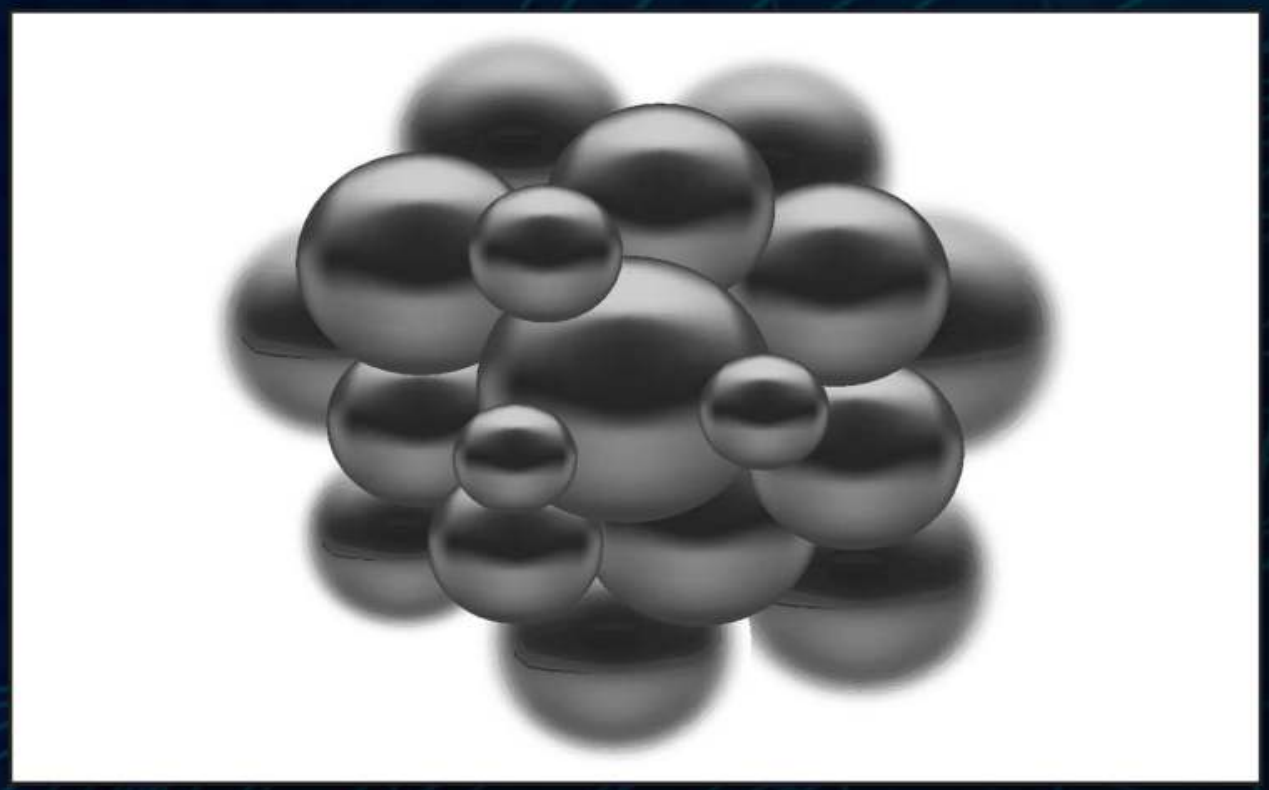

D.S. SOFRONOV • K.N. BELIKOV M. RUCKI • S.N. LAVRYNENKO Z. SIEMIĄTKOWSKI • E. YU. BRYLEVA O.M. ODNOVOLOVA 


\section{Synthetic Sorbent \\ Materials Based on Metal Sulphides and Oxides}




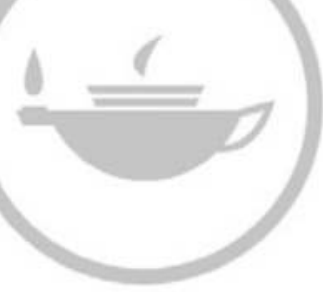

Taylor \& Francis Taylor \& Francis Group http://taylorandfrancis.com 


\section{Synthetic Sorbent \\ Materials Based on Metal Sulphides and Oxides}

D.S. Sofronov, K.N. Belikov, M. Rucki, S.N. Lavrynenko, Z. Siemiątkowski, E. Yu. Bryleva, and O.M. Odnovolova 
First edition published 2021

by Taylor \& Francis

6000 Broken Sound Parkway NW, Suite 300, Boca Raton, FL 33487-2742

and by Taylor \& Francis

2 Park Square, Milton Park, Abingdon, Oxon, OX14 4RN

(C) 2021 Taylor \& Francis Group, LLC

Reasonable efforts have been made to publish reliable data and information, but the author and publisher cannot assume responsibility for the validity of all materials or the consequences of their use. The authors and publishers have attempted to trace the copyright holders of all material reproduced in this publication and apologize to copyright holders if permission to publish in this form has not been obtained. If any copyright material has not been acknowledged, please write and let us know so we may rectify in any future reprint.

The Open Access version of this book, available at www.taylorfrancis.com, has been made available under a Creative Commons Attribution-Non Commercial-No Derivatives 4.0 license.

With the exception of the Introduction, Chapter 1.1, Final Remarks, and References no part of this book may be reprinted or reproduced or utilised in any form or by any electronic, mechanical, or other means, now known or hereafter invented, including photocopying and recording, or in any information storage or retrieval system, without permission in writing from the publishers.

The Introduction, Chapter 1.1, Final Remarks, and References of this book are available for free in PDF format as Open Access from the individual product page at www.routledge.com. It has been made available under a Creative Commons Attribution-Non Commercial-No Derivatives 4.0 license.

Trademark notice: Product or corporate names may be trademarks or registered trademarks, and are used only for identification and explanation without intent to infringe.

ISBN: 978-0-367-56675-3 (hbk)

ISBN: 978-0-367-60875-0 (pbk)

ISBN: 978-1-003-10233-5 (ebk)

Typeset in Palatino

by codeMantra 


\section{Contents}

Authors vii

Acknowledgments ..........................................................................................

Abbreviations and Nomenclature ......................................................................

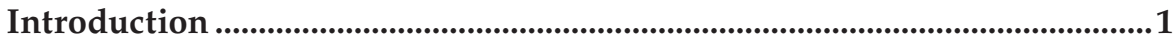

1. Synthesis of Zinc, Copper, Cadmium, and Iron Sulfides and Their Sorption Properties .......................................................................

1.1 Methodology of Synthesis ................................................................. 5

1.1.1 Overview and Classification of Synthesis Methods ............5

1.1.1.1 High-Temperature Methods .................................... 6

1.1.1.2 Solvothermal Decomposition Method .................... 8

1.1.2 Methodology and Equipment ................................................ 11

1.1.3 Procedures and Reactions ................................................... 13

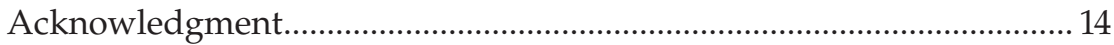

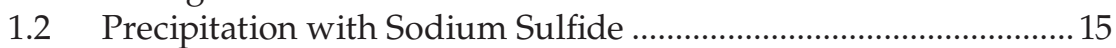

1.3 Particles Precipitation Out of Thiourea Solutions ............................ 16

1.3.1 Effect of Chemical Composition of the Reagent Environment on the Particle Formation of Zinc, Copper, and Cadmium Sulfides .......................................... 16

1.3.1.1 pH effect .............................................................. 16

1.3.1.2 Concentration Effect ..............................................23

1.3.1.3 Effect of the Anion Nature.....................................2.

1.3.2 Impact of the Organic Additives .........................................29

1.4 Effect of Microwave Activation on the Zinc, Cadmium, and Copper Sulfide Particles Formation ..................................................37

1.4.1 Effect of $\mathrm{pH}$ and Thiourea Concentration Combined with Microwave Activation ....................................................37

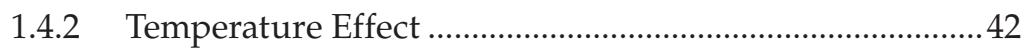

1.5 Effect of Metal Ion Doping on the Zinc Sulfide

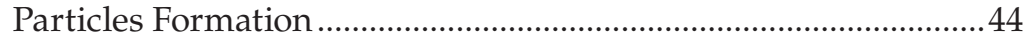

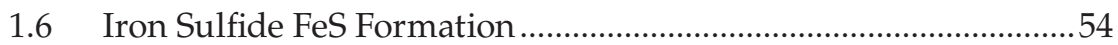

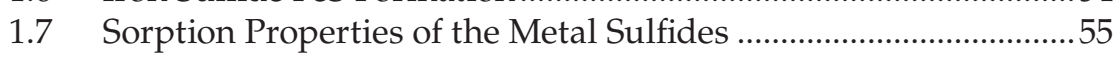

1.7.1 pH Impact on the Metal Sulfides Extraction

Efficiency and Particles Stability …………………………....56

1.7.2 Impact of Specific Surface on the Sorption

Capacity of Particles ................................................................58

1.7.3 Sorption Properties of Zinc Sulfide Particles

Doped with Copper, Manganese, and Cerium....................60 60

1.8 Conclusions on the Sorption Efficiency of Metal Sulfides ..............66 
2. Formation and Sorption Properties of Iron Oxides and

Manganese Oxyhydroxide

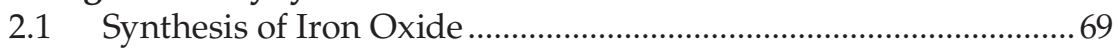

2.1.1 Synthesis of the Hematite Particles $\alpha-\mathrm{Fe}_{2} \mathrm{O}_{3} \ldots \ldots \ldots \ldots \ldots \ldots \ldots . . . . . .69$

2.1.2 Formation of Maghemite $\gamma-\mathrm{Fe}_{2} \mathrm{O}_{3}$ Particles ...................... 74

2.1.3 Peculiarities of the $\mathrm{Fe}_{3} \mathrm{O}_{4}$ Particle Formation from the Aqueous Solutions ..................................................... 75

2.2 Synthesis of Manganese Dioxide and Oxyhydroxide.....................80

2.2.1 Synthesis of Manganese Oxyhydroxide in Alkaline Solutions

2.2.2 Synthesis of Manganese Dioxide.........................................8 87

2.3 Sorption Characteristics of Iron Oxides and Manganese

Dioxide and Oxyhydroxide .......................................................... 88

2.3.1 Iron Oxides ................................................................... 88

2.3.2 Manganese Oxyhydroxide and Dioxide..........................91

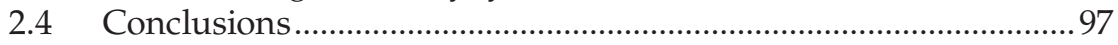

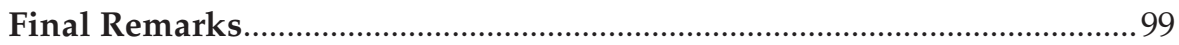

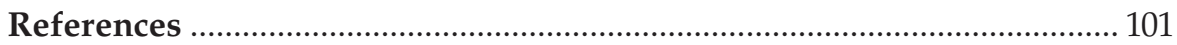

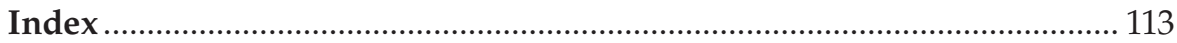




\section{Authors}

D.S. Sofronov received his PhD in inorganic chemistry in 2008. He was a younger researcher of State Scientific Institution, Institute for Single Crystals, National Academy of Sciences of Ukraine, Kharkov (Ukraine), from 2002-2014. Since 2014, he has been a researcher of State Scientific Institution, Institute for Single Crystals, National Academy of Sciences of Ukraine, Kharkov (Ukraine).

ORCID 0000-0003-4835-7001

K.N. Belikov received his PhD in analytical chemistry in 2002. He was deputy general director of the State Scientific Institution, Institute for Single Crystals, National Academy of Sciences of Ukraine, Kharkov (Ukraine), in 2015.

ORCID 0000-0002-1682-6064

M. Rucki received Polish Government Scholarship for PhD Studies, Poznan University of Technology (Poland), from 1994-1996. He obtained a PhD in metrology and measurement systems in 1997. He was an assistant professor at Poznan University of Technology, Institute of the Mechanical Engineering, Division of the Metrology and Measurement Systems, from 1997-2010. At present, he is working as a professor at Kazimierz Pulaski University of Technology and Humanities in Radom (Poland).

ORCID 0000-0001-7666-7686

S.N. Lavrynenko was a researcher at Kharkov State Polytechnic University from 1983-1994. He worked as an associate professor at National Technical University "KhPI" from 1994-2012. He graduated in 2001 from NATO Advanced Study Institute, "Responsive Systems for Active Vibration Control" at Universite Libre de Bruxelles, Faculte des Sciences, Brussels, Belgium. He was full professor at National Technical University "KhPI," Information Technology \& Systems, KGM Department from 2012-2018. He was a Senior Visiting Fellow of the DAAD, Otto-von-Guericke University Magdeburg, in 1997. He was an Honorary Research Fellow of the Royal Society at University College London, Optical Science Lab, from 1999-2000. He was author and coauthor of more than 200 papers, reports, and books. He passed away on March 7, 2018, before this book was finished.

ORCID 0000-0003-2229-4858

Z. Siemiatkowski received his PhD in mechanical engineering and technology in 2000. In 2000 he became assistant at Kazimierz Pulaski University of Technology and Humanities (UTH) in Radom (Poland), Mechanical Faculty. 
He was vice dean of Mechanical Faculty from 2012-2019, awarded with several individual awards for organizational and scientific achievements. Since 2019, he has been the head of the Division of Mechanical Engineering, UTH, Radom.

ORCID 0000-0002-6830-4479

E.Yu. Bryleva received his $\mathrm{PhD}$ in physical chemistry in 2008. He was a researcher at the State Scientific Institution, Institute for Single Crystals, National Academy of Sciences of Ukraine, from 2008-2013. Since 2013, he has been a senior researcher at the State Scientific Institution, Institute for Single Crystals, National Academy of Sciences of Ukraine.

ORCID 0000-0002-8903-4922

O.M. Odnovolova graduated from the State Scientific Institution Institute for Single Crystals, National Academy of Sciences of Ukraine in 2016. Since 2016, he has been a senior chemist in the analytical control sector of the chemical laboratory of the quality department, Kievmedpreparat, Kharkov, Ukraine.

ORCID 0000-0003-3497-1481 


\section{Acknowledgments}

The authors express their gratitude for cooperation to everybody who contributed to the research, especially to chemistry doctors Baumer V.N. and Puzan A.N. for X-ray structural analysis, to Bunina Z.Yu., Gudzenko L.V., and chemistry doctor Shcherbakov I.B.-Kh. for chemical analysis, to Mateichenko P.V. for microstructural analysis, to chemistry doctor Beda A.A. for specific surface determination, and to physics and mathematics doctor Katrunov K.A. for optical researches.

The Open Access was sponsored through funding by Precision Machine Parts Poland Sp. z o.o.

\section{PMP}




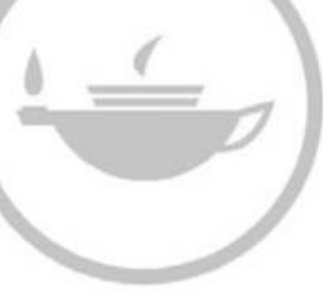

Taylor \& Francis Taylor \& Francis Group http://taylorandfrancis.com 


\title{
Abbreviations and Nomenclature
}

\author{
Abbreviations \\ BET Brunauer-Emmett-Teller model \\ CVD chemical vapor deposition \\ ICP-AES inductively coupled plasma atomic emission spectroscopy \\ IR infrared \\ MAC maximal acceptable concentration \\ MOCVD metal-organic chemical vapor deposition \\ MOCZ manganese oxide-coated zeolite \\ MW microwave \\ PCE power conversion efficiency \\ SSA specific surface area \\ TEM transmission electron microscopy \\ TGA thermal gravimetric analysis \\ XRD X-ray diffraction techniques, X-ray crystallography
}

\section{Nomenclature}

a

$c$

C

$C_{0}$

$c_{\text {BET }}$

$C_{e}$

$E \%$

$E_{g}$

H

$K_{L}$

m

$M$

$n$

$n_{m}$

$P$

$P_{0}$

$q$

$q_{e}$

$q_{\max }$

R

$R^{2}$ lattice constant $(\AA)$

concentration

concentration $(\mathrm{mg} / \mathrm{L}),(\mathrm{mmol} / \mathrm{L})$

initial metal ion concentration $(\mathrm{mg} / \mathrm{L}),(\mathrm{mmol} / \mathrm{L})$

BET constant

equilibrium metal ion concentration in $(\mathrm{mg} / \mathrm{L}),(\mathrm{mmol} / \mathrm{L})$

extraction efficiency in percentage

bandgap

magnetic field strength $(\mathrm{kA} / \mathrm{m})$

equilibrium adsorption constant $(\mathrm{L} / \mathrm{mmol})$

weight of substance in grams

magnetization of the particles $\left(\mathrm{A} \cdot \mathrm{m}^{2} / \mathrm{kg}\right)$

amount absorbed

monolayer capacity

pressure $(\mathrm{Pa})$

initial pressure $(\mathrm{Pa})$

sorption capacity $(\mathrm{mg} / \mathrm{g}),(\mathrm{mmol} / \mathrm{g})$

adsorption equilibrium metal ion uptake capacity $(\mathrm{mmol} / \mathrm{g}$ )

maximum amount/weight of metal ion per unit weight of a sorbent $(\mathrm{mg} / \mathrm{g}),(\mathrm{mmol} / \mathrm{g})$

reflectance

correlation factor of model approximation 
$S$

SSA

$T$

$t$

$v$

V

$\eta$

$\tau$ scattering coefficient

specific surface area $\left(\mathrm{m}^{2} / \mathrm{g}\right)$

infrared transmission (\%)

temperature $\left({ }^{\circ} \mathrm{C}\right)$

water-to-surfactant ratio (-)

volume

percentage yield (\%)

time 


\section{Introduction}

This book has been focused on the application of common nanomaterials for the removal of metallic species that are found in aqueous environment. The "most common" metallic species are $\mathrm{As}, \mathrm{Cd}, \mathrm{Cr}, \mathrm{Cu}, \mathrm{Pb}, \mathrm{Hg}$, and $\mathrm{Ni}$. $\mathrm{Sb}$, $\mathrm{Pd}, \mathrm{Pt}, \mathrm{U}$, and Th are the other miscellaneous metallic species where nanoparticles are applied for their removal from aqueous solutions and water (Dubey et al. 2017). It is important to develop robust, eco-friendly, and economically viable treatment methods for the removal of heavy metals from the aquatic system (Vardhan et al. 2019).

Zinc sulfide finds its applications in optics, electronics, laser technologies, solar energy solutions, etc. Zinc sulfide, with addition of small amounts of suitable activator, is used as phosphor in many areas (Bower et al. 2002). For example, when silver is added, the emitted color is bright blue, whereas manganese yields in orange-red color and copper provides greenish color. Electroluminescent materials based on $\mathrm{ZnS}$ perform high brightness and are used as flat vacuum-free light sources in panels, scoreboards, or screens for fluoroscopy (Mateleshko et al. 2004). Zinc sulfide is also used as an infrared optical material, planar or shaped into a lens (Gupta and Gupta 2016). Zinc sulfide-based scintillators have the largest light output per event in the family of imaging scintillators used so far in fast neutron radiography (Wu et al. 2013). Apart from widely known optical properties, ZnS nanocrystals were reported to serve as a sorbent for $\mathrm{Cu}$ (II) removal from water (Xu et al. 2016),

Despite a broad interest, general synthetic methods to prepare such materials are lacking, due to at least two reasons. First, it is a significant challenge to ensure homogenous and atomic-scale dispersion of the dopant within the matrix. Second, it is difficult to prepare powders, films, or nanoscale wires made out of zinc oxides and sulfides. Moreover, most synthetic methods require stringent processing conditions or very high temperatures (Acton 2013).

Additional issue is concerning green technologies. Intense development of the industry, power engineering, and agriculture continuously increases pollution of the air (Guttinkunda et al. 2019), water (Xie et al. 2020), and soil (Baltas et al. 2020), which have negative impact on human health. Despite the numerous proposed methods of contamination removal, such as filtration, sedimentation, reverse osmosis, chemical deposition, biological treatment, and so on, sorption methods remain one of the most economical effective ones (Jaspal and Malviya 2020). That is why, sorption is often applied in the final stages of wastewater treatment. A variety of the sorption materials are used, both natural, such as clays, minerals, plant materials, or biomaterials, and synthetic ones. The main advantage of the natural sorption materials is relatively low cost, whereas synthetic ones perform much higher sorption capacity. The aforementioned challenges pose some limitations on the 
production of the sorption materials, which must be greener itself through minimizing the energy consumption and other environment unfriendly factors. Thus, one of the trends in sorbent synthesis leads toward production of the same materials using different methods, with modification of the sorbent characteristics through different synthesis conditions. In this book, to achieve greener technology, the researches were focused on the water solutions without employment of any organic solvents.

This book proposes some solutions that address aforementioned challenges. Theoretical background of the sorption is described in detail in many works (Dąbrowski and Tertykh 1996; Ronco and Winchester 2001; Dragan 2014), but only experimental research makes it possible to evaluate practical advantages of the synthesized sorbent.

In this book, experimental data on the synthesis of micro- and nanoparticles of zinc, copper, and cadmium sulfides; iron oxides; and manganese oxyhydroxide are systematized and discussed. Much attention is paid to the processes of sulfide particles formation out of thiourea solutions, as well as to the thermal decomposition of precursors. The effect of decomposition processes on the morphological and structural properties of the obtained micro- and nanoparticles is emphasized. Especially emphasized are the sorption characteristics of the particles and their dependence on the synthesis conditions.

\section{Who Should Read This Book?}

The book is devoted to the researchers, students, and specialists who are interested in the inorganic synthesis and properties of the sorption materials. The presented material can be helpful as a review of methods and as a handbook of experimental research. It requires at least basic knowledge on chemistry and physics.

\section{How This Book Is Organized?}

In this book, we investigate the problems of the controlled synthesis of inorganic compounds and effect of their morphological characteristics on their sorption capacity. As the research objects, sulfides of divalent metals (zinc, cadmium, and copper), iron oxides, and manganese oxyhydroxide were chosen.

This book consists of introduction, two chapters, final remarks, and references.

In the first chapter, controlled synthesis of zinc, cadmium, and copper sulfide particles and their sorption properties are discussed. First, main methods of metal sulfides synthesis are described, emphasizing the impact of synthesis conditions on the structural and morphological characteristics of the obtained particles. After the discussion, investigations were focused on the method of particle precipitation from thiourea solutions. In this respect, detailed results for particle formation of zinc, copper, and cadmium sulfides in various synthesis conditions, such as $\mathrm{pH}$, anionic composition, temperature, and microwave activation, are presented and discussed. And finally, 
the sorption characteristics of the synthesized particles are described in connection with particles size and morphology and synthesis conditions.

The second chapter is dedicated to the production of iron oxides (hematite and magnetite) and manganese oxyhydroxide particles. Experimental data concerning the effects of iron oxides $\alpha-\mathrm{Fe}_{2} \mathrm{O}_{3}, \gamma-\mathrm{Fe}_{2} \mathrm{O}_{3}$, and $\mathrm{Fe}_{3} \mathrm{O}_{4}$ particles synthesis conditions on their structural and morphological characteristics. Next, the issues of the particles formation of manganese oxyhydroxide are discussed. Then, the experimental sorption characteristics of the synthesized particles are presented.

At the end of monography, final remarks and references are added.

\section{How to Use This Book?}

The main objective of this book is to provide possibly full review of the results related to the topic. This book will be interesting to anyone who works in the field of inorganic synthesis or is interested in particles of various inorganic compounds synthesis methods.

In this book, the experimental research results are presented in full. They may be helpful in any work aimed to control structural and morphological characteristics of sulfides of zinc, copper, and cadmium; iron oxides; and manganese oxyhydroxide, especially ones focused on obtaining certain sorption capacities. Moreover, the proposed approach may be applied to other compounds as well.

\section{Acknowledgments}

This chapter is made Open Access through funding by Precision Machine Parts Poland Sp. z o.o.

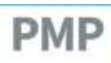




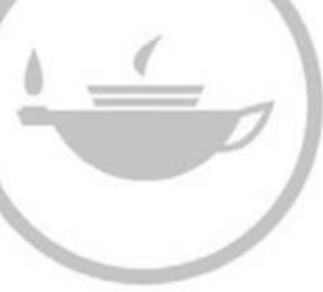

Taylor \& Francis Taylor \& Francis Group http://taylorandfrancis.com 


\section{1}

\section{Synthesis of Zinc, Copper, Cadmium, and Iron Sulfides and Their Sorption Properties}

\subsection{Methodology of Synthesis}

One of the most important steps in the study on metal sulfides sorption properties was the analysis of their synthesis methods. Different methods provide different particle sizes and surface morphology; thus, it was crucial to choose the proper method. The analysis was performed for zinc sulfide as an example.

\subsubsection{Overview and Classification of Synthesis Methods}

Due to its wide applications and potential use in high technology field, ZnS was one of the most studied luminescence, photocatalyst, special morphology, and mesoporous materials in inorganic synthesis (Wang M. et al. 2011). Zinc sulfide nanoparticles can be prepared by different methods, such as colloidal aqueous and micellar solution synthesis method, using ultrasonic waves, microwaves (MWs), and gamma irradiation (Tiquia-Arashiro and Rodrigues 2016). Zinc sulfide can be synthesized in the form of various nanostructures, and Fang et al. (2011) point out three types of them:

- OD nanostructures (nanocrystals of quantum dots type, core/shell nanocrystals, and hollow nanocrystals),

- 1D nanostructures (nanowires, nanorods, nanotubes, nanobelts, nanoribbons, and nanosheets), and

- 2D nanostructures.

Various surface morphologies of the $\mathrm{ZnS}$ particles may be obtained by different synthesis methods. To make the analysis more clear, we propose that those methods may be divided into two main groups:

- high-temperature methods (solid-state reaction or thermal evaporation of zinc powder and sulfur powder, thermal decomposition of precursors, etc.), 
- synthesis from aqueous and nonaqueous solutions (solvothermal and hydrothermal methods, precipitation from aqueous solutions, etc.).

The reaction may be activated traditionally by high temperature only or by ultrasonic, or by MWs.

\subsubsection{High-Temperature Methods}

Zinc and sulfur react with each other violently to produce zinc sulfide. To obtain pure $\mathrm{ZnS}$, the reaction should be performed in vacuum to prevent the oxidation processes. After the mixture of zinc and sulfur is heated, the elements react with each other at temperature range between $400^{\circ} \mathrm{C}$ and $600^{\circ} \mathrm{C}$. The reaction is highly exothermic. Temperature at which reaction is initiated is dependent on the dispersity of components, i.e., if the particles are smaller, the reaction starts at lower temperature. The reaction may be also activated in the MW field. For instance, Manoharan et al. (2001) demonstrated the capability of MW-aided process to perform in the atomic-level doping of "activator" ions in the host lattice. Stoichiometric amounts of reagent grade zinc and sulfur powders were placed in a quartz tube, which was then evacuated at $10^{-3}$ Torr and sealed. The contents of the tube were exposed to MW irradiation in a kitchen MW oven. The exposure time for the complete reaction was 20 minutes. The average size of the obtained crystallites was $1 \mu \mathrm{m}$. Dhara et al. (2018) reported also successful synthesis of Mn-doped ZnS nanocrystals by mechanically alloying the stoichiometric mixture of elemental Zn, S, and Mn powders at room temperature under inert atmosphere of Ar using a high-energy planetary ball mill. Different proportions of cubic and hexagonal phases were obtained dependent on milling time varying from 2 to 6 hours, with the crystallite size of cubic phase between $\sim 24$ and $\sim 40 \mathrm{~nm}$ and crystallite size of hexagonal phase from $\sim 15$ to $\sim 30 \mathrm{~nm}$. Since the interaction takes place at the temperatures above $400^{\circ} \mathrm{C}$, this method is classified as a high-temperature one.

In the present research, the reaction started after 1-2 minutes of MW irradiation of the stoichiometric mixture of zinc and sulfur. Then the mixture heats up very quickly, in several seconds, to the temperature of $500^{\circ} \mathrm{C}-600^{\circ} \mathrm{C}$. X-ray analysis informed that the obtained zinc sulfide crystallites had a structure of sphalerite. Both single-phase nanopowders and multiphase compositions perform high surface activity and agglomeration ability (Gevorkyan et al. 2019). Unlike interaction between zinc and selenium where the sintering of ZnSe particles takes place (Sofronov et al. 2013), no sintering was observed during $\mathrm{MW}$-assisted synthesis of ZnS. As it is seen in Figure 1.1, the spherical agglomerated particles are formed, and their size appears to be from 50 up to $200 \mathrm{~nm}$.

Solid-state synthesis is known as a very simple and cost-effective method that enables to obtain pure zinc sulfide nanoparticles (Jothibas et al. 2017). In our research, the infrared (IR) spectrum of the $\mathrm{ZnS}$ powder synthesized in the MW field out of zinc and sulfur did not show the absorption bands, as it is seen in Figure 1.2, which proved its high purity. In the IR spectrum, only 


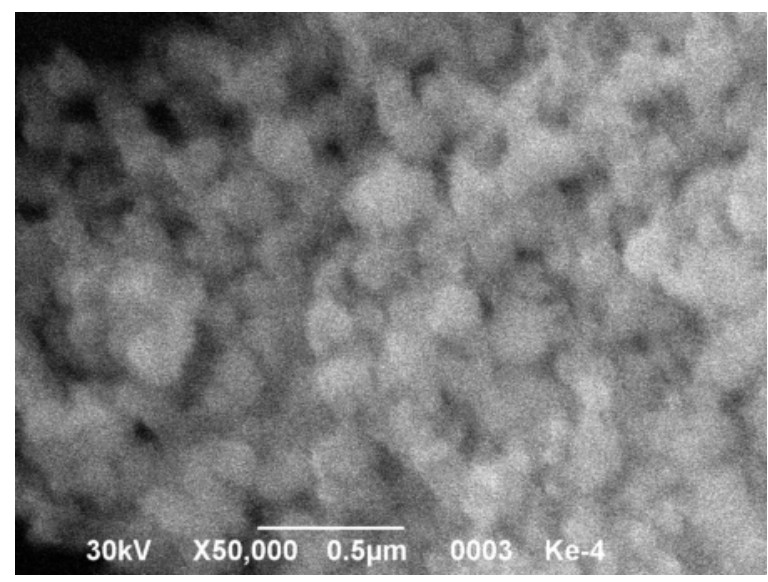

FIGURE 1.1

SEM image of the ZnS particles obtained with MW activation. MW, microwave; SEM, scanning electron microscope.

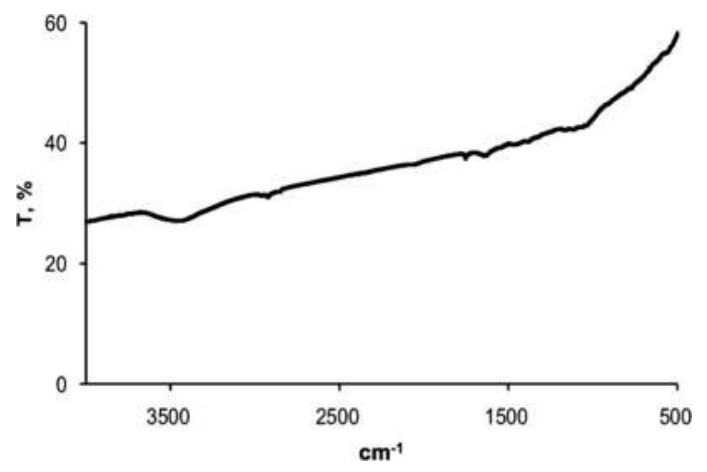

\section{FIGURE 1.2}

IR spectrum of the ZnS powder obtained in the MW field. IR, infrared; MW, microwave.

a weak absorption can be observed in the range of $3,200-3,700 \mathrm{~cm}^{-1}$, which was obviously related to the stretching vibrations of water molecules. These molecules were present due to the application of potassium bromide during the IR spectrum analysis.

To reduce the exothermic effect, the well-established technique of chemical vapor deposition (CVD) is applied. CVD methods of zinc sulfide can be separated into static and dynamic methods, as well as transport methods and conventional methods. The standard dynamic ZnS CVD process as practiced today involves a liquid zinc metal that combines with hydrogen sulfide gas in a higher-temperature deposition area (McCloy and Tustison 2013, p. 34). In the CVD method with Zn and S powder as precursors, both substances are loaded into a quartz tube at some distance from one another. In a low-temperature area of the tube, also a substrate or mandrel is placed, 
so the zinc sulfide can deposit on it. Then the tube is evacuated and heated up to $400^{\circ} \mathrm{C}-800^{\circ} \mathrm{C}$, and the carrier gas is injected (usually nitrogen or argon).

Zhuo et al. (2008) reported that with a gas transport method at $650^{\circ} \mathrm{C}$, the $\mathrm{ZnS}$ nanowires of 50-80 nm diameter and several dozens of microns long were obtained on the aluminum substrate. When the process temperature was increased up to $700^{\circ} \mathrm{C}$, the length of nanofibers decreased down to several microns, which turned the nanofibers into a nanorods. The use of graphite substrate caused the forming of nanowires with diameter ca. $50 \mathrm{~nm}$. Similarly, nanowire arrays of cubic zinc sulfide were synthesized on zinc foil by a simple thermal evaporation route at substantially lower temperature, below $500^{\circ} \mathrm{C}$ (Biswas et al. 2008). Interesting structures of manganese-, copper-, and cobalt-doped $\mathrm{ZnS}$ nanotowers are reported to be obtained on $\mathrm{Si}$ substrate at $750^{\circ} \mathrm{C}$ (Zhang et al. 2007).

Zinc sulfide may be obtained also from decomposition of some organic zinc complexes. For example, the polycrystalline $\mathrm{ZnS}$ nanotubes with diameters between 140 and $250 \mathrm{~nm}$ and the length up to tens of microns were obtained by using metal-organic chemical vapor deposition (MOCVD) template method out of the bis(diethyldithiocarbamate) $\left[\mathrm{Zn}\left(\mathrm{S}_{2} \mathrm{CNEt}_{2}\right)_{2}\right]$ at temperature $400^{\circ} \mathrm{C}$ (Zhai et al. 2006).

\subsubsection{Solvothermal Decomposition Method}

The method is used in order to obtain nanosize particles from high-temperature thermal decomposition of the compounds in the environment of high boiling organic solvents. Dependent on the solvent nature and initial components, as well as on the synthesis temperature and activation method, particles of various dimensions and shape can be obtained, such as nanorods, spheres, nanowhiskers, and so on. Geng et al. (2009) reported the synthesis of $\mathrm{Cu}^{2+}$-doped $\mathrm{ZnS}$ nanorods of $4 \mathrm{~nm}$ diameter and $15 \mathrm{~nm}$ length using a solution-phase thermal decomposition molecule precursor route at the following conditions: inert environment, oleylamine at $270^{\circ} \mathrm{C}$, and reaction time 7 hours. Zhai et al. (2012) reported preparation of rod-, dot-shaped, and quasi-cubic ZnS nanocrystals using oleylamine as coordinating solvent, zinc stearate as $\mathrm{Zn}$ precursor and sulfur powder, and thiourea and dodecanethiol as $S$ precursors, respectively. However, when thiourea and dodecanethiol took place of sulfur powder, no nanorods but dot-shaped and quasi-cubic $\mathrm{ZnS}$ nanocrystals were formed.

Pure and uniform hexagonal-phase $\mathrm{ZnS}$ nanorods with diameters 7-30 nm were synthesized by solvothermal decomposition of zinc diethyldithiocarbamate, Zn-(DDTC) $)_{2}$, in hydrazine hydrate aqueous solutions at $150^{\circ} \mathrm{C}-200^{\circ} \mathrm{C}$ during 3-48 hours (Zhang et al. 2006). During decomposition of zinc dithiocarbamate in ethanol at $150^{\circ} \mathrm{C}-200^{\circ} \mathrm{C}$, hexagonal-phase particles of spherical ZnS are formed, and their dimensions are 30-60 nm (Zhang et al. 2005). Others reported (Abdullah et al. 2016) that the precursor was decomposed to hexagonal zinc sulfide after $2-6$ hours of calcination duration at $400^{\circ} \mathrm{C}$, and the sizes of zinc sulfide nanoparticles were about $6-11 \mathrm{~nm}$. The existence of 
the hexagonal $\mathrm{ZnS}$ phase was not affected by the calcination duration. Sun et al. (2008) performed MW decomposition of zinc diethyldithiocarbamate at $110^{\circ} \mathrm{C}$ obtaining the $\mathrm{ZnS}$ particles size of $5 \mathrm{~nm}$. ZnS particles of two shapes were reported to be obtained from thiourea solutions at a thermal heating $\left(70^{\circ} \mathrm{C}-90^{\circ} \mathrm{C}\right)$ and $\mathrm{MW}$ irradiation (Sofronov, Sofronova et al., 2013). The dimensions of agglomerated particles of the spherical shape were $50-100 \mathrm{~nm}$ (particle size in agglomerates of 3-5nm), whereas the length of hexagonal columns was up to $2 \mu \mathrm{m}$ and diameter $80-100 \mathrm{~nm}$.

Li Y. et al. (2008) proposed a microemulsion-assisted solvothermal process to obtain $\mathrm{ZnS}$ nanospheres with rough surface of cubic modification with lattice constant $a=5.414 \AA$. Zinc acetate $\left(\mathrm{Zn}\left(\mathrm{CH}_{3} \mathrm{COO}\right)_{2} \cdot 2 \mathrm{H}_{2} \mathrm{O}\right)$ was used as starting material, and thiourea $\left(\left(\mathrm{NH}_{2}\right)_{2} \mathrm{CS}\right)$ as the source of $\mathrm{S}$, whereas cyclohexane served as the continuous oil phase, cetyltrimethylammonium bromide (CTAB) as the surfactant, 1-pentanol as the cosurfactant. The process lasted for 16 hours at temperature $120^{\circ} \mathrm{C}$. Theoretically, diameter of the nanoparticles is directly proportional to the size of the microemulsion water pools, which can be expressed by the water-to-surfactant ratio $\left(v=\left[\mathrm{H}_{2} \mathrm{O}\right] /\right.$ [surfactant $\left.]\right)$. When the $v$ value changed from 8 , to 16,24 , and 32 , the average diameter of $\mathrm{ZnS}$ nanosphere samples changed from 200 , to 250,350 , and $1500 \mathrm{~nm}$, respectively. When the temperature rose up to $180^{\circ} \mathrm{C}$, the diameters of nanospheres with rough surface increased up to 1.25 and even to $3 \mu \mathrm{m}$.

When zinc sulfate is contracting with $\mathrm{Na}_{2} \mathrm{~S}_{2} \mathrm{O}_{3}$ in cyclohexane with CTAB at $160^{\circ} \mathrm{C}$ during 12 hours, nanowires of zinc sulfide were obtained of cubic crystal system. The length of the particles was several micrometers, and diameter was 30-50 nm (Dong et al. 2007). ZnS microflowers composed of numerous nanowires with a cubic structure were reported to be synthesized in water below $100^{\circ} \mathrm{C}$ using an inorganic capping agent $\mathrm{K}_{2} \mathrm{~S}_{2} \mathrm{O}_{7}$ (Jaffres et al. 2017). Aguilar et al. (2017) proposed a synthesis of cubic-phase ZnS using synthesized hydrozincite $\mathrm{Zn}_{5}\left(\mathrm{CO}_{3}\right)_{2}(\mathrm{OH})_{6}$ as a novel zinc precursor in hydro- or solvothermal method.

Wurtzite structure of $\mathrm{ZnS}$ nanowires was obtained when zinc nitrate contracted with thiourea within the polyethylene glycol (PEG) gel and water at $172^{\circ} \mathrm{C}$ during 4 days (Cheng et al. 2006). The $\mathrm{Ag}_{2} \mathrm{~S}$-catalyzed zinc sulfide nanowires were reported to have a wurtzite structure with a width in the range of 30-80 $\mathrm{nm}$ and length of ca. $1 \mu \mathrm{m}$ (Kim et al., 2018).

Unlike in the case of solvothermal synthesis, in hydrothermal method, water is applied as a solvent. The process is carried out in an autoclave and takes place at increased pressure and temperature. Wang et al. (2017) reported preparation of $\mathrm{ZnS}$ nanoparticles by hydrothermal method using zinc nitrate $\left[\mathrm{Zn}\left(\mathrm{NO}_{3}\right)_{2} \cdot 6 \mathrm{H}_{2} \mathrm{O}\right]$ and thiourea $\left[\mathrm{SC}\left(\mathrm{NH}_{2}\right)_{2}\right]$ as sources of $\mathrm{Zn}^{2+}$ and $\mathrm{S}^{2-}$ ions and $\mathrm{CTAB}\left[\mathrm{CH}_{3}\left(\mathrm{CH}_{2}\right)_{15} \mathrm{~N}^{+}\left(\mathrm{CH}_{3}\right)_{3} \cdot \mathrm{Br}^{-}\right]$as a surface active agent. Hydrothermal synthesis may be initiated by MWs as well (Yan et al. 2013). Anand et al. (2009) proposed optimization of hydrothermal method for the synthesis of $\mathrm{ZnS}$ nanoparticles. The nanoparticles were stabilized using hexamethylenetetramine (HMTA) as a surfactant in aqueous solution, and 
average grain size of the nanoparticles of the order of $2 \mathrm{~nm}$ was obtained. Chanu et al. (2017) reported synthesis of zinc sulfide (ZnS) nanospheres using amino acid, L-histidine as a capping agent by hydrothermal method. A particle size of $5 \mathrm{~nm}$ was obtained after 3 hours at the temperature $120^{\circ} \mathrm{C}$. Other paper reported production of the spherical $\mathrm{ZnS}$ nanoparticles with diameter 100-300 nm from the reaction between zinc chloride and $\mathrm{Na}_{2} \mathrm{~S}_{2} \mathrm{O}_{3}$ at temperature $200^{\circ} \mathrm{C}$ during 4 hours (Jiang et al. 2007). Addition of acrylic amide $\mathrm{C}_{3} \mathrm{H}_{5} \mathrm{NO}$ caused the increase of the particle diameters up to $3 \mu \mathrm{m}$. When the process was performed in the conditions of MW activation, the monodisperse spherical particles of sphalerite structure $(a=5.406 \AA)$ were obtained with diameter ca. $100 \mathrm{~nm}$ (Yao et al. 2008). It was also proposed to apply thioacetamide (Zhu et al. 2001), thiourea (Chen et al. 2003), and sodium sulfide (Li W. et al. 2008) as reagents in the hydrothermal synthesis.

Precipitation from a water solution appears to be advantageous because of the simplicity of method and its high productivity. For example, it was reported that pure and $\mathrm{Ni}(0.5 \%-2.0 \%)$-doped $\mathrm{ZnS}$ nanoparticles were prepared by an inexpensive solid-state reaction method (Jothibas et al. 2018). A solution method for preparing oxygen-doped $\mathrm{ZnS}$ colloidal nanocrystals was demonstrated by Wang et al. (2018), where optimal power conversion efficiency $(\mathrm{PCE})$ of the device based on $\mathrm{ZnO} / \mathrm{ZnS}(\mathrm{O})$ reached $8.85 \%$. The average size of the nanoparticles was ca. $8.5 \mathrm{~nm}$. Song et al. (2008) reported that pure as well as $\mathrm{Mn}$ - and $\mathrm{Cu}$-doped zinc sulfide was obtained from the reaction between zinc ethylenediaminetetraacetate and thioacetamide at $60^{\circ} \mathrm{C}-100^{\circ} \mathrm{C}$. The dimensions of particles varied between 50 and $1000 \mathrm{~nm}$, dependent on the synthesis temperature and thioacetamide concentration. The smallest particles were obtained at the temperature $60^{\circ} \mathrm{C}$ and molar ratio TAA: $\mathrm{Zn}^{2+}=1: 1$.

The Mn-doped particles of $\mathrm{ZnS}(5 \%-20 \%$ in mass) with dimensions $2.5-4 \mathrm{~nm}$ were obtained by Wang et al. (2008) in the Ar atmosphere during 30 minutes. Xiao and Xiao (2008) proved that when the thioglycolic acid (TGA) is added, the particles size will be decreased down to $1.2-2.5 \mathrm{~nm}$. Labiadh et al. (2017) reported that undoped and Mn-doped ZnS nanoparticles (with $5 \%, 10 \%$, and $20 \%$ of Mn dopant) were synthesized at $95^{\circ} \mathrm{C}$ in basic aqueous solution using the nucleation doping strategy. Tripathi et al. (2007) reported synthesis of Mn-doped ZnS nanocrystals via aqueous solution precipitation method with hydrogen sulfide at room temperature in the air atmosphere during 5 hours. Obtained $\mathrm{Zn}_{1-x} \mathrm{Mn}_{x} \mathrm{~S}(x=0 \%-5 \%)$ nanoparticles of cubic modification had sizes in the range of $4-6 \mathrm{~nm}$.

Mei et al. (2017) proposed a facile MW-assisted aqueous route using sodium citrate and TGA as dual stabilizer in order to synthesize $\mathrm{Cu}-\mathrm{In}-\mathrm{S} / \mathrm{ZnS}$ quantum dots with the size of $3.8 \mathrm{~nm}$. Zinc sulfide $(\mathrm{ZnS})$, various concentrations of $\mathrm{Cu}^{2+}(0.25 \%-1.25 \%)$-doped $\mathrm{ZnS}$, and $\mathrm{ZnS}: \mathrm{Cu}^{2+}$ nanoparticles capped with various surfactants were reported to be successfully synthesized by a chemical precipitation method in ambient air at $80^{\circ} \mathrm{C}$ (Murugadoss 2013). The formation of a cubic phase was confirmed for all samples, and average size of the particles ranged from 3.2 to $5.3 \mathrm{~nm}$. 
Nanoparticles $\mathrm{ZnS}(\mathrm{Cu})$ were obtained from thiourea solution with additions of triethanolamine (TEA) and sodium polyphosphate (Kim et al. 2006; Lee et al. 2004). In other papers, precipitation of $\mathrm{ZnS}(\mathrm{Cu})$ was proposed using sodium sulfide (Corrado et al. 2009; Bol et al. 2002). Similarly, precipitation with sodium sulfide enabled to obtain nanoparticles of $\mathrm{ZnS}(1 \% \mathrm{Ag})$ using 3-mercaptopropionic acid (3-MPA) as a stabilizer (Jian et al. 2006).

In this chapter, the methods of metal sulfides synthesis were chosen on the basis of following requirements and assumptions:

- simple technology,

- avoidance of complicated and specific apparatus for synthesis,

- high productivity,

- potential for further increase of the process scale in order to produce larger amounts of the material.

After the thorough analysis, it was assumed that the method best meeting those requirements and providing metal sulfides for further utilization as sorbents was precipitation of them out of the aqueous solutions. As reagents, thiourea and sodium sulfide were chosen.

\subsubsection{Methodology and Equipment}

MW-activated synthesis was performed using an MW apparatus MARS (CEM Corporation Matthews, USA). The system uses integrated sensor technology to recognize the vessel type and the sample number in order to apply the appropriate amount of power. It has contactless in situ temperature measurement, is equipped with sensors that detect vessel type and count, and provides hundreds of preprogrammed methods.

The specific surface area (SSA) was determined with the method of thermal desorption of argon (10\% argon mixture with helium) with chromatographic analysis. As a standard, the samples of aluminum oxide were used with the SSA of 4.2 and $52 \mathrm{~m}^{2} / \mathrm{g}$. The weighed sample $(0.05-0.1 \mathrm{~g})$ was placed in a U-tube with inner diameter $4 \mathrm{~mm}$ and heated during an hour in the stream of argon of flow speed of $100 \mathrm{~cm}^{3} / \mathrm{min}$ at $100^{\circ} \mathrm{C}$ during 1 hour. This operation served for cleaning the surface and pores from the contaminations and moisture. After that, the gas was replaced by the mixture of $10 \%$ argon in helium, and flow speed was reduced down to $50 \mathrm{~cm}^{3} / \mathrm{min}$. The gas mixture is then passed through a katharometer. The tube with the sample was placed in liquid nitrogen where it was until the end of adsorption process indicated by the return of katharometer to the initial (zero) point. It lasts ca. 2-3 minutes. Next, the tube with the sample was placed in water at room temperature where desorption of argon takes place, and the katharometer's indication went to opposite direction. The area under desorption peak is proportional to the overall amount of desorbed argon. It is assumed that the argon adsorption at $77 \mathrm{~K}$ has a monolayer 
characteristics; thus, the area under peak is assumed to be proportional to the absolute surface of the sample. Along with each sample, the standard was measured, i.e., exact weighed sample of $\mathrm{Al}_{2} \mathrm{O}_{3}$ with known SSA. Two respective U-tubes with measured sample and the standard were connected in series.

Adsorption experiments were performed using the model solutions containing ions of investigated metals at the temperature $20^{\circ} \mathrm{C}\left( \pm 1^{\circ} \mathrm{C}\right)$. Measurement of the metals concentration in the solutions before and after sorption was performed with the inductively coupled plasma atomic emission spectroscopy (ICP-AES) (Moore 1989). The device was iCAP 6300 Duo made by Thermo Fisher Scientific.

The iCAP 6300 uses a simple pressure-controlled nebulizer gas flow or an optional factory-fitted nebulizer gas mass flow controller. Duo version of the instrument enables both radial and axial view. The device applies spectrometer of Echelle type, 52.91 grooves $/ \mathrm{mm}$ ruled grating, $383 \mathrm{~mm}$ effective focal length, and $9.5^{\circ} \mathrm{UV}$-fused silica cross-dispersion prism. The wavelength range is $166-847 \mathrm{~nm}$, spectral bandpass is $7 \mathrm{pm}$ at $200 \mathrm{~nm}$, and the device uses high-performance CID86 chip detector. Plasma gas flow is fixed $12 \mathrm{~L} / \mathrm{min}$ argon, and nebulizer gas is under pressure control from 0 to $0.4 \mathrm{MPa}$. Auxiliary gas has four fixed flows: $0,0.5,1.0$, and $1.5 \mathrm{~L} / \mathrm{min}$.

The IR spectra were obtained in tablets of $\mathrm{KBr}$ with Spectrum One FT-IR Spectrometer (made by PerkinElmer, USA). The device employs improved Michelson interferometer, self-compensating for dynamic alignment changes due to tilt and shear, incorporating high reflectivity first-surface aluminum-coated optics. The detectors are electrically, temperature-stabilized fast recovery deuterated triglycine sulfate (FR-DTGS) or lithium tantalate $\left(\mathrm{LiTaO}_{3}\right)$. Wavelength range is $7,800-350 \mathrm{~cm}^{-1}$ with $\mathrm{KBr}$ beam splitter, wavelength accuracy $0.1 \mathrm{~cm}^{-1}$ at $1,600 \mathrm{~cm}^{-1}$, and resolution is 0.5 to $64 \mathrm{~cm}^{-1}$. For the FR-DTGS detector, signal-to-noise ratio for $\mathrm{KBr}$ optics is 30,000/1 rms, 6,000/1 p-p for a 5-second measurement and 100,000/1 rms, 20,000/1 p-p for a 1-minute measurement. For the $\mathrm{LiTaO}_{3}$ detector, signal-to-noise ratio for $\mathrm{KBr}$ optics is 7,500/1 rms, 1,500/1 p-p for a 5-second measurement and $26,000 / 1 \mathrm{rms}, 5,000 / 1 \mathrm{p}$-p for a 1-minute measurement.

As for nontransparent powder sample, it is difficult to obtain the absorption spectrum, the diffuse reflection spectrum was used to calculate the bandgap of materials (Kaihara and Sato 2000). It should be remembered that the diffuse reflection spectrum always contains both absorption and reflection spectral components (Nishikida et al. 1995). The relationship of the intensity of the reflected radiation to the concentration is usually presented as follows (Byrn et al. 2017):

$$
F(R)=\frac{(1-R)^{2}}{2 R}=\frac{k}{s}=\frac{A c}{s}
$$

where $R$ is reflectance, $k$ is the absorption coefficient, $s$ is the scattering coefficient, $c$ is the concentration of the absorbing species, and $A$ is the absorbance. 
Based on the obtained spectra, the bandgap $E_{g}$ for the examined material was assessed (Katrunov et al. 2010).

Structural characterization of materials was performed with X-ray powder diffraction technique using Siemens D500 X-ray Diffractometer (XRD), with Ni-filtered $\mathrm{Cu}$ sources and graphite-diffracted beam monochrometers. In this work, the diffraction patterns were recorded in the $2 \theta$ angle range between $10^{\circ}$ and $110^{\circ}$ at room temperature, with steps of $0.02^{\circ}$ and counting time of $10 \mathrm{~s}$ at each point.

Particle shape and size are two concepts that are intrinsically connected (Pons and Dodds 2015). Thus, to evaluate morphology of obtained powders, scanning electron microscope (SEM) and transmission electron microscope (TEM) were applied.

The SEM was JSM-6390LV made by Jeol Ltd. (Japan) with a high resolution of $4.0 \mathrm{~nm}$. The JSM-6390 specimen chamber can accommodate a specimen of up to $150 \mathrm{~mm}$ in diameter. Standard automated features include autofocus/ autostigmator, autogun (saturation, bias, and alignment), and automatic contrast and brightness. Magnification is $\times 8$ to $\times 300,000$ (at $11 \mathrm{kV}$ or higher) and $\times 5$ to $\times 300,000$ (at $10 \mathrm{kV}$ or lower). The TEM was device of ПЭM-125 type made by SELMI (Ukraine).

The results of measurement and analysis are presented and discussed in the respective chapters, for each presented method.

\subsubsection{Procedures and Reactions}

The solutions were prepared using the following precursors: $\mathrm{Cu}\left(\mathrm{NO}_{3}\right)_{2} \cdot 3 \mathrm{H}_{2} \mathrm{O}$, $\mathrm{CuSO}_{4} \cdot 5 \mathrm{H}_{2} \mathrm{O}, \quad \mathrm{CuCl}_{2} \cdot 3 \mathrm{H}_{2} \mathrm{O}, \mathrm{Cd}\left(\mathrm{NO}_{3}\right)_{2} \cdot 4 \mathrm{H}_{2} \mathrm{O}, \mathrm{CdSO}_{4} \cdot \mathrm{H}_{2} \mathrm{O}, \quad \mathrm{CdCl}_{2} \cdot \mathrm{H}_{2} \mathrm{O}$, $\mathrm{Zn}\left(\mathrm{NO}_{3}\right)_{2} \cdot 6 \mathrm{H}_{2} \mathrm{O}, \mathrm{ZnSO}_{4} \cdot 7 \mathrm{H}_{2} \mathrm{O}, \mathrm{ZnCl}_{2}$, thiourea, and aqueous solution of ammonia. All the reagents were qualified as chemically pure. All solutions were made using the distillated water.

Precipitation of the zinc, copper(II), and cadmium was performed from 0.1 and $1 \mathrm{M}$ solutions of nitrate, chloride, and sulfate of the respective metal. To the volume of $1 \mathrm{~mL}$ of the metal salt solution, the aqueous solution of ammonia was added, or $0.1 \mathrm{M}$ solution of sodium hydroxide until the require $\mathrm{pH}$ was reached. The value of $\mathrm{pH}$ was varying between 8 and 12. Next, thiourea (Th) was added in proportion of $c(\mathrm{Th}): c\left(\mathrm{Me}^{2+}\right)$ 1:1, 2:1, or 4:1. The mixture was then heated up to boiling temperature and boiled during 1 hour. After synthesis, the obtained precipitate was filtered out, washed with distillated water, and dried at the room temperature during 24 hours.

MW-activated synthesis was performed using a MW apparatus MARS (CEM Corporation, Matthews, USA). Volume $50 \mathrm{~mL}$ of $0.1 \mathrm{M}$ solution of zinc, cadmium, or copper(II) nitrate, chloride, or sulfate of basicity $\mathrm{pH}=8,10$, and 12 was placed in a $250 \mathrm{~mL}$ glass. Then the thiourea was added in molar proportion $\mathrm{Me}^{2+}$ /Th 1:1, 1:2, or 1:4 with continuous stirring. Next, the mixture was placed in the viala of volume $100 \mathrm{~mL}$ and underwent $\mathrm{MW}$ activation during 30 minutes at temperature $100^{\circ} \mathrm{C}$ and $150^{\circ} \mathrm{C}$. After the synthesis was 


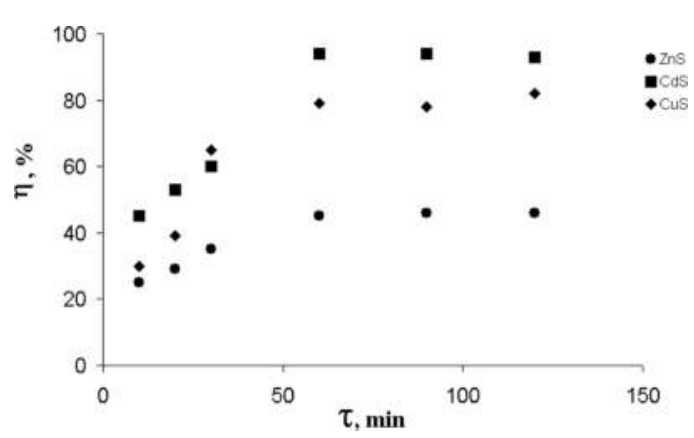

FIGURE 1.3

Percentage of the synthesized sulfides versus precipitation time from thiourea solution for the proportion $\mathrm{c}\left(\mathrm{Me}^{2+}\right): \mathrm{c}\left(\left(\mathrm{NH}_{2}\right)_{2} \mathrm{CS}\right) 1: 1, \mathrm{pH} 11.5$.

finished, the obtained precipitate was filtered out, several times washed with distillated water, and dried at the room temperature during 24 hours.

The synthesis time was selected based on the assumption of maximal amount of the final product. Figure 1.3 presents the experimental graph of precipitation time for metal sulfides precipitated with thiourea in proportion $c\left(\mathrm{Me}^{2+}\right): c\left(\left(\mathrm{NH}_{2}\right)_{2} \mathrm{CS}\right)$ 1:1 and $\mathrm{pH}$ 11.5.

The experimental data proved that the precipitation time between 10 and 30 minutes provides small amounts of the final products. When increased up to 60 minutes, the time becomes sufficient for obtaining $45 \%, 79 \%$, and $94 \%$ of zinc, cadmium, and copper(II) sulfides, respectively. Further prolongation of the synthesis time has no substantial impact on the product amount. Thus, it was assumed that the basic synthesis time using thiourea solutions was 1 hour.

Iron sulfide was obtained from the thermal reaction between sulfur and iron. Stoichiometric quantities of those substances were placed in the quartz ampule, which was then evacuated with a vacuum pump during 30-40 minutes until the pressure reached $1.3 \mathrm{~Pa}\left(10^{-2} \mathrm{mmHg}\right)$. Next, the ampule was sealed and placed in the oven to be heated up to $600^{\circ} \mathrm{C}$ at speed of $30^{\circ} \mathrm{C}$ per hour. The ampule stayed in the temperature $600^{\circ} \mathrm{C}$ for 5 hours, and then the temperature was risen to $800^{\circ} \mathrm{C}$. After 4 hours in the temperature of $800^{\circ} \mathrm{C}$, the ampule was cooled down to the room temperature and opened, and the obtained substance was milled in a porcelain mortar.

\section{Acknowledgment}

This chapter is made Open Access through funding by Precision Machine Parts Poland Sp. z o.o. 


\subsection{Precipitation with Sodium Sulfide}

Interaction of the metal salts with sodium sulfide can be described as follows:

$$
\begin{gathered}
\mathrm{Zn}\left(\mathrm{NO}_{3}\right)_{2}+\mathrm{Na}_{2} \mathrm{~S} \rightarrow \mathrm{ZnS} \downarrow+2 \mathrm{NaNO}_{3} \\
\mathrm{CdCl}_{2}+\mathrm{Na}_{2} \mathrm{~S} \rightarrow \mathrm{CdS} \downarrow+2 \mathrm{NaCl} \\
\mathrm{CuSO}_{4}+\mathrm{Na}_{2} \mathrm{~S} \rightarrow \mathrm{CuS} \downarrow+\mathrm{Na}_{2} \mathrm{SO}_{4}
\end{gathered}
$$

These reactions are typically applied to obtain metal sulfides insoluble in aqueous solutions, mainly copper(I and II), nickel, zinc, cadmium, lead(II), cobalt, silver, or gold. The precursors in these cases are metal salts soluble in water: halides, sulfates, or nitrates.

Figure 1.4 presents SEM images of the zinc, cadmium, and copper sulfides particles formed during the precipitation process performed with sodium sulfide. It can be seen that in case of zinc and cadmium sulfides, large shapeless agglomerates were formed of dimensions few dozens of micrometers, while in case of copper sulfide, thin scales are formed with dimensions up to $3 \mu \mathrm{m}$. However, the analysis of the precipitation conditions impact on the morphological features of the particles revealed no substantial relation between sodium sulfide precipitation process characteristics and the shape or dimensions of the obtained particles. The relative yield of zinc, cadmium, and copper sulfides was ca. $90 \%-95 \%$ which is considered an
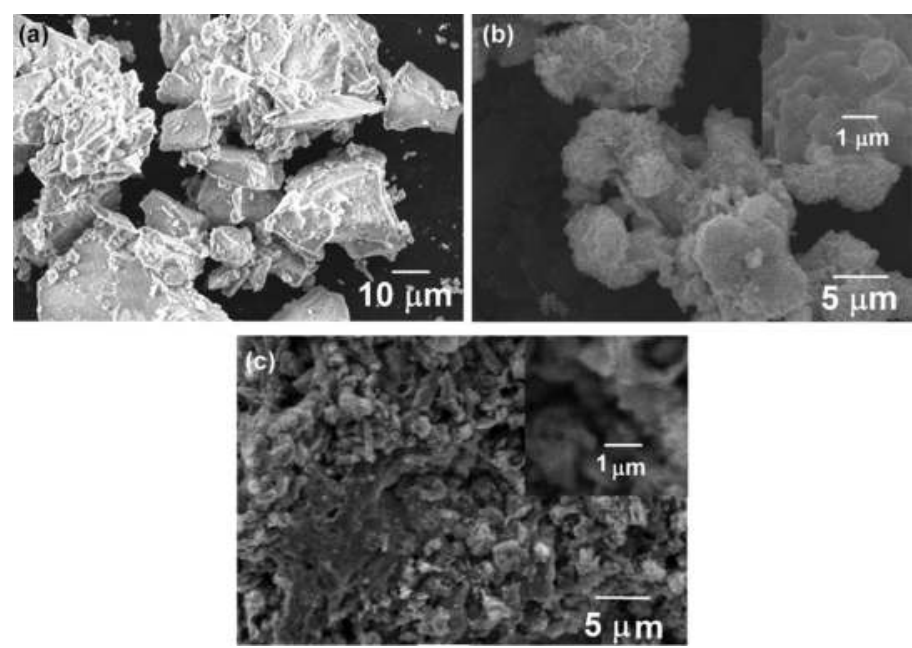

\section{FIGURE 1.4}

Images of the particles ZnS (a), CdS (b), and CuS (c), obtained by the sodium sulfide precipitation out of $0.1 \mathrm{M}$ solutions. 
excellent percentage yield. According to the recognized sources (Furniss et al. 1989, p. 33), the success of a reagent is judged as excellent when the percentage yield is $>90 \%$, very good for $>80 \%$, good for $>70 \%$, fair for $>50 \%$, and poor when it is below $40 \%$.

Variations of precipitation temperature and the initial concentration of the substances in the solutions did not effect on morphological features of the obtained particles. In all cases, shapeless large agglomerates were formed. Thus, the method of precipitation with sodium sulfide does not allow to control the formation process and growth of the metal sulfide particles.

\subsection{Particles Precipitation Out of Thiourea Solutions}

In the aqueous solutions, thiourea undergoes hydrolytic degradation dependent on $\mathrm{pH}$. When the environment is acidic, the ammonium ions $\mathrm{NH}_{4}{ }^{+}$and thiocyanate ions $\mathrm{SCN}^{-}$appear (Herrmann et al. 1995). The hydrolysis of thiourea in alkaline environment, in turn, leads to the formation of cyanamide and sulfide ions (Peters and Rauter 1974; Kitayev et al. 1989), according to the following reaction:

$$
\left(\mathrm{NH}_{2}\right)_{2} \mathrm{CS}+2 \mathrm{OH}^{-} \leftrightarrow \mathrm{S}^{2-}+\mathrm{H}_{2} \mathrm{CN}_{2}+\mathrm{H}_{2} \mathrm{O}
$$

When the alkaline hydrolysis is performed at increased temperatures above $80^{\circ} \mathrm{C}$ or $100^{\circ} \mathrm{C}$, formation of $\mathrm{S}^{2-}, \mathrm{CO}_{3}{ }^{2-}$, and $\mathrm{NH}_{3}$ takes place. It was assumed that higher temperature caused hydrolysis of cyanamide that resulted with formation of dicyanamide, guanidine, and guanidine-thiourea. These substances, in turn, became hydrolyzed to ammonium cyanate and then to ammonium carbonate (Marcotrigiamo et al. 1972).

Unlike the sodium sulfide precipitation process, the conditions such as $\mathrm{pH}$, concentration, anionic composition, or activation method have substantial effect on the particles formation in thiourea solutions. Thus, it is possible to control in some extent the functional characteristics of the obtained particles varying the synthesis conditions, as it was reported in case of ZnS (Jayalakshmi and Rao 2006; Sofronov, Kamneva et al., 2013).

\subsubsection{Effect of Chemical Composition of the Reagent Environment on the Particle Formation of Zinc, Copper, and Cadmium Sulfides}

\subsubsection{1 pH effect}

Figure 1.5 presents powders precipitated from nitrate solutions in relation $c\left(\mathrm{Zn}^{2+}\right): c\left(\left(\mathrm{NH}_{2}\right)_{2} \mathrm{CS}\right)$ 1:1. Fine bulk powder is formed at $\mathrm{pH} 8$, and the obtained particles are mainly spherical. When $\mathrm{pH}$ is increased, diameters of those spherical particles increase, too. For example, at $\mathrm{pH} \mathrm{8,} \mathrm{the} \mathrm{particles} \mathrm{of} \mathrm{ZnS}$ 

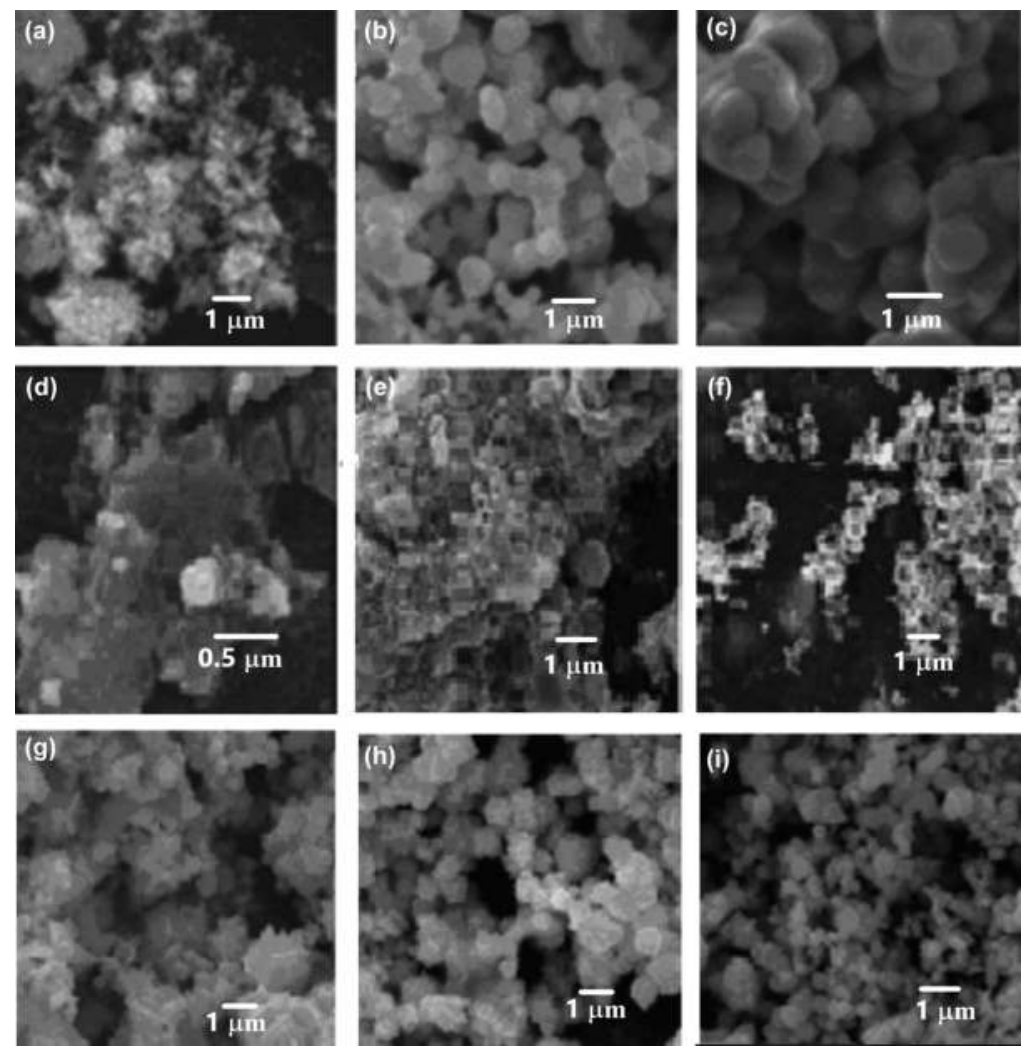

\section{FIGURE 1.5}

Particles ZnS (a, b, c), CuS (e, f, g), and CdS (h, i, j), obtained from nitrate solutions at the ratio $c\left(\mathrm{Zn}^{2+}\right): c\left(\left(\mathrm{NH}_{2}\right)_{2} \mathrm{CS}\right)$ 1:1 and different pH: $\mathrm{pH} 8(\mathrm{a}, \mathrm{e}, \mathrm{h}), \mathrm{pH} 10(\mathrm{~b}, \mathrm{f}, \mathrm{i})$, and $\mathrm{pH} 12(\mathrm{c}, \mathrm{g}, \mathrm{j})$.

with diameters $0.1-0.2 \mu \mathrm{m}$ are formed, whereas at $\mathrm{pH} 10$ and 12, the particle dimensions are 0.5 and $0.65 \mu \mathrm{m}$, respectively. It can be seen in Figure 1.5a-c. In case of copper sulfide, the particles below $0.1 \mu \mathrm{m}$ are formed at $\mathrm{pH} 8$, but when $\mathrm{pH}$ is increased up to $\mathrm{pH} 12$, the particles grow up to $0.3 \mu \mathrm{m}$, as it is shown in Figure 1.5d-f. Similar pattern takes place for the cadmium sulfide, where spherical particles of diameter $0.2 \mu \mathrm{m}$ are formed at $\mathrm{pH} 8$. When

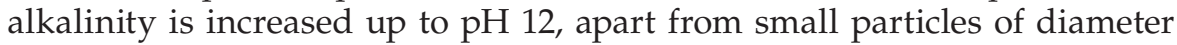
$0.1-0.3 \mu \mathrm{m}$, some larger spherical particles are found of diameter in average $0.75 \mu \mathrm{m}$.

Similarly, $\mathrm{pH}$ of the solution had an effect on the final product yield. In general, it was observed that the percentage yield can be increased for $5 \%-15 \%$ with the increase of $\mathrm{pH}$ value. Table 1.1 provides the examples of obtained yields dependent on $\mathrm{pH}$.

The results of X-ray structural analysis show that from thiourea solutions, zinc sulfide of sphalerite structure (some weak reflexes were noted, too, typical for zinc oxide) and copper sulfide of covellite structure are formed. 


\section{TABLE 1.1}

pH Solution Effect on the Percentage Yield of the ZnS, CdS, and CuS Precipitation

\begin{tabular}{lccc}
\hline & \multicolumn{3}{c}{ Percentage Yield (\%) } \\
\cline { 2 - 4 } $\mathrm{pH}$ & ZnS & CdS & CuS \\
8 & 40 & 70 & 75 \\
10 & 42 & 75 & 77 \\
12 & 45 & 85 & 80 \\
\hline
\end{tabular}

A slight difference takes place in the cadmium sulfide precipitation process (Sofronov et al. 2011). In that case, at the beginning, lemon yellow precipitate is formed, which gradually becomes red when the time of synthesis is prolonged. The first stage, when yellow precipitate is formed, lasts 15 minutes at temperature $90^{\circ} \mathrm{C}-95^{\circ} \mathrm{C}$ and is longer at lower temperatures. X-ray analysis revealed that the result of synthesis was cadmium sulfide with the following characteristics: the lemon yellow powder was a wurtzite modification with lattice parameters $a=4.136 \AA$ and $c=6.713 \AA$, very close to the data reported by Rantala (1999), whereas the red powder was a mixture consisting mainly of sphalerite with lattice constant $a=5.818 \AA$, but also wurtzite modification with lattice parameters $a=4.136 \AA$ and $c=6.713 \AA$. Hexagonal wurtzite component in the red powder is no more than $10 \%$.

Apart from zinc sulfide, some amounts of hydroxide, carbonate, hydrocarbonates, and oxides may be produced during the synthesis process, which leads to the contamination of the final product. Formation of carbonates and hydrocarbonates takes place because of carbonization of alkaline solution with the carbon dioxide from atmosphere, whereas zinc oxide is formed by the decomposition of zinc hydroxide. The simplest and most informative method for the inspection of oxygen-containing impurities is the IR spectrometry. The obtained sulfides do not absorb in the near middle IR region, i.e., there are no absorption bands in the spectrum $7800-400 \mathrm{~cm}^{-1}$, while oxygen-containing additions do absorb in their specific spectrum regions.

IR spectra of the synthesized samples are presented in Figures 1.6-1.8. In the IR spectrum of the $\mathrm{ZnS}$ powder obtained at $\mathrm{pH} 8$ and proportion $c\left(\mathrm{Zn}^{2+}\right): c\left(\left(\mathrm{NH}_{2}\right)_{2} \mathrm{CS}\right)$ 1:1 (Fig.ure1.6a), absorption in the region 3,000-3,600 $\mathrm{cm}^{-1}$ is seen with its maximum at $34,00 \mathrm{~cm}^{-1}$, as well as the absorption band at $1,620 \mathrm{~cm}^{-1}$. These data correspond with valence and deformation vibrations of water molecules absorbed on the surface of zinc sulfide particles. The absorption band $2,038 \mathrm{~cm}^{-1}$ can be ascribed to the vibrations of SCN (Egorov et al. 2010). The absorption band 1,385 $\mathrm{cm}^{-1}$ can be ascribed to the vibrations of ion $\mathrm{NO}_{3}{ }^{-}$(Adler and Kerr, 1965; Saha and Podder 2011), and the absorption band $900 \mathrm{~cm}^{-1}$ can be ascribed to the vibrations of the $\mathrm{Zn}-\mathrm{OH}$ bond (Adler and Kerr 1965). The absorption band at $1,028 \mathrm{~cm}^{-1}$ is related to the symmetric vibrations of C-S bond in thiourea (Saha and Podder 2011). 


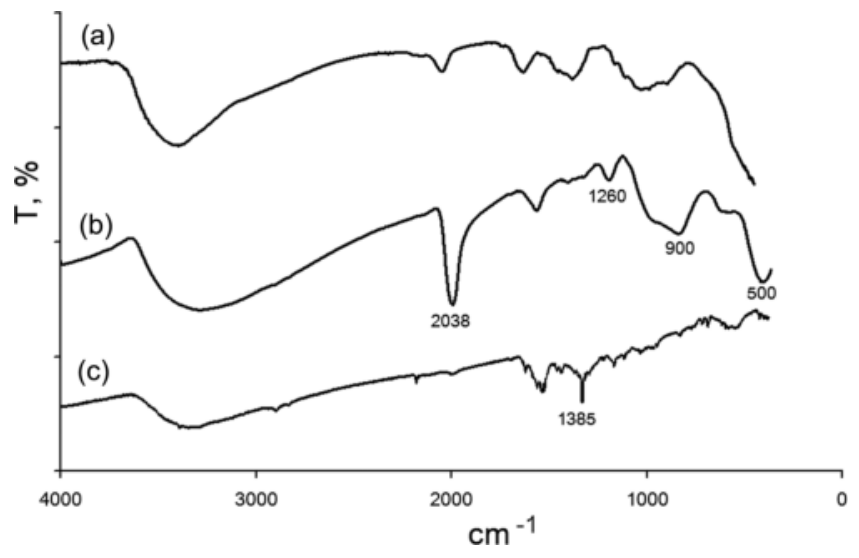

FIGURE 1.6

IR spectra of $\mathrm{ZnS}$ powders precipitated from nitrate solutions at various $\mathrm{pH}$ : (a) $\mathrm{pH}$ 8; (b) $\mathrm{pH}$ 10; and (c) pH 12 (Sofronov, Kamneva et al. 2013). IR, infrared.

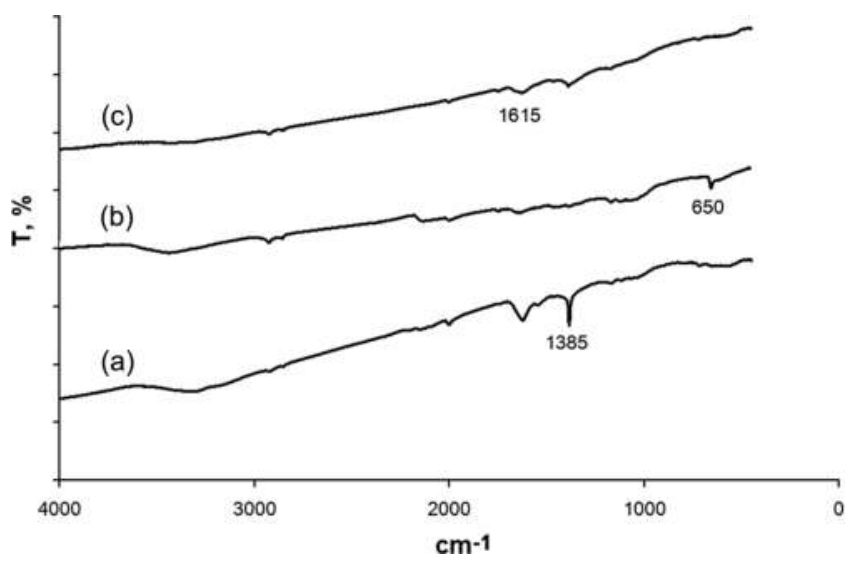

FIGURE 1.7

IR spectra of CdS powders obtained at various $\mathrm{pH}$ : (a) $\mathrm{pH}$ 8.5; (b) $\mathrm{pH}$ 9.5; and (c) $\mathrm{pH}$ 12.0. IR, infrared.

When $\mathrm{pH}$ is increased up to 10.9 , the bands 2038 and $900 \mathrm{~cm}^{-1}$ become stronger. Also the bands 1,260,685, and $500 \mathrm{~cm}^{-1}$ are stronger, perhaps because of vibrations of $\mathrm{S}-\mathrm{O}\left(685 \mathrm{~cm}^{-1}\right)$ and $\mathrm{Zn}-\mathrm{O}\left(500 \mathrm{~cm}^{-1}\right)$ bonds, as it was reported by Adler and Kerr (1965). The absorption band at $1,260 \mathrm{~cm}^{-1}$, in turn, is generated by thiourea adsorbed on the surface of zinc sulfide particles and corresponds with vibrations of N-CS-N group (Edrah 2010).

However, when alkalinity is increased to $\mathrm{pH} 12$, practically all absorption bands become weaker, as it is seen in Figure 1.6c. This phenomenon proves the decrease of impurities percentage in the obtained sulfide powder. 


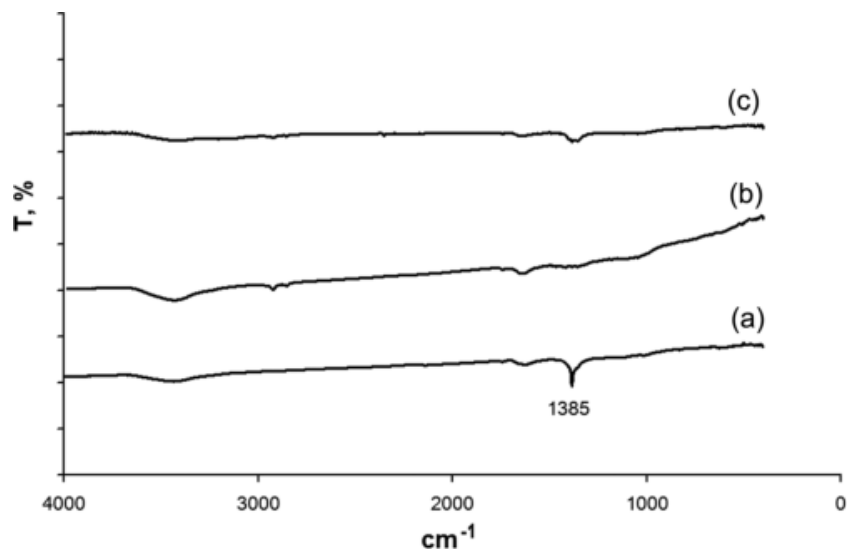

FIGURE 1.8

IR spectra of CuS powders obtained at various $\mathrm{pH}$ : (a) $\mathrm{pH}$ 8.2; (b) $\mathrm{pH}$ 9.5; and (c) $\mathrm{pH}$ 12.0. IR, infrared.

In Figure 1.7, IR spectra of CdS powders obtained at various $\mathrm{pH}$ are presented. The absorption band in the area $3,000-3,600 \mathrm{~cm}^{-1}$ is seen, with its maximum corresponding with $3,430 \mathrm{~cm}^{-1}$, as well as absorption band with maximum at $1,632 \mathrm{~cm}^{-1}$, both explained by the presence of the adsorbed water on the cadmium sulfide surface. Moreover, presence of the absorption band with its maximum at $1,384 \mathrm{~cm}^{-1}$, and in the range $900-1,200 \mathrm{~cm}^{-1}$ with its maximum at $1,060 \mathrm{~cm}^{-1}$, can be ascribed to the $\mathrm{NO}_{3}{ }^{-}$ions that appear because of cadmium nitrate application during synthesis.

On the other hand, in the CuS powders spectra shown in Figure 1.8, the absorption bands are very weak. Insignificant presence of water molecules was noticed $\left(3,000-3,600 \mathrm{~cm}^{-1}\right.$ with maximum at $3,400 \mathrm{~cm}^{-1}$, and the absorption band at $1,620 \mathrm{~cm}^{-1}$ ), as well as some number of $\mathrm{NO}_{3}{ }^{-}$ions (absorption band at $1,385 \mathrm{~cm}^{-1}$ ).

Investigation of the synthesis conditions effect on the zinc sulfide particles formation leads to the interesting observation. When the aqueous ammonia solution serving as an alkaline reagent was replaced by sodium hydroxide or potassium hydroxide, diameter of spherical particles substantially decreased. That fact is very important for the further investigation of the particle dimensions impact on fundamental absorption edge in cadmium sulfide, especially in case of optical materials production. In order to examine the aforementioned effect, chloride solutions were chosen, because they produced the particles with minimal dimensions and maximal yield.

Figures 1.9 and 1.10 present TEM images of the synthesized zinc sulfide particles. When $\mathrm{NaOH}$ was used at low $\mathrm{pH} 8.1$ and low concentration of thiourea in the proportion of $c\left(\mathrm{Zn}^{2+}\right): c(\mathrm{Th}) 1: 4$, the average dimensions of the agglomerates were ca. $20 \mathrm{~nm}$, as it is seen in Figure 1.9a. 

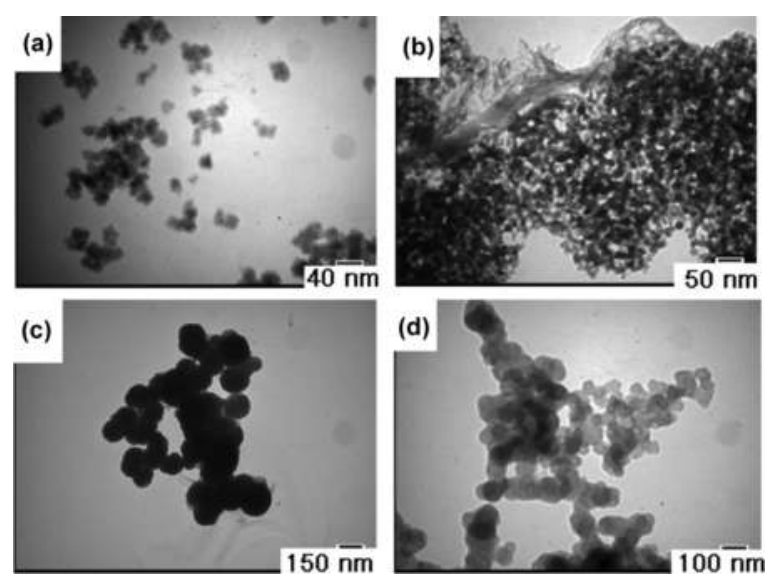

\section{FIGURE 1.9}

The particles obtained from chloride solutions $(\mathrm{NaOH})$, at respective $\mathrm{pH}$ and proportion $c\left(\mathrm{Zn}^{2+}\right): c(\mathrm{Th})$ : (a) 8.1 and 1:4; (b) 10.9 and 1:1; (c) 10.9 and 1:4; and (d) 12.0 and 1:1 (Sofronov et al. 2014).

When the thiourea concentration and $\mathrm{pH}$ increase, the obtained spherical particles become larger. At the proportion $c\left(\mathrm{Zn}^{2+}\right): c(\mathrm{Th}) 1: 4$ and $\mathrm{pH} 10.9$, the average particle dimension is $150 \mathrm{~nm}$ (Figure 1.9c), whereas at $c\left(\mathrm{Zn}^{2+}\right): c(\mathrm{TM})$ 1:1 and $\mathrm{pH} 12$, it is ca. $90 \mathrm{~nm}$ (Figure 1.9d). The particles became larger, but in different degree, compared with the ones obtained at $\mathrm{pH}$ 8.1.

In case of ammonia hydroxide application as a $\mathrm{pH}$ precursor, formation of the spherical agglomerate particles of average diameter $60 \mathrm{~nm}$ takes place at $\mathrm{pH} 8.9$ (Figure 1.10a). Here too, when the thiourea concentration and $\mathrm{pH}$ increase, the obtained spherical particles become larger with dimensions up to 90 and $150 \mathrm{~nm}$.

It is known that the size of particles can affect the functional features of a material (mechanical, optical, fluorescent, etc.). In the researches, it was found that zinc sulfide synthesis conditions might have effect on the shift of the basic adsorption band edge in the spectra of diffuse reflection (Katrunov et al. 2010; Sofronov et al. 2014). Figure 1.11 presents the diffuse reflection spectra for the obtained powders.

The results of bandgap $E_{g}$ assessment, synthesis conditions, and average dimensions of the particles are presented in Figure 1.12. The analysis of those data leads to conclusion that the samples obtained with $\mathrm{NaOH}$ as a precursor revealed some displacement of the fundamental absorption edge in the range of $20-30 \mathrm{~nm}$ dependent on the synthesis conditions. On the other hand, the samples obtained with $\mathrm{NH}_{4} \mathrm{OH}$ as a precursor revealed that position of the fundamental absorption edge varied insignificantly.

A wide range of obtained bandgap values versus particle dimensions are seen in Figure 1.12 indicating a variety of quantum size effects. It should be noted that the proposed methodology provides large possibilities to control these parameters through the synthesis conditions, compared with 

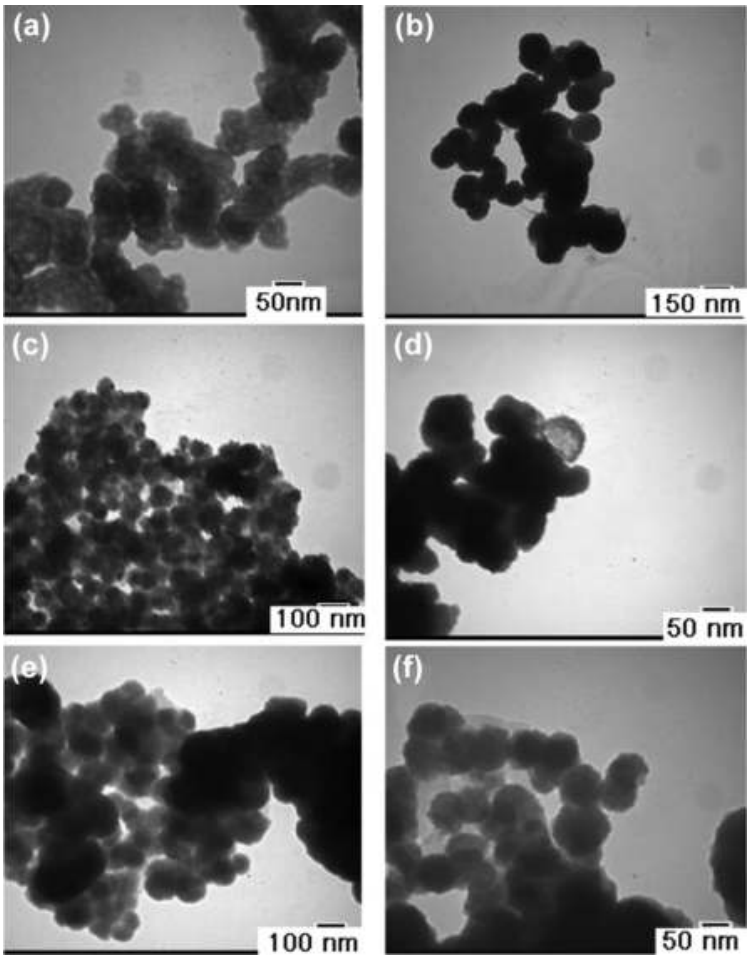

FIGURE 1.10

The particles obtained from chloride solutions (aqueous ammonia solution) at respective $\mathrm{pH}$ and proportion $c\left(\mathrm{Zn}^{2+}\right): c(\mathrm{Th})$ : (a) 8.9 and 1:4; (b) 10.9 and 1:1; (c) 10.9 and 1:4; (d) 12.0 and 1:1; (e) 12 and 1:4; and (f) 12 and 1:10 (Sofronov et al., 2014).
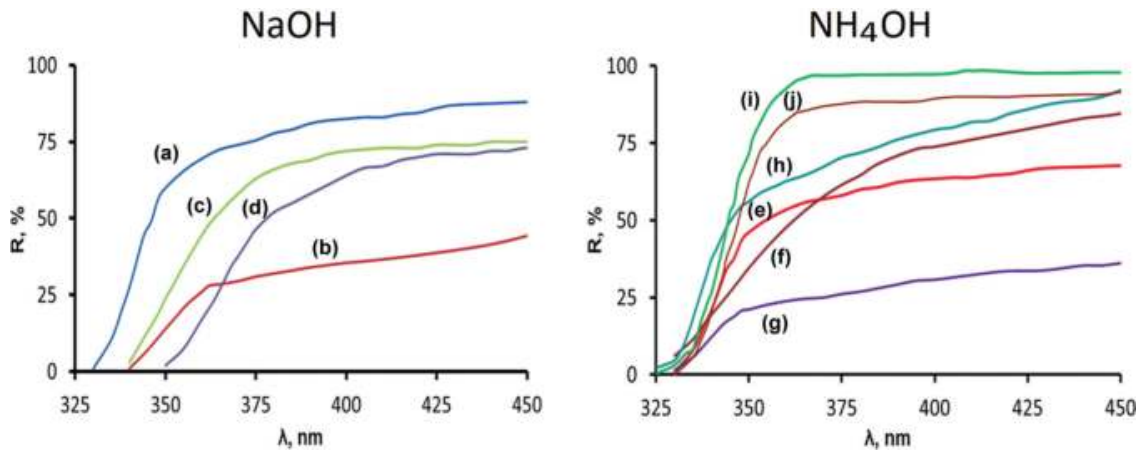

\section{FIGURE 1.11}

Diffuse reflection spectra of the $\mathrm{ZnS}$ powders precipitated from chloride solutions at $\mathrm{pH}$ values regulated by $\mathrm{NaOH}$ addition and concentration $c\left(\mathrm{Zn}^{2+}\right): c(\mathrm{Th})$, respectively: (a) 10.9 and 1:1; (b) 12.0 and 1:1; (c) 8.1 and 1:4; (d) 10.9 and 1:4; (e) 12.0 and 1:1; (f) 8.9 and 1:4; (g) 12.0 and 1:1; (h) 12.0 and 1:4; (i) 12.0 and 1:10; and (j) 12.0 and 1:4 (2 hours) (Sofronov et. al. 2014). 


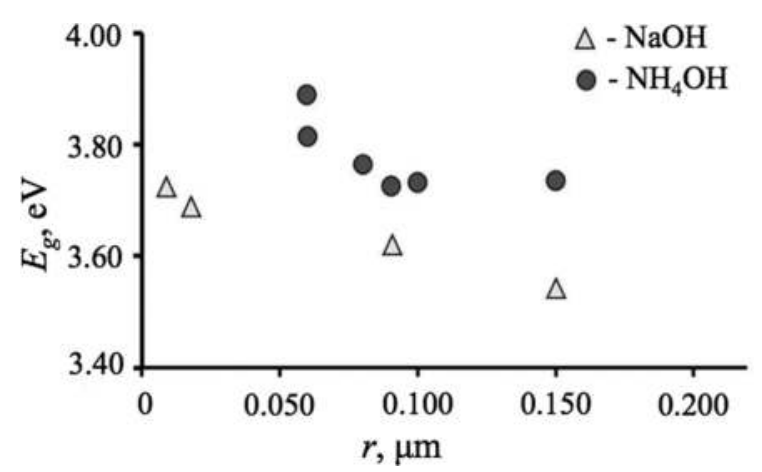

FIGURE 1.12

Dependence of the bandgap $E_{g}$ on the dimensions of obtained ZnS particles (Sofronov et al. 2014).

the reported values of $E_{g}=3.65 \mathrm{eV}$ for bulk $\mathrm{ZnS}$ material and $3.87 \mathrm{eV}$ for $\mathrm{MW}$-assisted self-assembled ZnS nanoballs (Zhao et al. 2004). The graph presents two main correlations:

- For the ZnS powders synthesized with sodium hydroxide, decrease of the particle dimensions caused "linear" shift of the $E_{g}$ value from 3.54 to $3.72 \mathrm{eV}$.

- For the ZnS powders synthesized with ammonia hydroxide, in the range of dimensions between 150 and $80 \mathrm{~nm}$, no substantial changes in $E_{g}$ are seen, but for further dimensional decrease, shift to $E_{g}=3.9 \mathrm{eV}$ takes place.

Important factor influencing these phenomena was the nature of hydroxide applied for the zinc sulfide synthesis, namely, cations $\mathrm{Na}^{+}$and $\mathrm{NH}_{4}{ }^{+}$. This correlation should be taken into consideration when the initial components are chosen in order to obtain the $\mathrm{ZnS}$ powder of desired functional characteristics.

\subsubsection{Concentration Effect}

More concentrated solutions of thiourea doz not provide distinguishable changes of phase composition of sulfides, but they have significant impact on the dimensions of the formed particles. Namely, when the ratio $c\left(\mathrm{Zn}^{2+}\right): c\left(\left(\mathrm{NH}_{2}\right)_{2} \mathrm{CS}\right)$ increases, dimensions of spherical nanoparticles decrease, as it can be seen in Figure 1.13. Larger thiourea concentrations during the copper(II) sulfide synthesis lead to the formation of spherical agglomerates with following parameters:

- average diameter $0.35 \mu \mathrm{m}$ (dispersion 0.030) at $\mathrm{pH} \quad 8$ and $c\left(\mathrm{Cu}^{2+}\right): c\left(\left(\mathrm{NH}_{2}\right)_{2} \mathrm{CS}\right)$ ratio 1:2, 

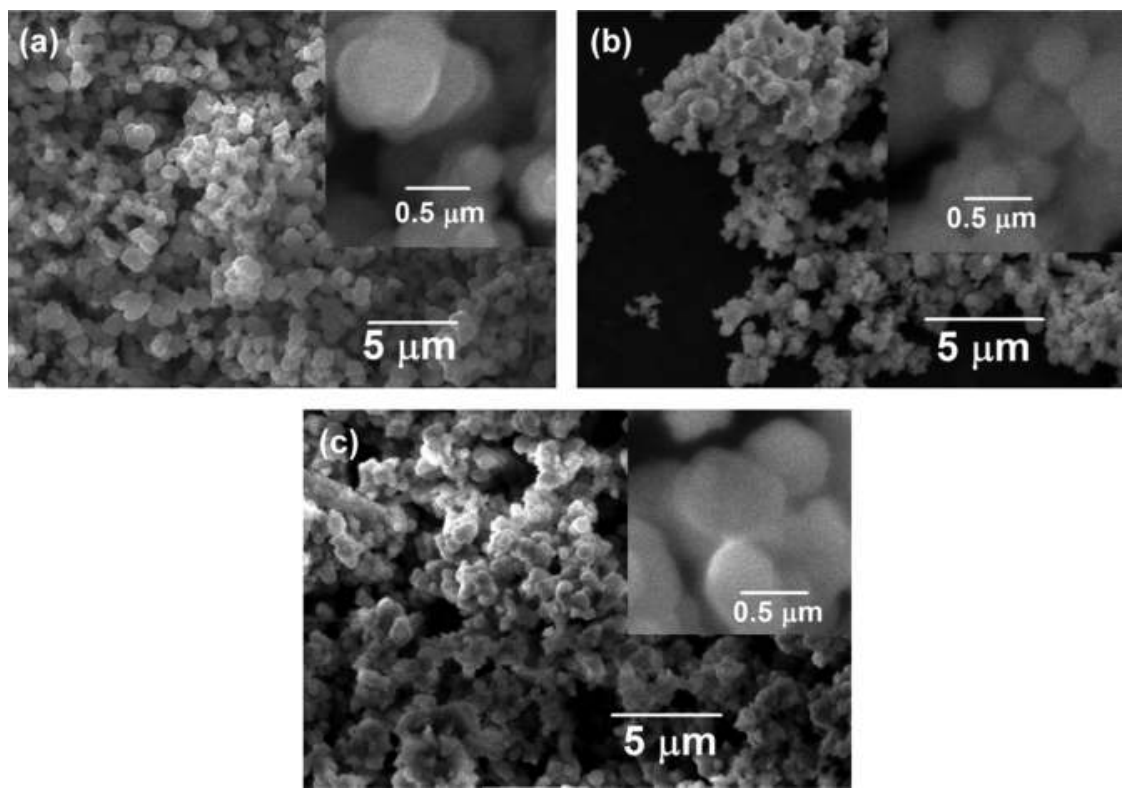

FIGURE 1.13

Images of the $\mathrm{ZnS}$ particles obtained from nitrate solutions at respective $\mathrm{pH}$ and $c\left(\mathrm{Zn}^{2+}\right): c\left(\left(\mathrm{NH}_{2}\right)_{2} \mathrm{CS}\right)$ ratios: (a) 8 and 1:4; (b) 12 and 1:4; and (c) 12 and 1:10.

- average diameter $0.54 \mu \mathrm{m}$ (dispersion 0.022) at $\mathrm{pH} 8$ and $c\left(\mathrm{Cu}^{2+}\right): c\left(\left(\mathrm{NH}_{2}\right)_{2} \mathrm{CS}\right)$ ratio 1:4,

- average diameter $0.52 \mu \mathrm{m}$ (dispersion 0.030) at $\mathrm{pH} 10$ and $c\left(\mathrm{Cu}^{2+}\right): c\left(\left(\mathrm{NH}_{2}\right)_{2} \mathrm{CS}\right)$ ratio 1:2,

- average diameter $0.43 \mu \mathrm{m}$ (dispersion 0.026) at $\mathrm{pH} 12$ and $c\left(\mathrm{Cu}^{2+}\right): c\left(\left(\mathrm{NH}_{2}\right)_{2} \mathrm{CS}\right)$ ratio 1:4.

In case of CdS particles, the most significant factor shaping morphological characteristics of the particles is the thiourea concentration in solution. Thus, introduction of the excessive thiourea in two or four times larger amounts causes formation of two types of spherical particles shown in Figure 1.14. Especially in Figure 1.14c, small spherical particles with diameters below $1 \mu \mathrm{m}$ are clearly seen between the larger formations of thin scales $(30-50 \mathrm{~nm})$ grouped together in large balls with diameters ca. $5 \mu \mathrm{m}$.

When the molar ratio $c\left(\mathrm{Me}^{2+}\right): c\left(\left(\mathrm{NH}_{2}\right)_{2} \mathrm{CS}\right)$ is increased, higher yield is obtained, as shown in Figure 1.15. The maximal yield for zinc sulfide is $65 \%$, and that for cadmium and copper sulfides is $95 \%$.

On the other hand, IR spectra of the powders obtained with excessive amounts of thiourea did not reveal any substantial differences. Only the spectra of zinc sulfide powder shown in Figure 1.16 have strengthened 

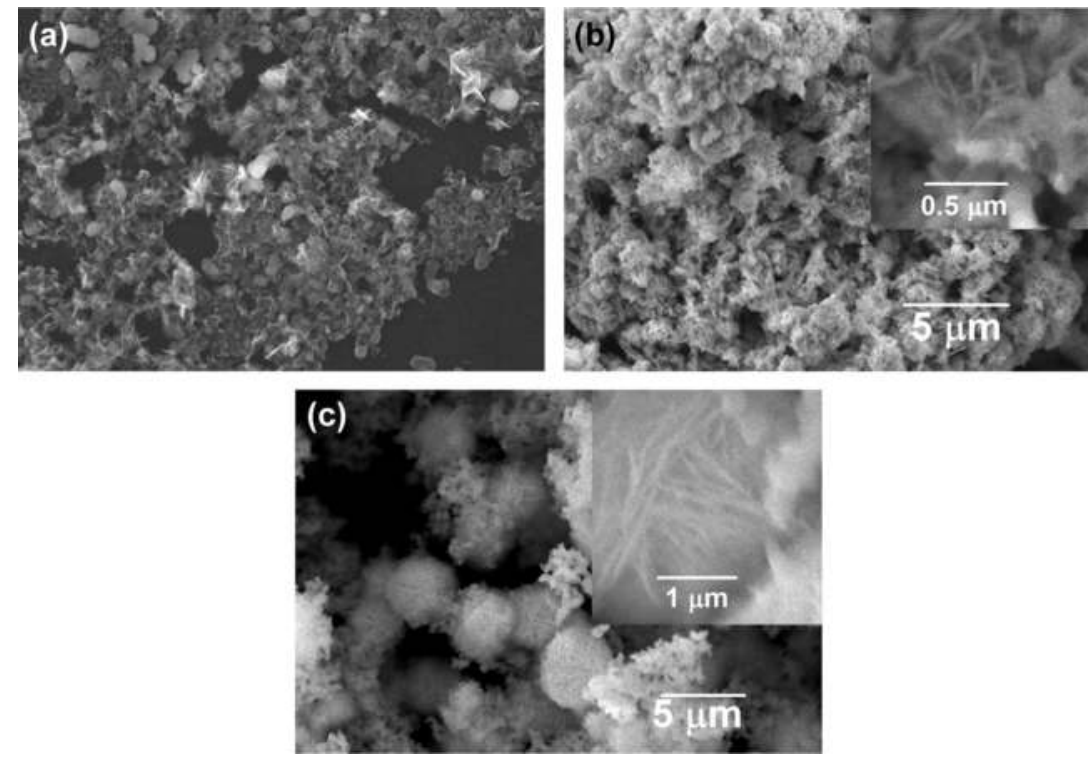

\section{FIGURE 1.14}

SEM images of the CdS particles obtained from nitrate solutions at $\mathrm{pH} 12$ and different $c\left(\mathrm{Zn}^{2+}\right): c\left(\left(\mathrm{NH}_{2}\right)_{2} \mathrm{CS}\right)$ ratios: (a) 1:1; (b) 1:2; and (c) 1:4. SEM, scanning electron microscope.
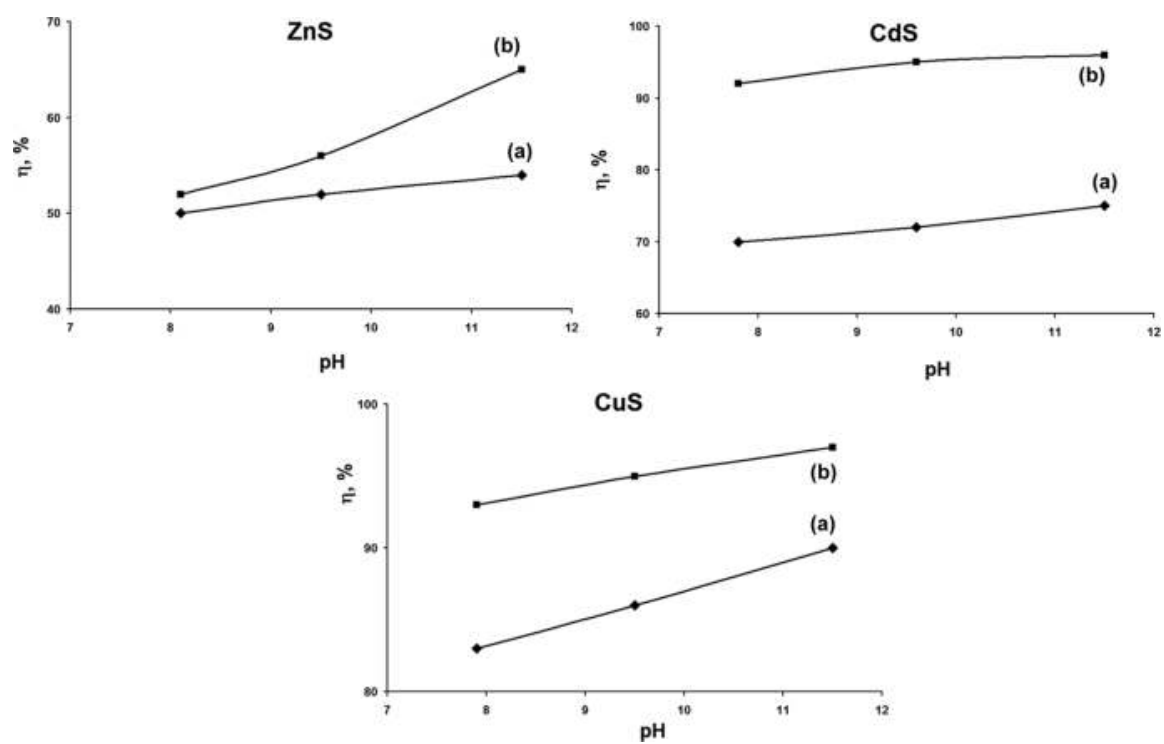

\section{FIGURE 1.15}

Graphs of $\mathrm{ZnS}, \mathrm{CdS}$, and $\mathrm{CuS}$ yield dependent on the $\mathrm{pH}$ value at different $c\left(\mathrm{Me}^{2+}\right): c\left(\left(\mathrm{NH}_{2}\right)_{2} \mathrm{CS}\right)$ concentrations: (a) 1:2 and (b) 1:4. 


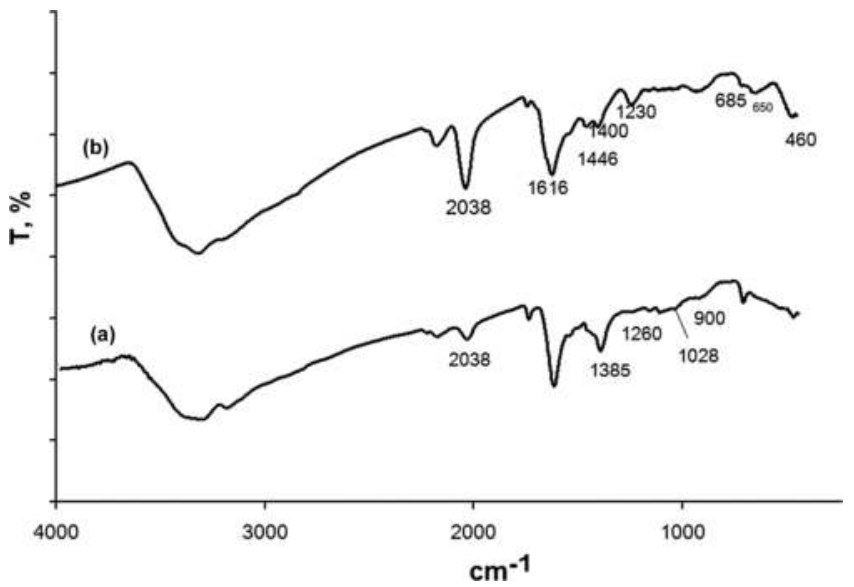

FIGURE 1.16

IR spectra of the $\mathrm{ZnS}$ powder precipitated from nitrate solutions at $\mathrm{pH} 12$ and different $c\left(\mathrm{Me}^{2+}\right): c\left(\left(\mathrm{NH}_{2}\right)_{2} \mathrm{CS}\right)$ concentrations: (a) 1:4 and (b) 1:10. IR, infrared.

absorption band at $2,038 \mathrm{~cm}^{-1}$, caused by SCN vibrations, and absorption band at $1,028 \mathrm{~cm}^{-1}$, which are different from the spectra corresponding with powders obtained at $c\left(\mathrm{Zn}^{2+}\right): c\left(\left(\mathrm{NH}_{2}\right)_{2} \mathrm{CS}\right)$ ratio 1:1.

\subsubsection{Effect of the Anion Nature}

In the investigations on the anion nature effect, chloride and sulfate ions were chosen. Two factors were decisive in this choice:

- Zinc chloride and sulfate are employed in the synthesis process.

- Chosen ions have different charges and enable to see how one-charged $\left(\mathrm{Cl}^{-}\right)$and two-charged $\left(\mathrm{SO}_{4}{ }^{2-}\right)$ ions can impact the particle formation process.

When the $\mathrm{Cl}^{-}$ion was replaced with $\mathrm{NO}_{3}{ }^{-}$, subsequent $\mathrm{X}$-ray structural analysis revealed no change in the phase components of the sulfide powders. However, in case of the synthesis from the sulfate solution, sulfite formation was observed only at $\mathrm{pH}$ over 11 with additions of $\mathrm{ZnO}$, as it is seen from the diagrams in Figure 1.17. When $\mathrm{pH}$ was decreased down to $\mathrm{pH} 8.1$ and 10.9 , unidentified precursors were formed. Even increase of excessive thiourea up to 4 and 10 times did not allow to obtain zinc sulfide without $\mathrm{ZnO}$ contaminations.

During the cadmium and copper sulfide synthesis, no effect of sulfate ions on the phase content formation was observed.

Images of the obtained zinc sulfide particles out of the chloride solutions are presented in Figure 1.18. It is noteworthy that at $\mathrm{pH} 8$ and $c\left(\mathrm{Zn}^{2+}\right): c\left(\left(\mathrm{NH}_{2}\right)_{2} \mathrm{CS}\right)$ 


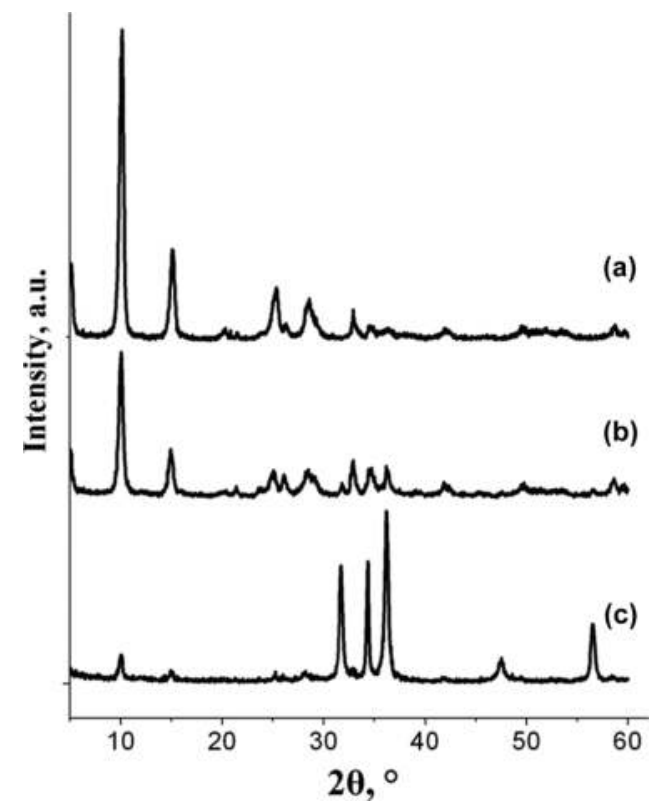

FIGURE 1.17

$\mathrm{X}$-ray analysis of the $\mathrm{ZnS}$ powder precipitated from sulfate solutions at different $\mathrm{pH}$ and respective $c\left(\mathrm{Zn}^{2+}\right): c\left(\left(\mathrm{NH}_{2}\right)_{2} \mathrm{CS}\right)$ concentrations: (a) 8.1 and 1:1; (b) 10.9 and 1:1; and (c) 12.0 and 1:1 (Sofronov, Kamneva et al. 2013).

ratio 1:1, the particles were formed as a thick-wall tubes of several microns length (Figure 1.18a). When $c\left(\mathrm{Zn}^{2+}\right): c\left(\left(\mathrm{NH}_{2}\right)_{2} \mathrm{CS}\right)$ ratio was increased up to 1:4, finely dispersed bulk sediment was formed consisting of particles of various shapes (Figure 1.18b).

When $c\left(\mathrm{Zn}^{2+}\right): c\left(\left(\mathrm{NH}_{2}\right)_{2} \mathrm{CS}\right)$ ratio was kept 1:1, but $\mathrm{pH}$ was increased up to 12, spherical particles 0.5-1.0 $\mathrm{m}$ large were formed, seen in Figure 1.18c and d. However, when $\mathrm{pH}$ was kept 12 and $\mathrm{c}\left(\mathrm{Zn}^{2+}\right): \mathrm{c}\left(\left(\mathrm{NH}_{2}\right)_{2} \mathrm{CS}\right)$ ratio was increased up to 1:10, the dimensions of spherical particles decreased (Figure 1.18e).

Along with large spherical particles $0.5-1.0 \mu \mathrm{m}$, numerous small spherical particles were formed with diameters ca. $0.1-0.2 \mu \mathrm{m}$. The average particle diameters obtained at $\mathrm{pH} 10$ and $\mathrm{c}\left(\mathrm{Zn}^{2+}\right): \mathrm{c}\left(\left(\mathrm{NH}_{2}\right)_{2} \mathrm{CS}\right)$ ratio 1:1, at $\mathrm{pH} 12$ and $\mathrm{c}\left(\mathrm{Zn}^{2+}\right): \mathrm{c}\left(\left(\mathrm{NH}_{2}\right)_{2} \mathrm{CS}\right)$ ratio 1:1, at $\mathrm{pH} 12$ and $\mathrm{c}\left(\mathrm{Zn}^{2+}\right): \mathrm{c}\left(\left(\mathrm{NH}_{2}\right)_{2} \mathrm{CS}\right)$ ratio 1:4, and at $\mathrm{pH} 12$ and $\mathrm{c}\left(\mathrm{Zn}^{2+}\right): \mathrm{c}\left(\left(\mathrm{NH}_{2}\right)_{2} \mathrm{CS}\right)$ ratio $1: 10$ were $0.19 \mu \mathrm{m}$ (dispersity 0.033$)$, $0.54 \mu \mathrm{m}$ (dispersity 0.034), $0.57 \mu \mathrm{m}$ (dispersity 0.023 ), and $0.19 \mu \mathrm{m}$ (dispersity $0.026)$, respectively. Hence, during the synthesis from chloride solutions, the smallest spherical particles with diameter $0.1-0.2 \mu \mathrm{m}$ were formed at $\mathrm{pH} 12$ and $\mathrm{c}\left(\mathrm{Zn}^{2+}\right): \mathrm{c}\left(\left(\mathrm{NH}_{2}\right)_{2} \mathrm{CS}\right)$ ratio 1:10.

Figure 1.19 presents SEM images of the particles obtained from sulfide solutions. When $\mathrm{c}\left(\mathrm{Zn}^{2+}\right): \mathrm{c}\left(\left(\mathrm{NH}_{2}\right)_{2} \mathrm{CS}\right)$ ratio was increased up to 1:4 and $\mathrm{pH}$ up to 11, no significant impact was observed on the morphological features of the particles (Figure 1.19b). However, at $\mathrm{pH} 12.0$ and $\mathrm{c}\left(\mathrm{Zn}^{2+}\right): \mathrm{c}\left(\left(\mathrm{NH}_{2}\right)_{2} \mathrm{CS}\right)$ ratios 

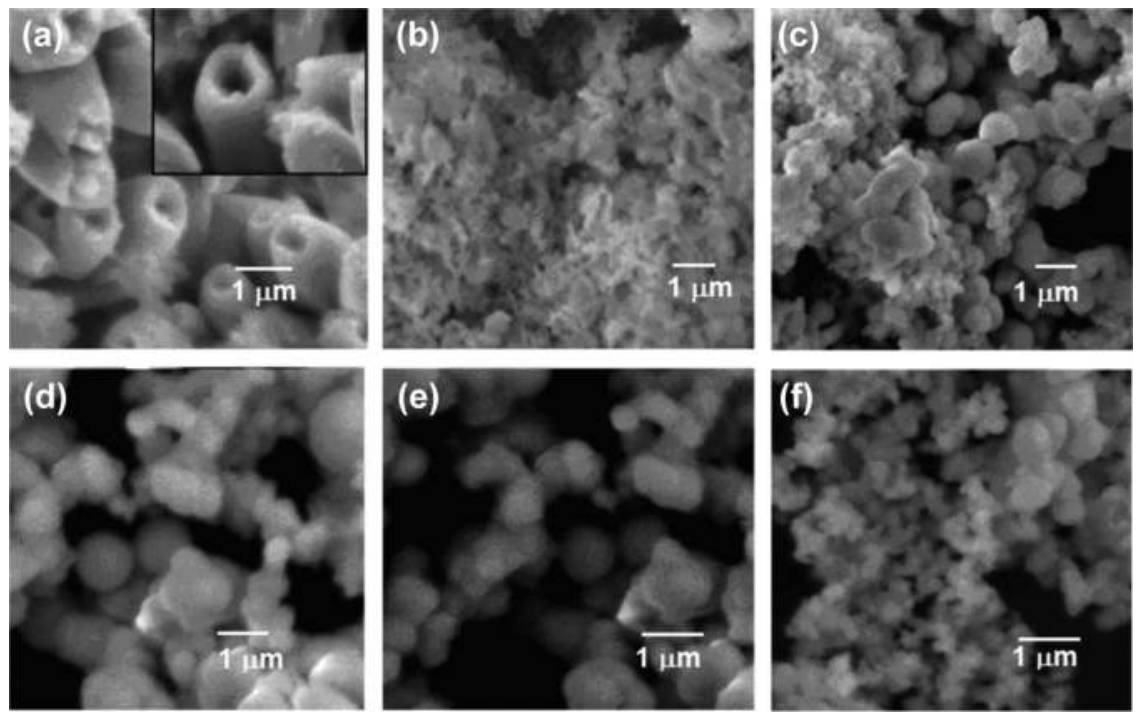

FIGURE 1.18

$\mathrm{ZnS}$ particles obtained from chloride solutions at different $\mathrm{pH}$ and $\mathrm{c}\left(\mathrm{Zn}^{2+}\right): \mathrm{c}\left(\left(\mathrm{NH}_{2}\right)_{2} \mathrm{CS}\right)$ ratios: (a) 8 and 1:1; (b) 8 and 1:4; (c) 10 and 1:1; (d) 12 and 1:1; (e) 12 and 1:4; (f) 12 and 1:10 (Sofronov, Kamneva et al., 2013).
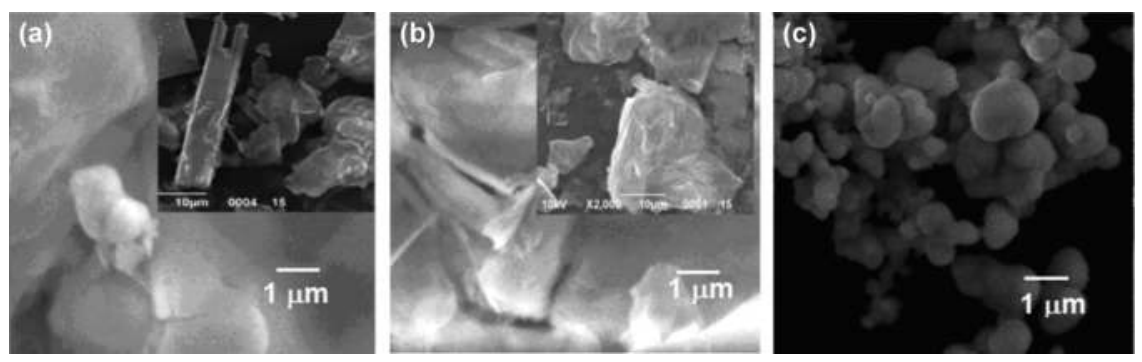

\section{FIGURE 1.19}

$\mathrm{ZnS}$ particles obtained from sulfate solutions at different $\mathrm{pH}$ and $\mathrm{c}\left(\mathrm{Zn}^{2+}\right): \mathrm{c}\left(\left(\mathrm{NH}_{2}\right)_{2} \mathrm{CS}\right)$ ratios: (a) 8 and 1:1; (b) 8 and 1:4; and (c) 12 and 1:4 (Sofronov, Kamneva et al., 2013).

1:1 and 1:4, the spherical agglomerates are formed along with scales. Further increase of the thiourea concentration leads to the formation of spherical agglomerates with diameters $0.2-1.0 \mu \mathrm{m}$ only (Figure 1.19c).

It was found that the anion composition change in case of cadmium and copper sulfides precipitation had no significant effect on the phase composition and morphological characteristics of the particles. Usually, finely dispersed sediment is observed, which consists of spherical particles, and their dimensions are larger when the thiourea concentration and $\mathrm{pH}$ are increased. 


\subsubsection{Impact of the Organic Additives}

One of the methods to control the morphological characteristics of the nanoparticles is the application of various surface-active additives as a coordinating solvents, in particular, amines, such as ethylenediamine (Mendil et al. 2016; Yao et al. 2005; Behboudnia et al. 2005; Song et al. 2008; Cheng et al. 2006), oleylamine (Geng et al. 2009; Zhai et al. 2012), TEA (Kim et al. 2006; Lee et al. 2004), as well as amino acids, e.g., glycine (Wang et al. 2000; Rakovich et al. 2008). The introduction of valine, proline, serine, cysteine, and methionine allows to control the morphological characteristics of the synthesized cadmium sulfide particles (Qiu et al. 2011).

In the present study, the main criteria for the amino acid choice were two: first, it had to be soluble in water, and secondly, it had to be easily accessible. Thus, the following substances were taken as object for further investigations: glycine, alanine, $\varepsilon$-aminocaproic, glutamic, and p-aminobenzoic acid (Sofronov, Belikov et al. 2013).

SEM images of cadmium sulfide particles synthesized in presence of glycine and alanine are shown in Figures 1.20-1.23. When the synthesis was conducted at the temperature $20^{\circ} \mathrm{C}$ and glycine content $0.005-0.01 \mathrm{M}$, large spherical particles resembling flowers were formed with diameters ca. $5 \mu \mathrm{m}$, irrespective of thiourea concentration, as it is seen in Figures 1.20a-f. In general, this additive plays no significant role in the cadmium sulfide precipitation process. When the concentration was $0.05 \mathrm{M}$, morphology of the particles changed dependent on the proportion of cadmium to thiourea $C_{\mathrm{Cd}} / C_{\mathrm{Th}}$. When $C_{\mathrm{Cd}} / C_{\mathrm{Th}}$ was 1:1, the sediment was formed as small spherical particles with diameters ca. $100 \mathrm{~nm}$ (Figure $1.20 \mathrm{~g}$ ). When $C_{\mathrm{Cd}} / C_{\mathrm{Th}}$ was 1:2, small plates were formed (Figure 1.20h), When $C_{\mathrm{Cd}} / C_{\mathrm{Th}}$ was 1:4, large, dense spherical particles appeared, with dimensions between 10 and $20 \mu \mathrm{m}$ (Figure 1.20i).

Increase of the concentration up to $0.1 \mathrm{M}$ caused formation of the large shapeless particles seen in Figure $1.20 \mathrm{k}$ and 1 . The higher the thiourea concentration, the larger the particles formed. Addition of the glycine $0.5 \mathrm{M}$ caused formation of the dense spherical particles with diameters ca. $0.5-1.0 \mu \mathrm{m}$, irrespective of thiourea concentration, as it is seen in Figure $1.20 \mathrm{~m}$.

Unlike the glycine, after addition of $0.005 \mathrm{M}$ alanine, the particles resembling flowers were formed (Figure 1.21), and their dimensions were smaller for larger concentrations of thiourea. When $C_{\mathrm{Cd}} / C_{\mathrm{Th}}$ was 1:1, the agglomerate dimensions were above $5 \mu \mathrm{m}$ (Figure 1.21a). When $C_{\mathrm{Cd}} / C_{\mathrm{Th}}$ was 1:4, dimensions were smaller, ca. 2-3 $\mu \mathrm{m}$ (Figure 1.21b). Increase of alanine concentration caused destruction of "flowers," and formation of the shapeless agglomerated sediments consisted of small plates or scales (Figure 1.21c-k). When amount of alanine was further increased up to $0.5 \mathrm{M}$, shapeless layered sediments were formed, as it is seen in Figure 1.21l. At the same time, when proportion of cadmium to thiourea $C_{\mathrm{Cd}} / C_{\mathrm{Th}}$ was increased up to 1:4, dense spherical particles of dimensions ca. $1 \mu \mathrm{m}$ were formed (Figure $1.21 \mathrm{~m}$ ).

The results were quite different when precipitation was performed at the temperature $100^{\circ} \mathrm{C}$. When glycine was added in amount of $0.005-0.010 \mathrm{M}$, 

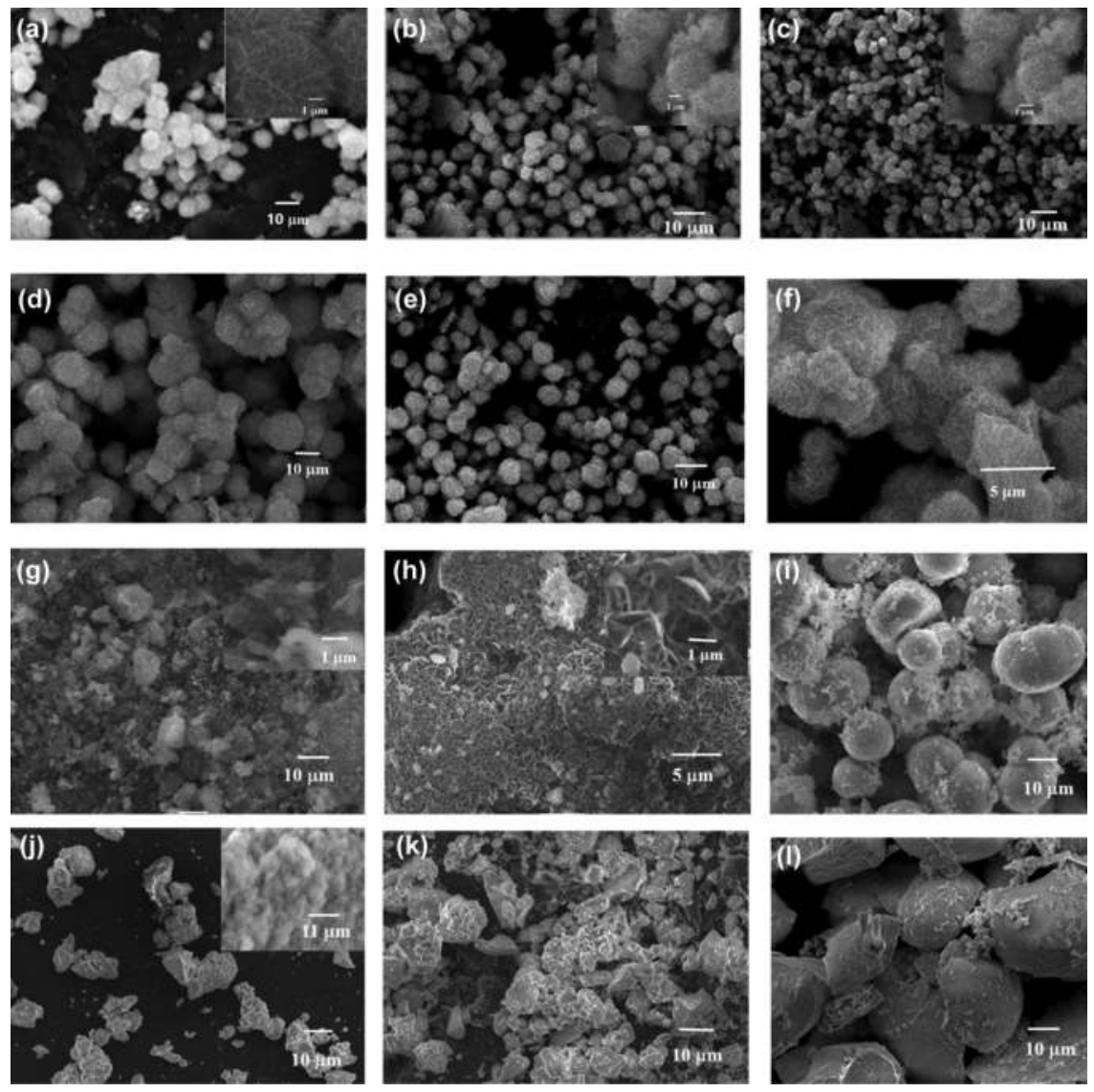

\section{FIGURE 1.20}

CdS particles obtained at $20^{\circ} \mathrm{C}$ and respective different glycine concentrations and proportions $C_{\mathrm{Cd}} / C_{\mathrm{Th}}$ : (a) $0.005 \mathrm{M}$ and $1: 1 ;$ (b) $0.005 \mathrm{M}$ and $1: 2$; (c) $0.005 \mathrm{M}$ and $1: 4$; (d) $0.01 \mathrm{M}$ and $1: 1 ;$ (e) $0.01 \mathrm{M}$ and 1:2; (f) $0.01 \mathrm{M}$ and 1:4; (g) $0.05 \mathrm{M}$ and 1:1; (h) $0.05 \mathrm{M}$ and 1:2; (i) $0.05 \mathrm{M}$ and 1:4; (j) $0.1 \mathrm{M}$ and $1: 2 ;(\mathrm{k}) 0.1 \mathrm{M}$ and $1: 4$; and (l) $0.5 \mathrm{M}$ and 1:2.

finely dispersed sediments were formed, consisting of spherical particles with diameters ca. $1 \mu \mathrm{m}$, as it is shown in Figure 1.22a-e. However, an increase of the proportion of cadmium to thiourea $C_{\mathrm{Cd}} / C_{\mathrm{Th}}$ caused the opposite effect than that observed at room temperature. Namely, at $20^{\circ} \mathrm{C}$, thiourea concentration increase caused formation of spherical particles, whereas at $100^{\circ} \mathrm{C}$, small scales appeared, especially distinguishable at $0.01 \mathrm{M}$ and $C_{\mathrm{Cd}} / C_{\mathrm{Th}}$ proportion 1:4 (Figure 1.22e). Further increasing the glycine amount up to $0.05 \mathrm{M}$ caused formation of the particles resembling flowers of dimensions $2-4 \mu \mathrm{m}$ irrespective of the thiourea concentration (Figure 1.22f-h). Still further increase of glycine concentration up to $0.1-0.5 \mathrm{M}$ caused formation of dense spherical particles of dimensions ca. 0.1-0.3 $\mu \mathrm{m}$ (Figure 1.22i-m). 

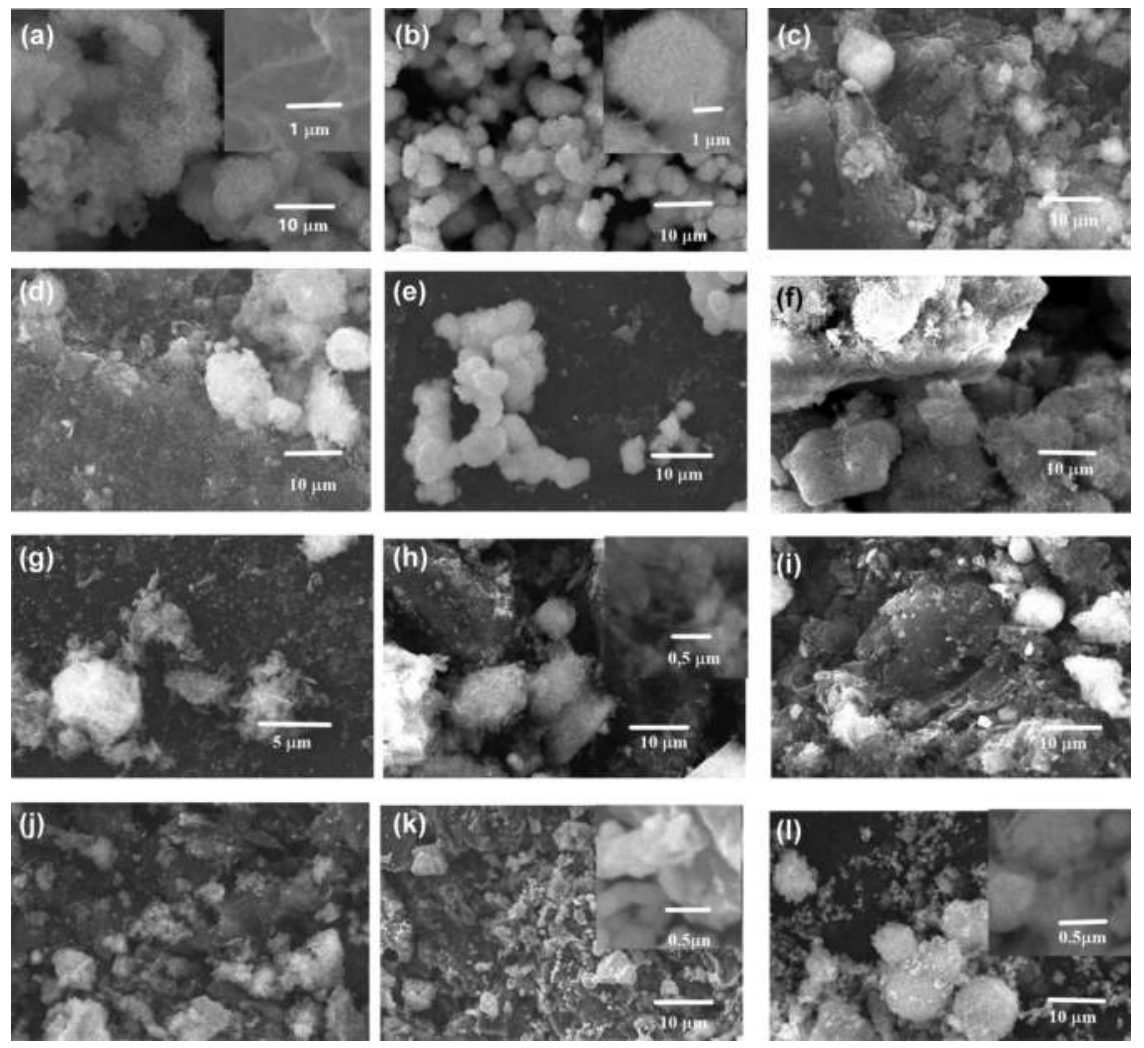

FIGURE 1.21

CdS particles obtained at $20^{\circ} \mathrm{C}$ and respective different alanine concentrations and proportions $C_{\mathrm{Cd}} / C_{\mathrm{Th}}$ : (a) $0.005 \mathrm{M}$ and $1: 1 ;$ (b) $0.005 \mathrm{M}$ and $1: 4$; (c) $0.01 \mathrm{M}$ and $1: 1 ;$ (d) $0.01 \mathrm{M}$ and $1: 2$; (e) $0.01 \mathrm{M}$ and $1: 4$; (f) $0.05 \mathrm{M}$ and $1: 1$; (g) $0.05 \mathrm{M}$ and $1: 4$; (h) $0.1 \mathrm{M}$ and $1: 1 ;$ (i) $0.1 \mathrm{M}$ and $1: 2$; (j) $0.1 \mathrm{M}$ and 1:4; (k) 0.5 M and 1:1; and (1) 0.5 M and 1:4 (Sofronov, Belikov et al. 2013).

Similar differences were observed in case of alanine application at $100^{\circ} \mathrm{C}$. Then, for $C_{\mathrm{Cd}} / C_{\mathrm{Th}}$ proportion 1:1 and alanine amount $0.005 \mathrm{M}$, sediments are much like in case of glycine application (Figure 1.23a), and with larger concentrations of thiourea, the "flowers" became a little more dense (Figure 1.23b). Increasing the amount above $0.01 \mathrm{M}$ causes formation of shapeless agglomerates of single small scales (Figure 1.23c and d). When the alanine amount was increased up to $0.05-0.10 \mathrm{M}$, flower-like structures were formed, and their dimensions were dependent on the $C_{\mathrm{Cd}} / C_{\mathrm{Th}}$ proportion. When the alanine concentration was increased up to $0.5 \mathrm{M}$ at $C_{\mathrm{Cd}} / C_{\mathrm{Th}}$ proportion 1:1, large layered agglomerates were formed (Figure $1.23 \mathrm{k}$ ), whereas at $C_{\mathrm{Cd}} / C_{\mathrm{Th}}$ proportion 1:4, the layered morphology changed into flower-like forms (Figure $1.23 \mathrm{~m}$ ).

Thus, it can be summarized that introduction of alanine caused more significant effect on the particle formation, compared with the glycine. 

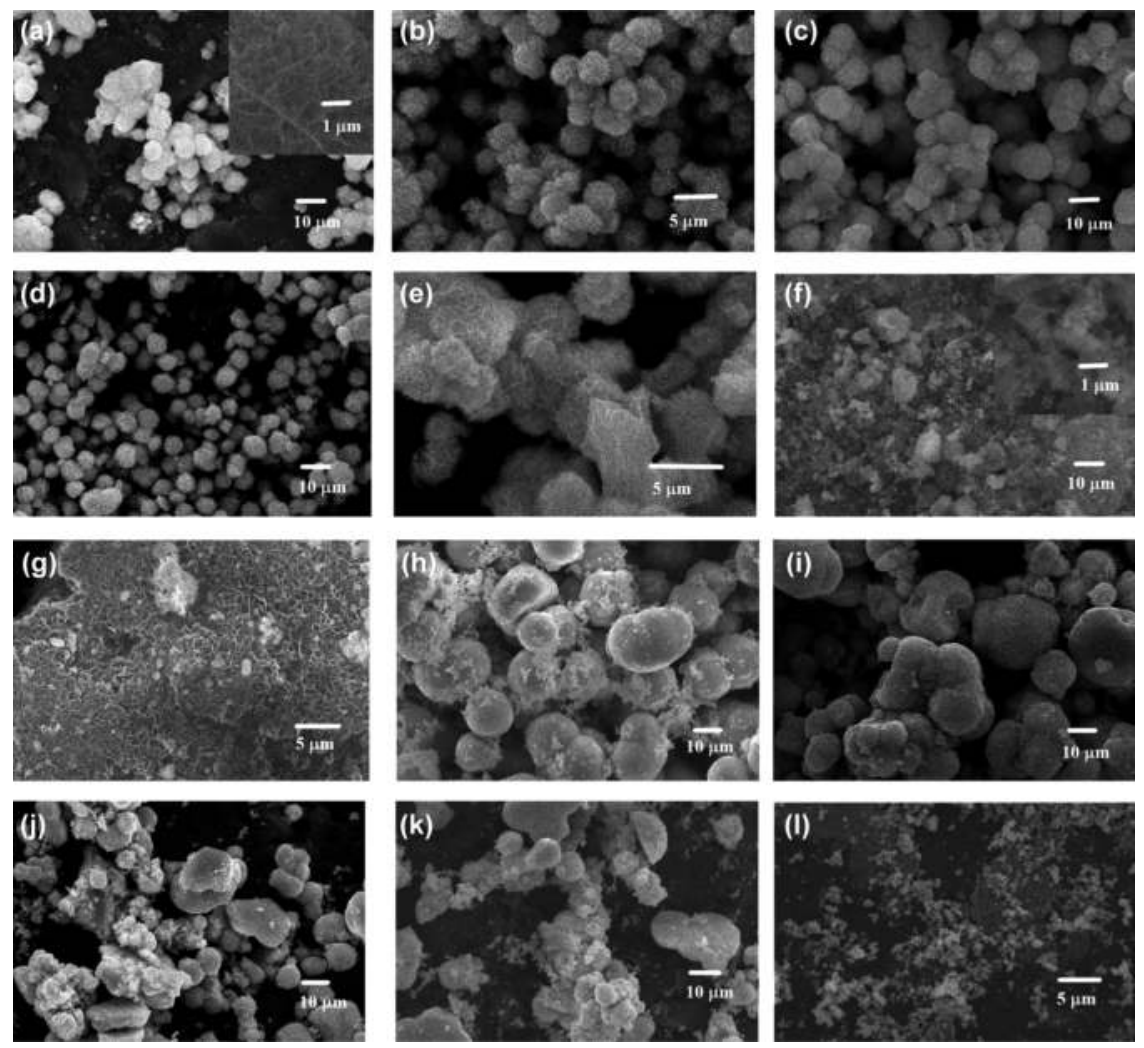

FIGURE 1.22

CdS particles obtained at $100^{\circ} \mathrm{C}$ and respective different glycine concentrations and $C_{\mathrm{Cd}} /$ $C_{\text {Th }}$ proportions: (a) $0.005 \mathrm{M}$ and $1: 1 ;$ (b) $0.005 \mathrm{M}$ and $1: 4$; (c) $0.01 \mathrm{M}$ and $1: 1$; (d) $0.01 \mathrm{M}$ and 1:2; (e) $0.01 \mathrm{M}$ and $1: 4$; (f) $0.05 \mathrm{M}$ and $1: 1$; (g) $0.05 \mathrm{M}$ and 1:2; (h) $0.05 \mathrm{M}$ and $1: 4$; (i) $0.1 \mathrm{M}$ and $1: 1$; (j) $0.1 \mathrm{M}$ and 1:2; (k) $0.1 \mathrm{M}$ and 1:4; and (1) $0.5 \mathrm{M}$ and 1:4.

Images of the cadmium sulfide particles obtained at the presence of $\varepsilon$-aminocaproic acid are shown in Figures 1.24 and 1.25. Addition of $0.005-0.100 \mathrm{M}$ of $\varepsilon$-aminocaproic acid into the synthesis at room temperature causes formation of the agglomerated bilk sediments seen in Figure 1.24a-f. When the amount of $\varepsilon$-aminocaproic acid was increased up to $0.5 \mathrm{M}$ at $C_{\mathrm{Cd}} / C_{\mathrm{Th}}$ proportion 1:1, formation of the microblocks with dimensions of several micrometers was observed (Figure 1.24g). Higher $C_{\mathrm{Cd}} / C_{\mathrm{Th}}$ proportion 1:4 caused spherical parts formation of two sorts (Figure 1.24h): smaller ones with dimensions $0.5-1.0 \mu \mathrm{m}$ and larger ones resembling flowers with dimensions ca. $10 \mu \mathrm{m}$. When synthesis was performed at $100^{\circ} \mathrm{C}$ and $\varepsilon$-aminocaproic acid concentration 0.005-0.100 M, mainly spherical flower-like particles were formed (Figure 1.25a-f) with dimensions between 5 and $10 \mu \mathrm{m}$. It can be noted that higher concentrations of thiourea caused formation of more homogeneous particles. When thiourea concentration was increased up to 

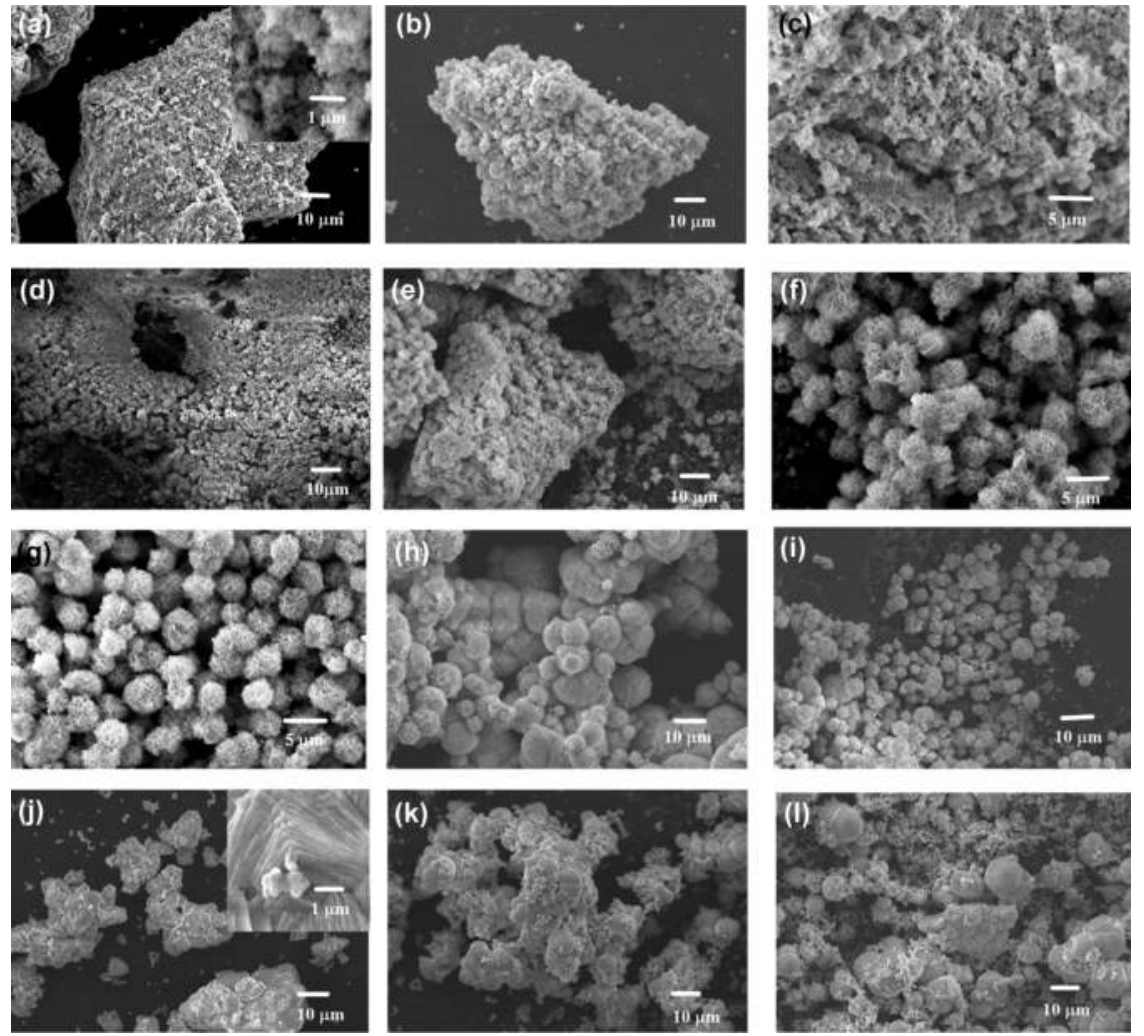

\section{FIGURE 1.23}

CdS particles obtained at $100^{\circ} \mathrm{C}$ and respective different alanine concentrations and $C_{\mathrm{Cd}} / C_{\mathrm{Th}}$ proportions: (a) $0.005 \mathrm{M}$ and 1:1; (b) $0.005 \mathrm{M}$ and 1:4; (c) $0.01 \mathrm{M}$ and 1:1; (d) $0.01 \mathrm{M}$ and 1:4; (e) $0.05 \mathrm{M}$ and 1:1; (f) $0.05 \mathrm{M}$ and 1:2; (g) $0.05 \mathrm{M}$ and $1: 4$; (h) $0.1 \mathrm{M}$ and 1:1; (i) $0.1 \mathrm{M}$ and 1:4; (j) $0.5 \mathrm{M}$ and 1:1; (k) 0.5 M and 1:2; and (l) 0.5 M and 1:4 (Sofronov, Belikov et al., 2013).

$0.5 \mathrm{M}$ at $C_{\mathrm{Cd}} / C_{\mathrm{Th}}$ proportion 1:1, spherical agglomerates were destroyed and bulk sediment appeared (Figure 1.25g). Increase of the thiourea concentration made it more dense (Figure 1.25h).

Thus, compared with additions of glycine and alanine, even small amounts of $\varepsilon$-aminocaproic acid (up to $0.1 \mathrm{M}$ ) added to the reaction at room temperature caused formation of mainly bulk sediments. Comparative analysis of glycine, alanine, and $\varepsilon$-aminocaproic acid revealed that the longer the carbon chain in the amino acid structure, the stronger its effect on the particles formation. Increase of the synthesis temperature up to $100^{\circ} \mathrm{C}$, however, neutralized the action of $\varepsilon$-aminocaproic acid and resulted in formation of large particles resembling flower shape.

Addition of the glutamic acid in concentration range between 0.005 and $0.05 \mathrm{M}$ at $20^{\circ} \mathrm{C}$ caused formation of the bulk sediments irrespective of the thiourea concentration (Figure 1.26). It was observed that the larger the 

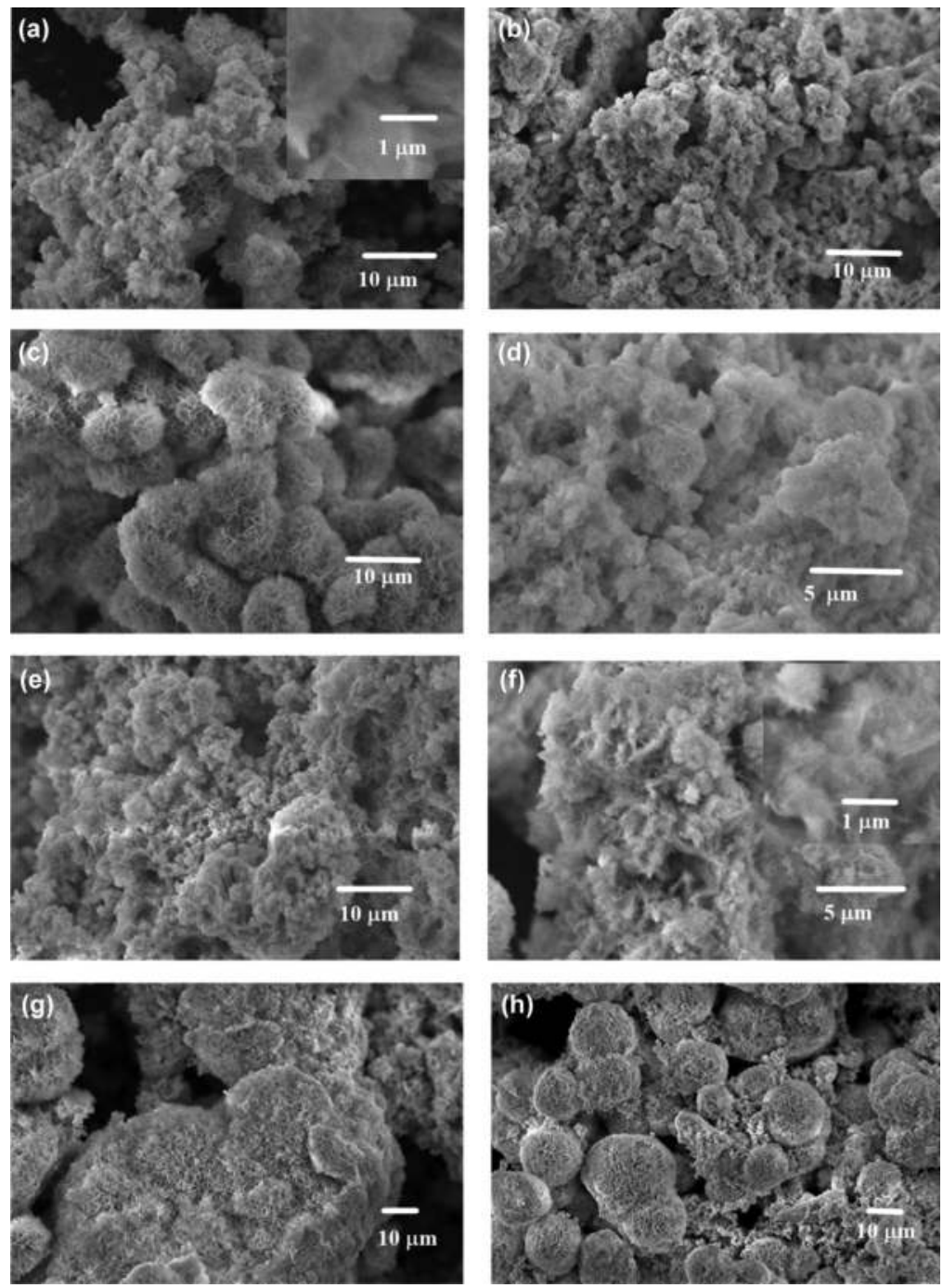

FIGURE 1.24

CdS particles obtained at $20^{\circ} \mathrm{C}$ and respective different $\varepsilon$-aminocaproic acid concentrations and $C_{\mathrm{Cd}} / C_{T h}$ proportions: (a) $0.005 \mathrm{M}$ and $1: 1 ;$ (b) $0.005 \mathrm{M}$ and $1: 4$; (c) $0.01 \mathrm{M}$ and $1: 1 ;$ (d) $0.01 \mathrm{M}$ and 1:4; (e) $0.1 \mathrm{M}$ and 1:1; (f) 0.1 M and 1:4; (g) 0.5 M and 1:1; and (h) 0.5 M and 1:4 (Sofronov, Belikov et al. 2013).

glutamic acid concentration and the smaller the $C_{\mathrm{Cd}} / C_{\mathrm{Th}}$ proportion, the more friable the bulk sediment. Increase of the synthesis temperature up to $100^{\circ} \mathrm{C}$ caused no considerable change in the particles morphology.

In Figures 1.27 and 1.28 , CdS particles obtained at $20^{\circ} \mathrm{C}$ and $100^{\circ} \mathrm{C}$ with additions of p-aminobenzoic acid are presented. Solubility of the p-aminobenzoic acid is poor; some sources provide percentage $0.34 \%$ at $12.8^{\circ} \mathrm{C}$ 

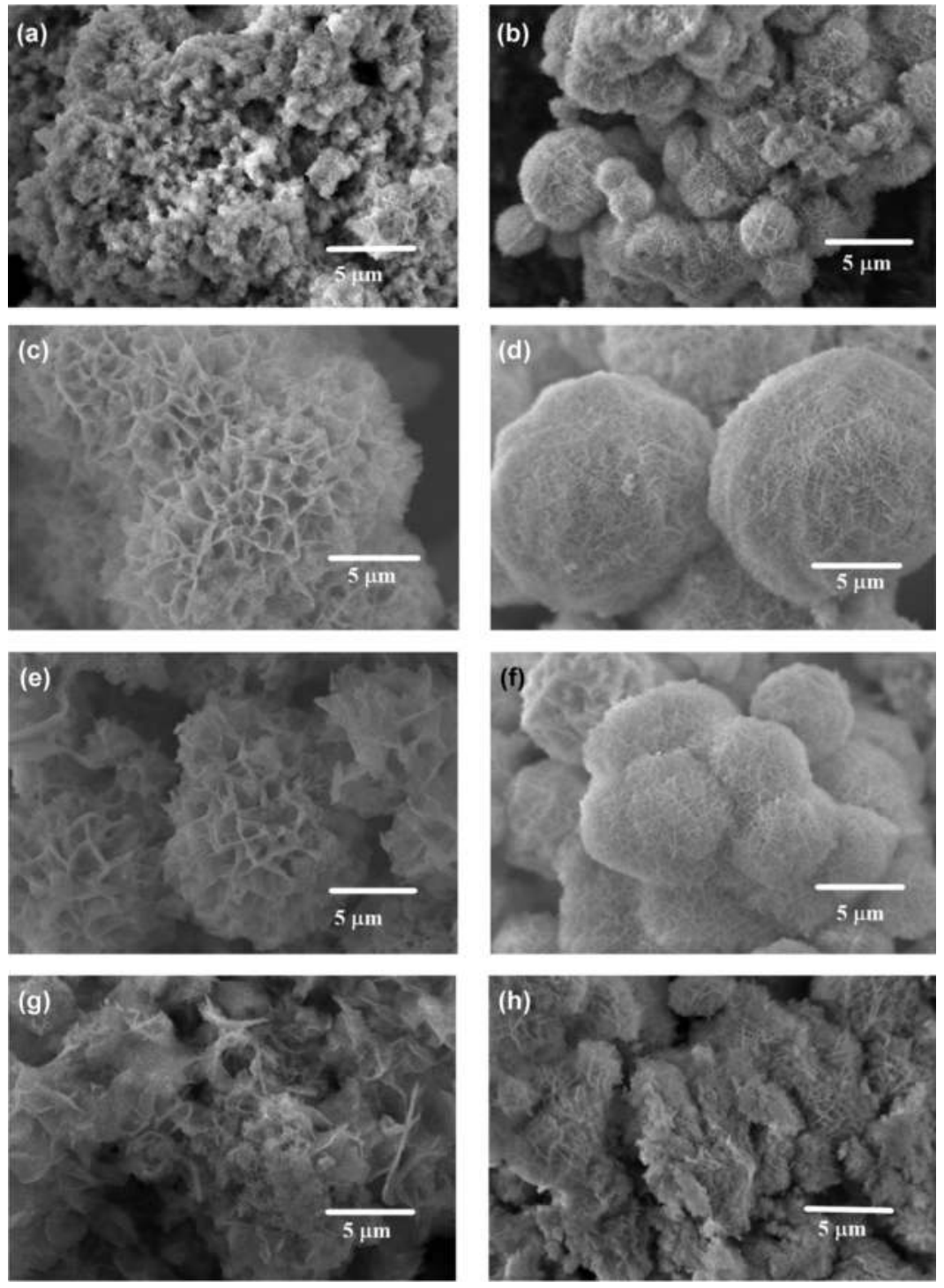

\section{FIGURE 1.25}

CdS particles obtained at $100^{\circ} \mathrm{C}$ and respective different $\varepsilon$-aminocaproic acid concentrations and $C_{\mathrm{Cd}} / C_{\mathrm{Th}}$ proportions: (a) $0.005 \mathrm{M}$ and $1: 1 ;$ (b) $0.005 \mathrm{M}$ and $1: 4$; (c) $0.05 \mathrm{M}$ and $1: 1 ;$ (d) $0.05 \mathrm{M}$ and 1:4; (e) $0.1 \mathrm{M}$ and $1: 1$; (f) $0.1 \mathrm{M}$ and 1:4; (g) $0.5 \mathrm{M}$ and 1:1; and (h) $0.5 \mathrm{M}$ and 1:4.

(Knunyantz 1983), and others inform that 1 gram of p-aminobenzoic acid dissolves in $170 \mathrm{ml}$ water or in $90 \mathrm{ml}$ boiling water (Brittain 1993). Taking this into consideration, experiments were performed only with its concentration $0.005 \mathrm{M}$. Irrespective of temperature and $C_{\mathrm{Cd}} / C_{\mathrm{Th}}$ proportion, mainly bulk sediment was formed. 

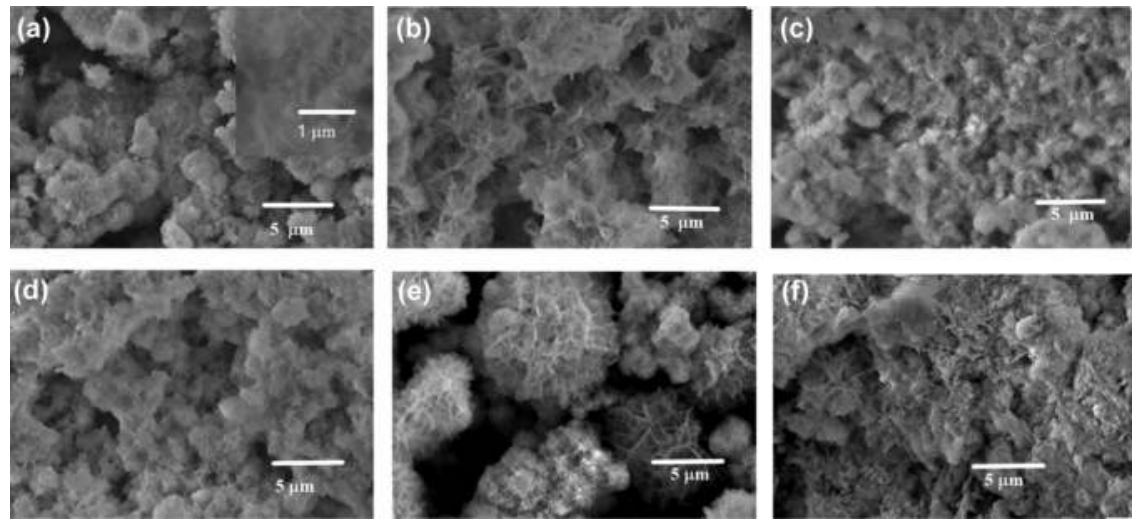

\section{FIGURE 1.26}

CdS particles obtained at $20^{\circ} \mathrm{C}$ and respective different glutamic acid concentrations and $C_{\mathrm{Cd}} / \mathcal{C}_{\mathrm{Th}}$ proportions: (a) $0.005 \mathrm{M}$ and 1:1; (b) $0.005 \mathrm{M}$ and 1:4; (c) $0.01 \mathrm{M}$ and 1:1; (d) $0.01 \mathrm{M}$ and 1:4; (e) 0.05 M and 1:1; and (f) 0.05 M and 1:4 (Sofronov, Belikov et al. 2013).
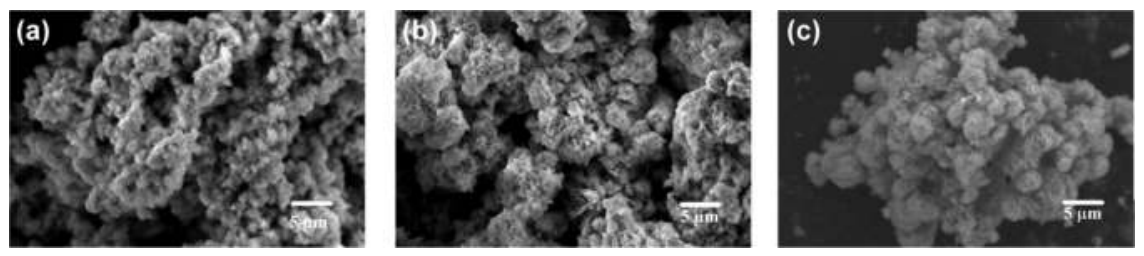

\section{FIGURE 1.27}

CdS particles obtained at $20^{\circ} \mathrm{C}$ at respective different p-aminobenzoic acid concentrations and $C_{\mathrm{Cd}} / C_{\mathrm{Th}}$ proportions: (a) $0.005 \mathrm{M}$ and 1:1; (b) $0.005 \mathrm{M}$ and $1: 4$; and (c) $0.01 \mathrm{M}$ and 1:1.
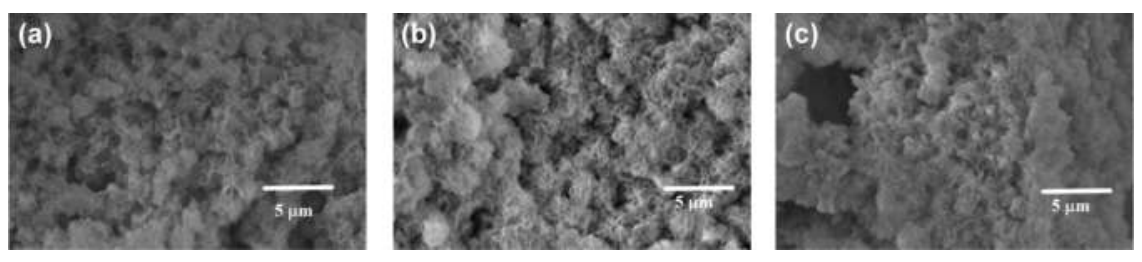

FIGURE 1.28

CdS particles obtained at $100^{\circ} \mathrm{C}$ at respective different p-aminobenzoic acid concentrations and $C_{\mathrm{Cd}} / C_{\mathrm{Th}}$ proportions: (a) $0.005 \mathrm{M}$ and $1: 1 ;$ (b) $0.005 \mathrm{M}$ and $1: 4$; and (c) $0.01 \mathrm{M}$ and $1: 4$.

Thus, addition of glycine in amounts $0.005-0.010 \mathrm{M}$ irrespective of thiourea concentration caused formation of large spherical flower-like particles with dimensions ca. $5 \mu \mathrm{m}$. Increase of its amount caused formation of large shapeless particles, and their dimensions were larger for higher concentrations of thiourea. When the synthesis temperature was increased up to $100^{\circ} \mathrm{C}$, at glycine amounts below $0.01 \mathrm{M}$, finely dispersed sediments were 
formed. The higher the $C_{\mathrm{Cd}} / C_{\mathrm{Th}}$ ratio, the smaller the obtained particles. At the same time, increase of the additive amount up to $0.05 \mathrm{M}$ caused formation of the flower-like particles with dimensions $2-4 \mu \mathrm{m}$, irrespective of thiourea concentration.

On the other hand, when small amounts of alanine were added $(0.005 \mathrm{M})$, the flower-like particles were formed, but their dimensions were smaller when thiourea concentration was higher. Further increase of the alanine concentration caused formation of shapeless agglomerated sediments consisting of small plates or scales. When the synthesis temperature was increased up to $100^{\circ} \mathrm{C}$ at alanine concentrations below $0.05 \mathrm{M}$, the shapeless agglomerates were formed consisting of single small scales, whereas increase of the alanine amount up to $0.1 \mathrm{M}$ caused formation of structures resembling flowers, and their dimensions were dependent on the $C_{\mathrm{Cd}} / C_{\mathrm{Th}}$ proportions.

Even small amounts of $\varepsilon$-aminocaproic acid $(0.1 \mathrm{M})$ added at room temperature caused formation of the bulk sediment. However, increase of the synthesis temperature up to $100^{\circ} \mathrm{C}$ neutralized effect of the $\varepsilon$-aminocaproic acid. As a result, large flower-like particles were formed.

Addition of the glutamic or p-aminobenzoic acid caused formation of mainly bulk sediment, irrespective of other synthesis conditions.

\subsection{Effect of Microwave Activation on the Zinc, Cadmium, and Copper Sulfide Particles Formation}

\subsubsection{Effect of $\mathrm{pH}$ and Thiourea Concentration Combined with Microwave Activation}

MW irradiation is widely applied in synthesis of nanoparticles of various applications (Qiao et al. 2017). For example, Zhu et al. (2001) proposed a method of $\mathrm{CdS}$ and $\mathrm{ZnS}$ nanoparticles preparation through the reaction between $\mathrm{CdCl}_{2}$ or $\mathrm{ZnZ}(\mathrm{Ac})_{2}$ and thioacetamide in aqueous solution using MW irradiation. However, production of zinc sulfide out of thiourea solutions with MW activation was not reported before.

Application of MWs allowed to obtain the individual phases of metal sulfides at $\mathrm{pH}$ close to 8 . Figure 1.29 presents the X-ray diagrams of zinc sulfide powder, as well as cadmium and copper(II) sulfides powder synthesized with MW activation at $c\left(\mathrm{Me}^{2+}\right): c\left(\left(\mathrm{NH}_{2}\right)_{2} \mathrm{CS}\right)$ ratio 1:1 and $\mathrm{pH}$ 8. In the diagrams, only reflexes related to the metal sulfides are seen. In case of zinc sulfide, sphalerite phase is observed, whereas for copper(II) sulfide, it was $\mathrm{CuS}$ covellite, and for cadmium sulfide, the hawleyite structure was formed.

IR spectrometry data also proved the decrease of oxygen-containing impurities concentration in the synthesized substances (Figures 1.30 and 1.31). 

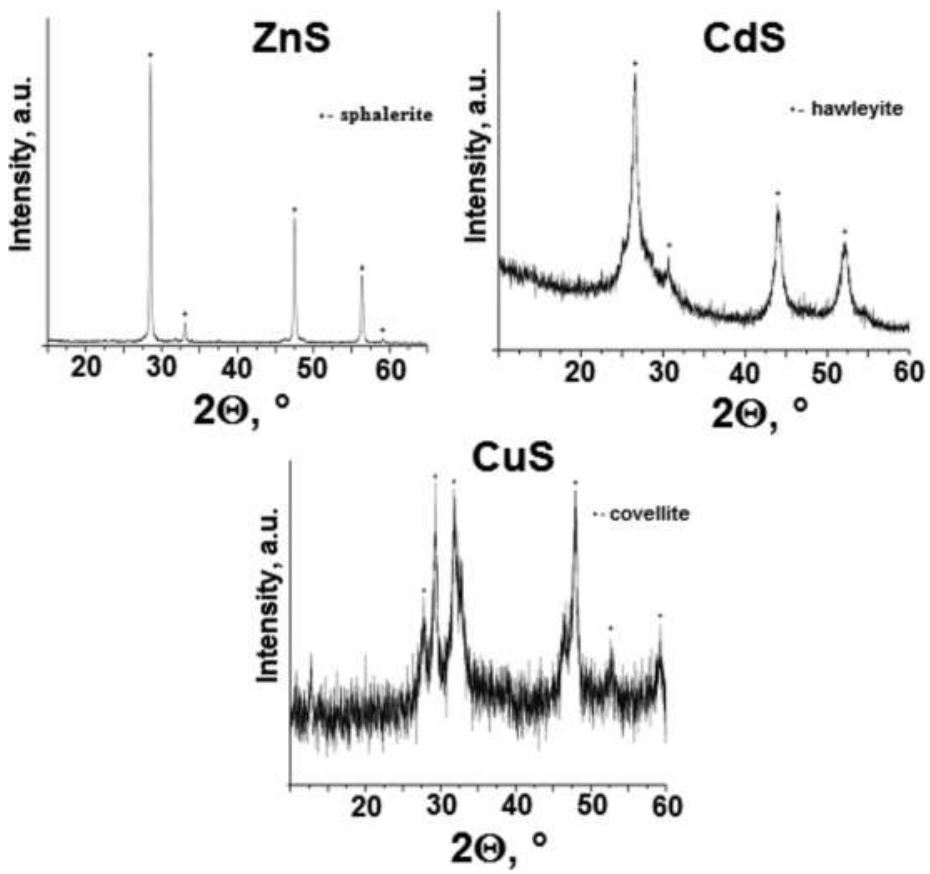

FIGURE 1.29

$\mathrm{X}$-ray diagrams of the powders obtained with microwave activation at $\mathrm{c}\left(\mathrm{Me}^{2+}\right): \mathrm{c}\left(\left(\mathrm{NH}_{2}\right)_{2} \mathrm{CS}\right)$ ratio $1: 1, \mathrm{pH} 8$, and temperature $90^{\circ} \mathrm{C}$.

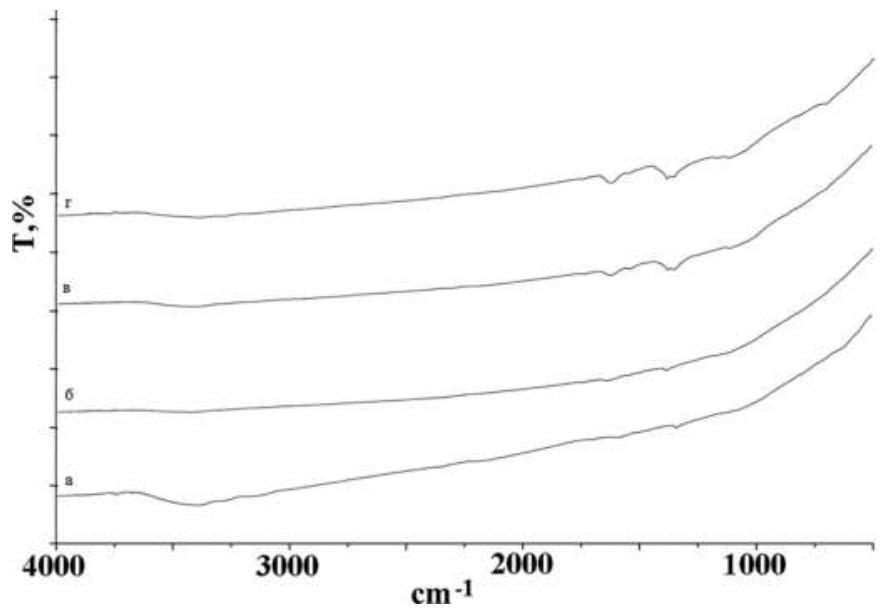

FIGURE 1.30

IR spectra of CdS powder precipitated from the nitrate solutions at temperature $90^{\circ} \mathrm{C}$ and $\mathrm{c}\left(\mathrm{Me}^{2+}\right): \mathrm{c}\left(\left(\mathrm{NH}_{2}\right)_{2} \mathrm{CS}\right)$ ratio 1:1 and different $\mathrm{pH}$ values: (a) $\mathrm{pH}$; (b) $\mathrm{pH} \mathrm{10;} \mathrm{(c)} \mathrm{pH} 11$; and (d) $\mathrm{pH}$ 12. IR, infrared. 


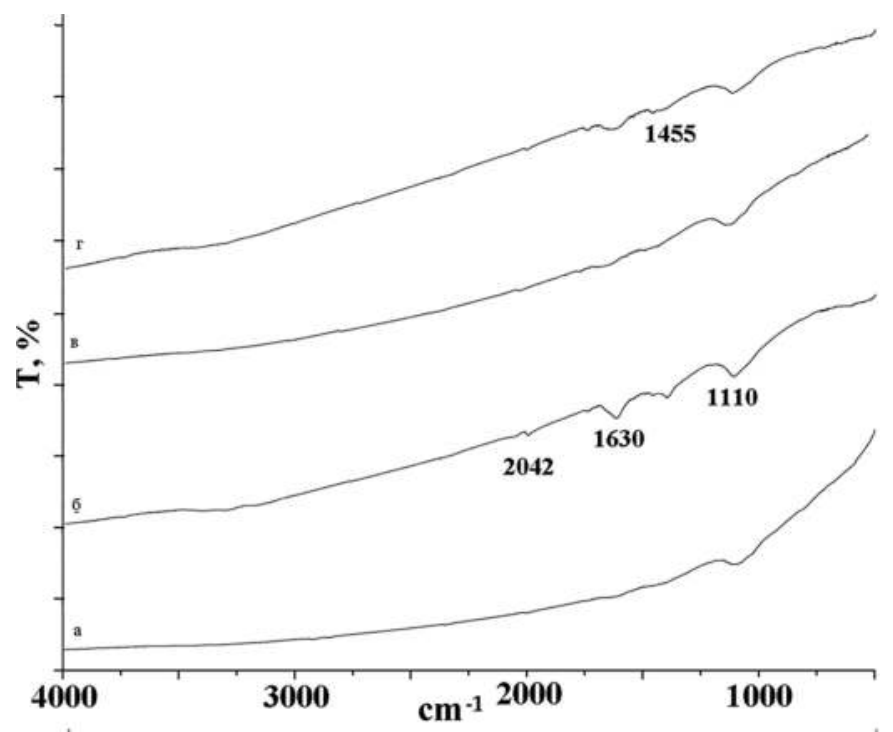

FIGURE 1.31

IR spectra of CuS powder precipitated from the nitrates solutions at temperature $90^{\circ} \mathrm{C}$, with different $\mathrm{c}\left(\mathrm{Me}^{2+}\right): \mathrm{c}\left(\left(\mathrm{NH}_{2}\right)_{2} \mathrm{CS}\right)$ ratios and respective $\mathrm{pH}$ values: (a) 1:1 and $\mathrm{pH}$ 8; (b) 1:1 and $\mathrm{pH}$ 10; (c) 1:1 and $\mathrm{pH} 12$; and (d) 1:4 and $\mathrm{pH} 12$.

In the spectra of powders obtained with MW activation, compared with IR spectra of powders synthesized with thermal activation, considerable decrease of absorption band intensity in the range of $500-1,500 \mathrm{~cm}^{-1}$ is observed. This indicates that impurities concentration is smaller in the obtained substances.

MW irradiation allowed to increase substantially both purity of the obtained compounds and their practical percentage yield. Thus, irrespective of $\mathrm{pH}$ and thiourea concentration, yield of $\mathrm{ZnS}, \mathrm{CdS}$, and $\mathrm{CuS}$ was excellent: $90 \%-92 \%, 93 \%-95 \%$, and $95 \%-97 \%$ by mass, respectively. A slight tendency of yield increase in the series of $\mathrm{ZnS}, \mathrm{CdS}$, and CuS is seen, and the thiourea concentration had no substantial effect on the product yield.

SEM images of the ZnS particles are presented in Figure 1.32. In general, synthesis with MW activation did not change the particle forms, and mainly spherical particles were formed. Thus, at $\mathrm{pH} 8.5$ and 9.5, when the $\mathrm{c}(\mathrm{Th}): \mathrm{c}\left(\mathrm{Zn}^{2+}\right)$ proportion was 1:1, diameters of formed particles were below $100 \mathrm{~nm}$ with average ca. $80 \mathrm{~nm}$, but single large particles were of diameters ca. $1.5 \mu \mathrm{m}$ (Figure 1.32a). Further increase of $\mathrm{pH}$ up to 10.8 caused increase of particle dimensions up to $0.3-1.5 \mu \mathrm{m}$ with average value $0.36 \mu \mathrm{m}$ (Figure $1.32 \mathrm{c}-\mathrm{d})$. When sodium hydroxide was applied, some plates of length and width ca. $1.2-1.5 \mu \mathrm{m}$ and thickness $0.1-0.2 \mu \mathrm{m}$ were formed along with spherical particles (Figure 2.30e). Increase of $\mathrm{pH}$ up to 12 caused formation of spherical particles with diameters $0.2-0.7 \mu \mathrm{m}$ (Figure 1.32f). 

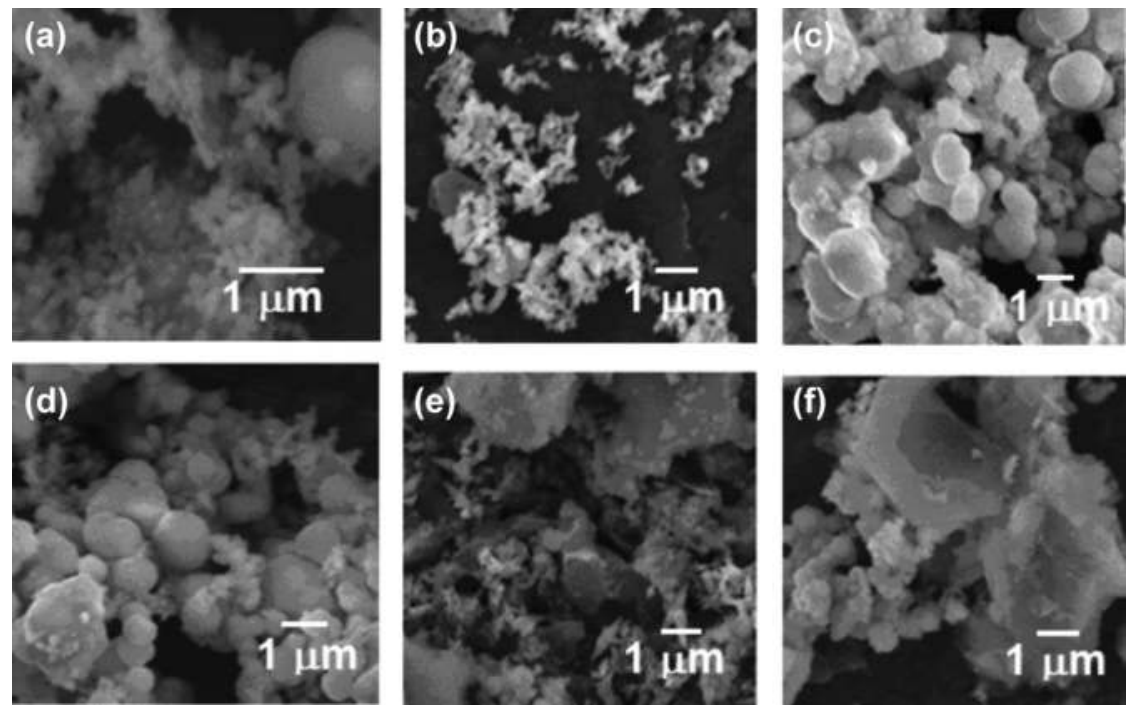

FIGURE 1.32

$\mathrm{ZnS}$ particles obtained at temperature $90^{\circ} \mathrm{C}$ and $\mathrm{c}(\mathrm{Th}): \mathrm{c}\left(\mathrm{Zn}^{2+}\right)$ proportion 1:1 with different $\mathrm{pH}$ : (a) 8.5 ; (b) 9.5 ; (c) 10.8; (d) 12; (e) $8(\mathrm{NaOH})$; and (f) $12(\mathrm{NaOH})$.

In case of cadmium sulfide, unlike zinc sulfide, at low values of $\mathrm{pH}$ 8-9, the formation of agglomerates was observed resembling flowers of dimensions $5 \mu \mathrm{m}$ consisting of plates with thickness ca. 50-80 nm (Figure 1.33a). When $\mathrm{pH}$ was increased up to 10, spherical dense particles with diameters $0.2-0.7 \mu \mathrm{m}$ were formed, along with some flower-like particles with dimensions $0.8-1.0 \mu \mathrm{m}$. Further $\mathrm{pH}$ increase had no substantial effect on the particles morphology (Figure 1.33b-c). However, when the alkalinity providing reagent was replaced with sodium hydroxide, exclusively spherical particles were formed with average dimensions ca. $0.4 \mu \mathrm{m}$ (Figure 1.33d-f).

In case of copper sulfide, only spherical particles were formed, and their dimensions were larger with $\mathrm{pH}$ increase (Figure 1.34). At $\mathrm{pH} 8$, obtained particle dimensions were below $50 \mathrm{~nm}$, but when $\mathrm{pH}$ increased up to 10 and 12 , dimensions were larger, up to $200 \mathrm{~nm}$ (Figure 1.34a-c). When sodium hydroxide was applied to regulate alkalinity, the agglomerates were formed consisting of spherical particles below $100 \mathrm{~nm}$ (Figure 1.34d-f).

Increase of thiourea concentration $\mathrm{c}(\mathrm{Th}): \mathrm{c}\left(\mathrm{Zn}^{2+}\right)$ in the solution during the synthesis of metal sulfides up to 1:4 and more had varying impact, as it can be seen in Figures 1.35-1.37. In case of zinc sulfide, the particles in agglomerates became larger up to $1-2 \mu \mathrm{m}$ at $\mathrm{pH} 8$, but increase of $\mathrm{pH}$ caused reduction of the dimensions down to $0.6-0.8 \mu \mathrm{m}$ at $\mathrm{pH}$ 12. In case of cadmium sulfide, increase of the thiourea concentration caused formation of the finely dispersed sediment consisting of the particles smaller than 100nm (Figure 1.36a). When $\mathrm{pH}$ increased, 

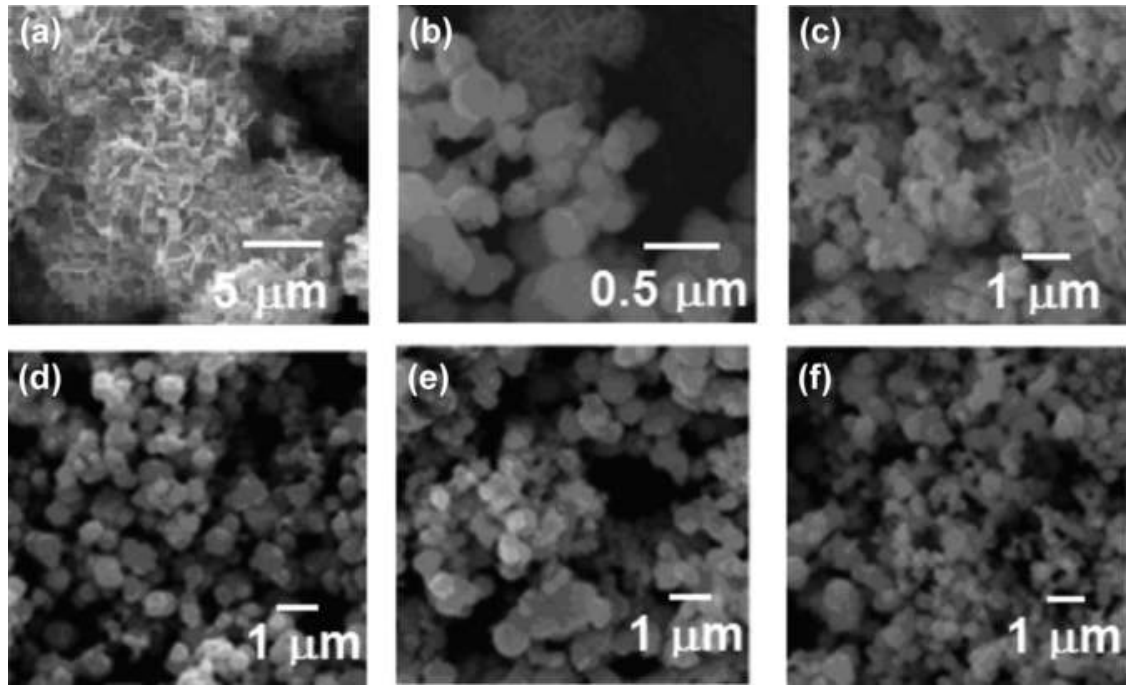

FIGURE 1.33

$\mathrm{CdS}$ particles obtained at temperature $90^{\circ} \mathrm{C}$ from nitrate solutions with $\mathrm{c}\left(\mathrm{Cd}{ }^{2+}\right): \mathrm{c}\left(\left(\mathrm{NH}_{2}\right)_{2} \mathrm{CS}\right)$ proportion 1:1 with different pH: (a) 8; (b) 10; (c) 12; (d) 8 (NaOH); (e) $10(\mathrm{NaOH})$; and (f) 12 $(\mathrm{NaOH})$.
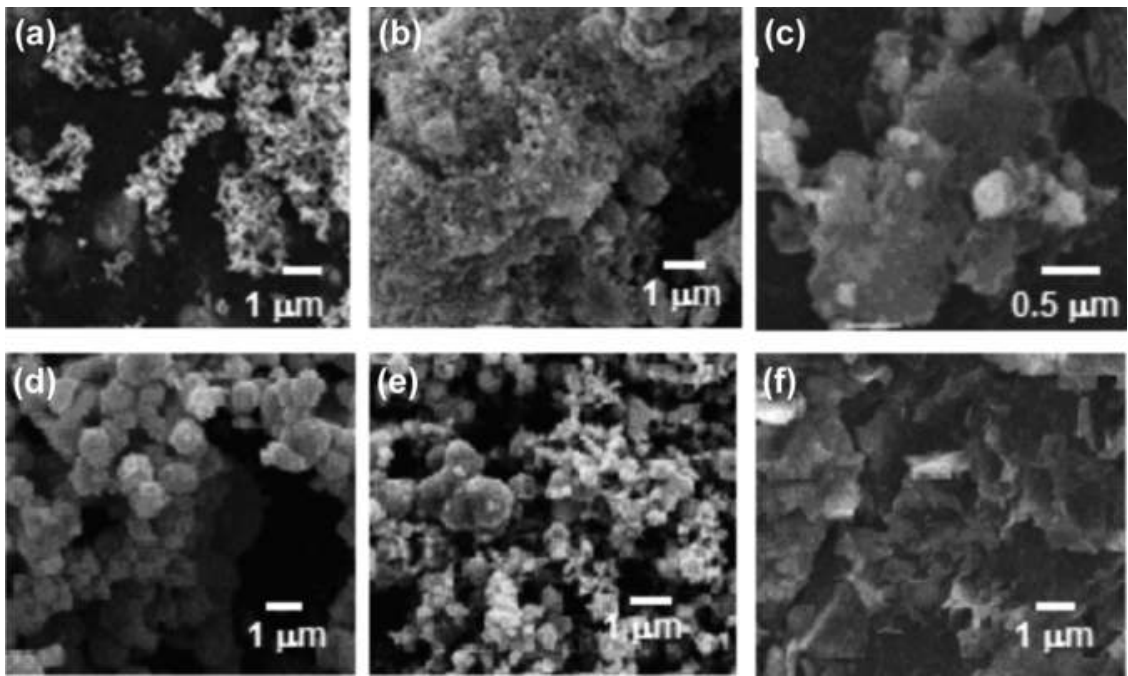

\section{FIGURE 1.34}

CuS particles obtained at temperature $90^{\circ} \mathrm{C}$ from nitrate solutions with $\mathrm{c}\left(\mathrm{Cu}^{2+}\right): \mathrm{c}\left(\left(\mathrm{NH}_{2}\right)_{2} \mathrm{CS}\right)$ proportion 1:1 with different $\mathrm{pH}$ : (a) 8 ; (b) 10; (c) 12; (d) 8 (NaOH); (e) $10(\mathrm{NaOH})$; and (f) $12(\mathrm{NaOH})$ (Bulgakova et al. 2016a). 

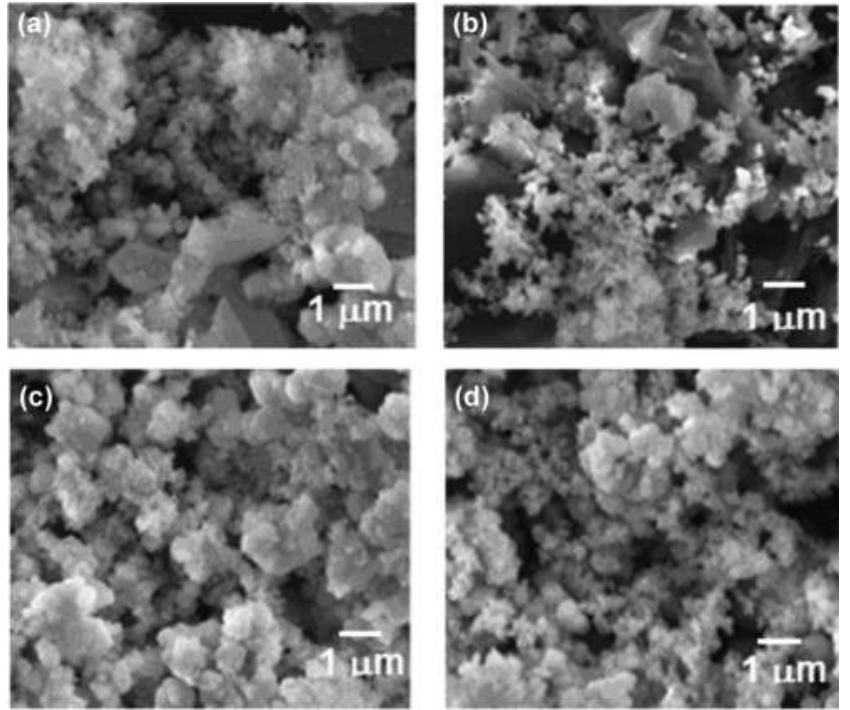

FIGURE 1.35

ZnS particles obtained at temperature $100^{\circ} \mathrm{C}$ and $\mathrm{c}(\mathrm{Th}): \mathrm{c}\left(\mathrm{Zn}^{2+}\right)$ proportion $1: 4$ with different $\mathrm{pH}$ : (a) 8; (b) 9.5; (c) 10.7; and (d) 12 .
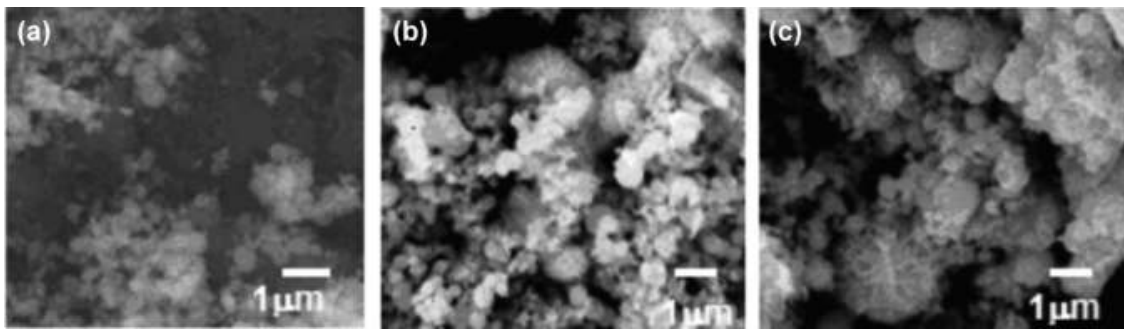

\section{FIGURE 1.36}

CdS particles obtained at temperature $90^{\circ} \mathrm{C}$ with $\mathrm{c}\left(\mathrm{Cd}^{2+}\right): \mathrm{c}\left(\left(\mathrm{NH}_{2}\right)_{2} \mathrm{CS}\right)$ proportion 1:4 with different pH: (a) 8; (b) 10; (c) 12 .

particles increased, too, and flower-like formations appeared (Figure 1.36c). In case of copper(II) sulfide precipitation, increased thiourea concentration caused formation of large spherical agglomerates with dimensions up to $1.5 \mu \mathrm{m}$. Their dimensions went smaller along with increase of $\mathrm{pH}$ (Figure 1.37).

\subsubsection{Temperature Effect}

When the temperature of synthesis was increased up to $150^{\circ} \mathrm{C}$, considerable change in the zinc and copper(II) sulfides particles morphology was observed. Thus, in case of $\mathrm{ZnS}$ particles obtained at $\mathrm{c}\left(\left(\mathrm{NH}_{2}\right)_{2} \mathrm{CS}\right): \mathrm{c}\left(\mathrm{Zn}^{2+}\right)$ ratio 1:1 and alkalinity $\mathrm{pH} 8$, smaller spherical particles had diameter $0.05-0.10 \mu \mathrm{m}$ and larger 

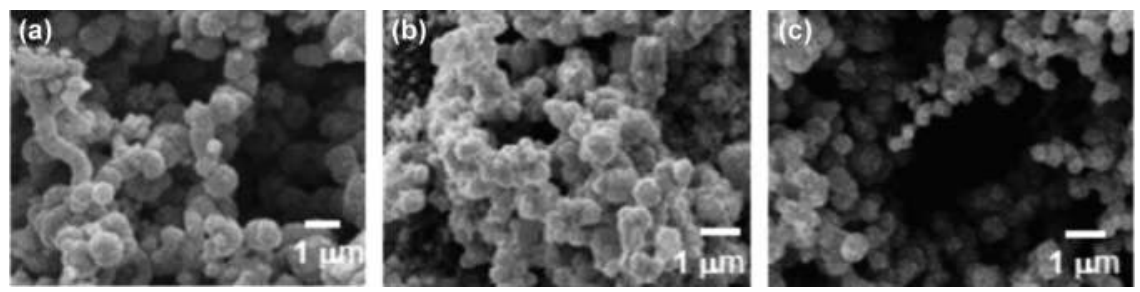

FIGURE 1.37

CuS particles obtained at temperature $90^{\circ} \mathrm{C}$ from nitrate solutions with $\mathrm{c}\left(\mathrm{Cu}^{2+}\right): \mathrm{c}\left(\left(\mathrm{NH}_{2}\right)_{2} \mathrm{CS}\right)$ proportion 1:4 with different $\mathrm{pH}$ : (a) 8; (b) 10; and (c) 12 .
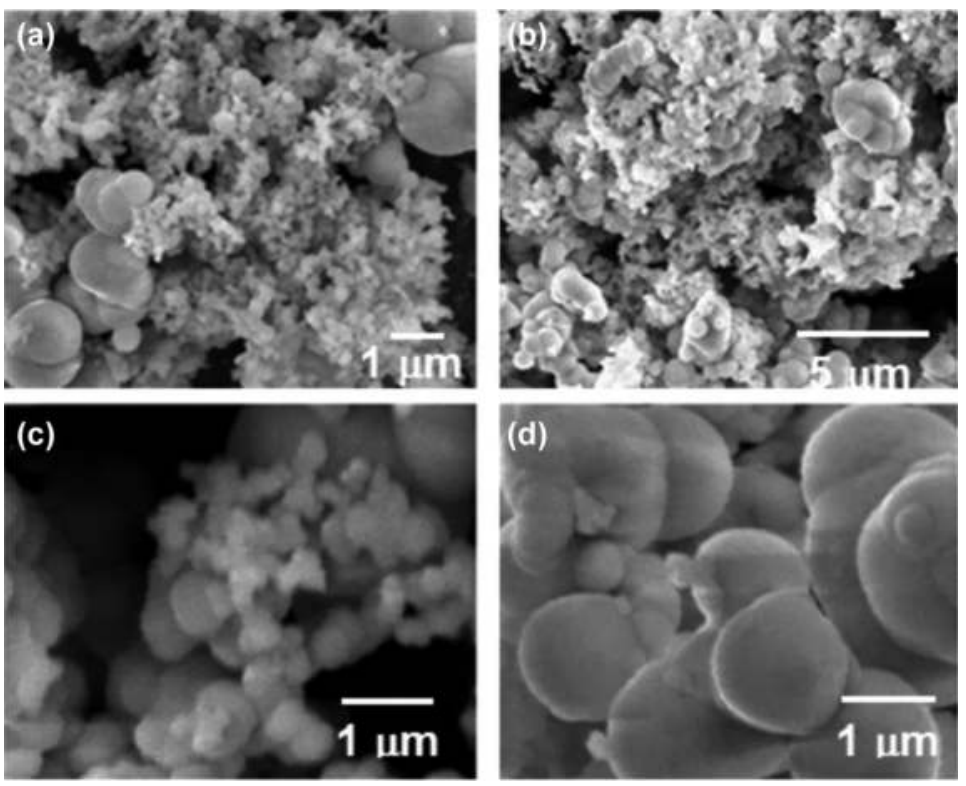

\section{FIGURE 1.38}

$\mathrm{ZnS}$ particles obtained at temperature $150^{\circ} \mathrm{C}$ and $\mathrm{c}\left(\left(\mathrm{NH}_{2}\right)_{2} \mathrm{CS}\right): \mathrm{c}\left(\mathrm{Zn}^{2+}\right)$ proportion 1:1 with different pH: (a) 8; (b) 9.5; (c) 10.5; and (d) 12 .

ones had diameter 0.8-1.5 $\mu \mathrm{m}$ (Figure 1.38). Average diameter of all particles was $0.16 \mu \mathrm{m}$. At higher $\mathrm{pH} 9.5$, particles in general grew larger with average diameter $0.44 \mu \mathrm{m}$. Further increase of $\mathrm{pH}$ up to 10.5 caused smaller content of large particles, and average diameter was $0.29 \mu \mathrm{m}$ and dispersity was 0.025 .

SEM images of the particles CdS obtained from $\mathrm{c}(\mathrm{Th}): \mathrm{c}\left(\mathrm{Cd}^{2+}\right)$ proportion 1:1 at temperature $150^{\circ} \mathrm{C}$ are presented in Figure 1.39. When alkalinity was $\mathrm{pH}$ 8 , the geometrically spherical particles were formed along with deformed spheres. Diameters of spherical particles were ca. 0.6-1.0 $\mu \mathrm{m}$. At higher $\mathrm{pH}$, formed spheres had larger diameters ca. $0.8-1.2 \mu \mathrm{m}$. 

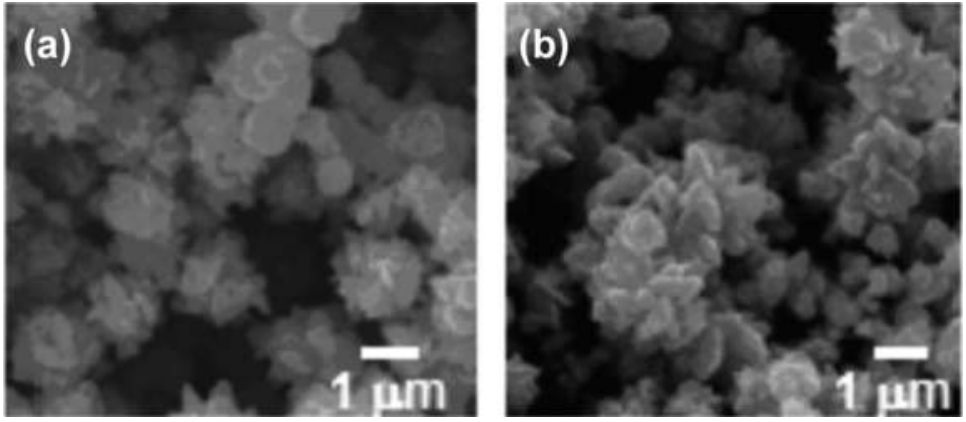

FIGURE 1.39

CdS particles obtained at temperature $150^{\circ} \mathrm{C}$ and $\mathrm{c}(\mathrm{Th}): \mathrm{c}\left(\mathrm{Cd}^{2+}\right)$ proportion 1:1 with different pH: (a) 8 and (b) 12 .
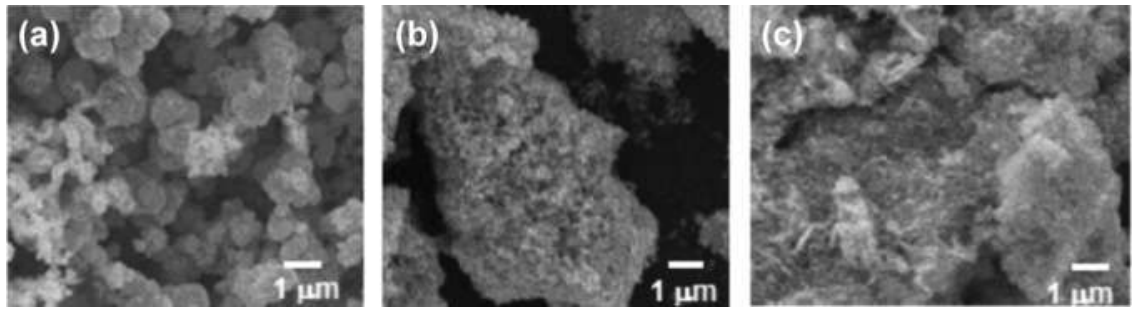

FIGURE 1.40

$\mathrm{CuS}$ particles obtained at temperature $150^{\circ} \mathrm{C}$ and $\mathrm{c}\left(\mathrm{Cu}^{2+}\right): \mathrm{c}\left(\left(\mathrm{NH}_{2}\right)_{2} \mathrm{CS}\right)$ proportion 1:1 with different $\mathrm{pH}$ : (a) 8; (b) 10; and (c) 12 .

As it is seen in Figure 1.40, no substantial impact of higher temperature on the morphological characteristics of particles was observed, unlike in case of $\mathrm{ZnS}$ and CdS.

\subsection{Effect of Metal Ion Doping on the Zinc Sulfide Particles Formation}

There are many published reports on the methodology of doped particles of metal sulfides synthesis (Alby et al. 2018). Recent papers emphasize, on the one hand, problems of green synthesis (Muraleedharan et al. 2015) and, on the other hand, energy-saving synthesis and high efficiency sorptive capture of radionuclides (Vellingiri et al. 2018). It is well documented that copper-doped, manganese-doped, and silver-doped zinc sulfides are excellent phosphors with good photoluminescence properties 
(Murugadoss 2013; Vadiraj and Belagali, 2017). Addition of the europium and cerium ions to the particles of $\mathrm{ZnS}$ and $\mathrm{CdS}$ has considerable impact enabling their photoluminescence properties (Syamchand and Sony 2015; Hurma 2016). However, the effect of the doping ions on the particles formation is still little known.

In order to examine the issue of dopant effect on the particles formation, zinc sulfide was chosen as a basic substance, whereas copper, silver, manganese, europium, and cerium were chosen as dopants. Concentration of dopants was varied between $0.01 \%$ and $5 \%$ by mass. Synthesis was performed at $\mathrm{pH} 12$ and $c\left(\mathrm{Zn}^{2+}\right): c\left(\left(\mathrm{NH}_{2}\right)_{2} \mathrm{CS}\right)$ ratio 1:1. The precipitation temperature with thermal activation was $100^{\circ} \mathrm{C}$, whereas the one with $\mathrm{MW}$ activation was $100^{\circ} \mathrm{C}$ and $150^{\circ} \mathrm{C}$. Duration of synthesis was 1 hour for thermal activation and 30 minutes for MW activation.

It is well known that copper and silver salts react with thiourea producing respective sulfides. In case of powders consisting of $\mathrm{ZnS}-\mathrm{CuS}$ obtained at thermal activation, no considerable effect of the copper concentration on the particles formation was observed. Always spherical agglomerated particles were formed with diameters between 0.5 and $1.2 \mu \mathrm{m}$, as it is seen in Figure 1.41. Similarly, precipitation with MW activation at temperature $100^{\circ} \mathrm{C}$ did not provide any substantial change in the particles morphology even when the copper concentration was increased up to $1 \%$ by mass. Always, the spherical particles with diameters between 0.2 and $0.6 \mu \mathrm{m}$ were formed, shown in Figure 1.42. However, when $\mathrm{Cu}$ concentration was $1 \%$ by mass, large plates (scales) with several microns dimensions and thickness $0.2 \mu \mathrm{m}$ were observed along with spherical particles. When copper concentration
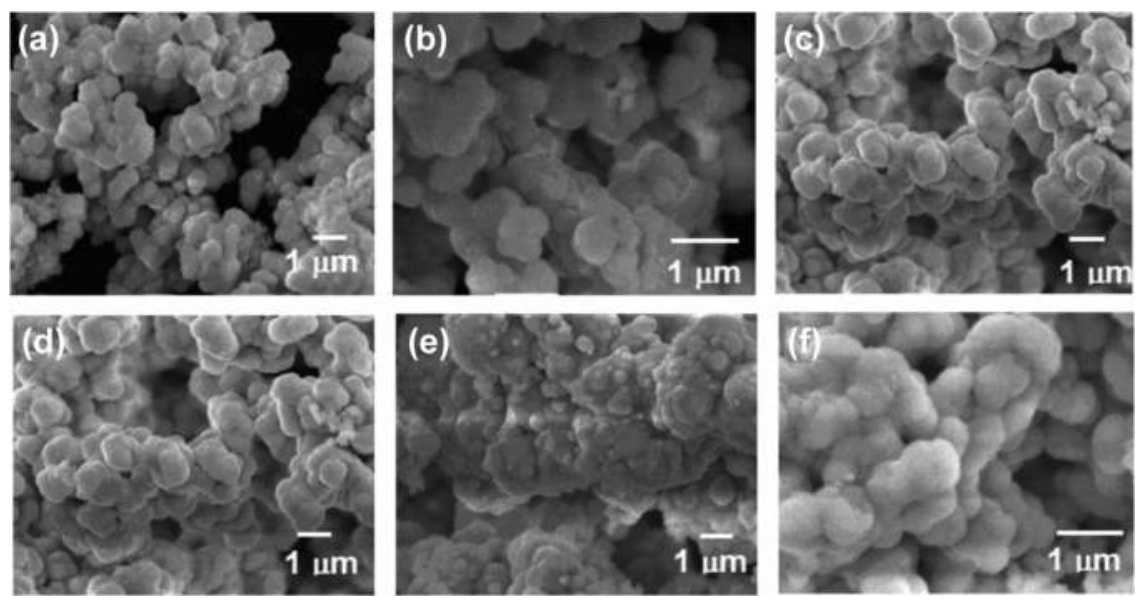

\section{FIGURE 1.41}

ZnS-CuS particles obtained at thermal activation with different concentrations of additives (\% by mass): (a) 0.01 ; (b) 0.05 ; (c) 0.1 ; (d) 0.5 ; (e) 1 ; (f) 5 . 

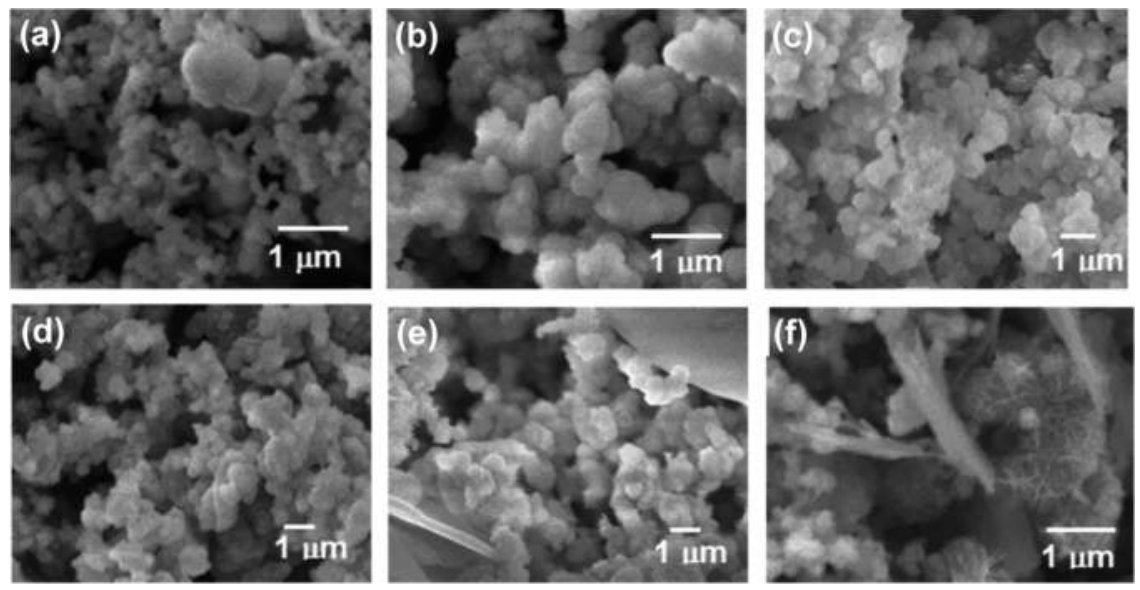

\section{FIGURE 1.42}

ZnS-CuS particles obtained at microwave activation $\left(100^{\circ} \mathrm{C}\right)$ with different concentrations of additives (\% by mass): (a) 0.01 ; (b) 0.05 ; (c) 0.1 ; (d) 0.5 ; (e) 1 ; (f) 5 .

was further increased up to $5 \%$ by mass, the particles resembling flowers were formed, as in case of cadmium sulfide.

When the synthesis temperature was increased up to $150^{\circ} \mathrm{C}$, spherical particles of diameters between 0.8 and $1.2 \mu \mathrm{m}$ were formed at the copper concentration $0.01 \%-1 \%$ by mass (Figure 1.43 ). Higher concentrations, $5 \%$ by mass, caused formation of rods several microns long with diameters of $0.3 \mu \mathrm{m}$.

Unusual feature was observed when the IR spectra of the obtained copper ions-doped zinc sulfide particles were analyzed. Namely, increase of the copper concentration caused considerable intensity decrease of the gap bands, as it is seen in Figure 1.44e and f, which proved decrease of the contaminations concentration. In general, the analyzed IR spectrum was similar to the spectra obtained for copper sulfide powders, where gap bands are practically absent. It is reasonable to formulate a hypothesis that perhaps in the solution where copper concentration is over $0.05 \%$ by mass, the $\mathrm{ZnS}$ particles became coated with CuS layer forming core-shell structures similar to the reported ones (Thuy et al. 2014). X-ray phase analysis provided data that the particles consist of different phases of zinc sulfide with sphalerite structure and copper sulfide with covellite structure. In the IR spectra of $\mathrm{ZnS}-\mathrm{CuS}$ particles obtained at MW activation $\left(150^{\circ} \mathrm{C}\right)$, no intensive bandgaps are seen, as in case of the spectra shown in Figure 1.44e and $\mathrm{f}$ obtained at copper concentration $0.05 \%$ by mass and higher.

As in case of $\mathrm{ZnS}-\mathrm{CuS}$ particles, synthesis of the $\mathrm{ZnS}_{-} \mathrm{Ag}_{2} \mathrm{~S}$ at different concentrations of silver sulfide between $0.1 \%$ and $5 \%$ by mass with thermal activation did not reveal any substantial differences. The spherical agglomerated particles were formed with dimensions between 0.5 and 

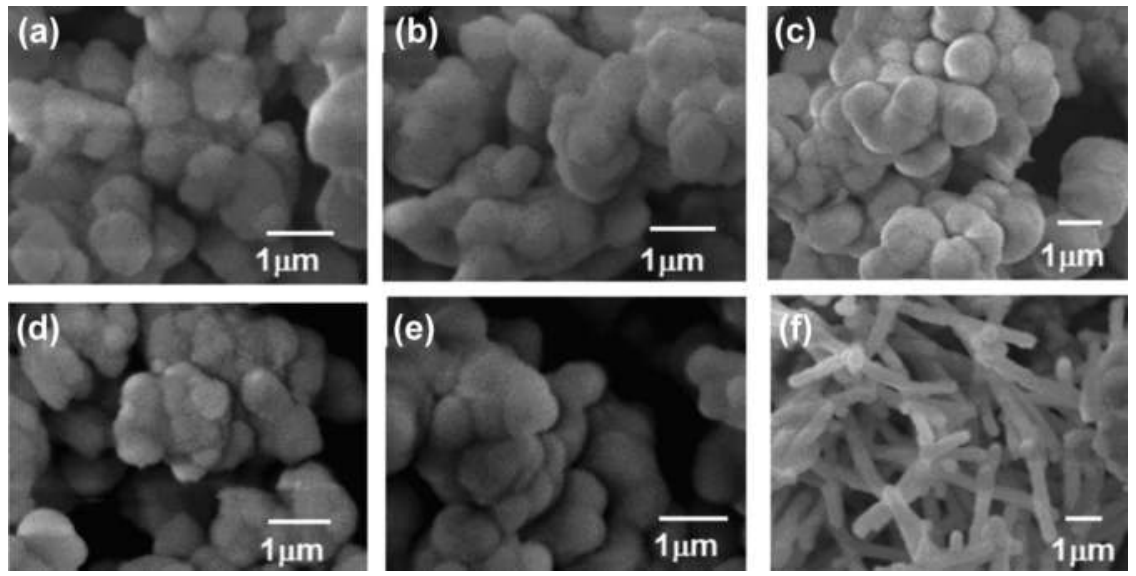

\section{FIGURE 1.43}

$\mathrm{ZnS}-\mathrm{CuS}$ particles obtained at microwave activation $\left(150^{\circ} \mathrm{C}\right)$ with different concentrations of additives (\% by mass): (a) 0.01 ; (b) 0.05 ; (c) 0.1 ; (d) 0.5 ; (e) 1 ; (f) 5 .

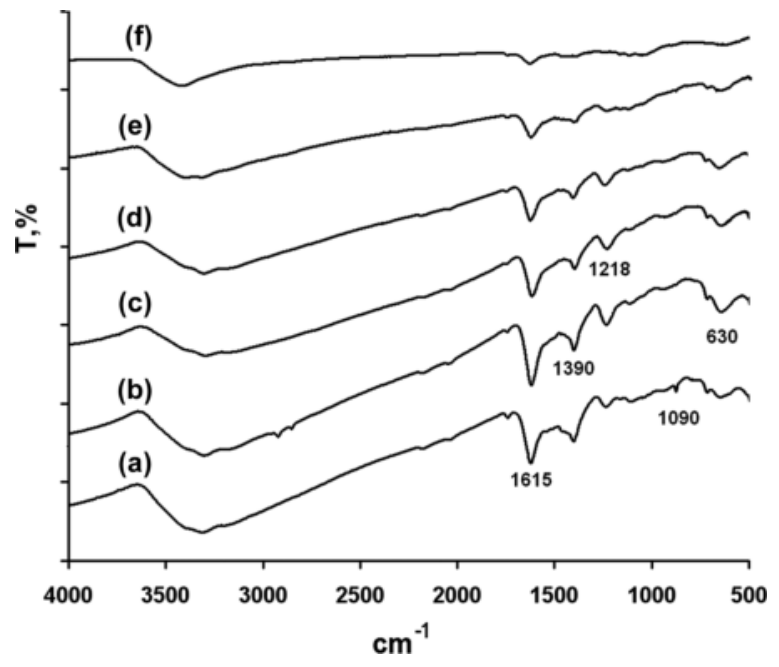

\section{FIGURE 1.44}

IR spectra of ZnS-CuS powders obtained at thermal activation with different concentrations of additives (\% by mass): (a) 0.01 ; (b) 0.05 ; (c) 0.1 ; (d) 0.5 ; (e) 1 ; and (f) 5 . IR, infrared.

$1.1 \mu \mathrm{m}$. However, when MW activation was applied at temperature $100^{\circ} \mathrm{C}$, increase of copper sulfide concentration up to $1 \%$ by mass caused increase of the spherical particles up to $1 \mu \mathrm{m}$. When the synthesis temperature was increased up to $150^{\circ} \mathrm{C}$, spherical particles of diameter $0.8-1.2 \mu \mathrm{m}$ were formed at the $\mathrm{Ag}_{2} \mathrm{~S}$ concentration in the range of $0.05 \%-1 \%$ by mass (Figure $1.45 \mathrm{a}-\mathrm{d}$ ). Further increase of the silver sulfide concentration up to $5 \%$ by mass caused 

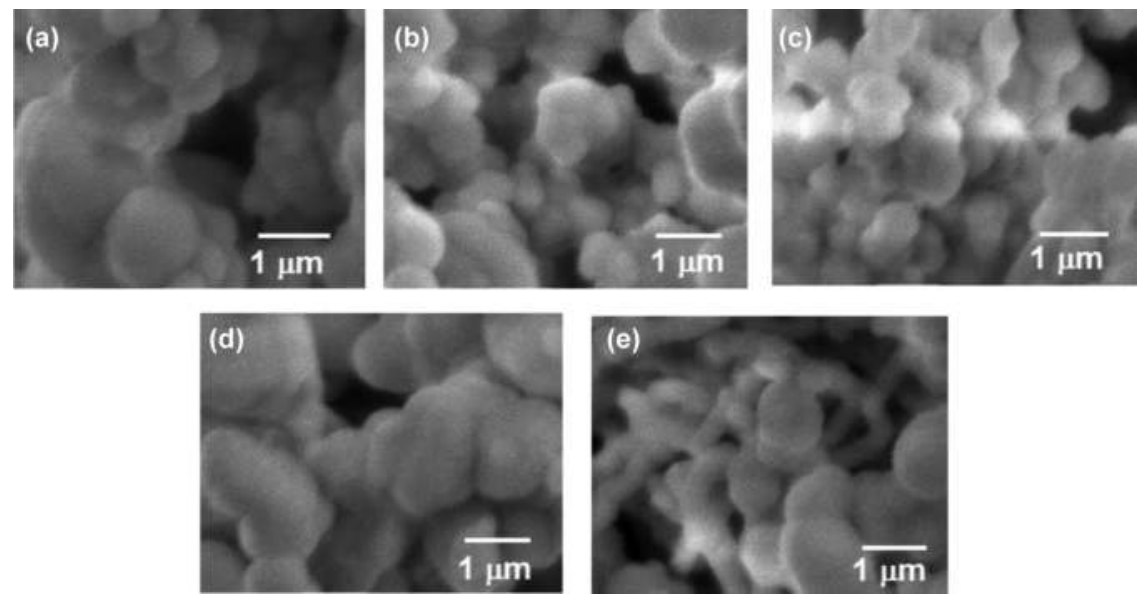

\section{FIGURE 1.45}

$\mathrm{ZnS}-\mathrm{Ag}_{2} \mathrm{~S}$ particles obtained at microwave activation $\left(150^{\circ} \mathrm{C}\right)$ with different concentrations of additives (\% by mass): (a) 0.05 ; (b) 0.1 ; (c) 0.5 ; (d) 1 ; and (e) 5 .

formation of rods up to $1 \mu \mathrm{m}$ long and $90-110 \mathrm{~nm}$ thick, along with the spherical particles (Figure 1.45e).

During the synthesis of ZnS-MnS particles, powders of light reddish color were obtained directly after precipitation, but after they were dried, the color became more brownish. Irrespective of manganese content in the range $0.05 \%-10 \%$ by mass, the spherical particles of dimensions between 0.6 and $1.2 \mu \mathrm{m}$ were formed. Hence, the addition of manganese during zinc sulfide particles precipitation had no impact on the particle formation.

It was expected that during the synthesis, manganese sulfide would appear along with the zinc sulfide particles. However, in the IR spectra corresponding with the powders obtained for manganese concentrations above $1 \%$ by mass, the absorption bands were observed at $1442,1385,1225,636$, and $460 \mathrm{~cm}^{-1}$ (Figure 1.46a). When the manganese concentration was increased, additional absorption bands appeared with maximums at 1112, 1076, 980, 680, 614 , and $480 \mathrm{~cm}^{-1}$ (Figure 1.46b). The absorption band 1,385 $\mathrm{cm}^{-1}$ appeared in all the spectra, which is explained by the vibrations of $\mathrm{NO}_{3}{ }^{-}$ion adsorbed on the surfaces of particles as a result of the application of zinc nitrate as a precursor. The absorption bands at 1,442 and $1,076 \mathrm{~cm}^{-1}$ corresponded with vibrations of $\mathrm{CO}_{3}{ }^{-2}$ anion, which was formed as a result of alkaline solutions carbonization processes.

Absorption band at $636 \mathrm{~cm}^{-1}$ may be ascribed to the vibrations of $\mathrm{OH}^{-}$groups (Nyquist and Kagel 1971), whereas the band at $460 \mathrm{~cm}^{-1}$ may be ascribed to the vibrations of $\mathrm{Zn}-\mathrm{O}$ bond (Sofronov, Bielikov et al. 2013). Absorption bands at 1225,1112 , and $614 \mathrm{~cm}^{-1}$ may correspond with sulfate ion vibrations (Nyquist and Kagel 1971). They are adsorbed on the surface of particles, and 


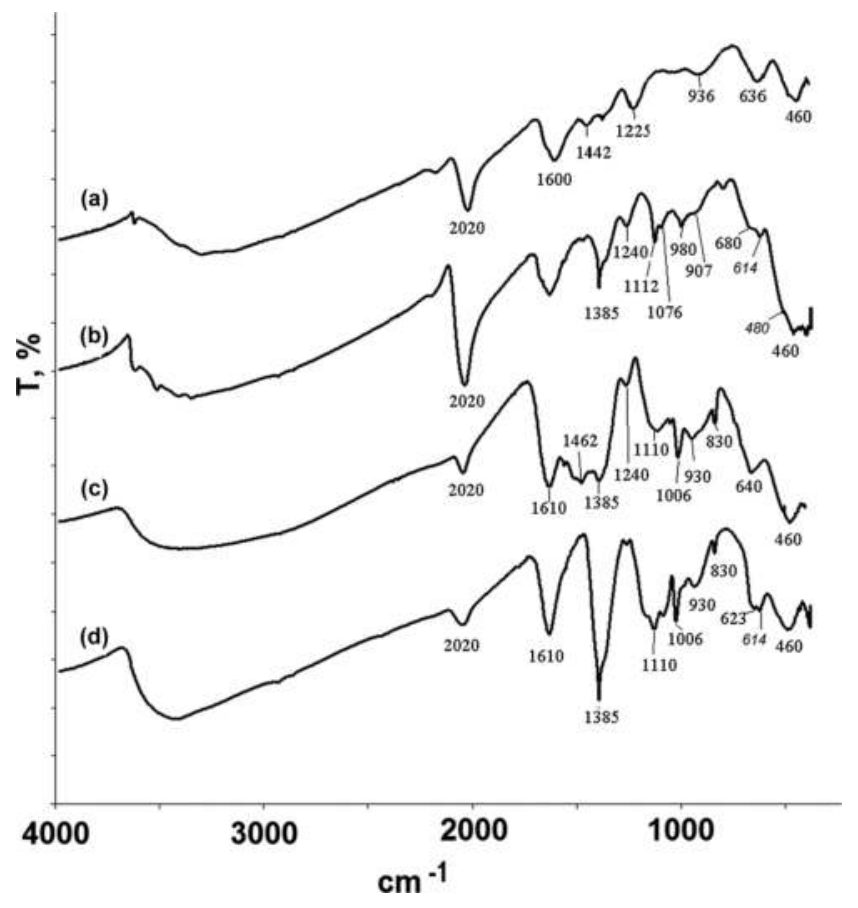

\section{FIGURE 1.46}

IR spectra of ZnS particles obtained during precipitation process from thiourea $(a, b)$ and sodium sulfide (c, d) with additions of manganese $1 \%(a, c)$ and $10 \%(b, d)$ (Sofronov et al. 2017). IR, infrared.

their appearance is a result of manganese sulfate application as a precursor of manganese. Absorption bands at 680, 614, and $480 \mathrm{~cm}^{-1}$ appeared in case of the samples with high manganese content and corresponded with the vibrations of $\mathrm{Mn}-\mathrm{O}$ bond. Presence of the absorption bands with peaks at 614 and $480 \mathrm{~cm}^{-1}$ is typical for the vibrations of $\mathrm{Mn}-\mathrm{O}$ bond in $\mathrm{Mn}_{3} \mathrm{O}_{4}$ (Baykal et al. 2007). Similar situation took place when the $\mathrm{ZnS}-\mathrm{MnS}$ system was precipitated with sodium sulfide. Initially, reddish powder was formed, but during drying process, it gradually became brownish. No difference was observed when the synthesis was performed in an inert atmosphere, and subsequently, the powder was dried in vacuum. The brownish color appeared anyway. In the IR spectra of the particles precipitated with sodium sulfide, the same absorption bands are seen as in case of samples obtained from thiourea solutions (Figure 1.46c and d).

In order to confirm $\mathrm{Mn}_{3} \mathrm{O}_{4}$ formation as a result of manganese application during $\mathrm{ZnS}$ synthesis, additional experiments were performed to observe manganese sulfate reaction with thiourea and sodium sulfide. In the IR spectra of the obtained particles shown in Figure 1.47, intensive 


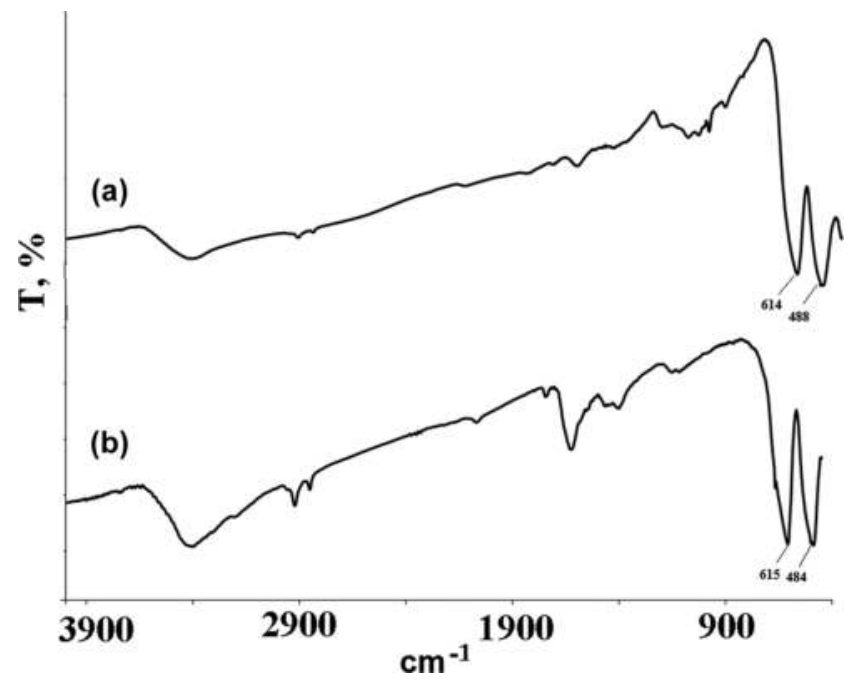

FIGURE 1.47

IR spectra of manganese oxide obtained during precipitation process with thiourea (a) and sodium sulfide (b) (Sofronov et al. 2017). IR, infrared.

absorption bands are seen at 488 and $614 \mathrm{~cm}^{-1}$. X-ray structure analysis provided information that the main phase of the synthesized powders was $\mathrm{Mn}_{3} \mathrm{O}_{4}$. It was formed as a result of manganese hydroxide and sulfide oxidation with the air oxygen during drying process. Thus, we were unable to obtain the manganese sulfide in the precipitation process from the aqueous solution.

When the copper or silver salts were applied as a dopant during zinc sulfide synthesis, respective sulfides were formed. On the other hand, when the europium or cerium salts were applied, the respective oxides appeared. In case of thermal precipitation of $\mathrm{ZnS}-\mathrm{CeO}_{2}$ particles, spherical agglomerated particles were formed. It was found that their dimensions were smaller with the increase of cerium dioxide content. Namely, dimensions of the particles were $0.7-1.1 \mu \mathrm{m}$ at $\mathrm{CeO}_{2}$ content $0.05 \%$ by mass and $100-200 \mathrm{~nm}$ at $\mathrm{CeO}_{2}$ content $5 \%$ by mass (Figure 1.48). MW activation at $100^{\circ} \mathrm{C}$ also caused decrease of the spherical agglomerates dimensions from 400 down to $100 \mathrm{~nm}$ along with increase of dioxide content (Figure 1.49). At higher temperature $150^{\circ} \mathrm{C}$ with MW activation, large spherical particles of $1-2 \mu \mathrm{m}$ diameters were formed along with small spherical particles below $0.5 \mu \mathrm{m}$ (Figure 1.50).

Particles formation process in the system $\mathrm{ZnS}-\mathrm{CeO}_{2}$ was similar to the one in the system $\mathrm{ZnS}-\mathrm{Eu}_{2} \mathrm{O}_{3}$. In case of both thermal and MW activations, increase of the additive concentration caused decrease of dimensions of spherical agglomerates from $1.2 \mu \mathrm{m}$ down to $100 \mathrm{~nm}$, as it is seen in 

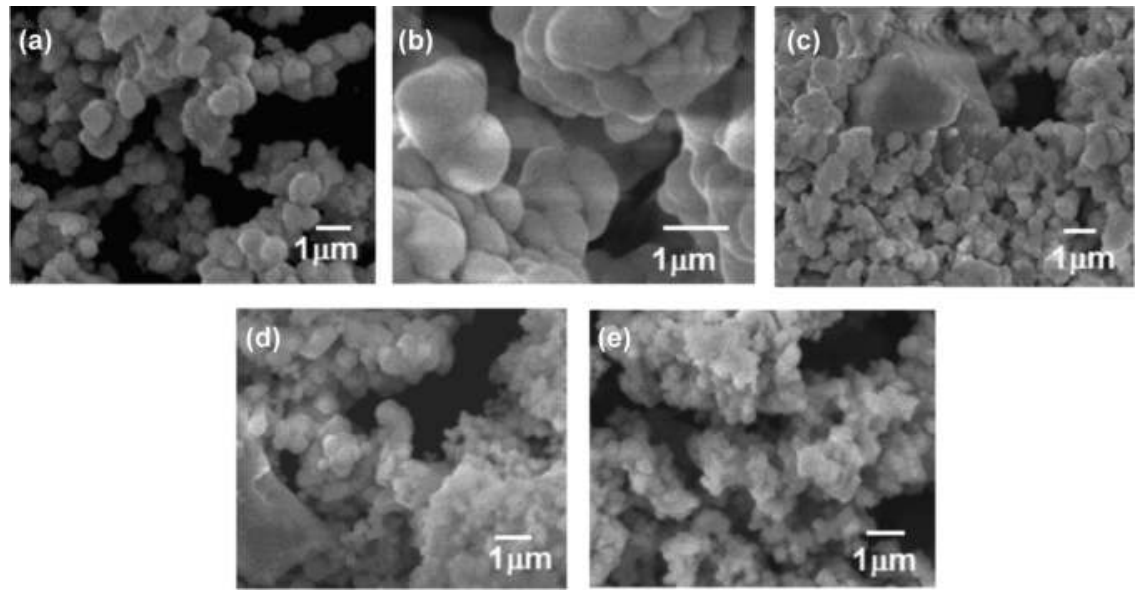

FIGURE 1.48

$\mathrm{ZnS}-\mathrm{CeO}_{2}$ particles obtained at thermal activation with different concentrations of additive cerium (\% by mass, recounted for $\mathrm{CeO}_{2}$ ): (a) 0.05 ; (b) 0.1 ; (c) 0.5 ; (d) 1 ; and (e) 5 .
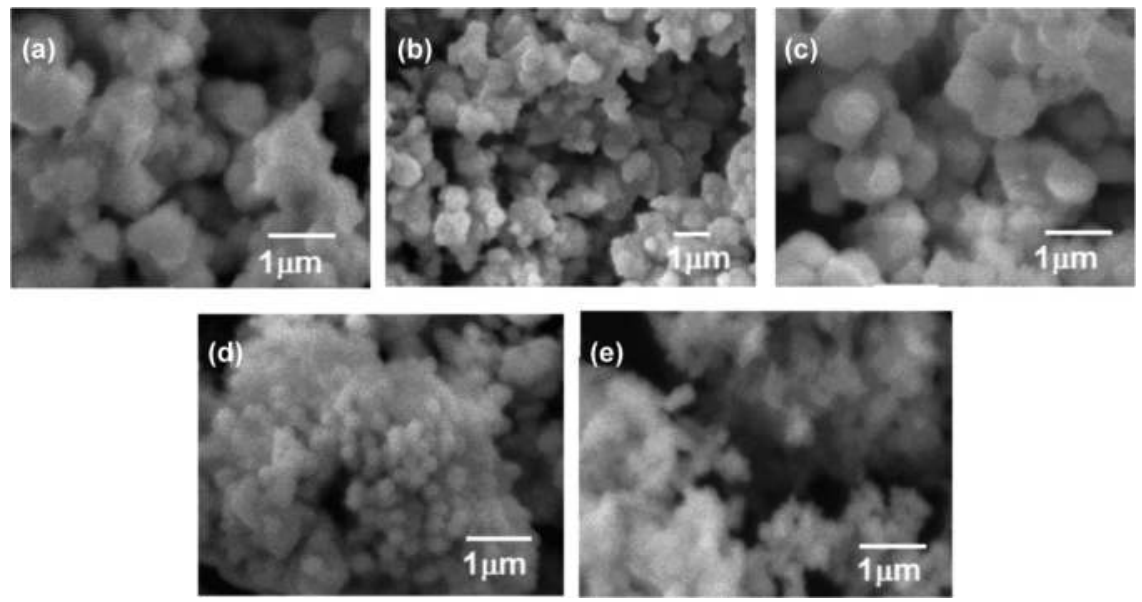

FIGURE 1.49

$\mathrm{ZnS}-\mathrm{CeO}_{2}$ particles obtained at microwave activation $\left(100^{\circ} \mathrm{C}\right)$ with different concentrations of additive cerium (\% by mass, recounted for $\mathrm{CeO}_{2}$ ): (a) 0.05 ; (b) 0.1 ; (c) 0.5 ; (d) 1 ; and (e) 5 .

Figures 1.51 and 1.52 . When the synthesis temperature was as high as $150^{\circ} \mathrm{C}$, large spherical particles were formed of dimensions 1-2 $\mu \mathrm{m}$ (Figure 1.53).

Thus, it was found that doping of the zinc sulfide with ions of copper, silver, and manganese had no effect on the particles formation when concentrations were below $1 \%$ by mass. However, doping with cerium and europium oxides caused decrease of the particles dimensions from $1 \mu \mathrm{m}$ down to $100 \mathrm{~nm}$ along with increase of the dopant concentrations. 

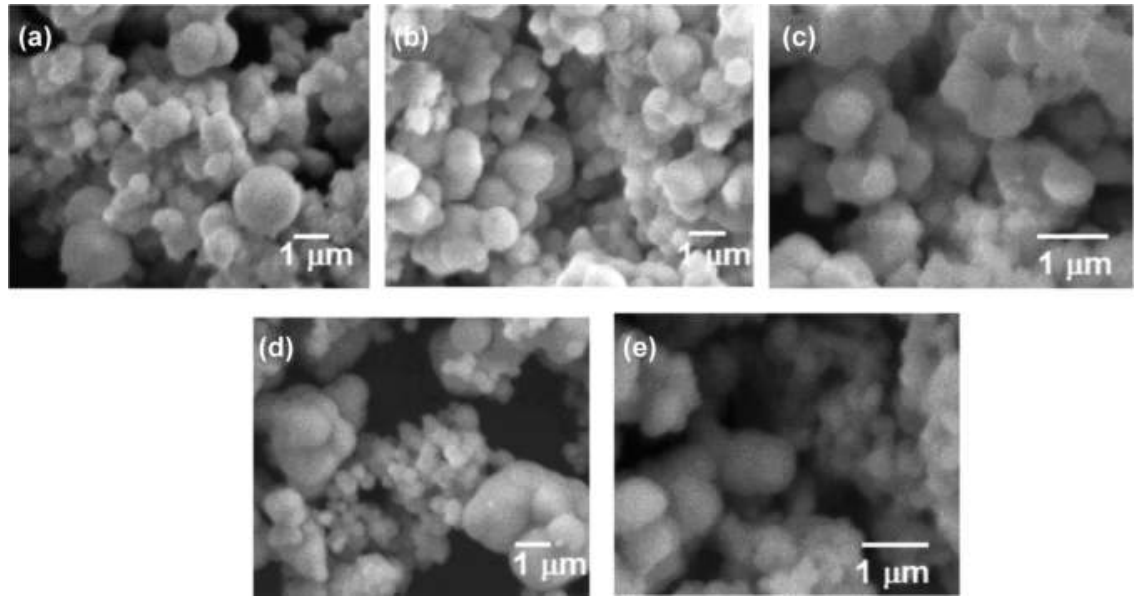

\section{FIGURE 1.50}

$\mathrm{ZnS}-\mathrm{CeO}_{2}$ particles obtained at microwave activation $\left(150^{\circ} \mathrm{C}\right)$ with different concentrations of additive cerium (\% by mass, recounted for $\mathrm{CeO}_{2}$ ): (a) 0.05 ; (b) 0.1 ; (c) 0.5 ; (d) 1 ; and (e) 5 .
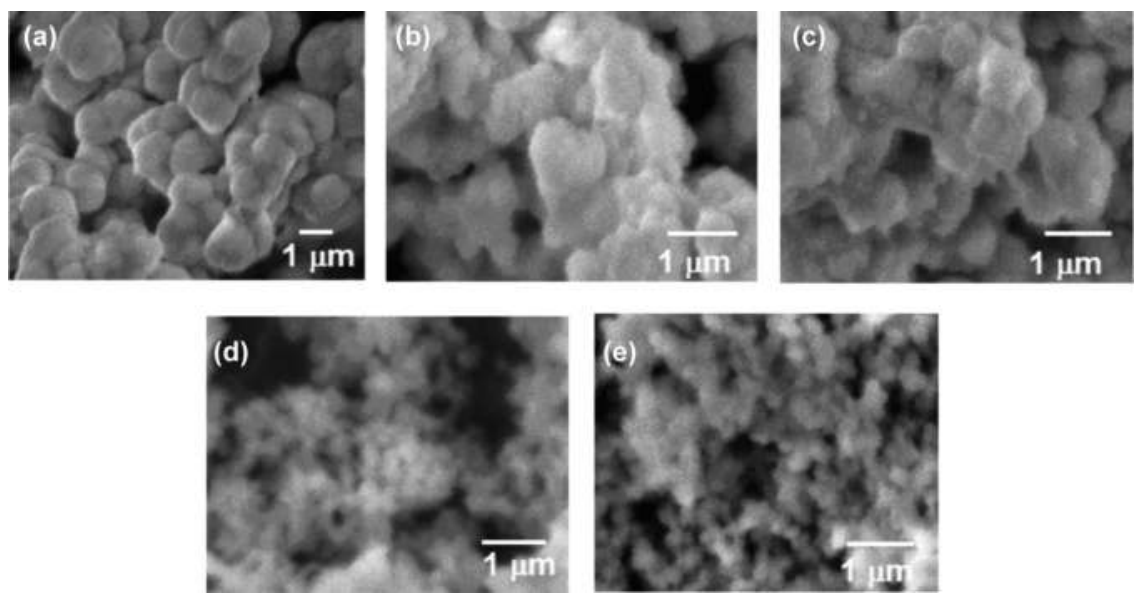

\section{FIGURE 1.51}

$\mathrm{ZnS}-\mathrm{Eu}_{2} \mathrm{O}_{3}$ particles obtained at thermal activation with different concentrations of additive europium (\% by mass, recounted for $\mathrm{Eu}_{2} \mathrm{O}_{3}$ ): (a) 0.05 ; (b) 0.1 ; (c) 0.5 ; (d) 1 ; and (e) 5 . 

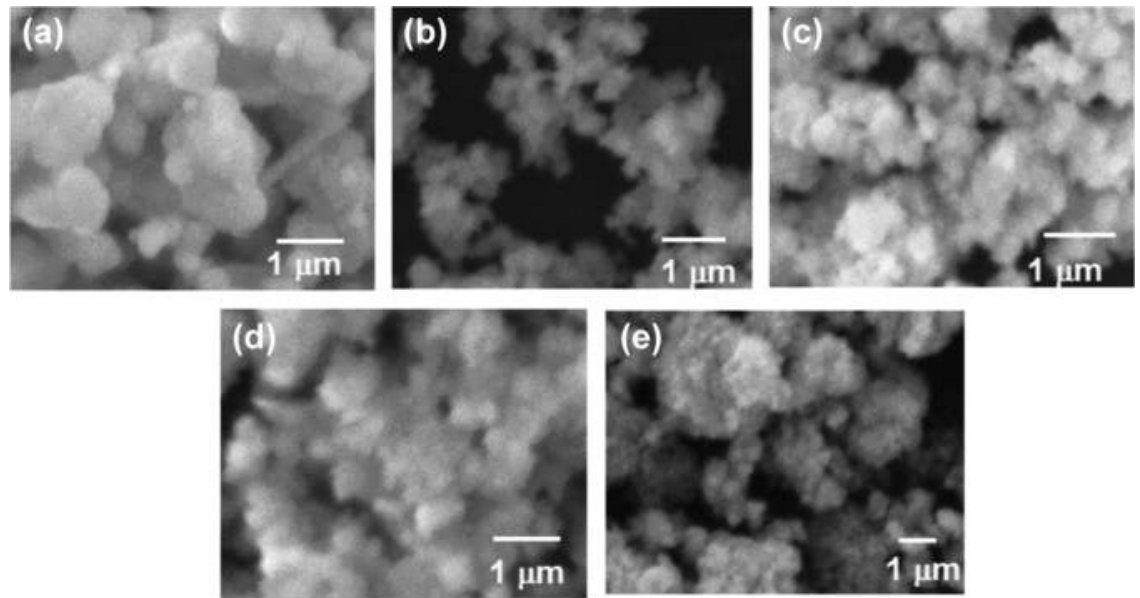

\section{FIGURE 1.52}

$\mathrm{ZnS}-\mathrm{Eu}_{2} \mathrm{O}_{3}$ particles obtained at microwave activation $\left(100^{\circ} \mathrm{C}\right)$ with different concentrations of additive europium (\% by mass, recounted for $\mathrm{Eu}_{2} \mathrm{O}_{3}$ ): (a) 0.05 ; (b) 0.1 ; (c) 0.5 ; (d) 1 ; and (e) 5 .
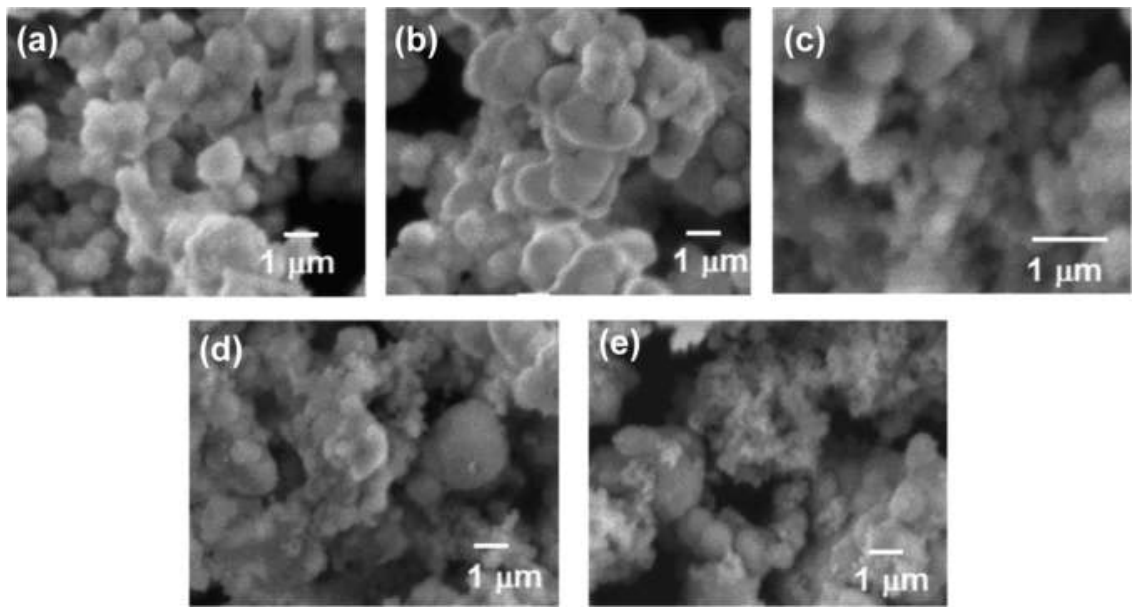

\section{FIGURE 1.53}

Images of $\mathrm{ZnS}-\mathrm{Eu}_{2} \mathrm{O}_{3}$ particles obtained at microwave activation $\left(150^{\circ} \mathrm{C}\right)$ with different concentrations of additive europium (\% by mass, recounted for $\mathrm{Eu}_{2} \mathrm{O}_{3}$ ): (a) 0.05 ; (b) 0.1 ; (c) 0.5 ; (d) 1 ; and (e) 5 . 


\subsection{Iron Sulfide FeS Formation}

In general, methodology of iron salts precipitation with thiourea or sodium sulfide does not succeed in production of iron sulfide nanoparticles. During the drying process, collateral oxidation processes lead to the formation of different phases of iron oxides such as hematite $\mathrm{Fe}_{2} \mathrm{O}_{3}$ and FeOOH. Hence, in order to obtain iron sulfide particles, the solid-phase interaction of iron and sulfur in vacuum quartz ampoule was performed. The temperature of the process was $700^{\circ} \mathrm{C}$, and duration was 8 hours. X-ray fluorescence analysis proved that the iron sulfide was obtained (Figure 1.54). No absorption bands are seen in the IR spectrum shown in Figure 1.55, which indicates high purity of the synthesized product (Figure 1.56).

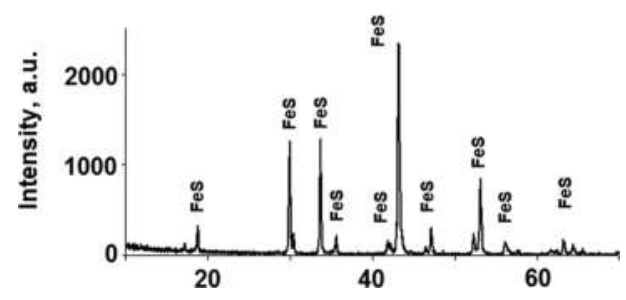

FIGURE 1.54

$\mathrm{XRF}$ diagram of the iron sulfide obtained at $700^{\circ} \mathrm{C}$ solid-phase interaction of iron and sulfur. $\mathrm{XRF}$, X-ray fluorescence.

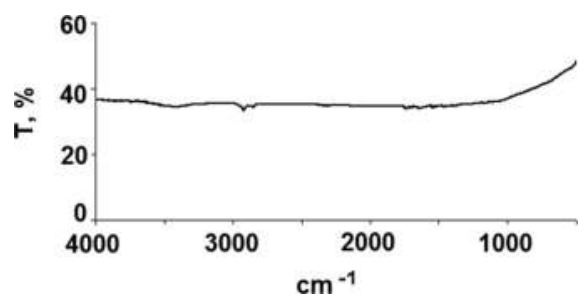

FIGURE 1.55

IR spectrum of the iron sulfide obtained from Fe and S interaction at $700^{\circ} \mathrm{C}$. IR, infrared.

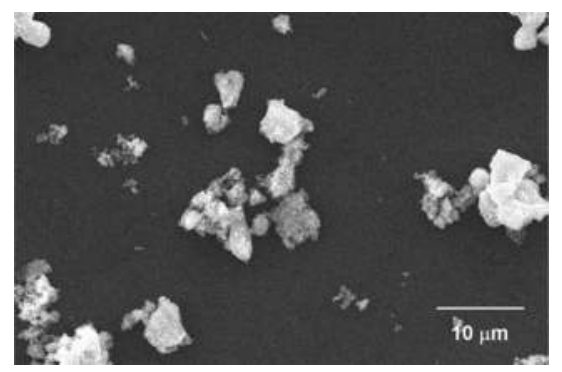




\subsection{Sorption Properties of the Metal Sulfides}

Sorption is used as one of the technologies for capturing/storing/immobilizing various pollutants and nuclear wastes. Among many materials with different chemical, physical, and structural properties applicable for this purpose (Vellingiri et al. 2018), metal sulfides can be considered.

It was proposed for silver removal to apply copper, cadmium, and nickel sulfides (Cheraneva et al. 2009). The authors demonstrated that in case of applications for dissolution of silver, sorption capacity of sulfides depends not only on the anion compounds but also on the type of salt used for the sulfide synthesis. It was found that the smallest impact on the sorption has nitrate ions. Namely, when the copper, cadmium, and nickel sulfides were extracted out of nitrate solutions and were applied for the silver removal from nitrate solutions, they performed maximal sorption capacity of 437, 365, and $255 \mathrm{mg} / \mathrm{g}$, respectively. However, when those sulfides were applied to remove the silver from solutions $\mathrm{AgI}_{4}{ }^{3-}$ or $\mathrm{Ag}(\mathrm{CNS})_{2}{ }^{-}$, their capacity reduced dramatically down to $10-30 \mathrm{mg} / \mathrm{g}$.

Barzyk et al. (2002) reported application of the copper sulfide for gold and silver removal. The sorption process here was equivalent to deposition of 50 uniform atomic layers of the metal on the surface of a copper sulfide particle. After sorption, on the copper sulfide surface, some mixed copper and silver sulfides were traced, as well as gold sulfide and crystalline gold. It was noted that the chloride ions have negative impact on the gold extraction process.

Mackinawite's (FeS) ability to adsorp of divalent metals was reported decades ago (Morse and Arakaki 1993). Nanoparticulate mackinawite can be an important host phase for highly effective trapping of mercury (Jeong et al. 2007; Liu et al. 2008; Xiong et al. 2009), lead, and cadmium (Coles et al. 2000). Moreover, iron sulfide is able to capture the ions of arsenic (Niazi and Burton 2016), chromium (Mullet et al. 2004), copper (Watson et al. 2000), nickel (Wilkin and Beak 2017), and zinc (Hamilton-Taylor et al. 1996). Degree of the mercury ions extraction with $\mathrm{FeS}$ can reach as high level as $99 \%$ at $\mathrm{pH}$ 5.6 (Liu et al. 2008). It can be attributed to the oxidation process of the iron sulfide particles in the water solution, with subsequent formation of $\mathrm{FeOOH}$, according to the following reaction:

$$
\mathrm{FeS}+\mathrm{H}_{2} \mathrm{O}+\mathrm{O}_{2} \rightarrow \mathrm{FeOOH}+\mathrm{S}^{0},
$$

where the sulfur oxidizes into sulfate ions. 24 hours of aeration leads to the full oxidation of iron sulfide, and then mercury ions adsorption takes place on the surface of $\mathrm{FeOOH}$, which is a good sorbent for $\mathrm{Hg}$. However, sorption capacity of FeS particles for europium is small, ca. $3 \mathrm{mg} / \mathrm{g}$ (Allan et al. 2015).

Wershin et al. (1994) examined uranyl cation $\left[\mathrm{UO}_{2}\right]^{2+}$ sorption on pyrite $\left(\mathrm{FeS}_{2}\right)$. The process is dependent on $\mathrm{pH}$ and reaches its highest effectiveness above $98 \%$ in the $\mathrm{pH}$ range between 4.8 and 5.5 . 
Perhaps, there is a difference between sorption mechanisms of oxides and hydroxides of metals. For example, it was reported that chromate anion $\mathrm{CrO}_{4}{ }^{2-}$ sorption degree on lead sulfide increases with higher $\mathrm{pH}$ values, whereas on hematite $\left(\alpha-\mathrm{Fe}_{2} \mathrm{O}_{3}\right)$, it decreases (Musić, 1985). It was reported also that at higher $\mathrm{pH}$, the extraction degree of $\mathrm{As}(\mathrm{III})$ ions with iron sulfides FeS and $\mathrm{FeS}_{2}$ increases. In that case, sorption process is performed according to the following reactions (Bostick and Fendorf 2003):

$$
\begin{gathered}
3 \mathrm{FeS}+\mathrm{As}(\mathrm{OH})_{3}=\mathrm{FeS}_{2}+\mathrm{FeAsS}+\mathrm{Fe}(\mathrm{OH})_{3} \\
7 \mathrm{FeS}_{2}+2 \mathrm{As}(\mathrm{OH})_{3}=3 \mathrm{FeS}_{4}+2 \mathrm{FeAsS}+2 \mathrm{Fe}(\mathrm{OH})_{3} .
\end{gathered}
$$

Balsley et al. (1996) did not oppose the hypothesis of similar sorption mechanism on metal sulfides and hydroxides.

For several decades, sorption properties of the metal sulfides are investigated by numerous scholars and teams who pointed out high perspectives of their application (Gong et al. 2016). However, many details concerning stability of the sulfide particles, extraction efficiency, and sorption capacity for heavy metal ions remain still not explored enough (Fu and Wang 2011). In this chapter, the analysis was aimed above all at the sorption properties, such as extraction efficiency and sorption capacity, for metal ions that have radioactive isotopes (such as cobalt, europium, and cerium). The main goal was to describe and evaluate variations of properties in the range of sulfides $\mathrm{FeS} \rightarrow \mathrm{ZnS} \rightarrow \mathrm{CdS} \rightarrow \mathrm{CuS}$, where solubility equilibrium is rising.

\subsection{1 pH Impact on the Metal Sulfides Extraction Efficiency and Particles Stability}

In the initial stage of the research, the question of the particles stability dependent on $\mathrm{pH}$ value was challenged. 1.57 presents the experimental results of metal concentration in solutions after 40 minutes of sorbent treatment. Respective curves correspond with (1) zinc, (2) copper, and (3) iron concentration.

It is clearly seen that at $\mathrm{pH}$ below 5, sulfides of zinc, copper, and iron start to dissolve, while at $\mathrm{pH}$ higher than 5.5, they are rather stable. Hence, the investigated sulfides can be successfully applied for removal of metals out of water solutions at $\mathrm{pH}$ above 5 .

Figures 1.58-1.61 present graphs of the metal ions extraction efficiency $E \%$ with the particles of zinc, cadmium, copper, and iron sulfides. The metal sulfides perform their best removal efficiency for europium, cerium, copper, and iron, which reached $100 \%$ in the $\mathrm{pH}$ range between 5 and 9 . When the environment was more acidic, efficiency dropped down, which can be attributed to the dissolution of the sulfides presented in Figure 1.57.

As it is seen from Figures 1.58-1.61, efficiency of zinc, cobalt, manganese, and strontium removal $E \%$ increased for higher $\mathrm{pH}$ values of the solutions. The highest efficiency was reached for copper sulfide, whereas the lowest 


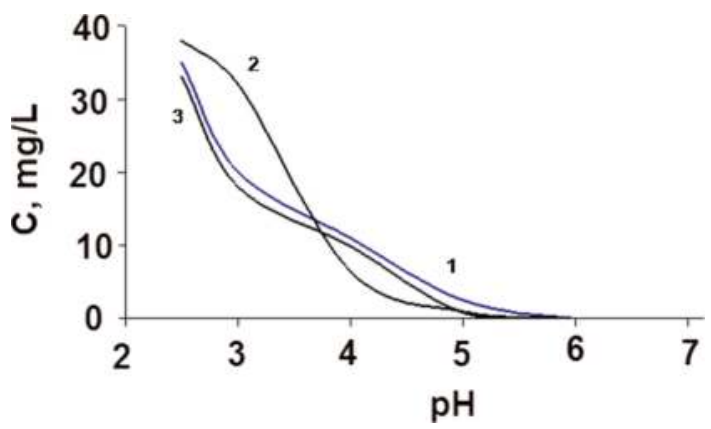

FIGURE 1.57

Graphs of zinc (1), copper (2), and iron (3) concentration in the solutions of different pH.
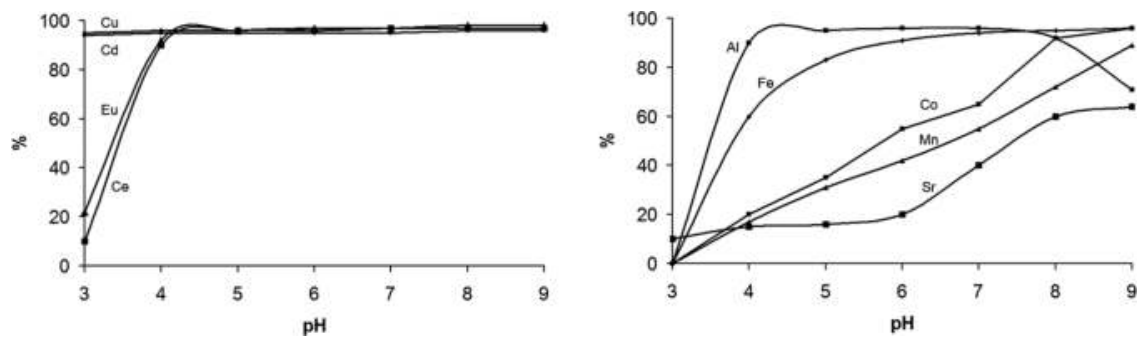

FIGURE 1.58

Removal of various metals with $\mathrm{ZnS}$ at different $\mathrm{pH}$.
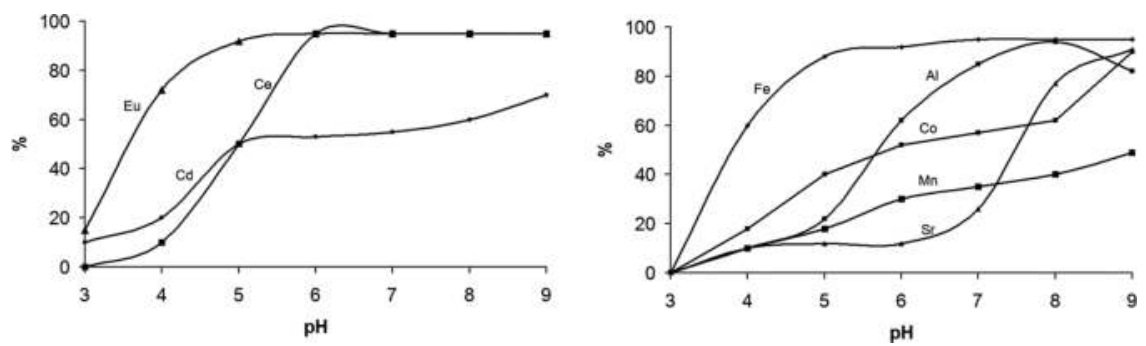

FIGURE 1.59

Removal of various metals with CuS at different $\mathrm{pH}$.

ones for iron sulfide. In particular, the extraction percentage of the copper sulfide for strontium, zinc, cobalt, and manganese at $\mathrm{pH} 9$ reached its maximal value $E \%_{\max }=45 \%, 97 \%, 98 \%$, and $80 \%$, respectively. In case of the iron sulfide, the extraction efficiency for strontium, zinc, and cobalt at $\mathrm{pH}$ reached $35 \%, 92 \%$, and $70 \%$, respectively. 

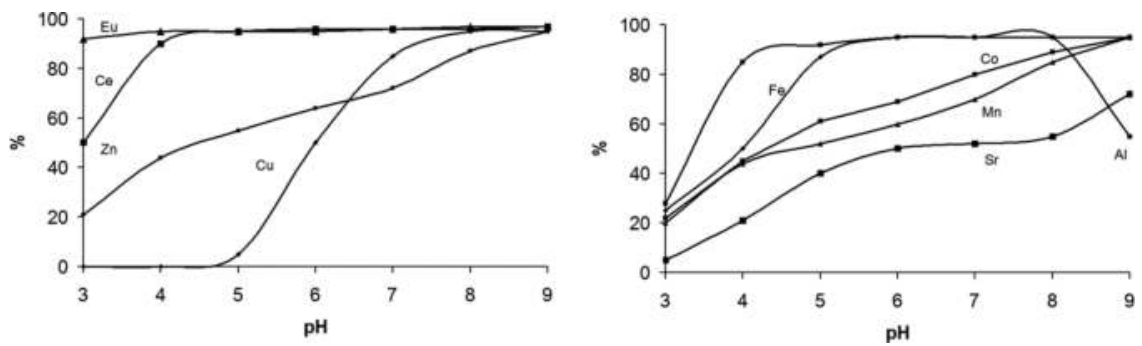

FIGURE 1.60

Removal of various metals with CdS at different $\mathrm{pH}$.
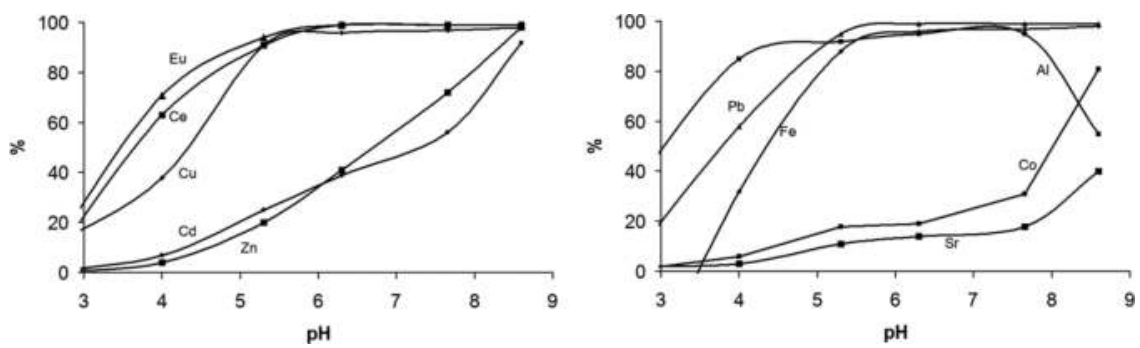

FIGURE 1.61

Removal of various metals with $\mathrm{FeS}$ at different $\mathrm{pH}$.

\subsubsection{Impact of Specific Surface on the Sorption Capacity of Particles}

In order to examine the impact of SSA on the sorption capacity of particles zinc, cadmium, and copper(II) sulfides, two samples of each were chosen. Table 1.2 describes these samples in detail including conditions of their synthesis from thiourea solutions. For the investigations, the ions Eu(III), Ce(III), $\mathrm{Co}(\mathrm{II})$, and $\mathrm{Sr}(\mathrm{II})$ were proposed because they have radioactive isotopes that are dangerous for the environment and humans.

\section{TABLE 1.2}

Synthesis Conditions and Specific Surface of the Zinc, Copper(II), and Cadmium Sulfide Particles Chosen for Experiments

\begin{tabular}{lcccc}
\hline & \multicolumn{2}{c}{ Synthesis Conditions } & Specific Surface \\
Sorbent & Activation Method & $c(\mathbf{M e}+\mathbf{m}): \boldsymbol{c}(\mathbf{T M})$ & $\mathbf{p H}$ & \\
\cline { 2 - 4 } ZnS-1 & Thermal & $1: 1$ & 10 & 1.3 \\
ZnS-2 & Microwave & $1: 4$ & 12 & 30 \\
CdS-1 & Thermal & $1: 1$ & 8 & 4.2 \\
CdS-2 & Thermal & $1: 1$ & 8 & 8.5 \\
CuS-1 & Thermal & $1: 1$ & 8 & 4.5 \\
CuS-2 & Thermal & $1: 4$ & 12 & 12 \\
\hline
\end{tabular}


The most widely used isotherm equation for modeling equilibrium data is the Langmuir model. The isotherm is valid for monolayer adsorption onto a surface containing a finite number of identical sites. It can be described by the linearized form (Zou et al. 2006):

$$
C_{e} / q_{e}=1 /\left(K_{L} q_{\max }\right)+C_{e} / q_{\max }
$$

where $q_{\max }(\mathrm{mmol} / \mathrm{g})$ is the maximum amount of metal ion per unit weight of manganese oxide-coated zeolite (MOCZ), $K_{L}(\mathrm{~L} / \mathrm{mmol})$ is the equilibrium adsorption constant, $C_{e}$ is the equilibrium metal ion concentration in $\mathrm{mmol} / \mathrm{L}$, and $q_{e}$ is the adsorption equilibrium metal ion uptake capacity in $\mathrm{mmol} / \mathrm{g}$. By plotting $C_{e} / q_{e}$ versus $C_{e}, q_{\max }$ and $K_{L}$ can be determined.

Figures 1.62-1.64 present sorption isotherms of metal on the zinc, copper, and cadmium sulfides, and the results of their processing are shown in Table 1.3. It should be noted that all the obtained isotherms can be classified as L-type, which is typical for microporous solid bodies with relatively small proportion of the outer surface. The investigated materials performed relatively low sorption capacity $(10-20 \mathrm{mg} / \mathrm{g})$, which increases together with the increase of particle SSA. Particles of iron sulfide (obtained with thermal method) for cobalt performed very little sorption capacity ( $4.5 \mathrm{mg} / \mathrm{g}$ ). Its sorption isotherm is shown in Figure 1.65.

Thus, it was found that the metal sulfides perform rather small values of sorption capacity, which depend on the SSA of particles.
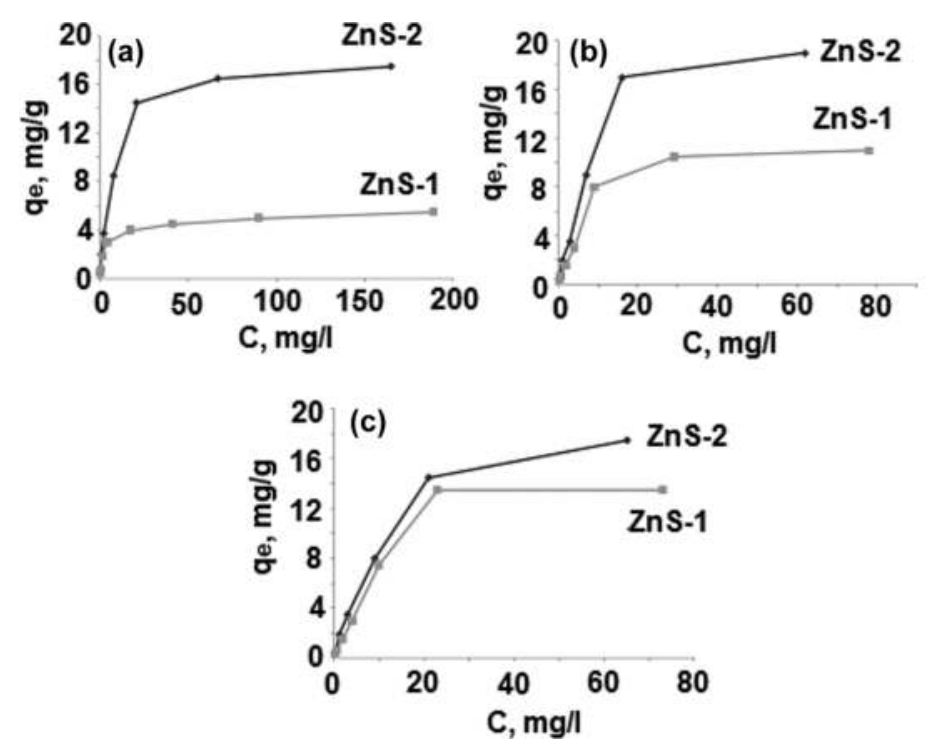

FIGURE 1.62

Sorption isotherms of Co (a), Eu (b), and Ce (c) on the ZnS particles. 

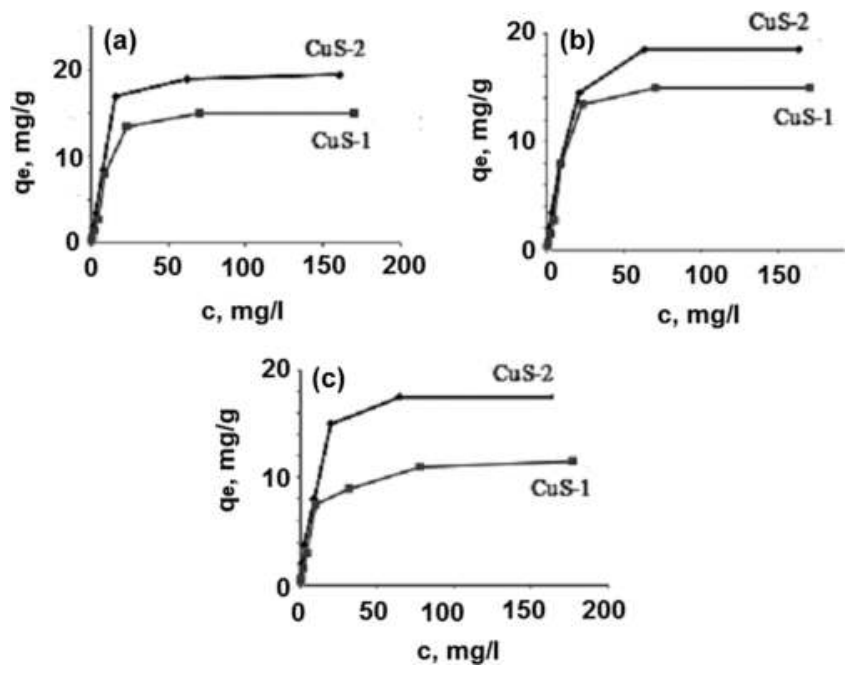

FIGURE 1.63

Sorption isotherms of Co (a), Eu (b), and Ce (c) on the CuS particles.

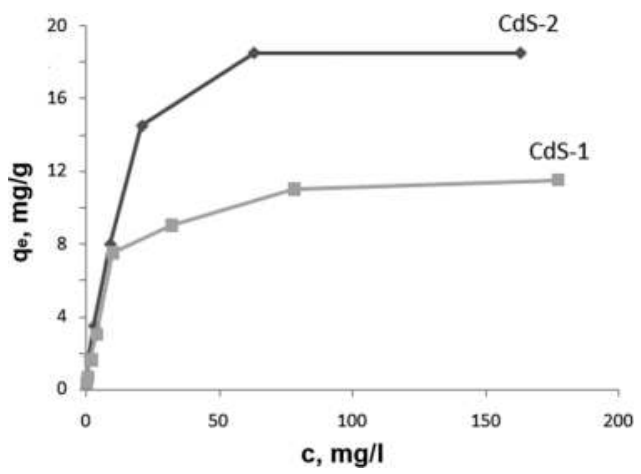

FIGURE 1.64

Sorption isotherms of Co(II) on the CdS particles.

\subsubsection{Sorption Properties of Zinc Sulfide Particles Doped with Copper, Manganese, and Cerium}

It is widely known that the sorption properties of particles may be improved with small additions of some substances with high sorbent characteristics. Thus, copper sulfide has much higher sorption capacity for many metals than zinc sulfide has. It is also known that manganese oxides perform high sorption properties (Con et al. 2013; Murray 1975) and added to various materials increases their sorption ability. In particular, it was reported that $\mathrm{MnO}_{2}$ loaded D301 resin was able to remove nearly $100 \%$ of cadmium in the range 


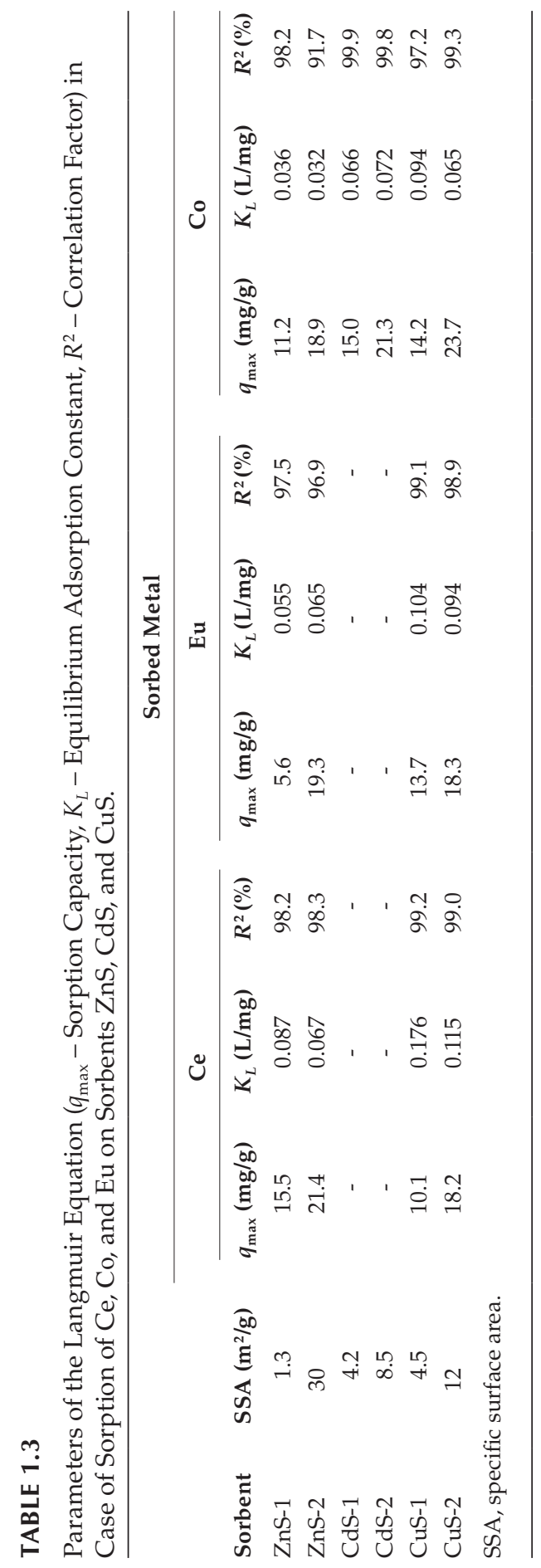




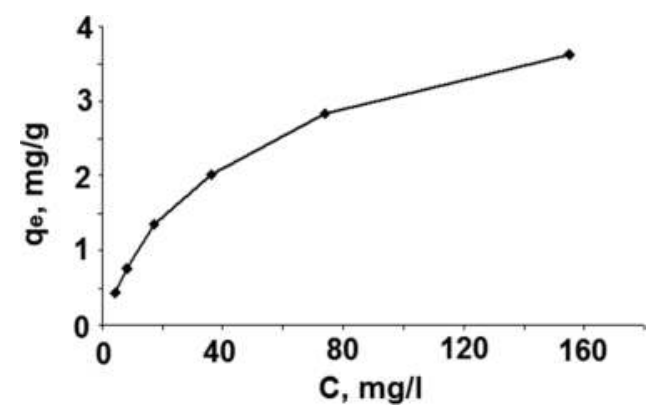

FIGURE 1.65

Sorption isotherm of cobalt on the iron sulfide.

between $\mathrm{pH} 3$ and $\mathrm{pH} 8$ performing sorption capacity for $\mathrm{Cd}^{2+}$ ca. $78 \mathrm{mg} / \mathrm{g}$ (Zhu et al. 2007).

Another interesting area of investigations is application of manganese oxide-coated zeolite (MOCZ) for the uranium (Han et al. 2007), copper, and lead ions removal (Zou et al. 2006). Sorption isotherms of MOCZ and pH effect on the process were discussed by Han et al. (2007). The authors reported that the equilibrium metal uptake capacity $q_{e}$ of uranium(VI) was found to be 15.1 $\mathrm{mg} / \mathrm{g}$ at $293 \mathrm{~K}$ and $\mathrm{pH}$ 4.0. They calculated it from the formula:

$$
q_{e}=v\left(C_{0}-C_{e}\right) / m
$$

where $q_{e}$ is the amount of uranium absorbed onto per unit mass of MOCZ at equilibrium in $\mathrm{mg} / \mathrm{g}, v$ is the sample volume in milliliters, $C_{0}$ is the initial metal ion concentration in $\mathrm{mg} / \mathrm{L}, C_{e}$ is the equilibrium metal ion concentration in $\mathrm{mg} / \mathrm{L}$, and $m$ is the weight of MOCZ in grams.

Interesting result was obtained when the removal capacity of MOCZ was compared with that of raw zeolite. The maximum adsorption capacities for zeolite and MOCZ were found to be $0.061 \mathrm{mmol} / \mathrm{g}$ zeolite and $0.108 \mathrm{mmol} / \mathrm{g}$ MOCZ for $\mathrm{Cu}(\mathrm{II})$, respectively. Adsorption capacities for $\mathrm{Pb}$ (II) were 0.134 $\mathrm{mmol} / \mathrm{g}$ zeolite and $0.243 \mathrm{mmol} / \mathrm{g} \mathrm{MOCZ}$, respectively. The results indicated that after introduction of manganese oxide, adsorption capacity of zeolite is almost twice larger than that of raw zeolite for the removal of $\mathrm{Cu}(\mathrm{II})$ and $\mathrm{Pb}(\mathrm{II})$.

Taffarel and Rubio (2010) investigated MOCZ and its ability in removing $\mathrm{Mn}^{2+}$ by adsorption. At $\mathrm{pH}$ 6, the attained $\mathrm{Mn}^{2+}$ uptake was as high as $1.1 \mathrm{meq}$ $\mathrm{Mn}^{2+} \mathrm{g}^{-1}$ at equilibrium. Nouh et al. (2015) reported $62 \%$ efficiency on the iron adsorption by MOCZ in all studied $\mathrm{pH}$ range (0.3-3), and they noted precipitate formed above $\mathrm{pH} 3$, so the efficiency of iron adsorption could not be detected. In three runs, the removal of $93 \%$ of the iron content was reached. They reported also that the uranium(VI) stripping efficiency was increased by increasing the aqueous to organic phase ratio to reach $93 \%$ at Aq./Org. ratio of 2:1 and reaching maximum (97\%) at Aq./Org. ratio of 4:1. Authors calculated the extraction percentage of uranium (VI) from the equation: 


$$
E \%=\frac{100 D_{u}}{D_{u}+V_{\text {aq }} / V_{\text {org }}},
$$

where distribution coefficient $D_{u}$ was calculated as follows:

$$
D_{u}=\frac{C(\text { org phase })}{C(\text { aq phase })} \times \frac{V(\text { org phase })}{V(\text { aq phase })},
$$

where $C$ is the concentration of uranium(VI) and $V$ is the volume.

Chen et al. (2018) applied nanostructured Ce-Mn binary oxide with a $\mathrm{Ce} / \mathrm{Mn}$ molar ratio of 3:1 to remove arsenite As(III) from water. They obtained maximal sorption capacity of As(III) as high as $97.7 \mathrm{mg} / \mathrm{g}$. The sorbent had an SSA of $157 \mathrm{~m}^{2} / \mathrm{g}$ with a pore volume of $0.28 \mathrm{~cm}^{3} / \mathrm{g}$ and a pore size of $7.5 \mathrm{~nm}$, which was higher than that of the pure ceria nanoparticles $\left(86.85 \mathrm{~m}^{2} / \mathrm{g}\right)$ and ceria-incorporated manganese oxide $\left(116.96 \mathrm{~m}^{2} / \mathrm{g}\right)$.

Based on these reports and experience, particles of zinc sulfide with additions of copper, manganese, and cerium were analyzed to evaluate their sorption capacity for cobalt.

Figure 1.66 presents ion sorption isoterms on the zinc sulfide particles with additions of copper(II) sulfide in proportions $1 \%$ and $10 \%$. The graphs can be classified as an L-sort, typical for the solid bodies with micropores, where ratio of outer surface is relatively low. They can be described with the Langmuir model for the cobalt ions adsorption. Obtained values of $q_{\text {max }}$ equilibrium adsorption constant $K_{L}$, and correlation ratio $R^{2}$ are shown in Table 1.4.

It was found that sorption capacity of the zinc sulfide is almost independent on the amount of added copper(II) sulfide in the range $1 \%-10 \%$ by mass. However, it differs substantially from the sorption capacity of the pure zinc

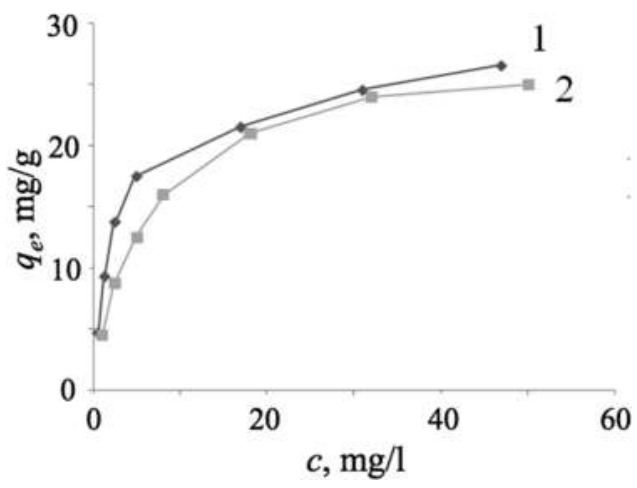

FIGURE 1.66

Sorption isotherm of $\mathrm{Co}$ (II) on the iron sulfide with additions of copper sulfide $1 \%$ (data 1 ) and $10 \%$ (data 2). 


\section{TABLE 1.4}

Maximal Sorption $q_{\max }$, Equilibrium Adsorption Constant $K_{L}$, and Correlation Ratio $R^{2}$ for Ions $\mathrm{Co}^{2+}$ Sorption on the Zinc Sulfide with Different Amounts of Copper Sulfide Added

\begin{tabular}{lccc}
\hline Content of CuS (\%) & $q_{\max }(\mathrm{mg} / \mathrm{g})$ & $\boldsymbol{K}_{L}(\mathrm{~L} / \mathbf{m g})$ & $\boldsymbol{R}^{\mathbf{2}}(\mathbf{\%})$ \\
1 & 26.1 & 430 & 99.9 \\
10 & 27.1 & 181 & 99.8 \\
\hline
\end{tabular}

sulfide which was ca. $19 \mathrm{mg} / \mathrm{g}$ for cobalt. Dimensions of the spherical ZnS particles with additions of $1 \%$ and $10 \%$ CuS were below $100 \mathrm{~nm}$.

In order to examine the effect of manganese presence on the sorption capacity of $\mathrm{ZnS}$ particles for cobalt, the zinc sulfide particles doped with manganese $1 \%$ (calculated for $\mathrm{Mn}_{3} \mathrm{O}_{4}$ ) through precipitation from thiourea solution as well as precipitation with sodium sulfide. In the first case, spherical particles of diameter $0.4-0.7 \mu \mathrm{m}$ were obtained, while in the last case, their dimensions were below $100 \mathrm{~nm}$. Photomicrographs of the respective particles are shown in Figure 1.67, and cobalt sorption isotherms in Figure 1.68.

When the isothermal data were processed according to the Langmuir model, it was found that sorption capacity for cobalt was $11.2 \mathrm{mg} / \mathrm{g}$ in case of particles precipitated with sodium sulfide (dimensions below $100 \mathrm{~nm}$ ), whereas it was ca. $2 \mathrm{mg} / \mathrm{g}$ in case of larger particles $0.4-0.7 \mu \mathrm{m}$ obtained from thiourea solution. Hence, introduction of manganese did not improve the sorption capacity of zinc sulfide.

To examine the systems of $\mathrm{ZnS}-\mathrm{CeO}_{2}$, the particles obtained from thiourea solution at different conditions were used. The respective information on those particles is presented in Table 1.5, whereas sorption isotherms of cobalt are shown in Figure 1.69. It is seen that the particles $\mathrm{ZnS}-\mathrm{CeO}_{2}$ perform lower sorption capacity for cobalt compared with that of the pure zinc sulfide.
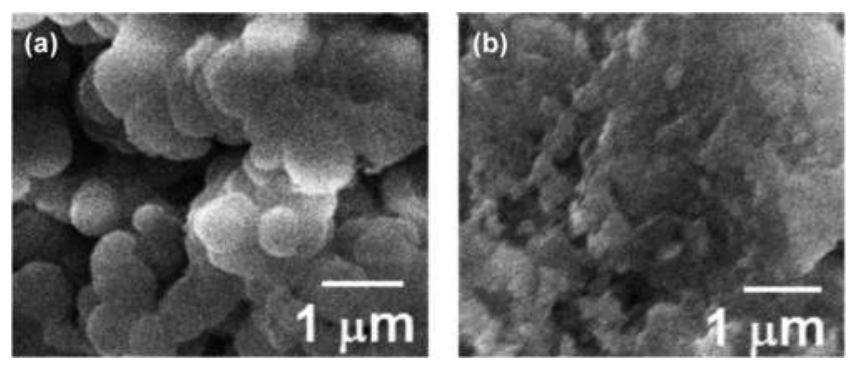

\section{FIGURE 1.67}

Photomicrographs of the particles obtained by (a) precipitation from thiourea solution and (b) precipitation with sodium sulfide. 


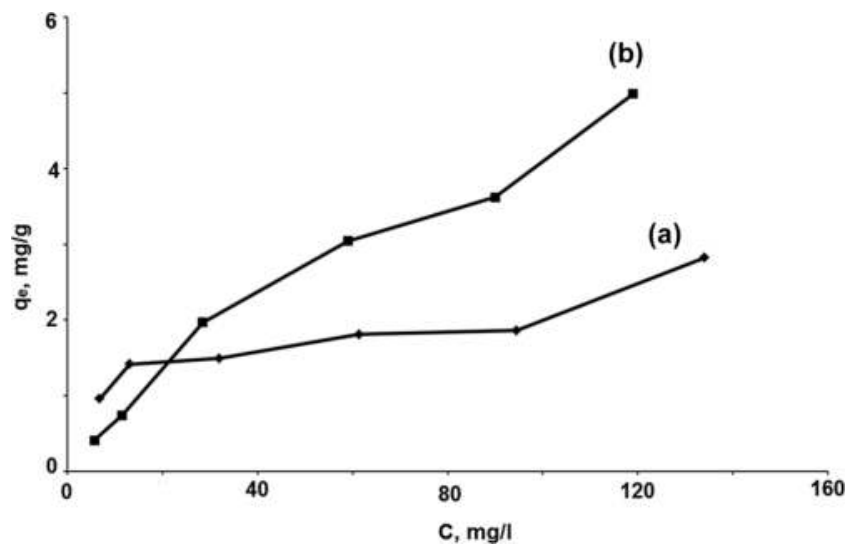

FIGURE 1.68

Sorption isotherms of $\mathrm{Co}(\mathrm{II})$ on the zinc sulfide obtained by (a) precipitation from thiourea solution and (b) precipitation with sodium sulfide.

\section{TABLE 1.5}

Synthesis Conditions and Sorption Capacity of the System $\mathrm{ZnS}-\mathrm{CeO}_{2}$

\begin{tabular}{lccc}
\hline Sample & Activation Method & Average Particle Dimension $(\boldsymbol{\mu m})$ & $\mathbf{S S A}\left(\mathbf{m}^{2} / \mathbf{g}\right)$ \\
$\mathrm{ZnS}\left(0.05 \mathrm{mass} \% \mathrm{CeO}_{2}\right)$ & Thermal & 220 & 11.5 \\
$\mathrm{ZnS}\left(0.5 \mathrm{mass}_{\mathrm{C}} \mathrm{CeO}_{2}\right)$ & Thermal & 120 & 12.0 \\
$\mathrm{ZnS}\left(0.5 \mathrm{mass} \% \mathrm{CeO}_{2}\right)$ & Microwave & 80 & 30 \\
& & & \\
\hline
\end{tabular}

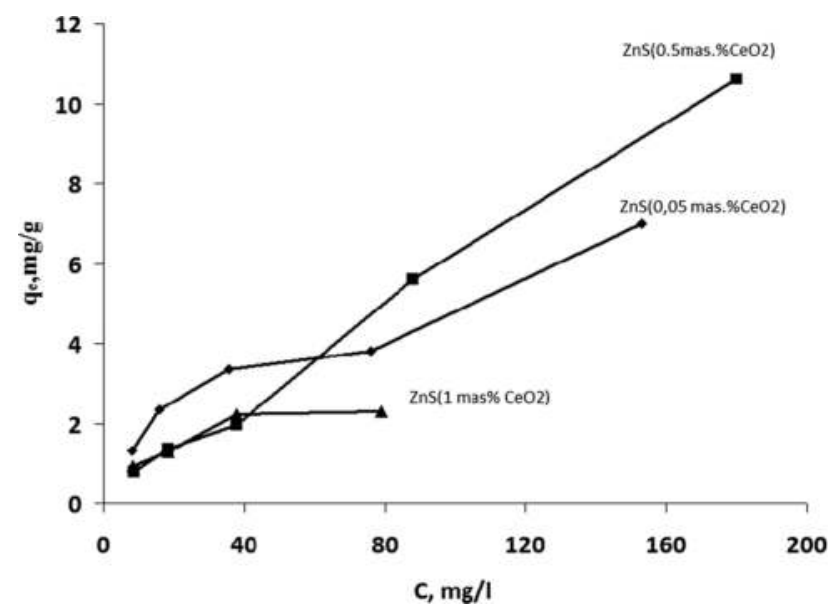

FIGURE 1.69

Sorption isotherms of $\mathrm{Co}(\mathrm{II})$ on the particles $\mathrm{ZnS}-\mathrm{CeO}_{2}$. 


\subsection{Conclusions on the Sorption Efficiency of Metal Sulfides}

Series of experiments were dedicated to the sorption capacity $q_{e}$ and extraction percentage $E \%$ of metal sulfides applied for the removal of radionuclides potentially dangerous for environment. The effect of synthesis conditions on the formed micro- and nanoparticles of sulfides and their performance was examined.

Among others, micro- and nanostructures of the synthesized metal sulfides depend on precipitation temperature, $\mathrm{pH}$, components concentration, activation type, etc. In case of water solutions, particles of zinc and copper sulfides are mainly of spherical form. Cadmium sulfide, apart from spherical particles, sometimes may form microscale flower-like structures, especially when MW activation is applied. These structures consist of thin plates of thickness up to $50 \mathrm{~nm}$, joined together into large spherical agglomerates of dimensions above $10 \mu \mathrm{m}$. When $\mathrm{pH}$ or temperature is increased, as well as when MW activation is applied, the obtained particles are larger. In addition, MW activation causes increased efficiency of the synthesis producing larger amount of metal sulfide. On the other hand, thiourea concentration in the solution leads to the decrease of the particles dimensions.

Metal sulfides are stable at $\mathrm{pH}$ above 5. Extraction percentage of the metals on iron, zinc, cadmium, and copper(II) sulfides is higher for higher $\mathrm{pH}$. The most effective performance (above $90 \%$ ) was noted in case of europium, cerium, copper, and iron uptake at $\mathrm{pH}$ above 5 . However, they perform rather low sorption capacity for metals such as europium, cerium, and cobalt. 


\section{Formation and Sorption Properties of Iron Oxides and Manganese Oxyhydroxide}

Among metal oxides, iron oxides are used as sorbents in practical applications (Pepper et al. 2017; Su et al. 2017). Iron oxide nanoparticles (in a variety of chemical and structural forms) have proved their potential in many applications on environmental area (Bhateria and Singh 2019). Their main merits are relatively cheap synthesis and stability of sorption performance. These materials, however, do not act selectively, and their extraction percentage and sorption capacity for metal ions are rather low. The iron oxides perform better sorption characteristics than aluminum oxides.

To increase the effectiveness of iron oxides, a wide range of modifications are being proposed and examined. In case of arsenic removal, Ociński et al. (2014) proposed to use a hybrid polymer containing iron oxides as $\mathrm{As}(\mathrm{III})$ and $\mathrm{As}(\mathrm{V})$ sorbent for drinking water purification. Moreover, magnetic iron oxides have been proposed to produce adsorbents for natural organic matter, so Lompe et al. (2017) examined effects of iron oxide nanoparticles on the adsorption of organic matter on magnetic powdered activated carbon. Iron oxide nanoflakes were tested in absorption of heavy metals, such as $\mathrm{Cd}$, As, Cr, and Pb (Afridi et al. 2019). Pandi et al. (2017) demonstrated that iron oxide coating on the hydrotalcite/chitosan composite performed good separation ability and displayed an extreme enhanced defluoridation capacity compared with other base components and composites.

Despite the long history of investigations on the sorption properties of iron oxides and their wide practical application, they are still subject of scholarly researches worldwide (Kolida et al. 2014). Cao and Zhu (2008) reported preparation of hierarchically nanostructured $\alpha-\mathrm{Fe}_{2} \mathrm{O}_{3}$ hollow spheres, whereas Zhu et al. (2013) synthesized hierarchical flower-like $\alpha-\mathrm{Fe}_{2} \mathrm{O}_{3}$ hollow spheres by one-pot solvothermal method. The latter had high specific surface area (SSA) of $98 \mathrm{~m}^{2} / \mathrm{g}$ and a total pore volume of $0.32 \mathrm{~cm}^{3} / \mathrm{g}$, which exhibited high removal capacities toward organic dyes and heavy metal ions. For heavy metal ion removal applications, Cao et al. (2012) proposed low-cost synthesis method of flower-like $\alpha-\mathrm{Fe}_{2} \mathrm{O}_{3}$ nanostructures. Composite sorption materials based on iron oxides were proposed, e.g., by Wang X. et al. (2011) who 
applied multishelled $\mathrm{Co}_{3} \mathrm{O}_{4}-\mathrm{Fe}_{3} \mathrm{O}_{4}$ hollow spheres with even magnetic phase distribution for water treatment or by Thirunavukkarasu et al. (2003) who used iron oxide-coated sand for arsenic removal from drinking water. $\mathrm{Wu}$ et al. (2005) prepared magnetic powder composite $\mathrm{MnO}-\mathrm{Fe}_{2} \mathrm{O}_{3}$ and examined its ability for the removal of azo dye from water. The iron oxide/carbon nanotubes/chitosan magnetic composite film was proved to be suitable for chromium species removal (Neto et al. 2019).

Another promising oxide is the manganese dioxide, usually applied in the chemical electrical current sources and catalysts, but little known as a sorption material. However, some reports indicate that manganese dioxide performs high sorption properties accompanied by low toxicity and cost-effective synthesis (Nagpal and Kakkar 2019). In particular, SSA of the manganese dioxide is $160 \mathrm{~m}^{2} / \mathrm{g}$, and its sorption capacity toward cobalt and zinc at $\mathrm{pH} 4$ is 81 and $65 \mathrm{mg} / \mathrm{g}$, respectively (Loganathan and Burau 1973). Other researchers reported its high sorption capacities toward copper $(98 \mathrm{mg} / \mathrm{g}$ at $\mathrm{pH} 5.5)$, zinc $(124 \mathrm{mg} / \mathrm{g}$ at $\mathrm{pH} 6)$, and lead $(80 \mathrm{mg} / \mathrm{g}$ at $\mathrm{pH}$ 6) (Pretorius and Linder 2001; Dong et al. 2010). Recently, a modified manganese dioxide composite was proposed as an innovative adsorbent for lead(II) ions (Mallakpour and Motirasoul 2019). Our own researches on the sorption characteristics of the manganese dioxides indicated that they perform high sorption properties and can be applied for removal of metal ions from water solutions.

One of the possibilities to control the properties of a material is to form the particles with desired phase composition and morphological characteristics. It is a widely known fact that "the control of composition, size, shape, and morphology of nanomaterials is an essential cornerstone for the development and application of nanomaterials" (Geckeler and Nishide 2010). In other words, controlling dimensions of the particles makes possible to determine their physical and chemical properties (Rasmussen et al. 2018). On the other hand, sorption characteristics of a sorbent depend substantially on its SSA, which, in turn, is determined not only by the particle dimensions but also by porosity and agglomeration degree (Deng et al. 2016). These features are "founded" directly during the synthesis of microand nanostructured materials. Accordingly, proper methodology and conditions of synthesis enable to obtain materials with desired properties. Thus, in order to perform controlled synthesis of the final material, it is necessary to know the rules how synthesis conditions effect on the properties of the obtained particles.

Hence, the researches were focused on the relations between the synthesis conditions and formation of micro- and nanoparticles of iron oxide, dioxide, and hydroxide. Subsequent examination of their sorption properties enabled to work out recommendations on the respective sorbent synthesis aimed to obtain improved materials. 


\subsection{Synthesis of Iron Oxide}

\subsubsection{Synthesis of the Hematite Particles $\alpha-\mathrm{Fe}_{2} \mathrm{O}_{3}$}

Among many methods to obtain $\alpha-\mathrm{Fe}_{2} \mathrm{O}_{3}$ particles, two should be emphasized:

- chemical precipitation out of aqueous solution with subsequent high-temperature calcining at $400^{\circ} \mathrm{C}-500^{\circ} \mathrm{C}$ and

- thermal decomposition of iron salts.

In the first case of chemical precipitation, the hematite particles formation may be influenced not only by the nature of precursors but also by the synthesis conditions, such as $\mathrm{pH}$, temperature, and concentration. Hence, in order to perform controlled synthesis of $\alpha-\mathrm{Fe}_{2} \mathrm{O}_{3}$ particles with desired morphological features, the effect of those factors should be analyzed.

Figure 2.1 presents scanning electron microscope (SEM) images of the hematite particles obtained through precipitation of iron nitrate with aqueous ammonia solution at various $\mathrm{pH}$. Irrespective of $\mathrm{pH}$ value, large agglomerates are formed of random shape, with dimensions between 5 and $200 \mu \mathrm{m}$. After high-temperature calcining at $450^{\circ} \mathrm{C}$, morphology of the particles did
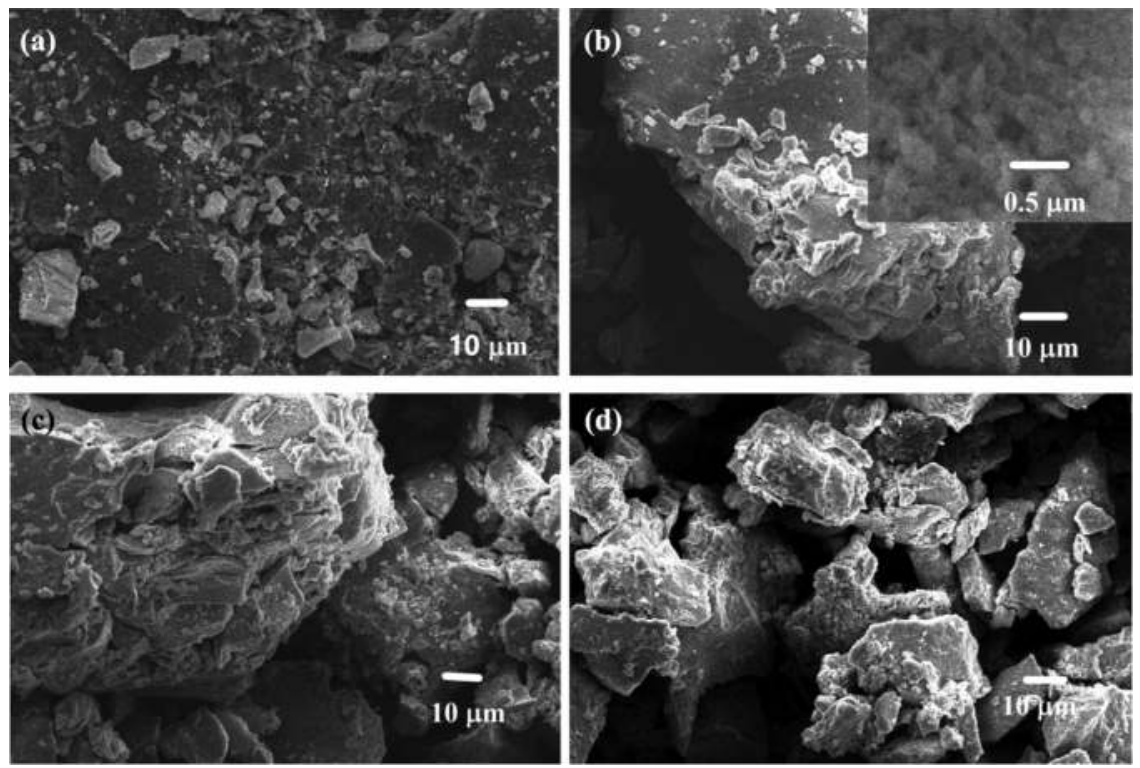

FIGURE 2.1

The particles obtained from nitrate solution at pH 12 (a), pH 9.1 (b), pH 8.3 (c), and pH 7.3 (d). 
not change much, as it is seen in Figure 2.2. Precipitation consists mainly of large agglomerates with side dimensions up to $200 \mu \mathrm{m}$ that are made up of spherical nanoparticles with diameters below $50 \mathrm{~nm}$.

Formation of the iron oxide was confirmed with infrared (IR) spectrometry analysis and with X-ray crystallography. The latter results obtained after high-temperature calcining are shown in Figure 2.3. Irrespective of
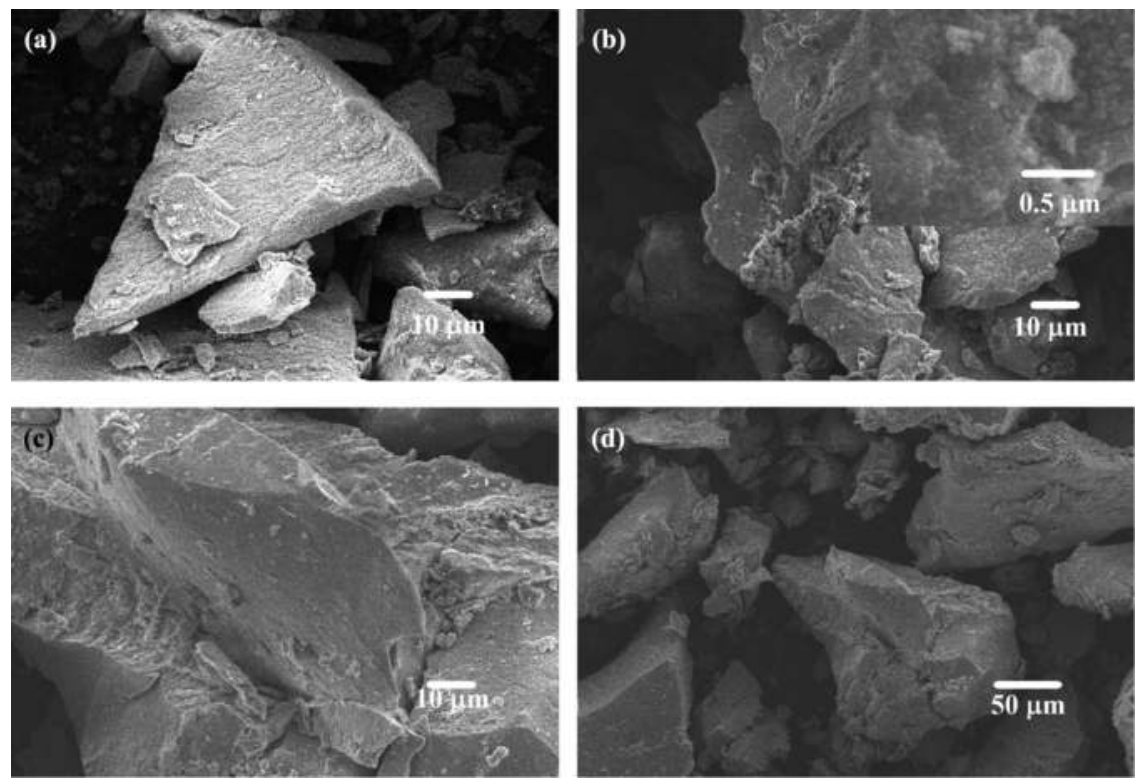

FIGURE 2.2

The particles obtained from nitrate solution at $\mathrm{pH} 12$ (a), pH 9.1 (b), $\mathrm{pH} 8.3$ (c), and pH 7.3 (d) and calcined at $450^{\circ} \mathrm{C}$ for 2 hours.

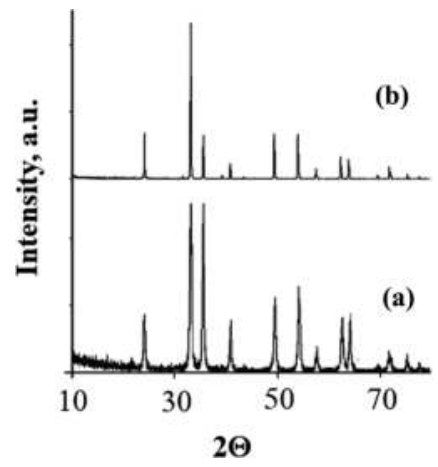

\section{FIGURE 2.3}

X-ray diagrams of the powder $\mathrm{Fe}_{2} \mathrm{O}_{3}$ calcined at $450^{\circ} \mathrm{C}$, precipitated from nitrate solutions at pH 12 (a) and $\mathrm{pH} 7.3$ (b). 
synthesis conditions, phase $\alpha-\mathrm{Fe}_{2} \mathrm{O}_{3}$ (hematite) is formed. In the IR spectra of the powders presented in Figure 2.4, absorption bands are seen in the area of $450-1,000 \mathrm{~cm}^{-1}$ at 545 and $555 \mathrm{~cm}^{-1}$. They can be attributed to the vibration of Fe-O bond (Ul-Haq and Haider 2010).

In case of different nature of the iron salt anion, no changes in the particle formation were noted. For instance, when iron chloride was used as a precursor for iron hydroxide particles formation, after subsequent thermal treatment, agglomerates with side dimensions up to $200 \mu \mathrm{m}$ made up of spherical nanoparticles with diameters below $50 \mathrm{~nm}$ were formed, too. The respective SEM image is presented in Figure 2.5.

Thus, it was demonstrated that the prehistory of iron hydroxide synthesis has no effect on subsequent process of the oxide particle formation through calcining.

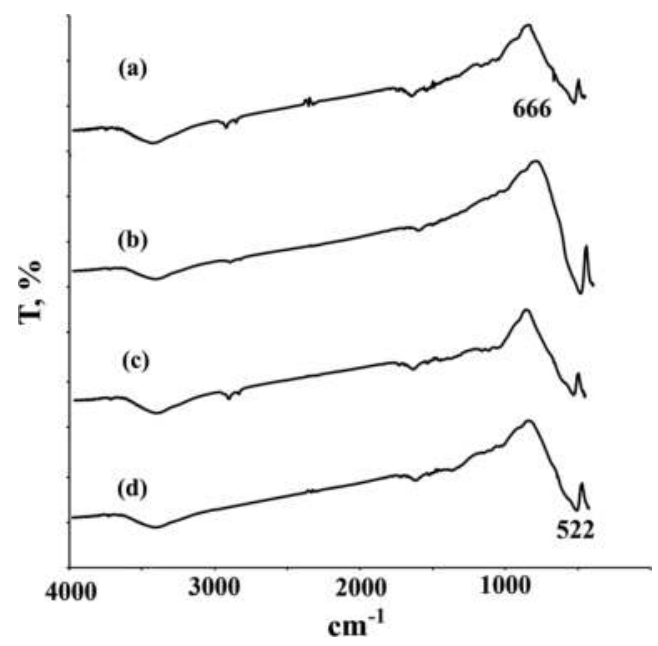

FIGURE 2.4

IR spectra of the powder $\mathrm{Fe}_{2} \mathrm{O}_{3}$ calcined at $450^{\circ} \mathrm{C}$, precipitated from nitrate solutions at $\mathrm{pH} 12$ (a), pH 9.1 (b), pH 8.3 (c), and pH 7.3 (d). IR, infrared.
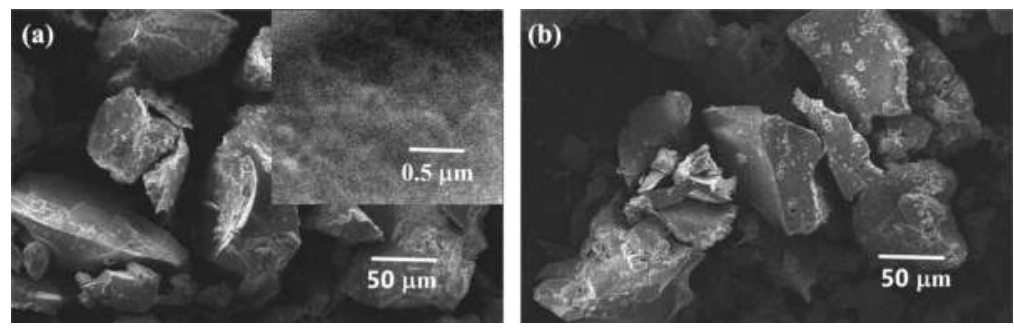

\section{FIGURE 2.5}

The iron oxide particles obtained from chloride solution at $\mathrm{pH} 8.0$ (a) and $\mathrm{pH} 11.5$ (b) and calcined at $450^{\circ} \mathrm{C}$ for 2 hours. 
As a rule, large agglomerates are formed with side dimensions from $10 \mu \mathrm{m}$ up to $200 \mu \mathrm{m}$, but with SSA ca. $140 \mathrm{~m}^{2} / \mathrm{g}$.

In order to decrease agglomerate dimensions and thus to increase SSA, organic acids were introduced, such as acetic, aminocaproic, and citric ones. They perform complexing properties, and their decomposition during high-temperature calcining may prevent formation of large agglomerates. Figures 2.6 and 2.7 present SEM images of the iron oxide after calcining of the precursors precipitated from aqueous solutions with carbon acids added.

The obtained results indicate that the chosen additions did not have substantial effect on the subsequent formation of the iron oxide during hightemperature calcining. In all cases, large agglomerates were formed with dimensions of hundreds of microns. Probably, the additions had no effect because they were lost during washing procedure before calcining. IR spectra did not reveal any absorption band typical for the added carbon acids.

Another method, as it was mentioned earlier, is hematite $\alpha-\mathrm{Fe}_{2} \mathrm{O}_{3}$ formation during thermal decomposition of iron salts. Typically, as a precursors in this method, iron nitrate and chloride are used. It is known that after they are calcined at $400^{\circ} \mathrm{C}-500^{\circ} \mathrm{C}$ for several hours, iron oxide of hematite structure is formed. However, published works do not provide systematic view on the anion nature effect on the particle formation during thermal decomposition.

In our research, it was noted during decomposition of iron nitrate at $450^{\circ} \mathrm{C}$ that fine sediment is formed, made up of spherical particles with diameters below 100 nm (Figure 2.8a). In case of iron chloride decomposition, oval and cubic particles were formed with dimensions between 1 and $5 \mu \mathrm{m}$
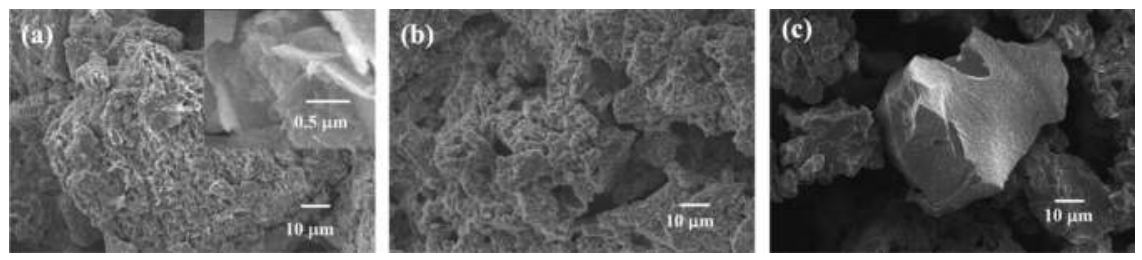

FIGURE 2.6

$\mathrm{Fe}_{2} \mathrm{O}_{3}$ particles obtained from aqueous solution of iron(II) nitrate with additions: acetic acid (a), aminocaproic acid (b), and citric acid (c)
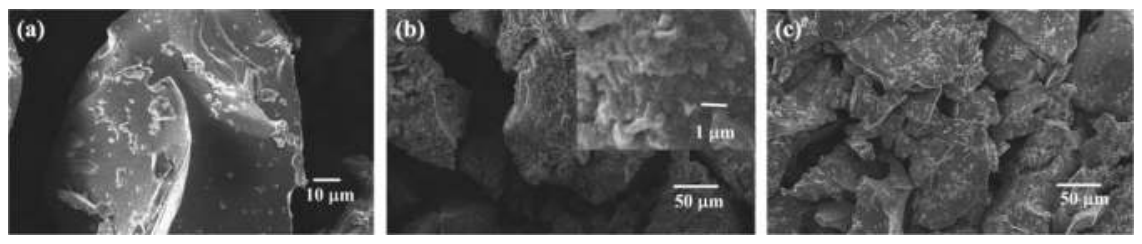

\section{FIGURE 2.7}

$\mathrm{Fe}_{2} \mathrm{O}_{3}$ particles obtained from aqueous solution of iron(III) chloride with additions: acetic acid (a), aminocaproic acid (b), and citric acid (c) 

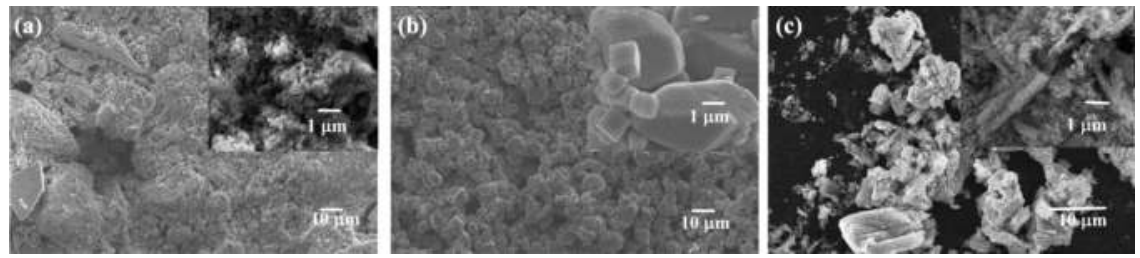

\section{FIGURE 2.8}

The particles obtained through decomposition of iron nitrate (a), chloride (b), and fluoride (c) at $450^{\circ} \mathrm{C}$ during 2 hours

(Figure 2.8b). When iron fluoride underwent calcining, fine sediment was noted made up of spherical and oval particles of dimensions ca. $0.1-0.2 \mu \mathrm{m}$ (Figure 2.8c). SSA of the particles obtained from iron nitrate was around $140 \mathrm{~m}^{2} / \mathrm{g}$, whereas in case of chloride precursor, obtained SSA was no more than $30 \mathrm{~m}^{2} / \mathrm{g}$.

Oval particles were formed also when iron nitrate and chloride underwent thermal decomposition together. They are seen in Figure 2.9. It was noted that decrease of chloride compound in the initial mixture caused formation of smaller particles. Presence of the fluoride ions into precursors had no substantial effect on the particles formation.

It was assumed that the fine sediment formation during iron nitrate decomposition is above all influenced by intense release of nitrogen oxide in gas phase. This phenomenon is accompanying the heating process and thus prevents formation of larger iron oxide particles, leaving their dimensions below $100 \mathrm{~nm}$. However, the effect may be caused also by the organic additions.

Figure 2.10 presents the effect of carbon acids additions on the iron oxide particles formation. In all cases, structures made up of submicron particles were formed. However, SSA of the obtained material was varying between 5 and $30 \mathrm{~m}^{2} / \mathrm{g}$.

The conclusion is that for the thermal decomposition of salts, the largest SSA of iron oxide particles can be obtained from iron nitrate at $450^{\circ} \mathrm{C}$. Obtainable SSA in that method reaches $140 \mathrm{~m}^{2} / \mathrm{g}$.
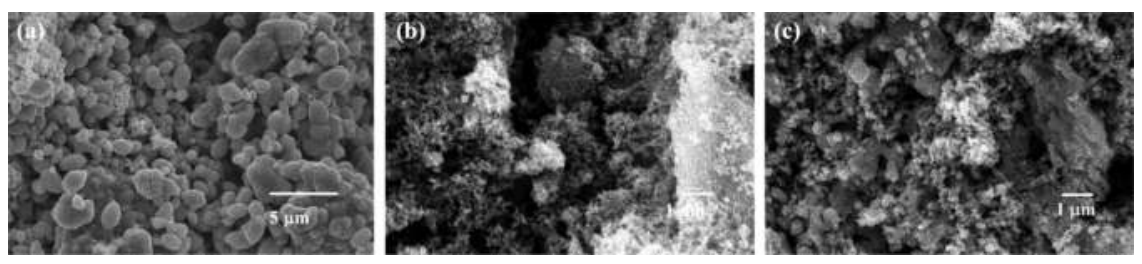

\section{FIGURE 2.9}

The particles obtained through decomposition of iron nitrate with addition of $\mathrm{FeCl}_{3}$ in molar proportion 1:1 (a) and 10:1 (b), as well as addition of $\mathrm{FeF}_{3}$ in molar proportion 1:1 (c). 

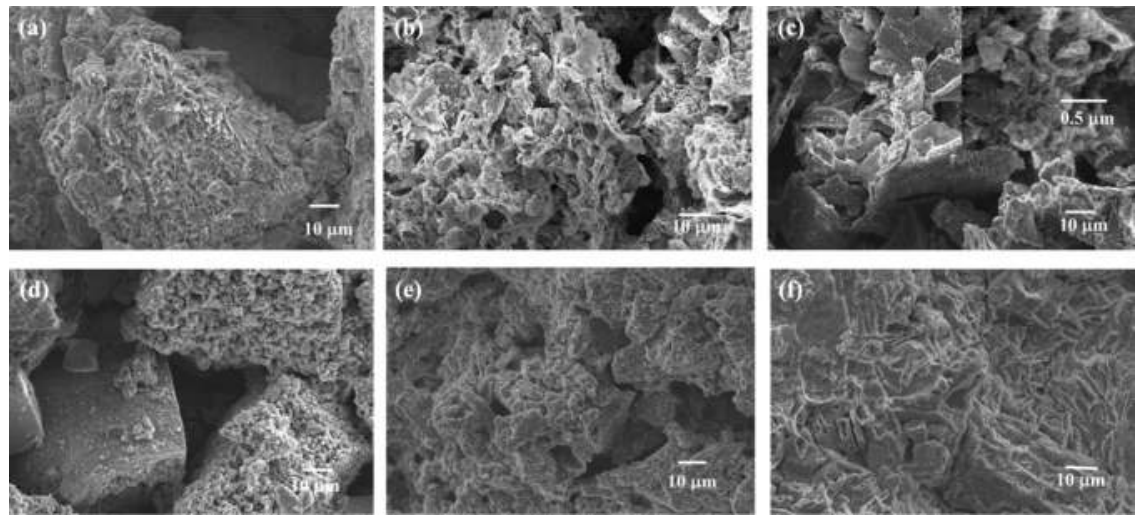

FIGURE 2.10

$\mathrm{Fe}_{2} \mathrm{O}_{3}$ particles obtained through decomposition of iron nitrate with addition of acetic acid $(a, b)$, aminocaproic acid (c, d), and citric acid (e, f) in molar proportions 1:1 (a, c, e) and 10:1 $(b, d, f)$.

\subsubsection{Formation of Maghemite $\gamma-\mathrm{Fe}_{2} \mathrm{O}_{3}$ Particles}

There were reports on experimental results that indicated similar roles of $\alpha-\mathrm{Fe}_{2} \mathrm{O}_{3}$ and $\gamma-\mathrm{Fe}_{2} \mathrm{O}_{3}$ in removal of elemental mercury (Liu et al. 2015). In order to examine and compare their sorption properties, ferrous oxalate was decomposed at $170^{\circ} \mathrm{C}$ during 20 minutes. Maghemite formation was confirmed by the X-ray phase analysis from the diagram shown in Figure 2.11. The obtained large agglomerates had side dimensions between 2 and $50 \mu \mathrm{m}$

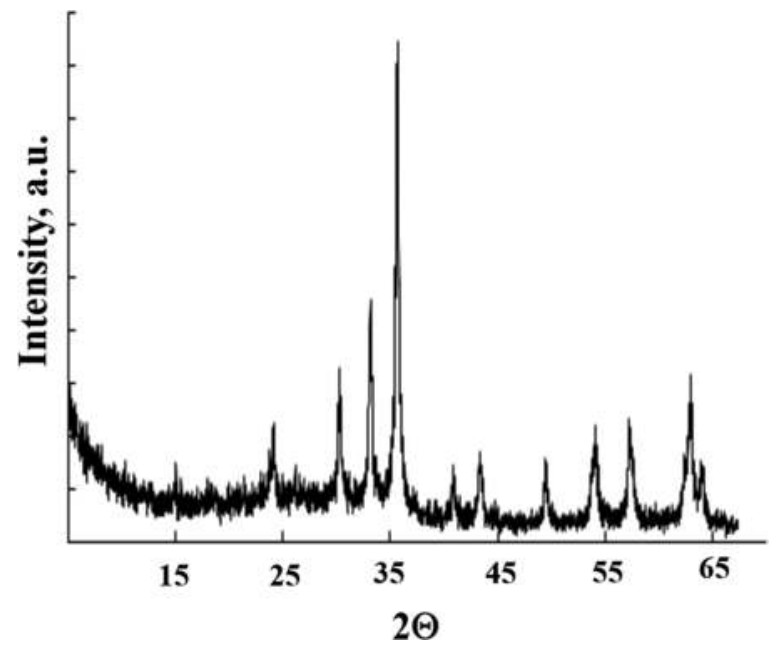

FIGURE 2.11

X-ray diagram of the particles obtained from decomposition of iron(II) oxalate at $170^{\circ} \mathrm{C}$. 


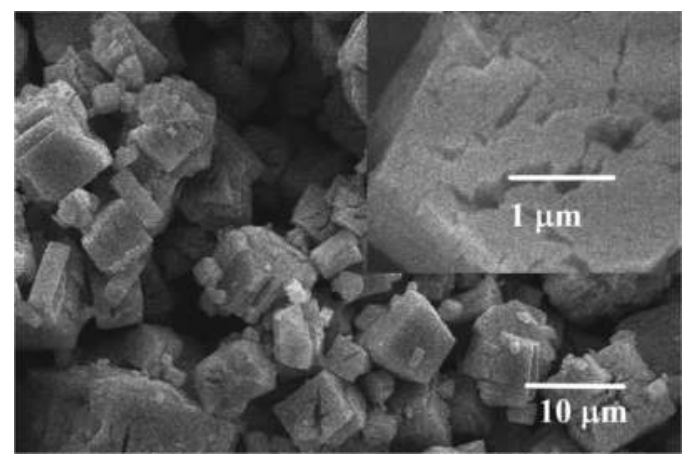

FIGURE 2.12

The particles obtained from decomposition of iron(II) oxalate at $170^{\circ} \mathrm{C}$.

and consisted of faceted particles with side dimensions up to $10 \mu \mathrm{m}$, as it is seen in Figure 2.12. SSA of those particles was $35 \mathrm{~m}^{2} / \mathrm{g}$.

\subsubsection{Peculiarities of the $\mathrm{Fe}_{3} \mathrm{O}_{4}$ Particle Formation from the Aqueous Solutions}

Synthesis of iron oxide nanopowders with high magnetic and sorption properties is for long time of great interest of researchers (Lavrynenko et al. 2018). Cheera et al. (2016) proposed green and cost-effective synthesis of iron oxide $\mathrm{Fe}_{3} \mathrm{O}_{4}$ magnetic nanoparticles. The obtained nanoparticles were spherical with an average diameter of $20-35 \mathrm{~nm}$, and they exhibited SSA of $26.21 \mathrm{~m}^{2} / \mathrm{g}$. Simple and effective method of $\mathrm{Fe}_{3} \mathrm{O}_{4}$ synthesis is precipitation from aqueous solutions of $\mathrm{Fe}^{2+}$ and $\mathrm{Fe}^{3+}$ salts at $\mathrm{pH}$ above 9 (Odnovolova et al. 2015). However, the particles obtained by this method were reported to perform variations of magnetic properties represented by magnetization - the magnetic moment per weight of the magnetic material - in the wide range from 5 up to $100 \mathrm{~A} \cdot \mathrm{m}^{2} / \mathrm{kg}$ (Baranov and Gubin 2009). No convincing explanation of magnetization variations was given despite many scholars have investigated this phenomenon (Wegmann and Scharr 2018), but some reports suggest their dependence on the particles morphology. For instance, Ge et al. (2009) reported variations of magnetization between 53.3 and $97.4 \mathrm{~A} \cdot \mathrm{m}^{2} / \mathrm{kg}$ attributed to the particles dimensions. In their experiments, iron oxide nanoparticles were synthesized by $\mathrm{FeCl}_{2} \cdot 4 \mathrm{H}_{2} \mathrm{O}$ oxidation in basic aqueous solution at $134^{\circ} \mathrm{C}$ and pressure 2 atmospheres. Diameters of the particles were tuned from 15 to $31 \mathrm{~nm}$ through the variation of the reaction conditions, and their magnetic behavior was either ferromagnetic or superparamagnetic depending on the particle size. Magnetization was noted to be lower for smaller particles. Tombácz et al. (2015) in their review draw the conclusion that in defining the magnetic behavior of iron oxide nanoparticles, the size distribution and morphology are essential. Baaziz et al. (2014) synthesized the 
iron oxide nanoparticles from iron stearate precursor in the presence of surfactants in high boiling solvents. The average sizes of the particles were obtained in the range $4-28 \mathrm{~nm}$ by varying parameters of the thermal decomposition of an iron precursor. It should be highlighted that, according some reports (Roth et al. 2015), formation of particles between 3 and $17 \mathrm{~nm}$ with higher saturation magnetization was found directly related to the bigger particle size. These were favored at the highest temperature, the highest iron salt concentrations, a molar ratio of $\mathrm{Fe}(\mathrm{III}) / \mathrm{Fe}(\mathrm{II})$ below 2:1, and a hyperstoichiometric molar ratio of hydroxide ions to iron ions of 1.4:1. Our researches confirmed that temperature of synthesis played a substantial role in the formation of iron oxide magnetic phase.

Figure 2.13 presents $X$-ray diagrams of the synthesized powders. The samples obtained at $15^{\circ} \mathrm{C}$ and iron concentration $1 \mathrm{M}$ appeared to be amorphous, as it is seen in Figure 2.13a. Decrease of iron concentration in solution at $15^{\circ} \mathrm{C}$ did not result with crystalline sediment formation. Only at temperature $20^{\circ} \mathrm{C}$, crystalline sediment is formed, but from the solution with iron concentration $1 \mathrm{M}$, magnetite was not being precipitated (see Figure 2.13b). Formation of pure magnetite was noted at $90^{\circ} \mathrm{C}$ when concentration of iron in the solution was $0.15 \mathrm{M}$ (Figure 2.13c). At lower temperatures between $20^{\circ} \mathrm{C}$ and $90^{\circ} \mathrm{C}$, X-ray diagrams revealed reflexes that corresponded with magnetite $\mathrm{Fe}_{3} \mathrm{O}_{4}$, maghemite $\gamma-\mathrm{Fe}_{2} \mathrm{O}_{3}$, and goethite $\alpha-\mathrm{FeOOH}$ in different proportions.

In Table 2.1, the results are presented on the phase components, as obtained from X-ray diagrams using Rietveld refinement technique. The experimental results indicated that magnetite presence is substantially dependent on the

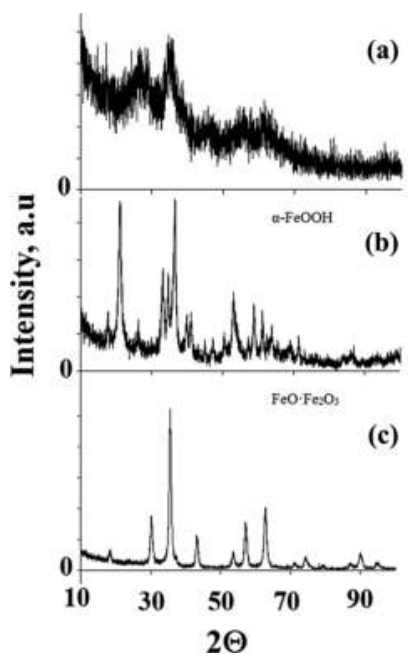

FIGURE 2.13

X-ray diagrams of the particles obtained at $15^{\circ} \mathrm{C}$ (a) and $20^{\circ} \mathrm{C}$ (b) from the solution with iron concentration $1 \mathrm{M}$ and obtained at $90^{\circ} \mathrm{C}$ from the solution with iron concentration $0.15 \mathrm{M}$ (c) (Odnovolova et al. 2015). 


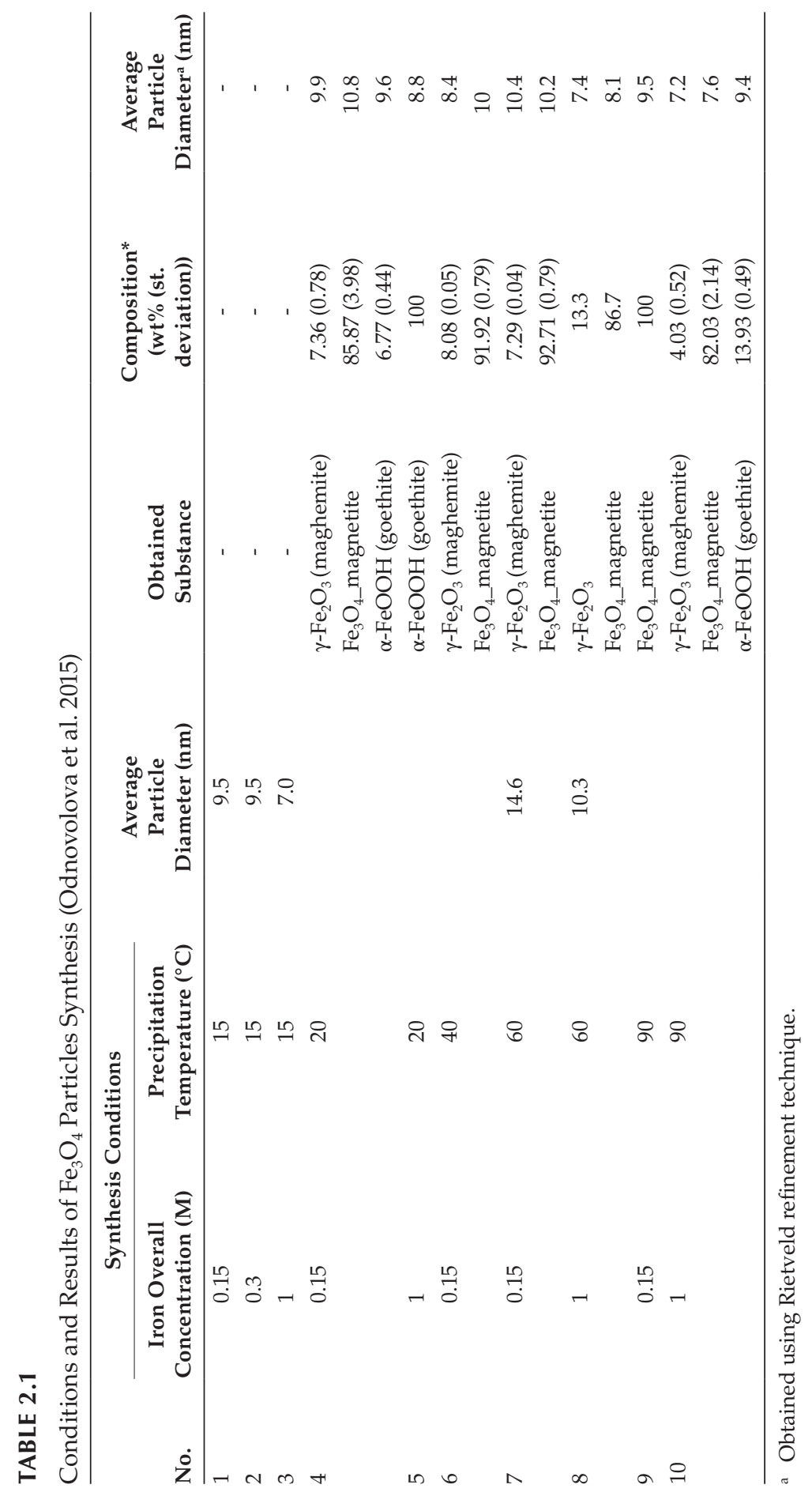


synthesis temperature and iron concentration. Both increase of the temperature and decrease of iron concentration in precursor solution resulted with larger concentration of magnetite phase in synthesized sediment. Eventually, $100 \%$ magnetite phase was noted in the samples precipitated at $90^{\circ} \mathrm{C}$ from solution with iron concentration $0.15 \mathrm{M}$. On the other hand, at the temperatures below $t=15^{\circ} \mathrm{C}, \mathrm{X}$-ray amorphous oxide was precipitated.

Figure 2.14 presents SEM images of synthesized iron oxide nanoparticles obtained using transmission electron microscopy (TEM). In case of initial iron concentration $0.15 \mathrm{M}$ at temperature $15^{\circ} \mathrm{C}$, spherical particles were formed with average diameters ca. $10 \mathrm{~nm}$, as it is seen in Figure 2.14a. When the overall concentration of iron ions was increased up to $0.3 \mathrm{M}$, it had no substantial effect on the particles' dimensions, which is illustrated in Figure 2.14b. For the powders obtained from $1 \mathrm{M}$ concentration of iron ions, however, dimensions of the particles were distinguishably smaller. Figure $2.14 \mathrm{c}$ shows that their average sizes were ca. $7 \mathrm{~nm}$.

On the other hand, higher process temperatures caused growth of the particles. Figures $2.14 \mathrm{~d}$ and e illustrates the particles with average diameters $15.2 \mathrm{~nm}$ obtained from $0.15-0.3 \mathrm{M}$ concentrations, and Figure $2.14 \mathrm{f}$ illustrates the particles with average diameters $10.5 \mathrm{~nm}$ obtained from solution of $1 \mathrm{M}$ concentration. SSA in all cases was $120-130 \mathrm{~m}^{2} / \mathrm{g}$, irrespective of iron ions concentration and synthesis temperature.

Particles' magnetization measurement results are presented in Figure 2.15. Samples obtained at temperature $15^{\circ} \mathrm{C}$ revealed very low magnetization below $5 \mathrm{~A} \cdot \mathrm{m}^{2} / \mathrm{kg}$ represented by curves $a$ and $b$. On the other hand, samples
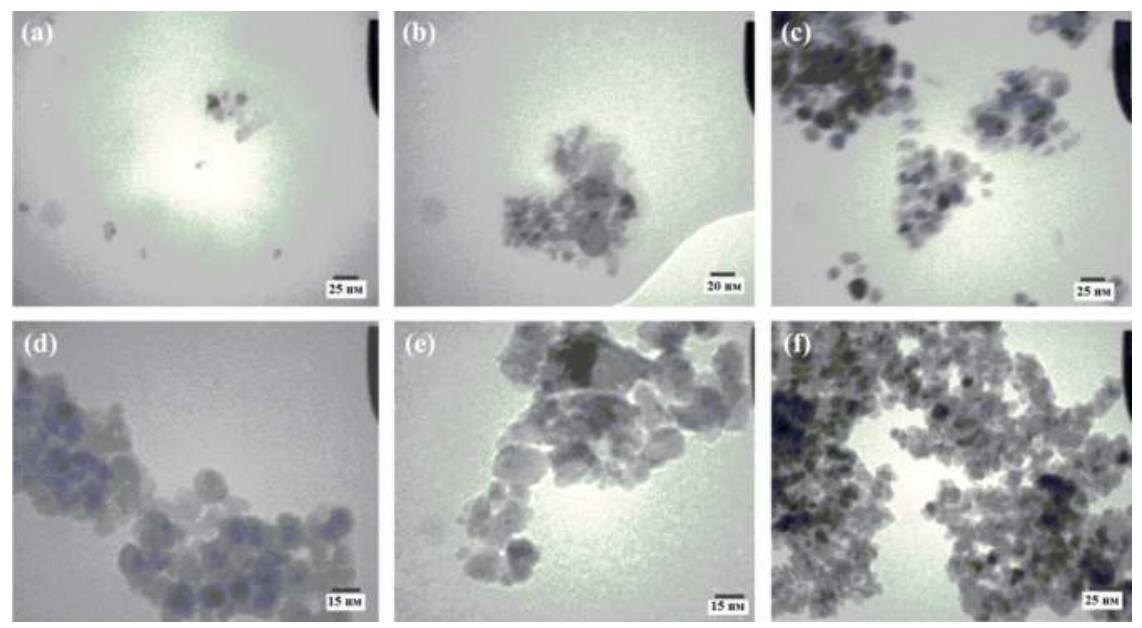

FIGURE 2.14

$\mathrm{Fe}_{3} \mathrm{O}_{4}$ nanoparticles synthesized from iron chloride and sulfate in $c\left(\mathrm{Fe}^{3+}\right): c\left(\mathrm{Fe}^{2+}\right)$ proportion 2:1, at pH 8.0-9 and different conditions: (a) $t=15^{\circ} \mathrm{C}$ and $C(\mathrm{Fe})=0.15 \mathrm{M}$; (b) $t=15^{\circ} \mathrm{C}$ and $C(\mathrm{Fe})=0.3 \mathrm{M}$; (c) $t=15^{\circ} \mathrm{C}$ and $C(\mathrm{Fe})=1 \mathrm{M}$; (d) $t=60^{\circ} \mathrm{C}$ and $C(\mathrm{Fe})=0.15 \mathrm{M}$; (e) $t=60^{\circ} \mathrm{C}$ and $C(\mathrm{Fe})=0,3 \mathrm{M}$; and (f) $t=60^{\circ} \mathrm{C}$ and $C(\mathrm{Fe})=1 \mathrm{M}$ (Odnovolova et al. 2015). 


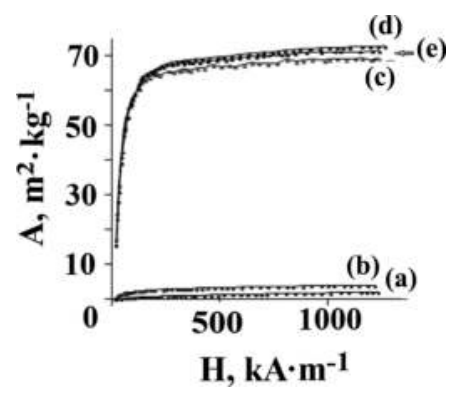

FIGURE 2.15

Magnetization $M$ versus magnetic field strength $H$ for the $\mathrm{Fe}_{3} \mathrm{O}_{4}$ samples obtained at different temperature $t$ and iron ions concentration: (a) $15^{\circ} \mathrm{C}$ and $1 \mathrm{M}$; (b) $15^{\circ} \mathrm{C}$ and $0.15 \mathrm{M}$; (c) $60^{\circ} \mathrm{C}$ and $1 \mathrm{M}$; (d) $60^{\circ} \mathrm{C}$ and $0.3 \mathrm{M}$; and (e) $60^{\circ} \mathrm{C}$ and $0.15 \mathrm{M}$ (Odnovolova et al. 2015).

obtained at $60^{\circ} \mathrm{C}$ had high magnetization ca. $70 \mathrm{~A} \cdot \mathrm{m}^{2} / \mathrm{kg}$ represented by curves $c$ and $d$ in Figure 2.15. It is seen that the magnetization is increased a little in case of smaller concentration of iron ions in the initial solution. Obviously, the higher the proportion of magnetite in a sample, the higher the magnetization it reveals. Moreover, higher magnetization can be expected for larger particles in general. Figure 2.16 presents IR spectra of the synthesized iron oxide samples.

It is seen in the IR spectra that there is absorption band in the area $450-1,000 \mathrm{~cm}^{-1}$ with its peak at 572 and $575 \mathrm{~cm}^{-1}$ in the curves $a$ and $b$, respectively. They are attributed to the vibration of $\mathrm{Fe}-\mathrm{O}$ bond in the iron oxide $\mathrm{Fe}_{3} \mathrm{O}_{4}$ (Ai et al. 2008; Odnovolova et al. 2014). Curve $b$ exhibits also absorption bands at 1,128 and 1,410 $\mathrm{cm}^{-1}$, which can be attributed to the presence of $\mathrm{SO}_{4}{ }^{2-}$ ions (Saha and Podder 2011) caused by the application of iron sulfate

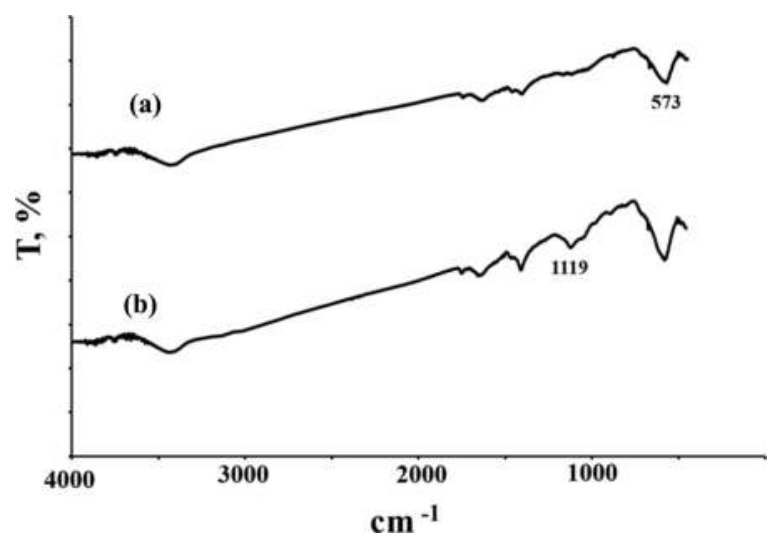

FIGURE 2.16

IR spectra of $\mathrm{Fe}_{3} \mathrm{O}_{4}$ particles obtained from chloride (a) and sulfate (b) aqueous solutions. IR, infrared. 
as a precursor in the synthesis. The band $1,410 \mathrm{~cm}^{-1}$ is attributed to the $\mathrm{CO}_{3}{ }^{2-}$ ion vibrations (Hong et al. 2006), which prove the presence of the carbonate contaminations produced by the side process of carbonization.

Hence, it was demonstrated that magnetite phase formation is under substantial influence of the precipitation temperature. The higher the temperature, the more the magnetite phase synthesized in a sample. When the synthesis is performed at temperature $90^{\circ} \mathrm{C}$ and iron concentration $0.15 \mathrm{M}$ in the initial solution, powder with pure magnetite $\mathrm{Fe}_{3} \mathrm{O}_{4}$ is formed (100 wt\%) that reveals magnetization of $70 \mathrm{~A} \cdot \mathrm{m}^{2} / \mathrm{kg}$. Irrespective of the precipitation process parameters, spherical nanoparticles are formed with average dimensions between 7 and $15 \mathrm{~nm}$. Increase of the synthesis temperature and decrease of the iron ions concentration cause formation of the powder made up of larger particles with higher magnetization.

\subsection{Synthesis of Manganese Dioxide and Oxyhydroxide}

Manganese oxide minerals occur in three polymorphic forms: $\alpha-, \beta-$, and $\delta-\mathrm{MnO}_{2}$. Typically, they have large surface area and more passive and active sites, allowing high adsorption and excellent oxidation and catalysis activity (Feng et al. 2007). $\mathrm{MnO}_{2}$ nanomaterials are the subject of many research works because of their importance and potential technological applications as heterogeneous catalysts for ozone decomposition, organic pollutants oxidation, nitric oxide detraction, carbon monoxide reduction, and degradation of dyes (Ahmed 2016). In his review, the author pointed out a range of synthesis methods such as sonochemical synthesis, solution combustion synthesis, thermal decomposition, hydrothermal synthesis, sol-gel, electrodeposition, and microwave-assisted synthesis processes. Recent progress focused on the synthesis and analysis of the novel characteristics of manganese oxide nanostructures, emphasizing critical experiments to determine the chemical and physical parameters and the interplay between synthetic conditions and nanoscale morphologies. Cao et al. (2009) investigated adsorption properties of microscale hollow structures of $\mathrm{Mn}_{2} \mathrm{O}_{3}$, such as sphere, cube, ellipsoid, or dumbbell. Their ability to remove $77 \%-83 \%$ of phenol from water was demonstrated. Singh et al. (2010) analyzed adsorption capacity of $\alpha-\mathrm{MnO}_{2}$ nanorods and $\delta-\mathrm{MnO}_{2}$ nanofiber clumps toward $\mathrm{As}(\mathrm{V})$. The nanostructures were synthesized using manganese pentahydrate in an aqueous solution.

\subsubsection{Synthesis of Manganese Oxyhydroxide in Alkaline Solutions}

It is known (Turner et al. 2008) that interaction of ions $\mathrm{Mn}^{2+}$ and $\mathrm{MnO}_{4}{ }^{-}$in alkaline environment produces manganese dioxide according to the following reaction: 


$$
3 \mathrm{Mncl}_{2}+2 \mathrm{KMnO}_{4}+4 \mathrm{NaOH} \rightarrow 5 \mathrm{MnO}_{2}+2 \mathrm{H}_{2} \mathrm{O}+2 \mathrm{KCl}+4 \mathrm{Nacl},
$$

However, it was indicated decades ago (Davies-Colley et al. 1984) that conditions of that kind lead to the formation of mineral called birnessite that contains manganese in two forms: (III) and (IV). Birnessite has a layered structure consisting of edge-shared $\mathrm{MnO}_{6}$ octahedra with a wide interlayer space of about $7 \AA$ (Liu et al. 2018). Other works indicate formation of manganese oxides mixture, too (Stone and Morgan 1984).

In attempts to obtain manganese dioxide from reaction (2.1), it was found that the resulting substance was not manganese dioxide. In various precipitation conditions, the sediment was formed with identical X-ray patterns. The example is shown in Figure 2.17, where the sample was obtained at temperature $80^{\circ} \mathrm{C}$. X-ray structural analysis revealed in the obtained powders only weak reflections that can be attributed to manganese oxyhydroxide $\mathrm{MnO}(\mathrm{OH})$ and manganese $(\mathrm{IV})$ dioxide $\mathrm{MnO}_{2}$.

IR spectra of the obtained powders are shown in Figure 2.18. The absorption bands at 443 and $505 \mathrm{~cm}^{-1}$ can be attributed to $\mathrm{Mn}-\mathrm{O}$ bond vibrations, and their presence was noted in $\mathrm{MnO}(\mathrm{OH})$ spectra (Crisostomo et al., 2007). Chemical analysis results are presented in Table 2.2. Data indicate mainly the presence of $\mathrm{Mn}(\mathrm{III})(36-41 \mathrm{wt} \%)$, as well as no more than $2 \mathrm{wt} \%$ of $\mathrm{Mn}$ (II) and no more than $6 \mathrm{wt} \%$ of Mn(IV). SEM images of the particles are shown in Figure 2.19.

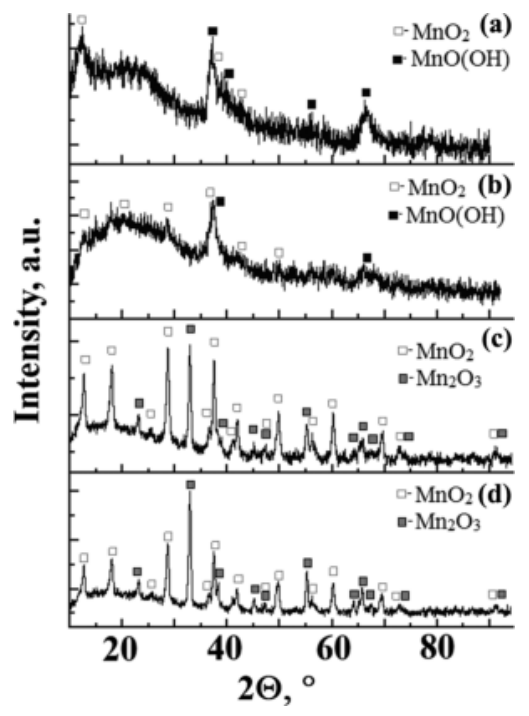

FIGURE 2.17

Diffraction diagrams of the synthesized powders: (a) after precipitation at $t=80^{\circ} \mathrm{C}$; (b) after calcining for 1 hour at $t=300^{\circ} \mathrm{C}$; (c) after calcining for 1 hour at $t=400^{\circ} \mathrm{C}$; and (d) after calcining for 1 hour at $t=700^{\circ} \mathrm{C}$. 


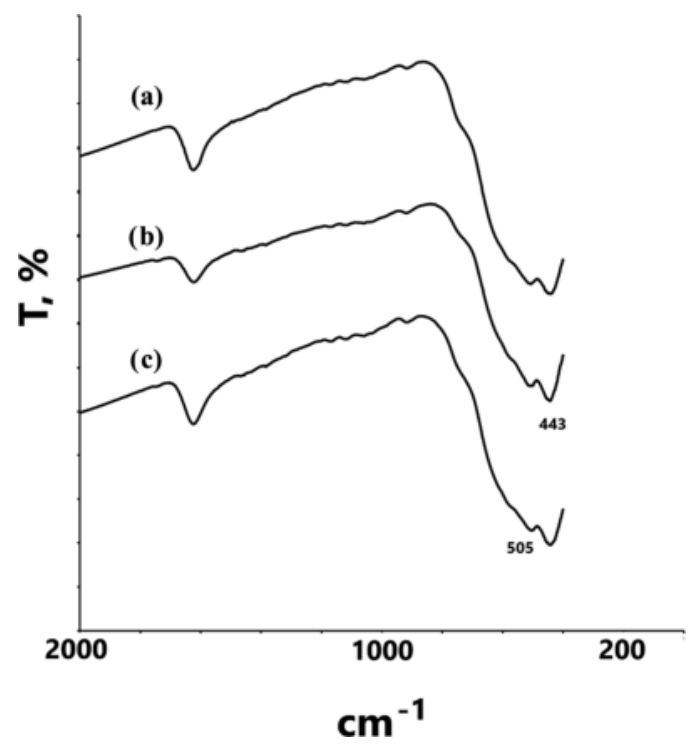

FIGURE 2.18

IR spectra of powders obtained from different concentrations of manganese solutions and at different temperatures: (a) $1 \mathrm{M}$ and $t=20^{\circ} \mathrm{C}$; (b) $1 \mathrm{M}$ and $t=80^{\circ} \mathrm{C}$; and (c) $0.1 \mathrm{M}$ and $t=80^{\circ} \mathrm{C}$. IR, infrared.

TABLE 2.2

Manganese Forms of Different Valence in the Synthesized Samples

\begin{tabular}{|c|c|c|c|c|c|}
\hline \multicolumn{2}{|c|}{ Synthesis Conditions } & \multicolumn{4}{|c|}{ Manganese Found (wt\%) } \\
\hline$V_{\text {all }}(\mathrm{mL})$ & $t\left({ }^{\circ} \mathrm{C}\right)$ & $\operatorname{Mn}(\mathrm{II})$ & Mn(III) & $\operatorname{Mn}(I V)$ & Overall Mn \\
\hline 750 & 20 & 1.7 & 36 & 6.3 & 44 \\
\hline 750 & 80 & 1.5 & 41 & 6.5 & 49 \\
\hline 75 & 20 & 1.8 & 40 & 2.2 & 44 \\
\hline 75 & 80 & 0.9 & 38 & 2.1 & 41 \\
\hline
\end{tabular}

Irrespective of the synthesis conditions, large agglomerates were formed, made up of particles with dimensions ca. $150 \mathrm{~nm}$. The SSA was calculated from the monolayer capacity using Brunauer-Emmett-Teller (BET) equation (Naderi, 2015):

$$
\theta_{c}=\frac{n}{n_{m}}=\frac{c_{\mathrm{BET}} \cdot x}{[1-x]\left[1+x\left(c_{\mathrm{BET}}-1\right)\right]}
$$

with relative pressure $x$ :

$$
x=\frac{P}{P_{o}}
$$



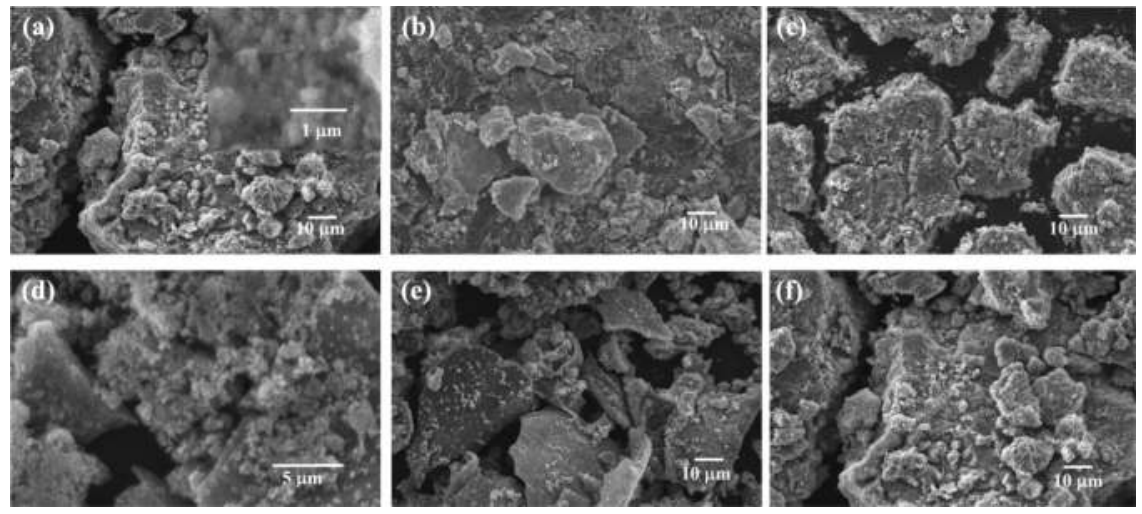

\section{FIGURE 2.19}

SEM images of manganese(III) particles obtained at different concentrations of manganese solutions and different temperatures: (a) $1 \mathrm{M}$ and $20^{\circ} \mathrm{C}$; (b) $1 \mathrm{M}$ and $60^{\circ} \mathrm{C}$; (c) $1 \mathrm{M}$ and $80^{\circ} \mathrm{C}$; (d) $0.1 \mathrm{M}$ and $20^{\circ} \mathrm{C}$; (e) $0.1 \mathrm{M}$ and $60^{\circ} \mathrm{C}$; and (f) $0.1 \mathrm{M}$ and $80^{\circ} \mathrm{C}$. SEM, scanning electron microscopy.

For the particles obtained from $0.1 \mathrm{M}$ solutions at temperatures $20^{\circ} \mathrm{C}$ and $80^{\circ} \mathrm{C}$, SSAs were 360 and $210 \mathrm{~m}^{2} / \mathrm{g}$, respectively. However, SSA of the particles obtained from $1 \mathrm{M}$ solutions at temperature $20^{\circ} \mathrm{C}$ was $160 \mathrm{~m}^{2} / \mathrm{g}$. This demonstrated that the SSA was larger when the manganese ions concentration in precursors was lower, but increase of the synthesis temperature caused decrease of SSA.

The samples of obtained powders underwent subsequent high-temperature calcination. X-ray diffraction measurement of the powders calcined at temperatures up to $300^{\circ} \mathrm{C}$ revealed practically no changes, as it was presented in Figure 2.17b. In contrast, diagrams of the powders calcined at $400^{\circ} \mathrm{C}$ intense reflections are seen in Figure 2.17c and d, which can be attributed to oxides $\mathrm{Mn}_{2} \mathrm{O}_{3}$ and $\mathrm{MnO}_{2}$. Results of chemical analysis of calcined powders are collected in Table 2.3.

\section{TABLE 2.3}

Percentage of Different Oxidation States in Calcined Samples

\begin{tabular}{lccc}
\hline & \multicolumn{3}{c}{ Mn Content (\%) } \\
\cline { 2 - 4 }$T_{\text {calc }}\left({ }^{\circ} \mathbf{C}\right)$ & Mn(II) & Mn(III) & Overall Mn (Mn(IV)) \\
\hline 25 & 0.9 & 37.5 & $41(2.6)$ \\
100 & 1.2 & 37.5 & $48(9.3)$ \\
200 & 2.2 & 37.5 & $51.5(11.8)$ \\
300 & 2.5 & 26 & $55(26.5)$ \\
400 & 2.2 & 24 & $60(33.8)$ \\
500 & 6.4 & 20.5 & $61.5(34.6)$ \\
700 & 6.8 & 25 & $63.5(31.7)$ \\
\hline
\end{tabular}


From the data, it can be derived that the samples calcined at lower temperatures up to $200^{\circ} \mathrm{C}$ contained similar proportion of $\mathrm{Mn}$ (III), but overall manganese content in a sample was increased. It is noteworthy that increase of overall manganese content took place in all temperature range from $25^{\circ} \mathrm{C}$ up to $700^{\circ} \mathrm{C}$. Further heating above $300^{\circ} \mathrm{C}$ caused substantial decrease of $\mathrm{Mn}$ (III) content down to $20 \mathrm{wt} \%$ at $500^{\circ} \mathrm{C}$, with simultaneous increase of $\mathrm{Mn}$ (II) content up to $6.4 \mathrm{wt} \%$. However, the sample calcined at $700^{\circ} \mathrm{C}$ contained higher proportion of $\mathrm{Mn}(\mathrm{III})$. Figure 2.20 presents IR spectra diagrams of the calcined powders.

It can be noted from Figure 2.20a-c that the powders calcined at temperatures $100^{\circ} \mathrm{C}-300^{\circ} \mathrm{C}$ are basically identical. Weak step-resembling absorption bands are seen at 752 and $585 \mathrm{~cm}^{-1}$, as well as absorption bands at 516 and $453 \mathrm{~cm}^{-1}$. The latter is typical for the bond $\mathrm{Mn}-\mathrm{O}$ in $\mathrm{MnOOH}$ molecule. On the other hand, the absorption band at $516 \mathrm{~cm}^{-1}$ can be attributed to Mn-O bond vibration in $\mathrm{Mn}_{2} \mathrm{O}_{3}$ (Kar et al. 2015), whereas the one at $585 \mathrm{~cm}^{-1}$ can be attributed to $\mathrm{Mn}-\mathrm{O}$ bond vibration either in $\mathrm{Mn}_{2} \mathrm{O}_{3}$ or $\mathrm{MnO}_{2}$ molecules (Khan et al. 2011). It is most probable that the absorption band at $752 \mathrm{~cm}^{-1}$ is the result of $\mathrm{Mn}-\mathrm{O}$ bond vibration, too.

When the powders were calcined at higher temperatures of $400^{\circ} \mathrm{C}-500^{\circ} \mathrm{C}$, their IR spectra revealed absorption bands at 706 to $703,585,516$, and $463 \mathrm{~cm}^{-1}$ as it is shown in Figure 2.20d and e. The first ones, corresponding with 706 to $703 \mathrm{~cm}^{-1}$, can be attributed to $\mathrm{Mn}-\mathrm{O}$ bond vibration in $\mathrm{MnO}_{2}$ (Khan et al. 2011),

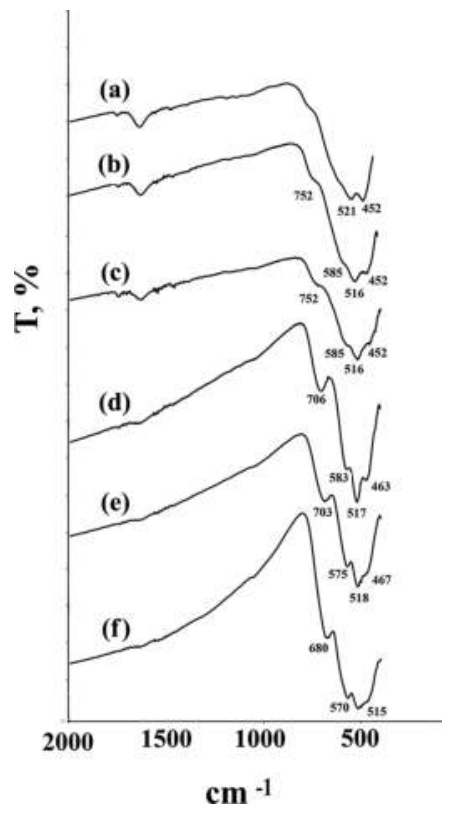

FIGURE 2.20

IR spectra of calcined samples for 1 hour at different temperatures: (a) $100^{\circ} \mathrm{C}$; (b) $200^{\circ} \mathrm{C}$; (c) $300^{\circ} \mathrm{C}$; (d) $400^{\circ} \mathrm{C}$; (e) $500^{\circ} \mathrm{C}$; and (f) $700^{\circ} \mathrm{C}$. IR, infrared. 
whereas the last one at $463 \mathrm{~cm}^{-1}$ to $\mathrm{Mn}-\mathrm{O}$ bond vibration in $\mathrm{MnOOH}$. It is noteworthy that for the sample calcined at $500^{\circ} \mathrm{C}$, the absorption band intensity at $463 \mathrm{~cm}^{-1}$ decreased, and it is present in the diagram as a weak step-resembling pulse. Furthermore, for the sample calcined at $700^{\circ} \mathrm{C}$, the absorption band at $463 \mathrm{~cm}^{-1}$ disappeared, but the bands at 680,570 , and $515 \mathrm{~cm}^{-1}$ are present. The one corresponding with $680 \mathrm{~cm}^{-1}$ can be attributed to $\mathrm{Mn}-\mathrm{O}$ bond vibration in $\mathrm{MnO}_{2}$ ( $\mathrm{Li}$ et al. 2010), while the one at $570 \mathrm{~cm}^{-1}$ can be attributed to $\mathrm{Mn}-\mathrm{O}$ bond vibration either in $\mathrm{Mn}_{2} \mathrm{O}_{3}$ or $\mathrm{MnO}_{2}$ molecules.

Thermogravimetric analysis results are presented in Figure 2.21. In the temperature range between $60^{\circ} \mathrm{C}$ and $350^{\circ} \mathrm{C}$, main mass loss of $24 \mathrm{wt} \%$ takes place with its peak at $130^{\circ} \mathrm{C}$. This may be attributed both to the removal of the adsorbed water from the particles surface and to the partial decomposition of manganese oxyhydroxide represented by the following reactions (Sampanthar et al. 2007):

$$
\begin{gathered}
4 \mathrm{MnOOH}+\mathrm{O}_{2} \rightarrow 4 \mathrm{MnO}_{2}+2 \mathrm{H}_{2} \mathrm{O} \\
2 \mathrm{MnO}(\mathrm{OH}) \rightarrow \mathrm{Mn}_{2} \mathrm{O}_{3}+\mathrm{H}_{2} \mathrm{O}
\end{gathered}
$$

Data obtained from chemical analysis and collected in Table 2.3 indicated that calcination at $100^{\circ} \mathrm{C}-200^{\circ} \mathrm{C}$ caused, on one hand, increased overall

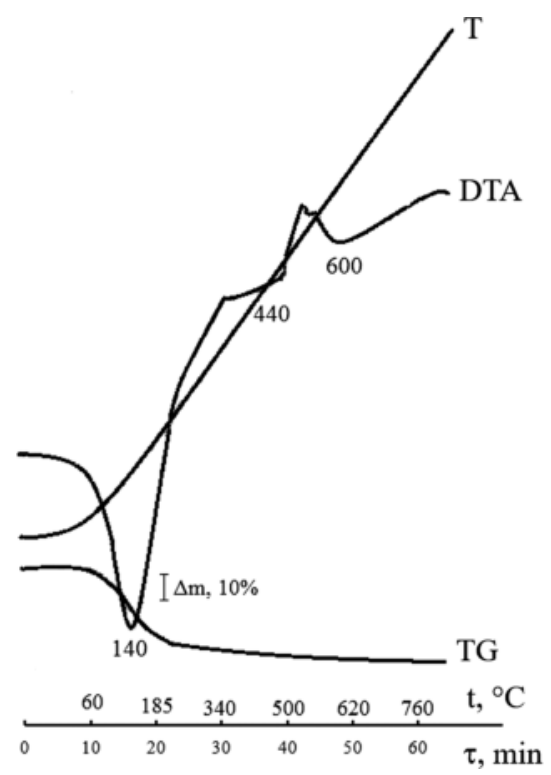

FIGURE 2.21

Thermogravimetric analysis of the dried sample of the powder obtained from manganese solution at $t=80^{\circ} \mathrm{C}, V_{\text {all }}=75 \mathrm{~mL}$. Curves: $T$ - temperature, $T G$ - mass changes, DTA - differential thermal analysis curve. 
content of manganese after removal of the adsorbed water and, on the other hand, increased content of $\mathrm{Mn}(\mathrm{IV})$ as a result of reaction (2.2). Consequently, in the IR spectra of the samples calcined at $200^{\circ} \mathrm{C}$, there were absorption bands corresponding with 752 and $585 \mathrm{~cm}^{-1}$. Appearance of the absorption band at $516 \mathrm{~cm}^{-1}$ indicates that reaction (2.3) took place.

Subsequent heating caused further loss of mass indicated in the thermogravimetric diagram by the curve marked TG in Figure 2.21. The differential thermal analysis curve DTA exhibits thermal peak in the range of 350-550 with its maximum at $440^{\circ} \mathrm{C}$. It corresponds with mass loss of $4 \%$ due to the manganese oxyhydroxide decomposition described by equation (2.2).

Chemical analysis presented in Table 2.3 shows the increase of Mn(IV) amount, whereas IR spectra reveal the absorption bands at 703 and $575 \mathrm{~cm}^{-1}$. The absorption band at $453 \mathrm{~cm}^{-1}$ that corresponds with bond $\mathrm{Mn}-\mathrm{O}$ vibrations in $\mathrm{MnO}(\mathrm{OH})$ becomes weaker. Thermal peak in the range of 500-800 with its maximum at $600^{\circ} \mathrm{C}$ (mass loss of $2 \%$ ) corresponds with decomposition of manganese dioxide according to the following equation:

$$
6 \mathrm{MnO}_{2} \rightarrow 3 \mathrm{Mn}_{2} \mathrm{O}_{3}+1.5 \mathrm{O}_{2}
$$

Thus, there is increase of $\mathrm{Mn}(\mathrm{III})$ in the examined samples.

Thus, the main product of the interaction between $\mathrm{Mn}^{2+}$ and $\mathrm{MnO}_{4}{ }^{2-}$ in alkaline environment is $\mathrm{MnO}(\mathrm{OH})$. Its decomposition produces the mixture of oxides $\mathrm{Mn}_{2} \mathrm{O}_{3}$ and $\mathrm{MnO}_{2}$. Formation process of the manganese oxyhydroxide is described by the reaction as follows:

$$
4 \mathrm{Mn}(\mathrm{OH})_{2}+\mathrm{KMnO}_{4} \rightarrow 5 \mathrm{MnO}(\mathrm{OH})+\mathrm{KOH}+\mathrm{H}_{2} \mathrm{O}
$$

Interaction of the manganese chloride and potassium permanganate in neutral environment $\mathrm{pH} 7$ caused the formation of spherical particles with diameters $0.4-0.7 \mu \mathrm{m}$. IR spectrum of this product revealed absorption bands at 560,513 , and $458 \mathrm{~cm}^{-1}$ as it is seen in Figure 2.22. Comparative analysis of this spectrum with the ones belonging to the samples precipitated in alkaline

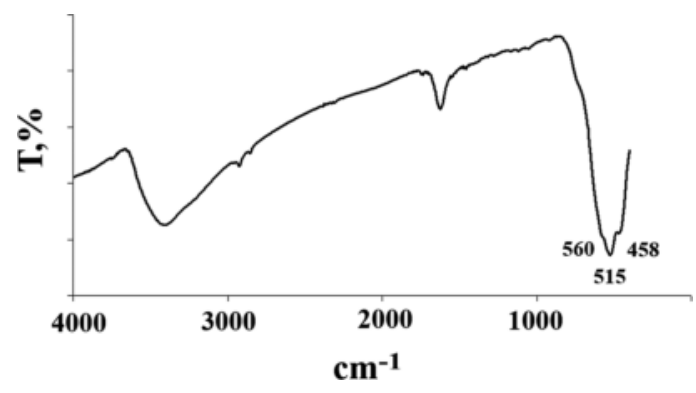

FIGURE 2.22

IR spectrum of the powder obtained from manganese chloride and potassium permanganate reaction in neutral environment $\mathrm{pH}$ 7. IR, infrared. 
environment indicated that the shift of absorption band from 443 to $458 \mathrm{~cm}^{-1}$ accompanied by its intensity decreases. The absorption band at $560 \mathrm{~cm}^{-1}$ is attributed to $\mathrm{Mn}-\mathrm{O}$ bond vibration either in $\mathrm{Mn}_{2} \mathrm{O}_{3}$ or in $\mathrm{MnO}_{2}$ molecules. It can be assumed that neutral environment $\mathrm{pH} 7$ results with decreased formation of manganese oxyhydroxide and thus increased proportion of obtained oxides.

\subsubsection{Synthesis of Manganese Dioxide}

$\mathrm{MnO}_{2}$ particles were obtained after thermal decomposition of manganese nitrate at $200^{\circ} \mathrm{C}$ during 2 hours. Presence of the manganese dioxide was confirmed by the IR structural analysis. In the IR spectrum of the obtained powder shown in Figure 2.23, absorption bands are seen at 680,650,600, and $522 \mathrm{~cm}^{-1}$. They can be attributed to $\mathrm{Mn}-\mathrm{O}$ bond vibration in $\mathrm{MnO}_{2}$.

Figure 2.24a presents SEM images of the samples obtained from reaction (2.5), and Figure 2.24b shows the samples from thermal decomposition. The latter consists of spherical nanoparticles below $50 \mathrm{~nm}$. However, their SSA was very small, just $5.3 \mathrm{~m}^{2} / \mathrm{g}$.

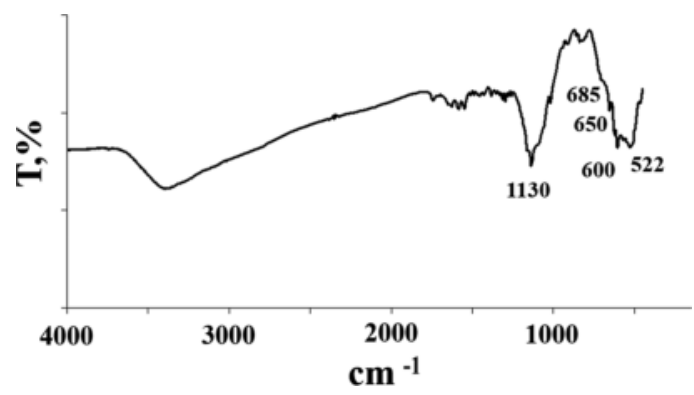

FIGURE 2.23

IR spectrum of the powder obtained from thermal decomposition of manganese nitrate at $200^{\circ} \mathrm{C}$ during 2 hours. IR, infrared.
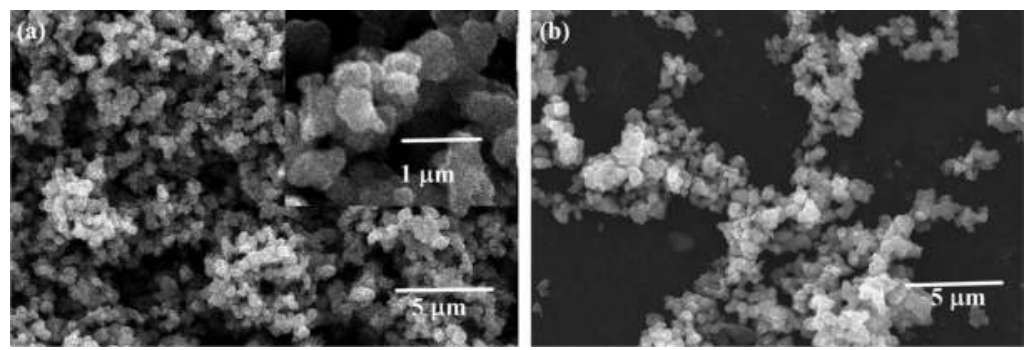

FIGURE 2.24

SEM images of the particles obtained from ions $\mathrm{Mn}^{2+}$ and $\mathrm{MnO}_{4}{ }^{2-}$ interaction at $\mathrm{pH} 7$ (a) and from thermal decomposition of manganese nitrate at $200^{\circ} \mathrm{C}(\mathrm{b})$. SEM, scanning electron microscopy. 


\subsection{Sorption Characteristics of Iron Oxides and Manganese Dioxide and Oxyhydroxide}

\subsubsection{Iron Oxides}

In Figures 2.25 and 2.26, diagrams of metal ions extraction percentage $E \%$ are shown for $\alpha-\mathrm{Fe}_{2} \mathrm{O}_{3}, \gamma-\mathrm{Fe}_{2} \mathrm{O}_{3}$, and $\mathrm{Fe}_{3} \mathrm{O}_{4}$ particles as a function of $\mathrm{pH}$. Figure 2.25 represents experiments where ammonia aqueous solution of $25 \%$ was used for $\mathrm{pH}$ regulation, whereas Figure 2.26 illustrates the case where $0.1 \mathrm{M}$ solution of $\mathrm{NaOH}$ was used. In the range of $\mathrm{pH}$ between 5 and 9, the

(a)

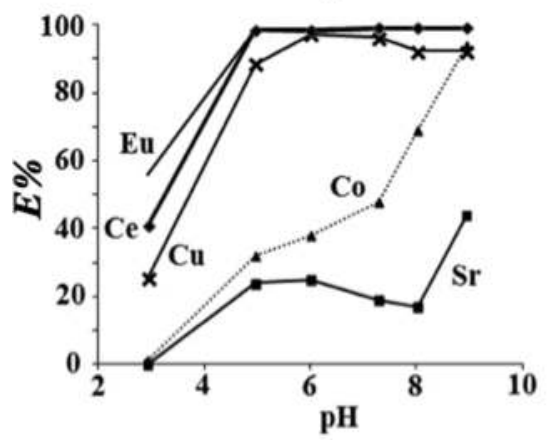

(b)

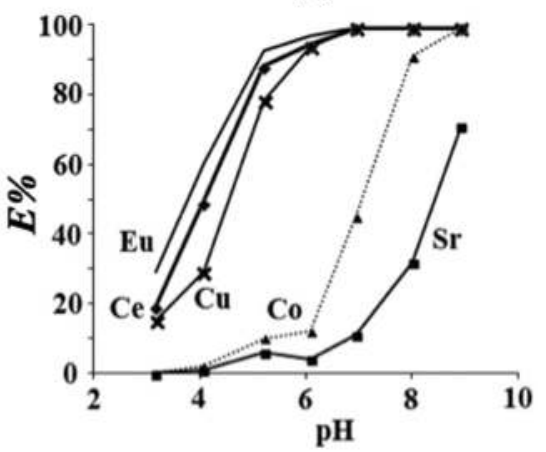

FIGURE 2.25

Extraction percentage $E \%$ as a function of $\mathrm{pH}$ for the particles $\alpha-\mathrm{Fe}_{2} \mathrm{O}_{3}$ (a) and $\mathrm{Fe}_{3} \mathrm{O}_{4}$ (b) at $\mathrm{pH}$ regulation with $25 \%$ ammonia aqueous solution.

(a)

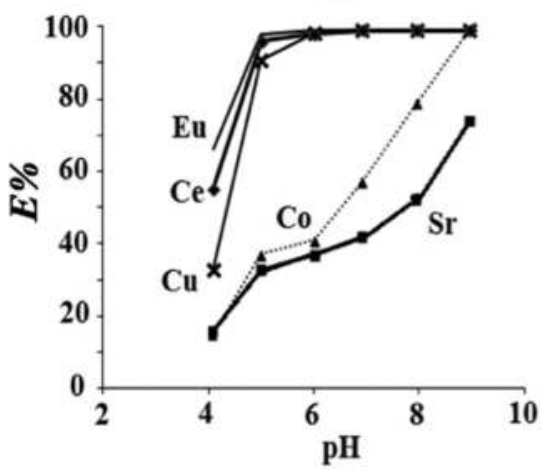

(b)

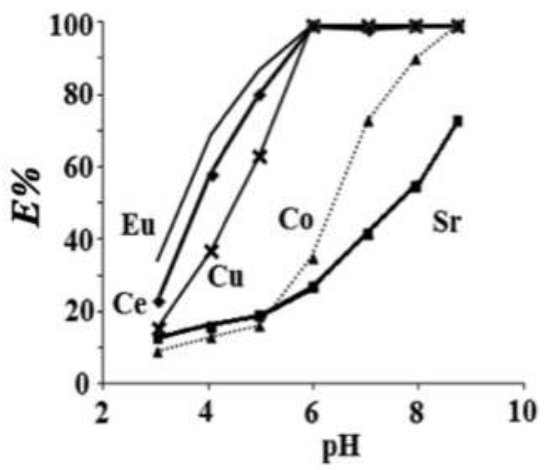

FIGURE 2.26

Extraction percentage as a function of $\mathrm{pH}$ for the particles $\alpha-\mathrm{Fe}_{2} \mathrm{O}_{3}$ (a) and $\mathrm{Fe}_{3} \mathrm{O}_{4}$ (b) at $\mathrm{pH}$ regulation with $0.1 \mathrm{M}$ solution of $\mathrm{NaOH}$. 
particles performed high ability to extract europium, cerium, and copper removing more than $95 \%$ of metal ions. Maximal values of $E \%$ were reached at $\mathrm{pH} 5.5$ for both $\alpha-\mathrm{Fe}_{2} \mathrm{O}_{3}$ and $\gamma-\mathrm{Fe}_{2} \mathrm{O}_{3}$, whereas in case of $\mathrm{Fe}_{3} \mathrm{O}_{4}$, maximal extraction percentage was reached at $\mathrm{pH}$ 6.5.

Moreover, iron oxide particles performed good selectivity toward copper, europium, and cerium, which is important in case of selective removal applications. Cobalt and strontium extraction percentage increased for higher $\mathrm{pH}$ values and became maximal at $\mathrm{pH}$ 9. Strontium exhibited small peak at $\mathrm{pH}$ 5.5 seen in Figure 2.25b.

According to the $\mathrm{pH}_{50}$ parameter, ions $\alpha-\mathrm{Fe}_{2} \mathrm{O}_{3}$ can be ordered from smaller to larger $\mathrm{pH}: \mathrm{Eu}^{3+}\left(\mathrm{pH}_{50} 3\right)>\mathrm{Ce}^{3+}\left(\mathrm{pH}_{50} 3.2\right)>\mathrm{Cu}^{2+}\left(\mathrm{pH}_{50} 3.5\right)>\mathrm{Zn}^{2+}\left(\mathrm{pH}_{50} 5\right)>$ $\mathrm{Cd}^{2+}\left(\mathrm{pH}_{50} 6\right)>\mathrm{Co}^{2+}\left(\mathrm{pH}_{50} 7.5\right)>\mathrm{Mn}^{2+}\left(\mathrm{pH}_{50}\right.$ 8). In case of strontium ions, $\mathrm{pH}_{50}$ is reached at $\mathrm{pH}$ over 9 . When the metals are ordered this way, the results stay in conformity with data reported by Takematsu (1979-1980). However, our values of $\mathrm{pH}_{50}$ parameter appear to be different. For instance, $\mathrm{pH}_{50}$ toward cerium is 5.8 with extraction percentage $100 \%$ reached at $\mathrm{pH} 7$, whereas for zinc, it is 7.5 (Musić and Ristic 1988), and for copper, it is 5.5 (Benjamin and Leckie 1981). Shift of the $\mathrm{pH}_{50}$ parameter toward acidity can be attributed to the state of the sorbent surface dependent on its synthesis prehistory.

As it is seen from Figure 2.26, replacement of ammonia solution with $\mathrm{NaOH}$ solution had no substantial effect on the subsequent $\mathrm{pH}_{50}$ parameter. However, additional peak for strontium removal disappeared, and $E \%$ curve rises plainly up to $70 \%$ at $\mathrm{pH} 9$.

It must be taken into account, however, that $\mathrm{pH}_{50}$ parameter is mainly a function of the solid-to-liquid ratio, with smaller effect of other variables. Kosmulski (2001, p. 355) indicated that according to systematic studies, $\mathrm{pH}_{50}$ parameter of metal cations decreases by one $\mathrm{pH}$ unit when the solid-to-liquid ratio increases by the order of magnitude, provided that the other variables remain unchanged.

Phase changes in $\mathrm{Fe}_{2} \mathrm{O}_{3}$ do not have noticeable effect on the extraction percentage from aqueous solutions. Thus, in case of $\gamma-\mathrm{Fe}_{2} \mathrm{O}_{3}$ phase, metal ions extraction dynamics is similar, as it is seen in Figure 2.27. Increase of $\mathrm{pH}$ caused increase of the extraction percentage up to maximal values of $90 \%$ at pH 5 for copper, cerium, and europium. Also in case of cobalt and strontium, extraction percentage increased for higher $\mathrm{pH}$ values and reached maximal $90 \%$ and $60 \%$, respectively, at $\mathrm{pH} 9$.

Figure 2.28 presents leaching of iron ions from the studies sorbent dependent on $\mathrm{pH}$. It is known that $\mathrm{Fe}_{3} \mathrm{O}_{4}$ is better soluble in acid environment than $\mathrm{Fe}_{2} \mathrm{O}_{3}$. The measurement results demonstrated that iron concentration in the solutions after sorption for both examined oxides at $\mathrm{pH} 5$ did not exceed maximal acceptable concentration $\left(\mathrm{MAC}_{\mathrm{Fe}}{ }^{3+}\right.$ ) of $0.3 \mathrm{mg} / \mathrm{L}$ (Mishukova et al. 2015). The World Health Organization indicated that in well water, iron concentrations below $0.3 \mathrm{mg} / \mathrm{L}$ were characterized as unnoticeable, whereas levels of $0.3-3 \mathrm{mg} / \mathrm{L}$ were found acceptable, especially for people drinking anaerobic well water (WHO 2003). Drinking Water Standards issued by the 


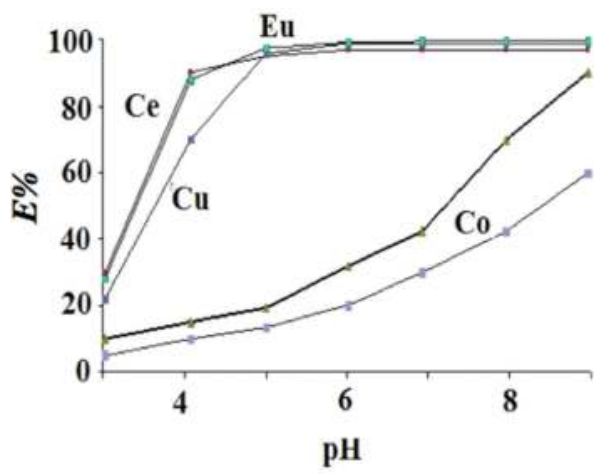

FIGURE 2.27

Extraction percentage $E \%$ as a function of $\mathrm{pH}$ for the particles $\gamma-\mathrm{Fe}_{2} \mathrm{O}_{3}$.

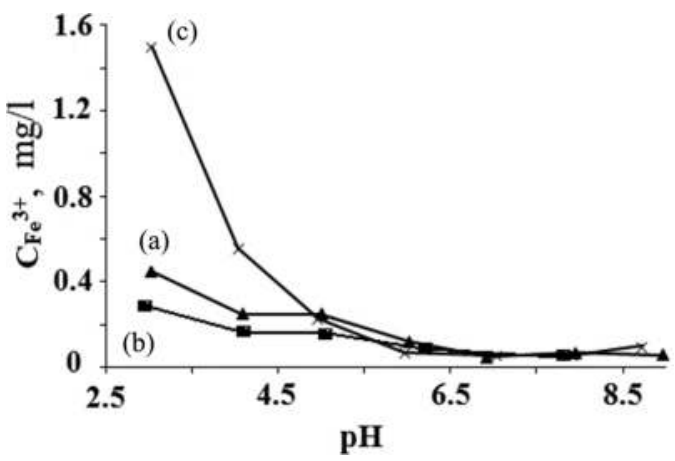

FIGURE 2.28

Iron concentration $\mathrm{C}_{\mathrm{Fe}}{ }^{3+}$ in the solution after 40 minutes: (a) $\alpha-\mathrm{Fe}_{2} \mathrm{O}_{3}$, (b) $\gamma-\mathrm{Fe}_{2} \mathrm{O}_{3}$, and (c) $\mathrm{Fe}_{3} \mathrm{O}_{4}$.

Bureau of Indian Standards (IS: 10500: 1991) sets desirable limit at $0.3 \mathrm{mg} / \mathrm{L}$ and permissible limit at $1.0 \mathrm{mg} / \mathrm{L}$. However, the European Union Drinking Water Directive (98/83/EC) prescribes limit value for iron as $200 \mu \mathrm{g} / \mathrm{L}$ (Environmental Protection Agency 2001).

To summarize, considering acceptable concentration of iron in drinking water as $0.3 \mathrm{mg} / \mathrm{L}$, iron oxides may be successfully applied for its removal at $\mathrm{pH}$ above 5 .

Figures 2.29-2.31 present adsorption isotherms of europium, cerium, copper, and cobalt. This sort of isotherms indicates that the sorbent surface is nonuniform. The results of calculation according to Langmuir model are shown in Table 2.4.

It should be noted that sorption capacity of $\mathrm{Fe}_{2} \mathrm{O}_{3}$ particles with SSA = $150 \mathrm{~m}^{2} / \mathrm{g}$ is higher than that of $\mathrm{Fe}_{3} \mathrm{O}_{4}$-based sorbents with $\mathrm{SSA}=130 \mathrm{~m}^{2} / \mathrm{g}$, which is true for all analyzed sorbed metals. The highest sorption capacity was observed for europium, and it was 21.3 and $19.7 \mathrm{mg} / \mathrm{g}$ on the $\mathrm{Fe}_{2} \mathrm{O}_{3}$ and 

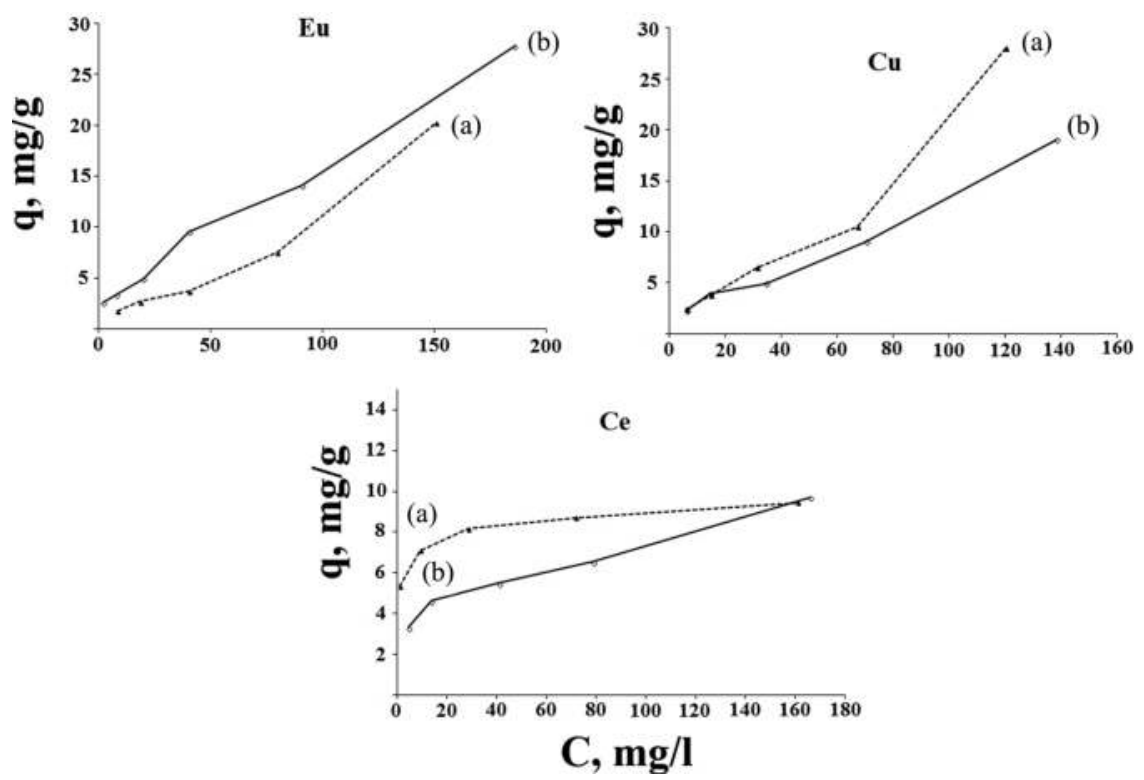

FIGURE 2.29

Isotherms of $\mathrm{Eu}, \mathrm{Cu}$, and $\mathrm{Ce}$ sorption onto iron oxides: (a) $\mathrm{Fe}_{2} \mathrm{O}_{3}$ and (b) $\mathrm{Fe}_{3} \mathrm{O}_{4}$.

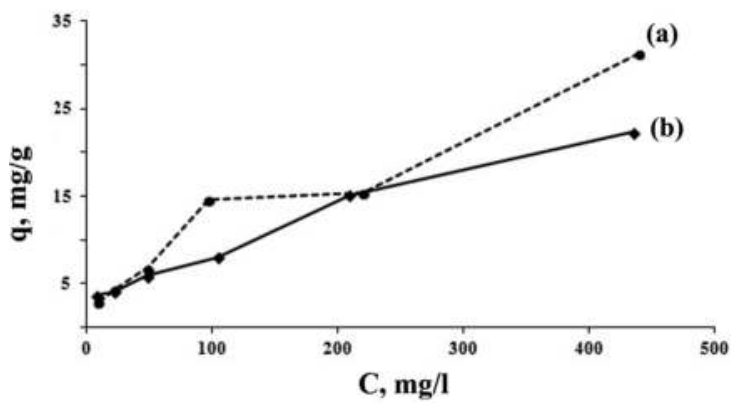

FIGURE 2.30

Cobalt sorption isotherms onto iron oxides: (a) $\mathrm{Fe}_{2} \mathrm{O}_{3}$ and (b) $\mathrm{Fe}_{3} \mathrm{O}_{4}$.

$\mathrm{Fe}_{3} \mathrm{O}_{4}$ particles, respectively. The smallest one took place in case of cerium and was $9.2 \mathrm{mg} / \mathrm{g}$ on $\mathrm{Fe}_{2} \mathrm{O}_{3}$ particles and $7.5 \mathrm{mg} / \mathrm{g}$ on $\mathrm{Fe}_{3} \mathrm{O}_{4}$ particles.

\subsubsection{Manganese Oxyhydroxide and Dioxide}

The experimental researches proved that the extraction percentage of $\mathrm{MnO}(\mathrm{OH})$ does not depend on the SSA, and it is over $90 \%$ in case of europium, cerium, cobalt, and strontium ions removal at $\mathrm{pH} 3-9$. Figure 2.32 presents extraction percentage $E \%$ of metal ions onto $\mathrm{MnO}(\mathrm{OH})$ particles 

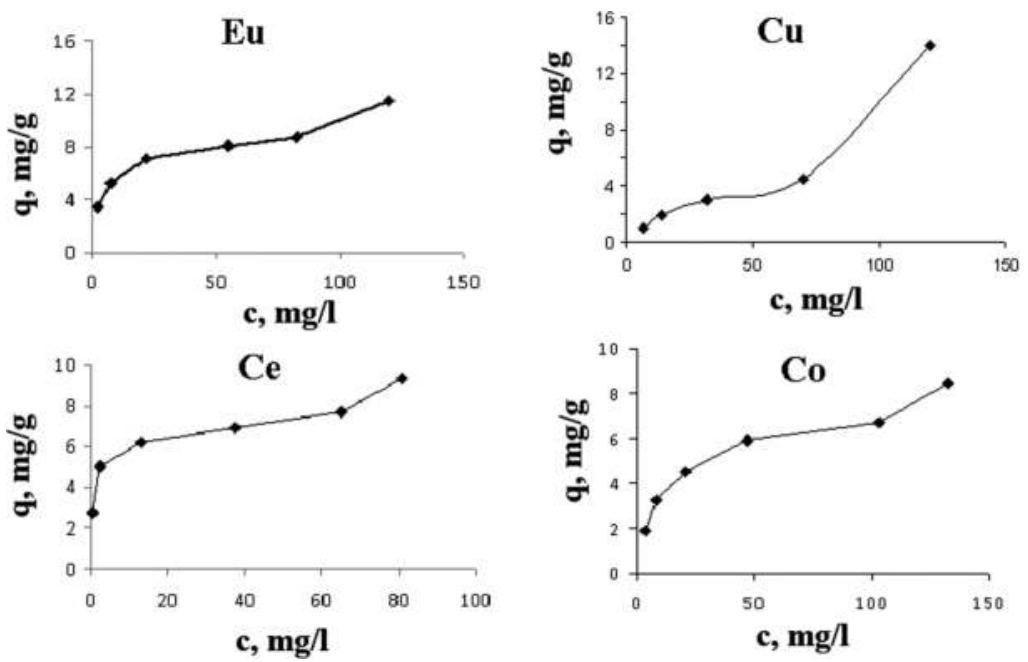

FIGURE 2.31

Isotherms of $\mathrm{Eu}, \mathrm{Cu}, \mathrm{Ce}$, and Co sorption onto iron oxide $\gamma-\mathrm{Fe}_{2} \mathrm{O}_{3}$.

TABLE 2.4

Parameters of Sorption Isotherms onto Iron Oxides $\mathrm{Fe}_{2} \mathrm{O}_{3}$ and $\mathrm{Fe}_{3} \mathrm{O}_{4}$

\begin{tabular}{lcccc}
\hline & \multicolumn{4}{c}{$q_{\max }(\mathbf{m g} / \mathbf{g})$} \\
\cline { 2 - 5 } & \multicolumn{2}{c}{$\boldsymbol{\alpha}-\mathrm{Fe}_{2} \mathrm{O}_{3}$} & $\mathrm{Fe}_{3} \mathbf{O}_{4}$ & $\boldsymbol{\gamma}-\mathrm{Fe}_{2} \mathrm{O}_{3}$ \\
\hline $\mathrm{SSA}\left(\mathrm{m}^{2} / \mathrm{g}\right)$ & 150 & 30 & 130 & 35 \\
$\mathrm{Eu}(\mathrm{pH} \mathrm{5)}$ & 21.3 & 9.1 & 19.7 & 8.8 \\
$\mathrm{Ce}$ (pH 5) & 9.2 & 6.2 & 8.9 & 7.1 \\
$\mathrm{Cu}$ (pH 5) & 15.7 & 6.5 & 14.6 & 6.5 \\
$\mathrm{Co}$ (pH 6.5) & 18.7 & 7.3 & 17.3 & 7.4 \\
\hline
\end{tabular}

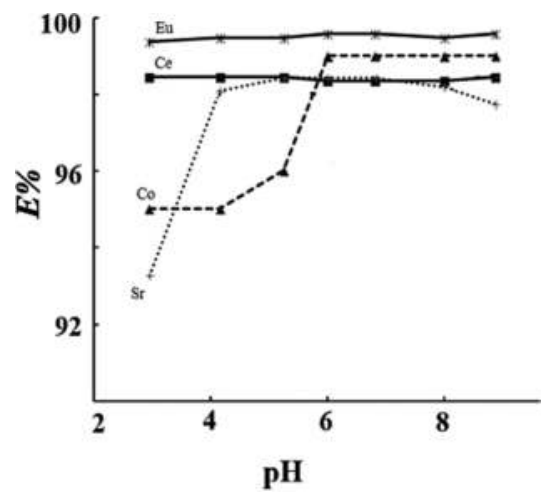

FIGURE 2.32

Extraction percentage $E \%$ of metal ions onto $\mathrm{MnO}(\mathrm{OH})$ particles at various $\mathrm{pH}$. 
with SSA $=160 \mathrm{~m}^{2} / \mathrm{g}$. In case of europium and cerium, $E \%$ is over $98 \%$ at any $\mathrm{pH}$. However, extraction of cobalt at $\mathrm{pH}$ below 6 decreases from $98 \%$ down to $95 \%$, whereas $E \%$ of strontium decreases even down to $93 \%$.

For the particles with different SSA, sorption capacity toward europium, cerium, strontium, and cobalt was determined. In Figure 2.33, there are sorption isotherms of these metals on the particles $\mathrm{MnO}(\mathrm{OH})$ with $\mathrm{SSA}=$ $360 \mathrm{~m}^{2} / \mathrm{g}$.

In all cases, isotherms are quite similar, especially the ones representing strontium and cobalt. Sorption isotherm for cerium exhibits almost the same shape, but the values are of ca. 50\% higher. Europium sorption isotherm at the beginning lays close to the lines 1 and 2 and then moves higher than the line 3. Similar curvature of isoterms can be noted for three samples of manganese oxyhydroxide with different SSAs.

Values of sorption capacity $q_{\max }$ of $\mathrm{MnO}(\mathrm{OH})$ particles with different SSA toward different metal ions are collected in Table 2.5. It is noteworthy that SSA has little effect on sorption capacity. For each sorbent, sorption capacity

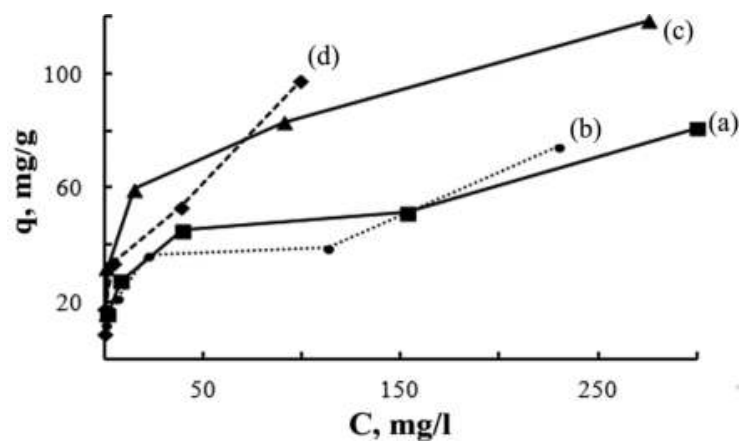

FIGURE 2.33

Sorption isotherms $q_{e}$ of different metal ions at $T=20^{\circ} \mathrm{C}$ on the $\mathrm{MnO}(\mathrm{OH})$ with SSA $=360 \mathrm{~m}^{2} / \mathrm{g}$ : (1) Sr; (2) Co; (3) Ce; and (4) Eu. SSA, specific surface area.

\section{TABLE 2.5}

Sorption Capacity of $\mathrm{MnO}(\mathrm{OH})$ Particles Toward Different Metals Calculated According to Langmuir Model

\begin{tabular}{|c|c|c|c|c|c|c|c|c|c|}
\hline \multirow[b]{2}{*}{ Metal } & \multicolumn{3}{|c|}{$\mathrm{SSA}=160 \mathrm{~m}^{2} / \mathrm{g}$} & \multicolumn{3}{|c|}{$\mathrm{SSA}=210 \mathrm{~m}^{2} / \mathrm{g}$} & \multicolumn{3}{|c|}{$\mathrm{SSA}=360 \mathrm{~m}^{2} / \mathrm{g}$} \\
\hline & $K_{L}$ & $\begin{array}{c}q_{\max } \\
(\mathrm{mg} / \mathrm{g})\end{array}$ & $R^{2}(\%)$ & $\boldsymbol{K}_{L}$ & $\begin{array}{c}q_{\max } \\
(\mathrm{mg} / \mathrm{g})\end{array}$ & $R^{2}(\%)$ & $\boldsymbol{K}_{L}$ & $\begin{array}{c}q_{\max } \\
(\mathrm{mg} / \mathrm{g})\end{array}$ & $R^{2}(\%)$ \\
\hline$\overline{\mathrm{Eu}(\mathrm{pH} 5)}$ & - & - & - & 0.02 & 49.5 & 96.64 & 22.78 & 49.1 & 96.67 \\
\hline $\mathrm{Ce}(\mathrm{pH} 5)$ & 1.59 & 100.0 & 95.14 & 0.05 & 83.2 & 91.77 & 0.22 & 98.0 & 86.59 \\
\hline $\mathrm{Sr}(\mathrm{pH} 5)$ & 0.73 & 45.2 & 88.61 & - & - & - & 0.30 & 50.6 & 91.47 \\
\hline $\mathrm{Co}(\mathrm{pH} 6.5)$ & - & - & - & 0.03 & 20.0 & 96.24 & 1.19 & 32.0 & 90.93 \\
\hline
\end{tabular}

SSA, specific surface area. 
remains almost unchanged for different values of specific surface, and it can be noted that $q_{\max }$ is largest in case of cerium and smallest in case of cobalt.

During the experimental works, it was found that the storage process had negative effect on the $\mathrm{MnO}(\mathrm{OH})$ sorption capacity toward cobalt. The hypothesis was proposed that the decrease of sorption capacity can be attributed to the changes in substance composition. In order to verify this hypothesis, composition of the manganese oxyhydroxide was examined after storage in various conditions. Namely, the group of samples $\mathrm{MnO}(\mathrm{OH})-1$ were stored for $\tau_{\text {stor }}=1$ year in the air environment, the samples $\mathrm{MnO}(\mathrm{OH})-2$ were stored in argon atmosphere and $\mathrm{MnO}(\mathrm{OH})-3$ were stored in high humidity. Some samples were taken from each group and checked after 3, 6, and 12 months. Before the measurement, the humid samples were dried in the air at room temperature for 24 hours.

X-ray diffraction (XRD) analysis of the samples indicated that, irrespective of storage conditions, all diagrams were similar to the one obtained for the freshly synthesized powder $\mathrm{MnO}(\mathrm{OH})$. Very weak reflections corresponding with $\mathrm{MnO}(\mathrm{OH})$ and $\mathrm{MnO}_{2}$ are distinguishable. In the IR spectrum of the fresh powder marked $a$ in Figure 2.34, there are clear main absorption bands at 443 and $505 \mathrm{~cm}^{-1}$ that correspond with $\mathrm{Mn}-\mathrm{O}$ bond vibrations in $\mathrm{MnO}(\mathrm{OH})$ molecules. It is noteworthy that apart from storage time 12 months, samples $\mathrm{MnO}(\mathrm{OH})-1,2$, and 3 were exposed to different environmental conditions: (1) in water, (2) in inert atmosphere, and (3) in air. For them, main peaks can

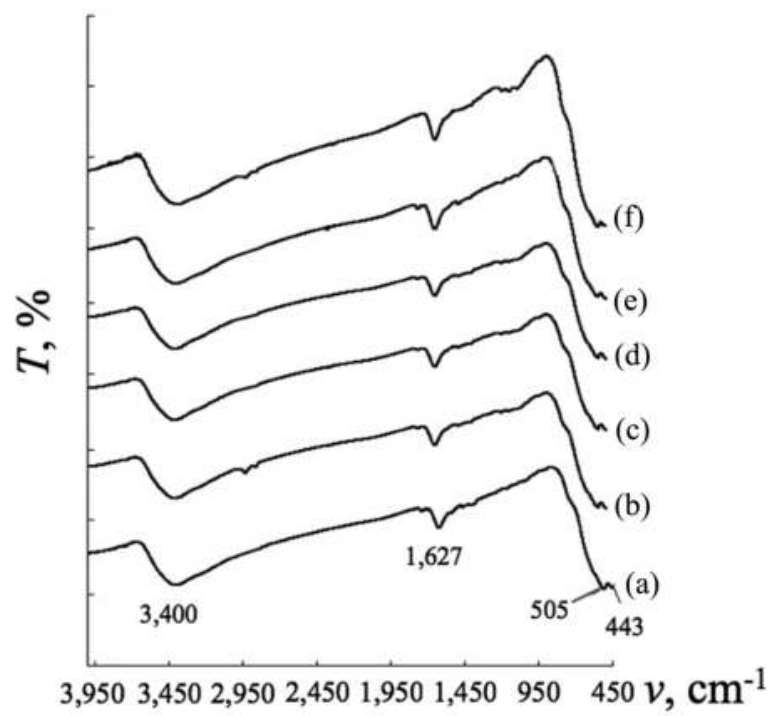

FIGURE 2.34

IR spectra of the samples: (a) freshly synthesized powder; (b) sample $\mathrm{MnO}(\mathrm{OH})-1$ after 3 months; (c) sample $\mathrm{MnO}(\mathrm{OH})-1$ after 6 months; (d) sample $\mathrm{MnO}(\mathrm{OH})-1$ after 12 months; (e) sample $\mathrm{MnO}(\mathrm{OH})-2$ after 12 months; and (f) sample $\mathrm{MnO}(\mathrm{OH})-3$ after 12 months. IR, infrared. 
be observed only at 443 and $505 \mathrm{~cm}^{-1}$, attributed to $\mathrm{Mn}-\mathrm{O}$ bond vibrations in $\mathrm{MnO}(\mathrm{OH})$ molecules.

Results of chemical analysis are collected in Table 2.6. They indicate that the main oxidation state of manganese is $\mathrm{Mn}$ (III). Variations of the $\mathrm{Mn}$ (II) and $\mathrm{Mn}(\mathrm{IV})$ content in the samples are omittable. However, the effect of the storage process on the decrease of SSA is substantial. The initial SSA for the samples $\mathrm{MnO}(\mathrm{OH})-1$ and $\mathrm{MnO}(\mathrm{OH})-2$ was $360 \mathrm{~m}^{2} / \mathrm{g}$, but after they were stored for 12 months, SSA decreased down to 266 and $258 \mathrm{~m}^{2} / \mathrm{g}$, respectively.

Thus, it was proved that storage of $\mathrm{MnO}(\mathrm{OH})$ powder for $\tau_{\text {stor }}=12$ months does not effect with its chemical composition changes.

Differentiation of the storage conditions had no effect on the extraction percentage, too. Figure 2.35 presents the $E \%$ results for strontium, europium, and cobalt removal onto freshly synthesized particles and onto the ones stored for 1 year in air. In the range $\mathrm{pH} 4-9$, extraction percentage was above $90 \%, 98 \%$, and $96 \%$, respectively.

In order to determine maximal sorption capacity toward cobalt, strontium, and europium, sorption isotherms were drawn. Table 2.7 presents results calculated from the Langmuir model for cobalt ions. Substantial decrease of

TABLE 2.6

Chemical Analysis Results for Sample Group $\mathrm{MnO}(\mathrm{OH})-1$

\begin{tabular}{lccc}
\hline & \multicolumn{3}{c}{ Content of Mn (\%) } \\
\cline { 2 - 4 }$\tau_{\text {stor }}$ (months) & Mn(II) & Mn(III) & Overall Mn (Mn(IV)) \\
\hline- & 1.8 & 39.5 & $44.0(2.7)$ \\
3 & 1.7 & 41.9 & $45.5(1.9)$ \\
6 & 1.7 & 42.7 & $46.0(1.6)$ \\
12 & 1.7 & 42.7 & $46.0(1.6)$ \\
\hline
\end{tabular}

(a)

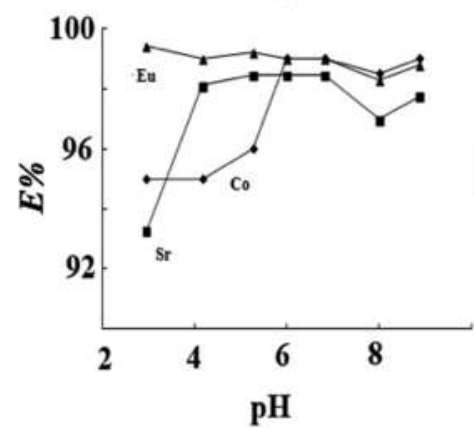

(b)

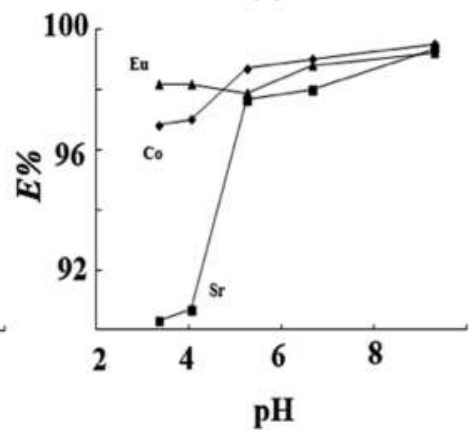

FIGURE 2.35

$\mathrm{MnO}(\mathrm{OH})$ extraction percentage $E \%$ versus $\mathrm{pH}$ : (a) freshly synthesized powder and (b) samples $\mathrm{MnO}(\mathrm{OH})-1$ after being stored for 12 months. 


\section{TABLE 2.7}

Sorption Characteristics of $\mathrm{MnO}(\mathrm{OH})$ Stored in Different Conditions

\begin{tabular}{|c|c|c|c|c|c|c|c|c|c|}
\hline \multirow[b]{3}{*}{$\tau_{\text {stor }}$ (months) } & \multicolumn{9}{|c|}{ Samples } \\
\hline & \multicolumn{3}{|c|}{$\mathrm{MnO}(\mathrm{OH})-1$} & \multicolumn{3}{|c|}{$\mathrm{MnO}(\mathrm{OH})-2$} & \multicolumn{3}{|c|}{$\mathrm{MnO}(\mathrm{OH})-3$} \\
\hline & $K_{L}$ & $\begin{array}{c}q_{\max } \\
(\mathrm{mg} / \mathrm{g})\end{array}$ & $R^{2}(\%)$ & $\boldsymbol{K}_{L}$ & $\begin{array}{c}q_{\max } \\
(\mathrm{mg} / \mathrm{g})\end{array}$ & $R^{2}(\%)$ & $\boldsymbol{K}_{L}$ & $\begin{array}{c}q_{\max } \\
(\mathrm{mg} / \mathrm{g})\end{array}$ & $R^{2}(\%)$ \\
\hline Fresh & 0.02 & 128.0 & 98.92 & - & - & - & - & - & - \\
\hline 3 & 0.05 & 53.5 & 99.19 & 0.09 & 48.0 & 93.70 & 0.16 & 45.1 & 90.43 \\
\hline 6 & 0.28 & 25.3 & 98.16 & 0.11 & 27.9 & 93.93 & 0.03 & 28.7 & 80.63 \\
\hline 12 & 0.03 & 25.4 & 96.24 & 0.12 & 25.6 & 95.81 & 0.07 & 26.2 & 91.25 \\
\hline
\end{tabular}

the sorption capacity toward cobalt was noted after 6 months, irrespective of the storage conditions. The capacity dropped from 128 down to $25 \mathrm{mg} / \mathrm{g}$. However, further storage time had no effect on the sorption capacity of the $\mathrm{MnO}(\mathrm{OH})$ particles.

There is noticeable decrease of the sorption capacity toward europium and strontium after storage. Fresh powder exhibited capacity $108.7 \mathrm{mg} / \mathrm{g}$, while after 1 year, its normal atmospheric conditions were decreased down to 48.8 $\mathrm{mg} / \mathrm{g}$ toward europium and $27.9 \mathrm{mg} / \mathrm{g}$ toward strontium. Hence, it may be assumed that after first 6 months of storage, $\mathrm{MnO}(\mathrm{OH})$ particles exhibited substantial loss of their sorption capacity toward cobalt, europium, and strontium.

Figure 2.36 presents comparative isotherms for the cobalt sorption onto $\mathrm{MnO}_{2}$ particles. They represent the particles obtained from decomposition of manganese nitrate at $200^{\circ} \mathrm{C}$ and the manganese oxyhydroxide calcined at $700^{\circ} \mathrm{C}$. The former exhibited sorption capacity toward cobalt $2.5 \mathrm{mg} / \mathrm{g}$, whereas the latter $4 \mathrm{mg} / \mathrm{g}$.
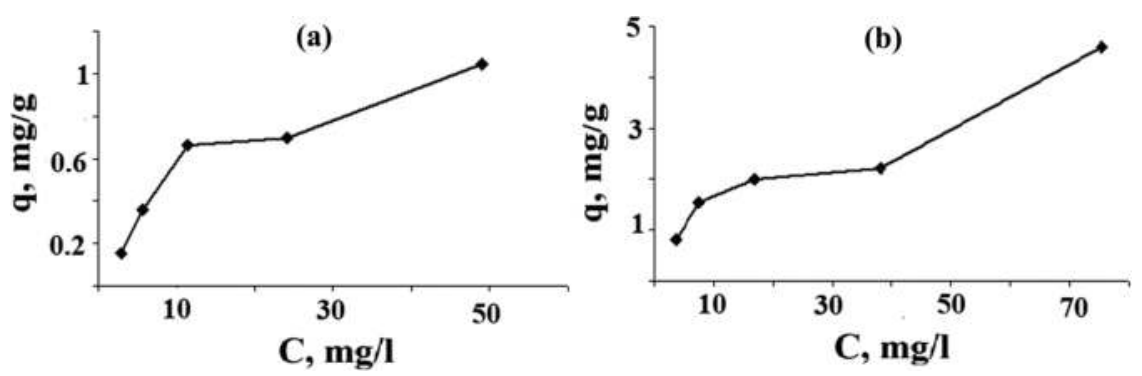

FIGURE 2.36

Sorption isotherms of cobalt at $\mathrm{pH} 5$ onto (a) $\mathrm{MnO}_{2}$ particles obtained from decomposition of manganese nitrate at $200^{\circ} \mathrm{C}$ and (b) the manganese oxyhydroxide calcined at $700^{\circ} \mathrm{C}$. 


\subsection{Conclusions}

To summarize the aforementioned experimental researches, it should be emphasized that formation process of iron oxide particles was examined in detail. In particular, effect of $\mathrm{pH}$ and precursor salt anions (chloride, nitrate, and hydrocarbonate anions) on the phase composition and morphological features of $\mathrm{Fe}_{2} \mathrm{O}_{3}$ was investigated in the process of ammonia precipitation from aqueous solutions.

Precipitation of iron(III) from nitrate solutions enables to obtain $\mathrm{Fe}_{2} \mathrm{O}_{3}$ particles made up of nanoparticles joined into larger agglomerates with dimensions over $50 \mu \mathrm{m}$, irrespective of the synthesis $\mathrm{pH}$.

The powder containing separate $\mathrm{Fe}_{2} \mathrm{O}_{3}$ particles of cubic and oval shapes is formed in presence of chloride anions. However, carbonate anion does not affect the morphology of particles. Hence, the form of the particles synthesized through thermal decomposition of iron(III) salts is highly dependent on the nature of anions of the iron(III) salt precursors. It is possible to control anion composition and thus to obtain iron oxide particles with desired functional characteristics.

Furthermore, the effect of the precipitation conditions, such as temperature and iron concentration in a solution, on the phase content, as well as the particle dimensions and magnetization, was analyzed. Comparative analysis of the extraction percentage and sorption capacity of magnetite and hematite toward cobalt was performed. It was found that the magnetite phase formation is dependent substantially on the precipitation temperature. The higher the temperature, the higher the magnetite content in samples. When synthesis was performed at $90^{\circ} \mathrm{C}$ in $0.15 \mathrm{M}$ concentration of iron, the powder with $100 \mathrm{wt} \% \mathrm{Fe}_{3} \mathrm{O}_{4}$ magnetite was obtained. It exhibited magnetization ca. $70 \mathrm{~A} \cdot \mathrm{m}^{2} / \mathrm{kg}$. Increase of initial concentration of iron in the solution resulted with slight decrease of magnetization.

The obtained particle shape was spherical irrespective of the precipitation conditions, and their dimensions were between 7 and $15 \mathrm{~nm}$. Larger particles with higher magnetization were noted to be formed in higher precipitation temperatures and lower iron concentrations.

During the interaction of ions $\mathrm{Mn}^{2+}$ and $\mathrm{MnO}_{4}{ }^{2-}$ in alkaline environment, the main component is manganese oxyhydroxide $\mathrm{MnO}(\mathrm{OH})$, not manganese dioxide. It was proved by the IR spectrometry. SSA of the particles increases, when the synthesis temperature is lower, and concentration of $\mathrm{Mn}^{2+}$ ions is smaller, and the obtained SSA is located in the range between 160 and $360 \mathrm{~m}^{2} / \mathrm{g}$. Particles with the largest SSA of $360 \mathrm{~m}^{2} / \mathrm{g}$ can be formed in the $0.1 \mathrm{M}$ solution at $t=20^{\circ} \mathrm{C}$.

Thermal decomposition of $\mathrm{MnO}(\mathrm{OH})$ proceeds in several stages. In the first stage, at the temperature between $60^{\circ} \mathrm{C}$ and $350^{\circ} \mathrm{C}$, the adsorbed water is removed from the surfaces of particles. Partial oxidation of manganese 
oxyhydroxide to $\mathrm{MnO}_{2}$ takes place. In the second stage, at the temperature between $350^{\circ} \mathrm{C}$ and $550^{\circ} \mathrm{C}$, main oxidation of $\mathrm{MnO}(\mathrm{OH})$ to manganese dioxide is completed. Further heating above $600^{\circ} \mathrm{C}$ will cause decomposition of manganese dioxide and formation of $\mathrm{Mn}_{2} \mathrm{O}_{3}$.

Compared with the particles of iron oxides, manganese oxyhydroxide particles perform substantially better sorption capacity toward the metals. Sorption capacity of iron oxides does not depend on phase composition but is increased when SSA is larger. On the other hand, changes in particles of manganese oxohydroxide SSA have no effect on their sorption capacity.

However, sorption properties of the manganese oxyhydroxide particles worsen during the first 6 months of storage. Among others, its sorption capacity toward cobalt drops down to $20 \%$ of initial value after 6 months and then remains almost constant at the level of $25 \mathrm{mg} / \mathrm{g}$. In case of sorption capacity toward strontium and europium, it decreases $50 \%$ during 12 months and then remains 30 and $50 \mathrm{mg} / \mathrm{g}$, respectively. 


\section{Final Remarks}

There are no doubts that sorption materials have wide perspectives of application in contemporary complex systems of water treatment. Modern trends of their development are dependent on the need of appropriate water supply, necessary for life of present and future generations. Thus, the main problem of the technological systems is to work out ecologically safe technologies with minimal amounts of wastes. The researches are focused on the improvement of existing materials and development of new ones of high sorption efficiency. These materials are to be used in complex and selective processes of wastewater treatment in the context of ecology, energy, and resource savings, as well as social life.

One of the solutions leading to achievement of proper materials is the development of methods of controlled synthesis of particles with presumed desirable characteristics. New technologies can be developed after thorough analysis of a wide range of factors that have effect on the particles structure and morphology formation, such as temperature, $\mathrm{pH}$, composition, activation method, and so on. These technologies may be applied also to production of other materials, not only for sorption purposes.

Physical and chemical characteristics of the metal sulfides, iron oxides, and manganese oxyhydroxide allow their application as sorbents. They may be used for heavy metals and radionuclides uptake from wastewater practically down to any residual concentration at $\mathrm{pH}$ above 5. The controlled inorganic synthesis allows forming of sorbents particles with certain morphological characteristics, which effects with increase of sorption capacity even several times.

It appears to be the most promising to apply manganese oxyhydroxide as a sorbent. It is able to uptake heavy metal ions and radionuclides with high efficiency above $95 \%$ (Sofronov et al. 2019), including isotopes ${ }^{90} \mathrm{Sr}$ and ${ }^{137} \mathrm{Cs}$ (Krasnopyorova et al. 2017), and perform higher sorption capacity than that of metal sulfides and iron oxides.

The research results presented in this work are aimed on the controlled synthesis of inorganic particles with presumed structural, morphological, and functional properties.

\section{Acknowledgments}

The authors express their gratitude for cooperation to everybody who contributed to the researches, especially to chemistry doctors Baumer V.N. and Puzan A.N. for X-ray structural analysis, to Bunina Z.Yu., Gudzenko L.V., and 
chemistry doctor Shcherbakov I.B.-Kh. for chemical analysis, to Mateichenko P.V. for microstructural analysis, to chemistry doctor Beda A.A. for specific surface determination, and to physics and mathematics doctor Katrunov K.A. for optical researches.

This chapter is made Open Access through funding by Precision Machine Parts Poland Sp. z o.o. 


\section{References}

Abdullah, N.H., Z. Zainal, S. Silong, M.I.M. Tahir, K.B. Tan, and S.K. Chang. 2016. Synthesis of zinc sulphide nanoparticles from thermal decomposition of zinc N-ethyl cyclohexyl dithiocarbamate complex. Materials Chemistry and Physics 173:33-41.

Acton, Q.A. (ed.), 2013. Zinc Compounds-Advances in Research and Application: 2013 Edition. Atlanta: Scholarly Editions.

Adler, H.H., and P.F. Kerr. 1965. Variations in infrared spectra, molecular symmetry and site symmetry of sulfate minerals. American Mineralogist 50(1-2):132-47.

Afridi, M.N., W.-H. Lee, and J.-O. Kim. 2019. Effect of phosphate concentration, anions, heavy metals, and organic matter on phosphate adsorption from wastewater using anodized iron oxide nanoflakes. Environmental Research 171:428-36.

Aguilar, O., F. Tzompantzi, R. Pérez-Hernández, R. Gómez, and A. HernándezGordillo. 2017. Novel preparation of $\mathrm{ZnS}$ from $\mathrm{Zn}_{5}\left(\mathrm{CO}_{3}\right)_{2}(\mathrm{OH})_{6}$ by the hydro- or solvothermal method for $\mathrm{H}_{2}$ production. Catalysis Today 287:91-8.

Ahmed, K.A.M. 2016. Exploitation of $\mathrm{KMnO}_{4}$ material as precursors for the fabrication of manganese oxide nanomaterials. Journal of Taibah University for Science 10(3):412-29.

Ai, Zh., Y. Cheng, L. Zhang, and J. Qiu 2008. Efficient Removal of Cr(VI) from Aqueous Solution with $\mathrm{Fe}-\mathrm{Fe}_{2} \mathrm{O}_{3}$ Core-Shell Nanowires. Environmental Science E Technology 42(18):6955-60.

Alby, D., C. Charnay, M. Heran, B. Prelot, and J. Zajac. 2018. Recent developments in nanostructured inorganic materials for sorption of cesium and strontium: Synthesis and shaping, sorption capacity, mechanisms, and selectivity A review. Journal of Hazardous Materials 344:511-530.

Allan, K.F., S. Labib, and M. Holeil. 2015. Synthesis and characterization of iron sulfide powders and its application for sorption of europium radionuclides. Desalination and Water Treatment 51:1-15.

Anand, K.V., M.K. Chinnu, R. Mohan Kumar, R. Mohan, and R. Jayavel. 2009. Formation of zinc sulfide nanoparticles in HMTA matrix. Applied Surface Science 255(21):8879-82.

Balsley, S.D., P.V. Brady, J.L. Krumhansl, et al. 1996. Iodide retention by metal sulfide surfaces: Cinnabar and chalcocite. Environmental Science $\mathcal{E}$ Technology 30(10):3025-7.

Baltas, H., M. Sirin, E. Gökbayrak, and A.E. Ozcelik. 2020. A case study on pollution and a human health risk assessment of heavy metals in agricultural soils around Sinop province, Turkey. Chemosphere 241:125015.

Baranov, D.A., and S.P. Gubin. 2009. Radioelectronics: Nanosystems. Information Technologies 1(1-2):129. (in Russian).

Barzyk, W., A. Kowal, and A. Pomianowski. 2002. Noble metal (Ag, Au) cementation on non-stoichiometric cuprous sulphide grains. Colloids and Surfaces A: Physicochemical and Engineering Aspects 208:321-35. 
Baykal, A., Y. Köseolu, and M. Senel. 2007. Low temperature synthesis and characterization of $\mathrm{Mn}_{3} \mathrm{O}_{4}$ nanoparticles. Central European Journal of Chemistry 5(1):169-76.

Behboudnia, M., M.H. Majlesara, and B. Khanbabaee. 2005. Preparation of ZnS nanorods by ultrasonic waves. Materials Science and Engineering B 122:160-3.

Benjamin, M.M. and J.O. Leckie. 1981. Multiple-site adsorption of Cd, Cu, Zn, and $\mathrm{Pb}$ on amorphous iron oxyhydroxide. Journal of Colloid and Interface Science 79(1):209-21.

Bhateria, R., and R. Singh. 2019. A review on nanotechnological application of magnetic iron oxides for heavy metal removal. Journal of Water Process Engineering 31:100845.

Biswas, S., T. Ghoshal, S. Kar, S. Chakrabarti, and S. Chaudhuri. 2008. ZnS nanowire arrays: Synthesis, optical and field emission properties. Crystal Growth $\mathcal{E}$ Design 8(7):2171-6.

Bol, A.A., J. Ferwerda, J.A. Bergwerff, and A. Meijerink. 2002. Luminescence of nanocrystalline ZnS:Cu${ }^{2+}$. Journal of Luminescence 99:325-34.

Bostick, B.C., and S. Fendorf. 2003. Arsenite sorption on troilite (FeS) and pyrite (FeS ${ }_{2}$. Geochimica et Cosmochimica Acta 67(5):909-21.

Bower, K.E., Y.A. Barbanel, Y.G. Shreter, and G.W. Bohnert (eds.). 2002. Polymers, Phosphors, and Voltaics for Radioisotope Microbatteries. Boca Raton, FL: CRC Press.

Brittain, H.G. (ed.) 1993. Analytical Profiles of Drug Substances and Excipients, Vol. 22. San Diego, CA: Academic Press Inc.

Bulgakova, A.V., D.S. Sofronov, P.V. Mateichenko, V.N. Baumer, A.A. Beda, and V.A. Chebanov. 2016. The effect of the precipitation conditions on the morphology and the sorption properties of CuS particles. Protection of Metals and Physical Chemistry of Surfaces 52(3):448-53.

Bulgakova, A.V., D.S. Sofronov, P.V. Mateychenko, V.N. Baumer, A.A. Beda, and V.A. Chebanov. 2016. Effect of the precipitation conditions on morphology and sorption characteristics of CuS. Surface Physics and Chemistry and Materials Protection 52(3):295-300. (in Russian).

Byrn, S.R., G. Zografi, and X. Chen. 2017. Solid-State Properties of Pharmaceutical Materials. Hoboken, NJ: John Wiley \& Sons, Inc.

Cao, Ch.Y., J. Qu, W.-Sh. Yan, J.-F. Zhu, Z.-Y. Wu, and W.-G. Song. 2012. Low-cost synthesis of flowerlike $\alpha-\mathrm{Fe}_{2} \mathrm{O}_{3}$ nanostructures for heavy metal ion removal: Adsorption property and mechanism. Langmuir 28(9):4573-9.

Cao, J., Y. Zhu, K. Bao, L. Shi, Sh. Liu, and Y. Qian. 2009. Microscale $\mathrm{Mn}_{2} \mathrm{O}_{3}$ hollow structures: Sphere, cube, ellipsoid, dumbbell, and their phenol adsorption properties. Journal of Physical Chemistry C 113(41):17755-60.

Cao, Sh.W., and Y.J. Zhu. 2008. Hierarchically nanostructured $\alpha-\mathrm{Fe}_{2} \mathrm{O}_{3}$ hollow spheres: Preparation, growth mechanism, photocatalytic property, and application in water treatment. Journal of Physical Chemistry C 112(16):6253-7.

Chanu, T.I., Dh. Samanta, A. Tiwari, and S. Chatterjee. 2017. Effect of reaction parameters on photoluminescence and photocatalytic activity of zinc sulfide nanosphere synthesized by hydrothermal route. Applied Surface Science 391(Part B):548-56.

Cheera, P., S. Karlapudi, G. Sellola, and V. Ponneri. 2016. A facile green synthesis of spherical $\mathrm{Fe}_{3} \mathrm{O}_{4}$ magnetic nanoparticles and their effect on degradation of methylene blue in aqueous solution. Journal of Molecular Liquids 221:993-8.

Chen, D., K. Tang, G. Shen, et al. 2003. Microwave-assisted synthesis of metal sulfides in ethylene glycol. Materials Chemistry and Physics 82:206-9. 
Chen, J., J. Wang, G. Zhang, Q. Wu, and D. Wang. 2018. Facile fabrication of nanostructured cerium-manganese binary oxide for enhanced arsenite removal from water. Chemical Engineering Journal 334:1518-26.

Cheng, Ch., G. Xu, H. Zhang, J. Cao, P. Jiao, and X. Wang. 2006. Low-temperature synthesis and optical properties of wurtzite $\mathrm{ZnS}$ nanowires. Materials Letters 60:3561-4.

Cheraneva, L.G., M.A. Shvetsova, and V.V. Volkhin. 2009. Impact of the sorbents synthesis conditions on the structure and characteristics of metals sulfides. Bullettin of Perm National Research Polytechnic Institute: Chemical and Bio Technology 9(1):19-25. (in Russian).

Coles, C.A., S.R. Rao, and R.N. Yong. 2000. Lead and cadmium interactions with mackinawite: Retention mechanisms and the role of $\mathrm{pH}$. Environmental Science E Technology 34(6):996-1000.

Con, T.H., Ph. Thao, T.X. Dai, and D.K. Loan. 2013. Application of nano dimensional $\mathrm{MnO}_{2}$ for high effective sorption of arsenic and fluoride in drinking water. Environmental Sciences 1(1-2):69-77.

Corrado, C., Y. Jiang, F. Oba, M. Kozina, F. Bridges, and J.Z. Zhang. 2009. Synthesis, structural, and optical properties of stable $\mathrm{ZnS}: \mathrm{Cu}, \mathrm{Cl}$ nanocrystals. Journal of Physical Chemistry A 113(16):3830-9.

Crisostomo, V.-M.B., J.K. Ngala, S. Alia, et al. 2007. New synthetic route, characterization, and electrocatalytic activity of nanosized manganite. Chemistry of Materials 19(7):1832-39.

Davies-Colley, R.J., P.O. Nelson, and K.J. Williamson. 1984. Copper and cadmium uptake by estuarine sedimentary phases. Environmental Science E Technology 18(7):491-9.

Dąbrowski, A., and V.A. Tertykh (eds.). 1996. Adsorption on New and Modified Inorganic Sorbents. Amsterdam: Elsevier.

Deng X., Zh. Huang, W. Wang, and R.N. Davé. 2016. Investigation of nanoparticle agglomerates properties using Monte Carlo simulations. Advanced Powder Technology 27(5):1971-9.

Dhara, A., S. Sain, S. Das, and S.K. Pradhan. 2018. Microstructure, optical and electrical characterizations of Mn doped ZnS nanocrystals synthesized by mechanical alloying. Materials Research Bulletin 97:169-75.

Dong L., Zh. Zhu, H. Ma, Y. Qiu, and J. Zhao. 2010. Simultaneous adsorption of lead and cadmium on $\mathrm{MnO}_{2}$-loaded resin. Journal of Environmental Sciences 22(2):225-9.

Dong, L., Y. Chu, and Y. Zhang. 2007. Microemulsion-mediated solvothermal synthesis of ZnS nanowires. Materials Letters 61:4651-4.

Dragan, E.S. (ed.) 2014. Advanced Separations by Specialized Sorbents. Boca Raton, FL: CRC Press.

Dubey, Sh., S. Banerjee, S.N. Upadhyay, and Y.Ch. Sharma. 2017. Application of common nano-materials for removal of selected metallic species from water and wastewaters: A critical review. Journal of Molecular Liquids 240:656-77.

Edrah, S. 2010. Synthesis, characterization and biological activities of ureas and thioureas derivatives. Journal of Applied Sciences Research 4(8):1014-8.

Egorov, N.B., L.P. Eremin, A.M. Larionov, and V.F. Usov. 2010. Transformations of the thiosulfate-thiourea lead complexes under heating. Bullettin of Tomsk Polytechnic University 317(3):99-102. (in Russian). 
Environmental Protection Agency. 2001. Parameters of Water Quality: Interpretation and Standards. Wexford: Environmental Protection Agency.

Fang, X., T. Zhai, U.K. Gautam, et al. 2011. ZnS nanostructures: From synthesis to applications. Progress in Materials Science 56:175-287.

Feng, X.H., L.M. Zhai, W.F. Tan, F. Liu, and J.Z. He. 2007. Adsorption and redox reactions of heavy metals on synthesized Mn oxide minerals. Environmental Pollution 147:366-73.

Fu, F., and Q. Wang. 2011. Removal of heavy metal ions from wastewaters: A review. Journal of Environmental Management 92(3):407-18.

Furniss, B.S., A.J. Hannaford, P.W.G. Smith, and A.R. Tatchell (eds.). 1989. Vogel's Textbook of Practical Organic Chemistry, 5th edn. Harlow: Longman Scientific \& Technical.

Ge, S., X. Shi, K. Sun, et al. 2009. Facile hydrothermal synthesis of iron oxide nanoparticles with tunable magnetic properties. Journal of Physical Chemistry C 113(31):13593-9.

Geckeler, K., and H. Nishide (eds.). 2010. Advanced Nanomaterials. Weinheim: Wiley-VCH.

Geng, B., J. Ma, and F. Zhan. 2009. A solution phase thermal decomposition molecule precursors route to $\mathrm{ZnS}: \mathrm{Cu} 2+$ nanorods and their optical properties. Materials Chemistry and Physics 113:534-8.

Gevorkyan, E.S., M. Rucki, V.A. Chishkala, M.V. Kislitsa, Z. Siemiatkowski, and D. Morozow. 2019. Hot pressing of tungsten monocarbide nanopowder mixtures by electroconsolidation method. Journal of Machine Construction and Maintenance 113(2):67-73.

Gong, Y., J. Tang, and D. Zhao. 2016. Application of iron sulfide particles for groundwater and soil remediation: A review. Water Research 89:309-20.

Gupta, K.M., and N. Gupta. 2016. Advanced Semiconducting Materials and Devices. Cham: Springer.

Guttikunda, S.K., K.A. Nishadh, and P. Jawahar. 2019. Air pollution knowledge assessments (APnA) for 20 Indian cities. Urban Climate 27:124-41.

Hamilton-Taylor, J., W. Davison, and K. Morfett. 1996. The biogeochemical cycling of $\mathrm{Zn}, \mathrm{Cu}, \mathrm{Fe}, \mathrm{Mn}$, and dissolved organic $\mathrm{C}$ in a seasonally anoxic lake. Limnology and Oceanography 41(3):408-18.

Han, R., W. Zou, Y. Wang, and L. Zhu. 2007. Removal of uranium(VI) from aqueous solutions by manganese oxide coated zeolite: Discussion of adsorption isotherms and pH effect. Journal of Environmental Radioactivity 93(3):127-43.

Herrmann J., W. Knoche, and R. Neugebauer. 1995. Hydrolysis of thiamine. Journal of the Chemical Society. Perkin Transactions Part 2 3:463-8.

Hong, R.Y., T.T. Pan, and H.Z. Li. 2006. Microwave synthesis of magnetic $\mathrm{Fe}_{3} \mathrm{O}_{4}$ nanoparticles used as a precursor of nanocomposites and ferrofluids. Journal of Magnetism and Magnetic Materials 303:60-8.

Hurma, T. 2016. Effect of cerium incorporation on the structural and optical properties of CdS film. Optik - International Journal for Light and Electron Optics 127(22):10670-5.

Jaffres, A., D. Bregiroux, D. Reekie, and R. Shears. 2017. Morphological control of ZnS nanopowders by different capping molecules. Materials Letters 209:539-542.

Jaspal, D., and A. Malviya. 2020. Composites for wastewater purification: A review. Chemosphere 246:125788. 
Jayalakshmi, M., and M.M. Rao. 2006. Synthesis of zinc sulphide nanoparticles by thiourea hydrolysis and their characterization for electrochemical capacitor applications. Journal of Power Sources 157(1):624-9.

Jeong, H.Y., B. Klaue, J.D. Blum, et al. 2007. Sorption of mercuric ion by synthetic nanocrystalline mackinawite $(\mathrm{FeS})$. Environmental Science \& Technology 41(22):7699-705.

Jian, W., J. Zhuang, D. Zhang, J. Dai, W. Yang, and Y. Bai. 2006. Synthesis of highly luminescent and photostable ZnS:Ag nanocrystals under microwave irradiation. Materials Chemistry and Physics 99:494-7.

Jiang, Ch., W. Zhang, G. Zou, W. Yu, and Y. Qian. 2007. Hydrothermal synthesis and characterization of $\mathrm{ZnS}$ microspheres and hollow nanospheres. Materials Chemistry and Physics 103, 24-7.

Jothibas, M., S. Johnson Jeyakumar, C. Manoharan, I.K. Punithavathy, P. Praveen, and J.P. Richard. 2017. Structural and optical properties of zinc sulphide nanoparticles synthesized via solid state reaction method. Journal of Materials Science: Materials in Electronics 28:1889-94.

Jothibas, M., C. Manoharan, S. Johnson Jeyakumar, P. Praveen, I.K. Punithavathy, and J.P. Richard. 2018. Synthesis and enhanced photocatalytic property of Ni doped ZnS nanoparticles. Solar Energy 159:434-43.

Kar, P., S. Sardar, S. Ghosh, et al. 2015. Nano surface engineering of $\mathrm{Mn}_{2} \mathrm{O}_{3}$ for potential light-harvesting application. Journal of Materials Chemistry C 3:8200-11.

Katrunov, K., D. Sofronov, N. Starzhynskiy, et al. 2010. Quantum-size effects in nanosize particles $\mathrm{ZnS}$ and CdS obtained by precipitation from alkaline solutions. Technology, Instrumentation and Production of Electonic Technique 28(2):3-7. (in Russian).

Khan, Y., Sh.Kh. Durrani, M. Mehmood, and M.R. Khan. 2011. Mild hydrothermal synthesis of $\gamma-\mathrm{MnO}_{2}$ nanostructures and their phase transformation to $\alpha-\mathrm{MnO}_{2}$ nanowires. Journal of Materials Research 26(17):2268-75.

Kim, D., K.-D. Min, J. Lee, J.H. Park, and J.H. Chun. 2006. Influences of surface capping on particle size and optical characteristics of $\mathrm{ZnS}: \mathrm{Cu}$ nanocrystals. Materials Science and Engineering B 131:13-7.

Kim, J.H., J.G. Kim, J. Song, et al. 2018. Investigation of the growth and in situ heating transmission electron microscopy analysis of $\mathrm{Ag}_{2} \mathrm{~S}$-catalyzed $\mathrm{ZnS}$ nanowires. Applied Surface Science 436:556-61.

Kitayev, G.A., V.F. Markov, and L.N. Maskayeva. 1989. Investigations on chalcogenide films of solid solutions CdXPb1-XS. Bullettin of SU Academy of Sciences: Inorganic Materials 26(8):1262-4 (in Russian).

Knunyantz, I.L., 1983. Chemical Ecyclopaedic Dictionary. Moscow: Soviet Encyclopedia Publisher (in Russian).

Kolida, Yu.Ya., A.S. Antonova, T.N. Kropacheva, and V.I. Kornev. 2014. Magnetic iron oxides as sorbents of hard metals cations. Bullettin of Udmurt University 4:52-61 (in Russian).

Kosmulski, M. 2001. Chemical Properties of Material Surfaces. New York; Basel: Marcel Dekker AG.

Krasnopyorova, A.P., N.V. Efimova, G.D. Yuhno, and D.S. Sofronov. 2017. Impact of ion force and solution acidity on sorption capability of $\mathrm{MnO}(\mathrm{OH})$ toward radionuclides ${ }^{90} \mathrm{Sr},{ }^{137} \mathrm{Cs}$ and ${ }^{60} \mathrm{Co}$. Vestnik of Novgorod State University 103(3):22-5. (in Russian) 
Labiadh, H., B. Sellami, A. Khazri, W. Saidani, and S. Khemais. 2017. Optical properties and toxicity of undoped and Mn-doped $\mathrm{ZnS}$ semiconductor nanoparticles synthesized through the aqueous route. Optical Materials 64:179-86.

Lavrynenko, S., A.G. Mamalis, D. Sofronov, A. Odnovolova, and V. Starikov. 2018. Synthesis features of iron oxide nanopowders with high magnetic and sorption properties. Materials Science Forum 915:116-20.

Lee, S., D. Song, D. Kim, et al. 2004. Effects of synthesis temperature on particle size/ shape and photoluminescence characteristics of $\mathrm{ZnS}: \mathrm{Cu}$ nanocrystals. Materials Letters 58:342-6.

Li, F., J. Wu, Q. Qin, Zh. Li, and X. Huang. 2010. Facile synthesis of $\gamma-\mathrm{MnOOH}$ micro/nanorods and their conversion to $\beta-\mathrm{MnO}_{2}, \mathrm{Mn}_{3} \mathrm{O}_{4}$. Journal of Alloys and Compounds 492(1-2):339-46.

Li, W., D. Li, Zh. Chen, et al. 2008. High-efficient degradation of dyes by ZnxCd1-xS solid solutions under visible light irradiation. Journal of Physical Chemistry C 112:14943-7.

Li, Y., X. He, and M. Cao. 2008. Micro-emulsion-assisted synthesis of ZnS nanospheres and their photocatalytic activity. Materials Research Bulletin 43:3100-10.

Liu, C., Y. Chen, W. Huang, Y. Situ, and H. Huang. 2018. Birnessite manganese oxide nanosheets assembled on $\mathrm{Ni}$ foam as high-performance pseudocapacitor electrodes: Electrochemical oxidation driven porous honeycomb architecture formation. Applied Surface Science 458:10-7.

Liu, J., K.T. Valsaraj, I. Devai, and R.D. DeLaune, 2008. Immobilization of aqueous $\mathrm{Hg}$ (II) by mackinawite (FeS). Journal of Hazardous Materials 157:432-40.

Liu, T., L. Xue, and X. Guo, 2015. Study of $\mathrm{Hg}^{0}$ removal characteristics on $\mathrm{Fe}_{2} \mathrm{O}_{3}$ with $\mathrm{H}_{2}$ S. Fuel 160:189-95.

Loganathan, P., and R.G. Burau. 1973. Sorption of heavy metal ions by a hydrous manganese oxide. Geochimica et Cosmochimica Acta 37(5), 1277-93.

Lompe, K.M., D. Menard, and B. Barbeau. 2017. The influence of iron oxide nanoparticles upon the adsorption of organic matter on magnetic powdered activated carbon. Water Research 123:30-9.

Mallakpour, Sh., and F. Motirasoul. 2019. Cross-linked poly(vinyl alcohol)/modified $\alpha$-manganese dioxide composite as an innovative adsorbent for lead(II) ions. Journal of Cleaner Production 224:592-602.

Manoharan, S., S. Goyal, M.L. Rao, M.S. Nair, and A. Pradhan. 2001. Microwave synthesis and characterization of doped $\mathrm{ZnS}$ based phosphor materials. Materials Research Bulletin 36:1039-47.

Marcotrigiamo, G., G. Peyronel, and R. Battisturzi. 1972. Kinetics of desulphuration of thiourea in sodium hydroxide studied by chromatographic method. Journal of the Chemical Society. Perkin Transactions Part 2 11:1539-41.

Mateleshko, N., V. Mitsa, and S. Sikora. 2004. Electrooptical properties of DC electroluminescent $\mathrm{ZnS}: \mathrm{Mn}$, Cu powder panels with chalcogenide glass intermediate layer. Journal of Optoelectronics and Advanced Materials 6(1):329-32.

McCloy, J.S., and R.W. Tustison. 2013. Chemical Vapor Deposited Zinc Sulfide. Washington: SPIE Press.

Mendil, R., Z. Ben Ayadi, and K. Djessas. 2016. Effect of solvent medium on the structural, morphological and optical properties of $\mathrm{ZnS}$ nanoparticles synthesized by solvothermal route. Journal of Alloys and Compounds 678:87-92. 
Mishukova, T.G., A.A. Osipov, and I.A. Salnikov. 2015. Determination of the microelements content in drinking waters of the Orenburg Region. Bullettin of Orenburg State University 185(10):303-7 (in Russian).

Moore, G.L. 1989. Introduction to Inductively Coupled Plasma Atomic Emission Spectrometry. Amsterdam: Elsevier.

Morse, J.W., and T. Arakaki. 1993. Adsorption and coprecipitation of divalent metals with mackinawite (FeS). Geochimica et Cosmochimica Acta 57(15):3635-40.

Mullet, M., S. Boursiquot, and J.J. Ehrhardt. 2004. Removal of hexavalent chromium from solutions by mackinawite, tetragonal FeS. Colloids and Surfaces A Physicochemical and Engineering Aspects 244(1):77-85.

Muraleedharan, K., V.K. Rajan, and V.M. Abdul Mujeeb. 2015. Green synthesis of pure and doped semiconductor nanoparticles of $\mathrm{ZnS}$ and CdS. Transactions of Nonferrous Metals Society of China 25(10):3265-70.

Murray, J.W. 1975. The interaction of cobalt with hydrous manganese dioxide. Geochimica et Cosmochimica Acta 39(5):635-47.

Murugadoss, G. 2013. Synthesis and photoluminescence properties of zinc sulfide nanoparticles doped with copper using effective surfactants. Particuology 11(5):566-73.

Musić, S. 1985. Sorption of chromium(III) and chromium(VI) on lead sulfide. Journal of Radioanalytical and Nuclear Chemistry 91(2):337-47.

Musić, S. and M. Ristić. 1988. Adsorption of trace elements or radionuclides on hydrous iron oxides. Journal of Radioanalytical and Nuclear Chemistry 120(2):289-304.

Naderi, M. 2015. Surface area: Brunauer-Emmett-Teller (BET). In: S. Tarleton (ed.) Progress in Filtration and Separation, pp. 585-608. London: Academic Press/ Elsevier.

Nagpal, M., and R. Kakkar. 2019. Use of metal oxides for the adsorptive removal of toxic organic pollutants. Separation and Purification Technology 211:522-39.

Neto, J.O.M., C.R. Bellato, and D.C. Silva. 2019. Iron oxide/carbon nanotubes/ chitosan magnetic composite film for chromium species removal. Chemosphere 218:391-401.

Niazi, N.K., and E.D. Burton. 2016. Arsenic sorption to nanoparticulate mackinawite (FeS): An examination of phosphate competition. Environmental Pollution 218:111-7.

Nishikida, K., E. Nishio, and R.W. Hannah. 1995. Selected Applications of Modern FT-IR Techniques. Tokyo: Kodansha.

Nouh, S.A., M. Amin, M. Gouda, and A. Abd-Elmagid. 2015. Extraction of uranium(VI) from sulfate leach liquor after iron removal using manganese oxide coated zeolite. Journal of Environmental Chemical Engineering 3:523-8.

Nyquist, R.A., and R.O. Kagel. 1971. Infrared Spectra of Inorganic Compounds. New York; London: Academic Press.

Ociński, D., I. Jacukowicz-Sobala, J. Raczyk, and E. Kociołek-Balawejder. 2014. Evaluation of hybrid polymer containing iron oxides as As(III) and As(V) sorbent for drinking water purification. Reactive and Functional Polymers 83:24-32.

Odnovolova, A.M., D.S. Sofronov, P.V. Mateichenko, et al. 2014. Role of anion composition of aqueous solution in forming morphology and surface of particles $\mathrm{Fe}_{2} \mathrm{O}_{3}$ in the course of deposition and their sorption properties. Russian Journal of Applied Chemistry 87(8):1060-4. 
Odnovolova, A.M., D.S. Sofronov, A. Puzan, et al. 2015. Formation characteristics of $\mathrm{Fe}_{3} \mathrm{O}_{4}$ magnetic particles precipitated from aqueous solutions and their sorption properties. Functional materials 22(4):475-81.

Pandi K., S. Periyasamy, and N. Viswanathan. 2017. Remediation of fluoride from drinking water using magnetic iron oxide coated hydrotalcite/chitosan composite. International Journal of Biological Macromolecules Part B 104:1569-77.

Pepper, R.A., S.J. Couperthwaite, and G.J. Millar. 2017. Value adding red mud waste: High performance iron oxide adsorbent for removal of fluoride. Journal of Environmental Chemical Engineering 5(3):2200-6.

Peters, O.M., and C.J. Rauter. 1974. Pathways in thioacetamide hydrolysis in aqueous acid: detection by kinetic analysis. Journal of the Chemical Society. Perkin Transactions Part 2 15:1832-5.

Pons, M.N., and J. Dodds. 2015. Particle shape characterization by image analysis. In: S. Tarleton (ed.) Progress in Filtration and Separation, pp. 609-636. London: Academic Press/Elsevier.

Pretorius, P.J., and P.W. Linder. 2001. The adsorption characteristics of $\delta$-manganese dioxide: A collection of diffuse double layer constants for the adsorption of $\mathrm{H}^{+}$, $\mathrm{Cu}^{2+}, \mathrm{Ni}^{2+}, \mathrm{Zn}^{2+}, \mathrm{Cd}^{2+}$ and $\mathrm{Pb}^{2+}$. Applied Geochemistry 16(7):1067-82.

Qiao, S.-Z., J. Liu, and G.Q. Max Lu. 2017. Synthetic chemistry of nanomaterials. In: R. Xu, and Y. Xu (eds.) Modern Inorganic Synthetic Chemistry, 2nd Edn, pp. 613640. Amsterdam: Elsevier.

Qiu, W., M. Xu, X. Yang, F. Chen, Y. Nan, and H. Chen. 2011. Novel hierarchical CdS crystals by an amino acid mediated hydrothermal process. Journal of Alloys and Compounds 509:8413-20.

Rakovich, A.Y., V.Stockhausen, A.S. Susha, S. Sapra, and A.L. Rogach. 2008. Decorated wires as a reaction product of the microwave-assisted synthesis of CdSe in the presence of glycine. Colloids and Surfaces A: Physicochemical and Engineering Aspects 317:737-41.

Rantala, T.T. 1999. Ab initio studies of compound semiconductor surfaces. In: Th.F. George, and D.A. Jelski (eds.), Computational Studies Of New Materials, pp. 6-26. Singapore: World Scientific Publishing Co.

Rasmussen, K., H. Rauscher, A. Mech, et al. 2018. Physico-chemical properties of manufactured nanomaterials - Characterisation and relevant methods. An outlook based on the OECD Testing Programme. Regulatory Toxicology and Pharmacology 92:8-28.

Ronco, C., and J.F. Winchester (eds.). 2001. Dialysis, Dialyzers and Sorbents: Where Are We Going? (Contributions to Nephrology, Vol. 133). Basel: Karger.

Roth, H.-C., S.P. Schwaminger, M. Schindler, F.E. Wagner, and S. Berensmeier. 2015. Influencing factors in the co-precipitation process of superparamagnetic iron oxide nano particles: a model based study. Journal of Magnetism and Magnetic Materials 377:81-9.

Saha, J.K., and J. Podder. 2011. Crystallization of zinc sulphate single crystals and its structural, thermal and optical characterization. Journal of Bangladesh Academy of Sciences 35(2):203-10.

Sampanthar, J.T., J. Dou, G.G. Joo, W. Effendi, and Q.H.E. Low. 2007. Templatefree low temperature hydrothermal synthesis and characterization of rodshaped manganese oxyhydroxides and manganese oxides. Nanotechnology 18(2):025601. 
Singh, M., D.N. Thanh, P. Ulbrich, N. Strnadová, and F. Štěpánek. 2010. Synthesis, characterization and study of arsenate adsorption from aqueous solution by $\alpha-$ and $\delta$-phase manganese dioxide nanoadsorbents. Journal of Solid State Chemistry 183(12):2979-86.

Sofronov, D.S., K.N. Belikov, N.N. Kamneva, E.Yu. Bryleva, and A.V. Bulgakova. 2014. Synthesis of submicron ZnS particles and their sorption characteristics. Sorption and Chromatographic Processes 14(1):159-65. (in Russian).

Sofronov, D.S., K.N. Belikov, E.M. Sofronova, P.V. Mateichenko, and N.V. Babayevskaya. 2013. Production of disperse particles of CdS from thiourea solutions in the presence of amino acids. Functional Materials 20(1):118-22.

Sofronov, D.S., N.N. Kamneva, A.V. Bulgakova, et al. 2013. Effect of anions and medium $\mathrm{pH}$ on the formation of $\mathrm{ZnS}$ micro- and nanoparticles from thiourea solutions. Journal of Biological Physics and Chemistry 13:85-9.

Sofronov, D.S., N.N. Kamneva, K.A. Katrunov, et al. 2014. Effect of precipitation conditions on the particle size and optical properties of ZnS. Inorganic Materials 50(7):817-21.

Sofronov, D., A. Krasnopyorova, N. Efimova, et al. 2019. Extraction of radionuclides of cerium, europium, cobalt and strontium with $\mathrm{Mn}_{3} \mathrm{O}_{4}, \mathrm{MnO}_{2}$, and $\mathrm{MnOOH}$ sorbents. Process Safety and Environmental Protection 125:157-63.

Sofronov, D.S., A.M. Odnovolova, L.V. Gudzenko, et al. 2017. Study of $\mathrm{Mn}^{2+}$ and $\mathrm{MnO}^{4-}$ products interaction in alkaline solution. Functional Materials 24(2):322-7.

Sofronov, D.S., E.M. Sofronova, V.N. Baumer, K.A. Kudin, O.M. Vovk, and P.V. Mateychenko. 2011. Formation of nano- and microparticles CdS from thiourea solutions. Functional materials 18(4):523-8.

Sofronov, D.S., E.M. Sofronova, V.V. Starikov, et al. 2013. Microwave synthesis of ZnSe. Journal of Materials Engineering and Performance 22(6):1637-41.

Song, H., Y.-M. Leem, B.-G. Kim, and Y.-T. Yu. 2008. Synthesis and fluorescence properties of pure and metal-doped spherical ZnS particles from EDTA-metal complexes. Journal of Physics and Chemistry of Solids 69:153-60.

Stone, A.T., and J.J. Morgan. 1984. Reduction and dissolution of manganese(III) and manganese(IV) oxides by organics: 2. Survey of the reactivity of organics. Environmental Science \& Technology 18(8):617-24.

Su, Y.M., Ch.-Y. Huang, Y.-P. Chyou, and K. Svoboda. 2017. Sulfidation/regeneration multi-cyclic testing of $\mathrm{Fe} 2 \mathrm{O} 3 / \mathrm{Al} 2 \mathrm{O} 3$ sorbents for the high-temperature removal of hydrogen sulfide. Journal of the Taiwan Institute of Chemical Engineers 74:89-95.

Sun, J.Q., X.-P. Shen, K.-M. Chen, Q. Liu, W. Liu. 2008. Low-temperature synthesis of hexagonal $\mathrm{ZnS}$ nanoparticles by a facile microwave-assisted single-source method. Solid State Communications 147:501-4.

Syamchand, S.S., and G. Sony. 2015. Europium enabled luminescent nanoparticles for biomedical applications. Journal of Luminescence 165:190-215.

Taffarel, S.R. and J. Rubio. 2010. Removal of $\mathrm{Mn}^{2+}$ from aqueous solution by manganese oxide coated zeolite. Minerals Engineering 23:1131-8.

Takematsu, N. 1979-1980. Sorption of transition metals on manganese and iron oxides, and silicate minerals. Journal of the Oceanographical Society of Japan 35(1):36-42.

Thirunavukkarasu, O.S., T. Viraraghavan, and K.S. Subramanian. 2003. Arsenic removal from drinking water using iron oxide-coated sand. Water, Air, and Soil Pollution 142(1):95-111. 
Thuy, U.Th.D., N.Q. Liem, Ch.M.A. Parlett, G.M. Lalev, and K. Wilson. 2014. Synthesis of $\mathrm{CuS}$ and $\mathrm{CuS} / \mathrm{ZnS}$ core/shell nanocrystals for photocatalytic degradation of dyes under visible light. Catalysis Communications 44:62-7.

Tiquia-Arashiro, S. and D.F. Rodrigues. 2016. Extremophiles: Applications in Nanotechnology. Cham: Springer.

Tombácz, E., R. Turcu, V. Socoliuc, and L. Vékás. 2015. Magnetic iron oxide nanoparticles: Recent trends in design and synthesis of magnetoresponsive nanosystems. Biochemical and Biophysical Research Communications 468(3):442-53.

Tripathi, B., Y.K. Vijay, S. Wate, F. Singh, and D.K. Avasthi. 2007. Synthesis and luminescence properties of manganese-doped $\mathrm{ZnS}$ nanocrystals. Solid-State Electronics 51:81-4.

Turner, A., S.M. Le Roux, and G.E. Millward. 2008. Adsorption of cadmium to iron and manganese oxides during estuarine mixing. Marine Chemistry 108(1-2):77-84.

Ul-Haq, I., and F. Haider. 2010. Synthesis and characterization of uniform fine particles of iron(III) hydroxide/oxide. Journal of the Chinese Chemical Society 57(2):174-9.

Vadiraj, K.T. and Sh.L. Belagali. 2017. Photoluminescence behavior of manganese doped zinc sulphide, synthesized by hydrothermal process. Materials Today: Proceedings Part 3 4(11):11696-9.

Vardhan, K.H., P.S. Kumar, and R.C. Panda. 2019. A review on heavy metal pollution, toxicity and remedial measures: Current trends and future perspectives. Journal of Molecular Liquids 290:111197.

Vellingiri, K., K-H. Kim, A. Pournara, and A. Deep. 2018. Towards high-efficiency sorptive capture of radionuclides in solution and gas. Progress in Materials Science 94:1-67.

Wang, C., Q. Li, and B. Hu. 2017. Preparation and characterization of ZnS nanoparticles prepared by hydrothermal method. International Journal of Modern Physics B 31(16-19):6 p. Article 1744055

Wang, M., L. Sun, X. Fu, Ch. Liao, and Ch. Yan. 2000. Synthesis and optical properties of ZnS:Cu(II) nanoparticles. Solid State Communications 115:493-496.

Wang, M., Q. Zhang, W. Hao, and Zh.-X. Sun. 2011. Surface stoichiometry of zinc sulfide and its effect on the adsorption behaviors of xanthate. Chemistry Central Journal 5:73.

Wang, X., Y. Zhong, T. Zhai, et al. 2011. Multishelled $\mathrm{Co}_{3} \mathrm{O}_{4}-\mathrm{Fe}_{3} \mathrm{O}_{4}$ hollow spheres with even magnetic phase distribution: Synthesis, magnetic properties and their application in water treatment. Journal of Materials Chemistry 21:17680-7.

Wang, X.F., J.-J. Xu, and H.-Y. Chen. 2008. A new electrochemiluminescence emission of $\mathrm{Mn}^{2+}$-doped $\mathrm{ZnS}$ nanocrystals in aqueous solution. Journal of Physical Chemistry C 112 (45):17581-5.

Wang, Y., J. Li, J. Li, et al. 2018. Solution prepared O-doped ZnS nanocrystals: Structure characterization, energy level engineering and interfacial application in polymer solar cells. Solar Energy 160:353-9.

Watson, J.H.P., B.A. Cressey, A.P. Roberts, et al. 2000. Structural and magnetic studies on heavy-metal-adsorbing iron sulphide nanoparticles produced by sulphatereducing bacteria. Journal of Magnetism and Magnetic Materials 214:13-30.

Wegmann, M., and M. Scharr. 2018. Synthesis of magnetic iron oxide nanoparticles. In: H.-P. Deigner, and M. Kohl (eds.) Precision Medicine: Tools and Quantitative Approaches, pp. 145-181. London: Elsevier Academic Press. 
Wershin, P., M.H.R. Person, G. Redden, et al. 1994. Interaction between aqueous uranium (VI) and sulfide minerals: Spectroscopic evidence for sorption and reduction. Geochimica et Cosmochimica Acta 58(13):2829-43.

WHO (World Health Organization). 2003. Iron in Drinking-water. Geneva. http:// www.who.int/water_sanitation_health/dwq/chemicals/iron.pdf.

Wilkin, R.T., and D.G. Beak. 2017. Uptake of nickel by synthetic mackinawite. Chemical Geology 462:15-29.

$\mathrm{Wu}, \mathrm{R} ., \mathrm{J}$. Qu, and Y. Chen. 2005. Magnetic powder $\mathrm{MnO}-\mathrm{Fe}_{2} \mathrm{O}_{3}$ composite-a novel material for the removal of azo-dye from water. Water Research 39(4):630-8.

Wu, Y., B. Tang, H. Huo, et al. 2013. The study of zinc sulphide scintillator for fast neutron radiography. Physics Procedia 43:205-15.

Xiao, Q., and Ch. Xiao. 2008. Synthesis and photoluminescence of water-soluble $\mathrm{Mn}^{2+}$-doped ZnS quantum dots. Applied Surface Science 254:6432-5.

Xie, X., X. Jiang, T. Zhang, and Zh. Huang. 2020. Study on impact of electricity production on regional water resource in China by water footprint. Renewable Energy 152:165-78.

Xiong, Z., F. He, D. Zhao, and M.O. Barnett. 2009. Immobilization of mercury in sediment using stabilized iron sulfide nanoparticles. Water Research 43:5171-9.

Xu, J., Z. Qu, N. Yan, et al. 2016. Size-dependent nanocrystal sorbent for copper removal from water. Chemical Engineering Journal 284:565-70.

Yan, X., E. Michael, S. Komarneni, J.R. Brownson, and Z.-F. Yan. 2013. Microwaveand conventional-hydrothermal synthesis of CuS, SnS and ZnS: Optical properties. Ceramics International 39(5):4757-63.

Yao, J., G. Zhao, D. Wang, and G. Han. 2005. Solvothermal synthesis and characterization of CdS nanowires/PVA composite films. Materials Letters 59:3652-5.

Yao, Q.Z., G. Jin, and G.-T. Zhou. 2008. Formation of hierarchical nanospheres of ZnS induced by microwave irradiation: A highlighted assembly mechanism. Materials Chemistry and Physics 109:164-8.

Zhai, T., Zh. Gu, Y. Ma, W. Yang, L. Zhao, and J. Yao. 2006. Synthesis of ordered ZnS nanotubes by MOCVD-template method. Materials Chemistry and Physics 100:281-4.

Zhai, X., X. Zhang, Sh. Chen, W. Yang, and Zh. Gong. 2012. Oleylamine as solvent and stabilizer to synthesize shape-controlled $\mathrm{ZnS}$ nanocrystals with good optical properties. Colloids and Surfaces A: Physicochemical and Engineering Aspects 409:126-9.

Zhang, Y., F. Lu, Zh. Wang, et al. 2007. ZnS nanoparticle-assisted synthesis and optical properties of ZnS nanotowers. Crystal Growth \& Design 7(8):1459-62.

Zhang, Y.C., G.Y. Wang, X.Y. Hu, and W.W. Chen. 2006. Solvothermal synthesis of uniform hexagonal-phase $\mathrm{ZnS}$ nanorods using a single-source molecular precursor. Materials Research Bulletin 41:1817-24.

Zhang, Y.C., G.Y. Wang, X.Y. Hu, Q.F. Shi, T. Qiao, and Y. Yang. 2005. Phasecontrolled synthesis of $\mathrm{ZnS}$ nanocrystallites by mild solvothermal decomposition of an air-stable single-source molecular precursor. Journal of Crystal Growth 284:554-60.

Zhao, Y., J.-M. Hong, and J.-J. Zhu. 2004. Microwave-assisted self-assembled ZnS nanoballs. Journal of Crystal Growth 270:438-45.

Zhu, D., J. Zhang, J. Song, et al. 2013. Efficient one-pot synthesis of hierarchical flower-like $\alpha-\mathrm{Fe}_{2} \mathrm{O}_{3}$ hollow spheres with excellent adsorption performance for water treatment. Applied Surface Science 284(1):855-61. 
Zhu, J., M. Zhou, J. Xu, and X. Liao. 2001. Preparation of CdS and ZnS nanoparticles using microwave irradiation. Materials Letters 47:25-9.

Zhu, Zh., H. Ma, R. Zhang, Y. Ge, and J. Zhao. 2007. Removal of cadmium using $\mathrm{MnO}_{2}$ loaded D301 resin. Journal of Environmental Sciences 19(6):652-6.

Zhuo, R.F., H.T. Feng, D. Yan, et al. 2008. Rapid growth and photoluminescence properties of doped ZnS one-dimensional nanostructures. Journal of Crystal Growth 310:3240-6.

Zou, W., R. Han, Z. Chen, J. Shi, and H. Liu. 2006. Characterization and properties of manganese oxide coated zeolite as adsorbent for removal of copper(II) and lead(II) ions from solution. Journal of Chemical E Engineering Data 51(2):534-41.

This chapter is made Open Access through funding by Precision Machine Parts Poland Sp. z o.o. 


\section{Index}

agglomerate 6, 9, 15, 16, 21, 23, 28, 29, $31,32,33,37,40,42,45,50,66$, $69-72,74,82,97$

anion $26,28,48,55,56,71,72,97$

birnessite 81

cadmium 13, 29-30, 55, 60

sulfide $2,3,14-19,24,26,29,37,40$, $44-42,46,55,56,58,59,66$

nitrate 20

cation $23,55,89$

cerium 45, 51, 52, 56, 60, 63, 66, 89-91, 93, 94

oxide 50,51

salt 50

cobalt $8,15,56,57,59,62,63,64,66,68$, $89,90,91,93-98$

copper $1,8,13,45,46,50,51,55-57,62$, $63,66,68,89,90$

sulfide $2,3,14-17,23,26,28,37,40,42$, $46,47,55-61,63,64,66$

core-shell 5, 46

covellite 17, 37, 46

europium 45, 50, 52, 53, 55, 56, 66, 89-91, $93,95,96,98$

oxide $51-53$

hawleyite 37

hematite $3,54,56,69,71,72,97$

ion $6,9,12,20,21,26,45,46,48,51,55$, $56,58,59,62-64,67,68,73,76$, 78-80, 83, 87-89, 91-93, 95, 97,99

iron $14,54,56,57,62,66,76-80,89,90,97$ chloride $71,72,78$

fluoride 73

hydroxide 68,71

nitrate $69,72-74,97$

oxalate 74,75

oxide $2,3,54,67,68,70-73,75,76,78$, $79,88-92,97-99$ stearate 76

sulfate 79

sulfide $14,54-57,59,62,63$

magnetite $3,76,77,78,79,80,97$

manganese $1,8,45,48,49,51,56,57,63$, $64,81-86,95$

chloride 86

hydroxide 50

nitrate 87,94

oxide $50,59,60,62,63,68,80,81,86$, $87,91,97,98$

oxyhydroxide $2,3,81,85-87,91,93$, 94, 96-98

pentahydrate 80

sulfate 49

sulfide 48,50

microwave $2,5,7,38,46-48,51-53,58$, 65,80

monolayer $11,59,82$

nanoparticle 1, 2, 5, 6, 8-11, 23, 29, 37, 54, $63,66-68,70,71,75,76,78,80$, 87,97

nanostructure 5, 63, 66-68, 80

potassium

bromide 7

hydroxide 20

permanganate 86

pyrite 55

sodium

citrate 10

hydroxide 13, 20, 23, 39, 40

polyphosphate 11

sulfide 10, 11, 15, 16, 49, 50, 54, 64, 65 sorption capacity $1,2,55,56,58-68,90$, 93-99

specific surface $11,58,61,67,93,94$

sphalerite $6,10,17,18,37,46$

strontium 56, 57, 89, 91, 93, 95, 96, 98

wurtzite 9, 18 
yield 15, 16, 17, 18, 20, 24, 25, 39

zinc 5, 6, 7, 8, 13, 55, 56, 57, 68, 89 acetate 9

chloride 10, 26

diethyldithiocarbamate 8,9

dithiocarbamate 8

ethylenediaminetetraacetate 10 hydroxide 18 nitrate $9,13,48$

oxide $1,17,18$

stearate 8

sulfate 9

sulfide $1,2,3,5,6,7,8,9,10,14,15,17$, $18,19,20,21,23,24,26,37,39$,

$40,42,44,45,46,48,50,51,58$,

$59,60,63,64,65,66$ 